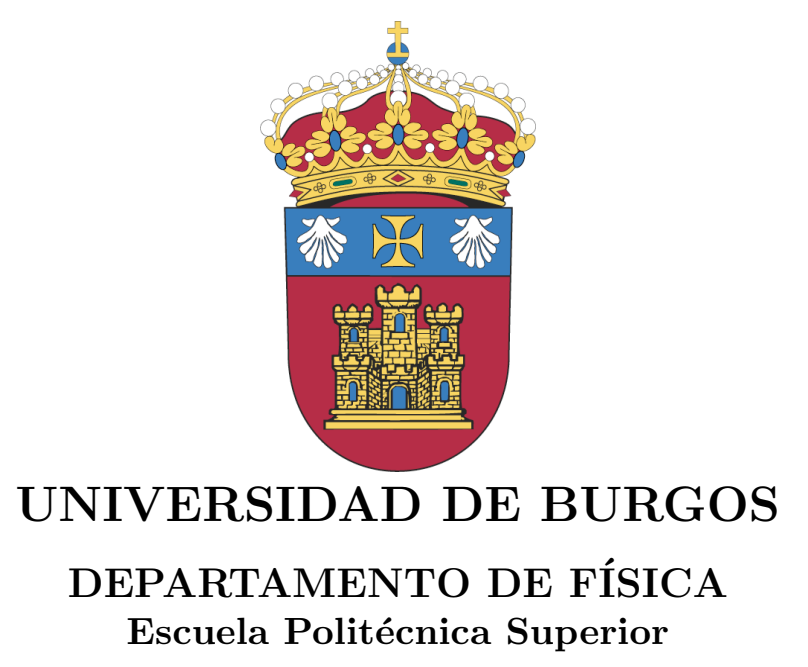

\title{
INTEGRABILIDAD DE SISTEMAS NO LINEALES HAMILTONIANOS CON N GRADOS DE LIBERTAD
}

\author{
Tesis Doctoral
}

Alfonso Blasco Sanz 2009

PROGRAMA DE DOCTORADO INTERUNIVERSITARIO "MÉTODOS AVANZADOS EN FÍSICA MODERNA" 

D. Ángel Ballesteros Castañeda, Profesor Titular de Física Aplicada del Departamento de Física de la Universidad de Burgos,

\section{CERTIFICA que la Tesis Doctoral}

"Integrabilidad de sistemas no lineales hamiltonianos con $N$ grados de libertad"

ha sido realizada bajo su dirección en el Departamento de Física de la Universidad de Burgos por el licenciado D. Alfonso Blasco Sanz y, por medio del presente,

INFORMA FAVORABLEMENTE su presentación.

De lo cual doy constancia a los efectos oportunos, en Burgos a 9 de junio de 2009.

Fdo.: Ángel Ballesteros Castañeda 

Dedicado a mis padres y a Amanda 



\section{AGRADECIMIENTOS}

Al final de todo este trabajo, son muchas las personas que me vienen a la memoria y a las que de una forma u otra quisiera agradecerles su apoyo, ayuda y comprensión.

En primer lugar a mi director de tesis Ángel Ballesteros, que de manera certera, concienzuda y sabia, ha guiado mis pasos por los terrenos de la física matemática. Su paciencia y confianza en mi trabajo a lo largo de estos años conoce ahora los frutos de ese esfuerzo en forma de esta Memoria de Tesis.

Igualmente quisiera agradecer a F. J. Herranz y a N. Cordero, profesores del Departamento de Física de esta Universidad, sus comentarios y ayuda a lo largo de este trabajo. Quiero agradecer aquí, la atención del profesor O. Ragnisco, responsable de mi estancia en la Universidad de Roma III en 2008. De igual manera, tengo presentes a S. Sanchez, T. Pérez, L. Sarabia y P. de las Heras, del Departamento de Matemáticas de la Universidad de Burgos, que desde siempre han mostrado interés por mi trabajo. Por supuesto, no olvido tampoco, a mis compañeros del Departamento de Física, y en especial a los miembros de la Politécnica del Vena, que facilitaron en todo momento mi estancia en Italia durante parte del año pasado.

Los amigos han jugado un papel muy importante a lo largo de mi vida, y es por ello que quiero dedicarles en parte mi trabajo. Desde mis amigos de la infancia del barrio, que todavía conservo, pasando por mis compañeros del Colegio Mayor en Valladolid, hasta mis antiguos colegas del conservatorio. Todo sigue vivo en mi recuerdo gracias a vuestra amistad

En este momento quiero nombrar de manera especial y sentida a Dani, Yasmina, Fernando... bueno... 'Curi', Jesús, Antonio, Ángela y Kike, a quien seguro le hubiera gustado ver los resultados de este trabajo. Javi, 'Herr Kapellmeister', Yolanda y Lucía, joven promesa de la ciencia burgalesa en el extranjero. Vuestra compañía a lo largo de los años no sólo me ha brindado momentos divertidos y entrañables, sino que me ha hecho crecer como persona.

A Vicente Elizondo, mi antiguo 'maestro' y actual amigo, responsable de mi pasión por la música en general y por el oboe en particular.

No quisiera olvidar tampoco mis orígenes profesionales como profesor de matemáticas y miembro del equipo directivo en el I.E.S. Félix Rodríguez de la Fuente de Burgos. Principalmente con personas de este centro, pero también de otros muchos, he tenido la suerte de compartir trabajo y experiencias que han dejado en mí una profunda huella. La enumeración no es exhaustiva, pero sí conmutativa: Eduardo, José Luis, Mari Luz, Ana, Pilar, Carlos, Chechu, Merche, Mónica, Inma, ... y muchos otros. 
A mi prima Lourdes, cuyo excelso conocimiento de la lengua inglesa se plasma en las maravillosas traducciones de las citas utilizadas. Y en general a toda mi familia (tíos, primos ...) que siempre ha seguido con atención mi trayectoria personal y profesional.

Para Amanda, de quien soy deudor de mucho tiempo. Ella ha animado, aguantado y sufrido todo el proceso de creación de este trabajo, sobre todo estos dos últimos años. Siempre estuvo ahí para dar una palabra de ánimo y cariño en los momentos de duda, que no han sido pocos.

Finalmente quisiera dar las gracias a mis padres. Podría llenar páginas acerca de sus virtudes, pero baste decir que sin su ayuda nada, absolutamente nada, hubiera sido posible. 


\section{Índice}

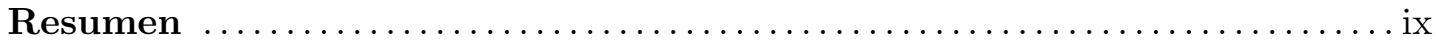

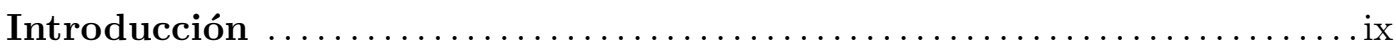

Sistemas integrables con simetría de coálgebra $\ldots \ldots \ldots \ldots \ldots \ldots \ldots$ xii

Coálgebras en dimensiones más altas $\ldots \ldots \ldots \ldots \ldots \ldots \ldots \ldots \ldots \ldots \ldots \ldots \ldots \ldots$

Integrabilidad ND a partir de la coálgebra 'two-photon' $\ldots \ldots \ldots \ldots \ldots$ xix

Perturbaciones integrables del oscilador armónico en ND $\ldots \ldots \ldots \ldots$ xxvii

Extendiendo la integrabilidad de $2 \mathrm{D}$ a $\mathrm{ND} \ldots \ldots \ldots \ldots \ldots \ldots \ldots \ldots \ldots \ldots \ldots \ldots$

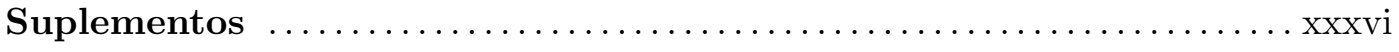

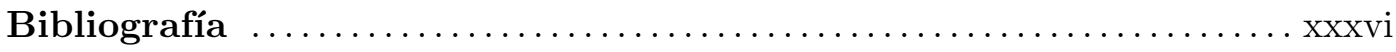

Conclusiones y problemas abiertos $\ldots \ldots \ldots \ldots \ldots \ldots \ldots \ldots \ldots \ldots \ldots \ldots \ldots \ldots \ldots \ldots \ldots$

Traducción del Índice de la versión inglesa $\ldots \ldots \ldots \ldots \ldots \ldots \ldots \ldots \ldots \ldots \ldots \ldots$

Ph.D. Thesis 'Integrability of nonlinear Hamiltonian systems

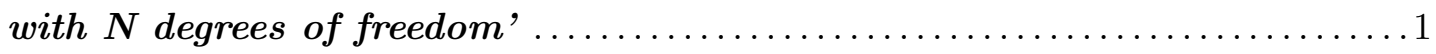




\section{Resumen}

Presentamos a continuación un resumen de cada uno de los Capítulos que constituyen esta Memoria de Tesis Doctoral. Por motivos de simplicidad en la presentación, prescindiremos de las referencias bibliográficas correspondientes, que se detallarán adecuadamente en la versión inglesa.

\section{Capítulo 1. Introducción}

Tanto la Mecánica Clásica como la Mecánica Cuántica, encuentran su marco más natural dentro del formalismo hamiltoniano. De hecho, el enfoque más usual de un sistema desde el punto de vista físico consiste en formular la función hamiltoniana para el caso clásico o su correspondiente operador para el caso cuántico. Desde una perspectiva estrictamente matemática, el formalismo hamiltoniano está ligado a la estructura de álgebra de Lie, dando una idea unitaria de la simetrías subyacentes en Mecánica Clásica y en Mecánica Cuántica. De hecho, aunque en esta Memoria nos concentraremos en el estudio de sistemas clásicos, el enfoque algebraico de este trabajo permitiría la formulación cuántica de los resultados aquí presentados.

Consideremos un sistema de partículas clásicas con $N$ grados de libertad. A partir del hamiltoniano del sistema, $\mathcal{H}^{(N)}\left(q_{1}, \ldots, q_{N}, p_{1}, \ldots, p_{N}\right)$ escrito en función de las variables canónicas, las ecuaciones de Hamilton:

$$
\dot{q}_{i}=\frac{\partial \mathcal{H}^{(N)}}{\partial p_{i}} \quad \dot{p}_{i}=-\frac{\partial \mathcal{H}^{(N)}}{\partial q_{i}} \quad i=1, \ldots, N
$$

nos suministran toda la información dinámica del sistema. El problema fundamental es, por tanto, encontrar la solución de ese sistema de ecuaciones diferenciales. En general, esto no es sencillo y en ocasiones ni siquiera posible, ya que los sistemas físicamente interesantes normalmente dan origen a un sistema de ecuaciones no lineales acopladas. 
Por ello, de entre todos los sistemas hamiltonianos, podemos extraer un conjunto muy interesante denominado 'sistemas exactamente o completamente resolubles': es decir, aquéllos para los cuales las ecuaciones de Hamilton pueden ser resueltas de manera exacta. El problema es que el número de sistemas que verifican esta propiedad es muy pequeño y, normalmente, la existencia de soluciones exactas está profundamente ligada a existencia de simetrías subyacentes del modelo en estudio.

Esta Memoria de Tesis Doctoral se ocupa de la construcción de nuevos sistemas hamiltonianos exactamente resolubles. La piedra angular de nuestro enfoque radica en la siguiente afirmación: si para un sistema hamiltoniano dado tenemos un número 'suficiente' de constantes del movimiento independientes, entonces las ecuaciones de Hamilton pueden ser integradas mediante 'cuadraturas'. Esto significa que las soluciones del sistema pueden ser obtenidas mediante un número finito de operaciones algebraicas (incluyendo inversión de funciones) y cuadraturas, es decir, la evaluación de integrales de ciertas funciones dadas. Este resultado, reformulado en un contexto más técnico quiere decir:

Sea $\mathcal{R}^{2 N}=\left(q_{1}, \ldots, q_{N}, p_{1}, \ldots, p_{N}\right)$ el espacio de fases de un sistema hamiltoniano descrito mediante la función $\mathcal{H}^{(N)}\left(q_{1}, \ldots, q_{N}, p_{1}, \ldots, p_{N}\right)$, junto con la definición habitual del corchete de Poisson

$$
\{f, g\}=\sum_{i=1}^{N}\left(\frac{\partial f}{\partial q_{i}} \frac{\partial g}{\partial p_{i}}-\frac{\partial g}{\partial q_{i}} \frac{\partial f}{\partial p_{i}}\right) .
$$

Si el sistema anterior tiene $(N-1)$ integrales del movimiento funcionalmente independientes $\left(\mathcal{F}_{1}, \mathcal{F}_{2}, \ldots, \mathcal{F}_{N-1}\right)$ y en involución,

$$
\left\{\mathcal{H}, \mathcal{F}_{j}\right\}=0 \quad\left\{\mathcal{F}_{i}, \mathcal{F}_{j}\right\}=0 \quad i, j=1, \ldots,(N-1)
$$

entonces las ecuaciones de Hamilton del sistema pueden resolverse mediante cuadraturas.

De hecho, un sistema hamiltoniano $\mathcal{H}^{(N)}$ con un número arbitrario, pero finito, de grados de libertad se dice que es completamente integrable (en el sentido de Liouville, anteriormente descrito), si existe ese conjunto de $(N-1)$ integrales $\left(\mathcal{F}_{1}, \ldots, \mathcal{F}_{N-1}\right)$ funcionalmente independientes. Por tanto, la integrabilidad completa de un sistema supone que podemos ser capaces de encontrar la solución explícita de su comportamiento dinámico. De hecho, es muy importante enfatizar que los sistemas integrables son el paradigma del movimiento regular, y pueden ser interpretados desde ese punto de vista como el extremo opuesto a los sistemas caóticos. Pero llegados a este punto, es muy importante subrayar que la integrabilidad de un hamiltoniano no es la regla, sino claramente la excepción, dentro de los sistemas hamiltonianos. 
Existen sistemas que tienen incluso más de $(N-1)$ integrales del movimiento funcionalmente independientes en involución con $\mathcal{H}^{(N)}$ son los denominados sistemas superintegrables. Es importante señalar que aunque existan más de $(N-1)$ integrales sólo $(N-1)$ de ellas pueden conmutar mutuamente entre sí bajo la acción del corchete de Poisson. Así, un sistema $N$-dimensional hamiltoniano $\mathcal{H}^{(N)}$ se dice que es maximalmente superintegrable (MS), si existe un conjunto máximo posible de $(2 N-2)$ integrales del movimiento globalmente definidas y funcionalmente independientes que conmutan con el hamiltoniano. A partir de la afirmación anterior se deduce que para estos sistemas, es posible extraer al menos dos conjuntos diferentes de tamaño $(N-1)$ de integrales que conmutan entre sí. Finalmente, un sistema hamiltoniano $N$-dimensional se dice cuasi-maximalmente superintegrable, si tiene $(2 N-3)$ integrales independientes verificando las propiedades anteriormente reseñadas.

Solamente se conocen un pequeño número de sistemas que son MS para cualquier número de grados de libertad. Los dos ejemplos más significativos lo constituyen el oscilador armónico y el potencial de Kepler. La superintegrabilidad es una propiedad que tiene profundas implicaciones geométricas, ya que todas las trayectorias acotadas de un sistema MS son necesariamente periódicas. De esta forma, los sistemas superintegrables serían el ejemplo paradigmático del comportamiento absolutamente no caótico.

Debido a todas estas propiedades, la construcción de sistemas hamiltonianos completamente integrables (en dimensión finita e infinita) ha merecido atención destacada desde hace más de un siglo. De hecho, las técnicas y enfoques que se han utilizado para su tratamiento han sido de lo más variado. A pesar de todo ello, uno de los principales problemas que persisten es la ausencia de un criterio suficiente y/o métodos sistemáticos para decidir si un sistema hamiltoniano dado es o no integrable. De hecho se han desarrollado algunas técnicas para la caracterización de ciertas condiciones de suficiencia como por ejemplo el test de Painlevé o el denominado test de YoshidaZiglin, aunque, a pesar de ello, el acercamiento actual a los sistemas integrables es de tipo fundamentalmente constructivo.

Además, es importante añadir que incluso para los sistemas hamiltonianos con tan sólo dos o tres grados de libertad, la clasificación de aquéllos que son integrables no es en absoluto trivial. Obviamente, las dificultades crecen de manera exponencial cuando el estudio se realiza en dimensiones más altas. De hecho, en la mayoría de los casos $N$-dimensionales conocidos, las propiedades de integrabilidad están basadas en la existencia de ciertas simetrías que permiten una adecuada extensión de la integrabilidad desde dimensiones bajas.

El objetivo principal de esta Memoria de Tesis Doctoral es la construcción de nuevos sistemas hamiltonianos integrables con $N$-grados de libertad que incluyan interacciones de tipo no lineal, para los cuales se pretende también la obtención explícita de sus in- 
tegrales del movimiento. El enfoque que hemos adoptado para la construcción de estos sistemas es la aplicación de la denominada simetría de coálgebra. Este método, cuando es aplicable, proporciona explícitamente las constantes del movimiento y permite igualmente la introducción de deformaciones integrables de los sistemas originales. En este contexto las funciones de Casimir de las álgebras utilizadas serán objetos esenciales ya que de ellas obtendremos las integrales de movimiento del sistema.

A continuación se resume el contenido de cada uno de los capítulos en que se divide esta Memoria, enfatizando las aportaciones originales realizadas. Debemos añadir finalmente que una parte significativa de dichos resultados originales aquí presentados, se han recogido en los trabajos que figuran como referencias con números [23], [27], 28], 30], 31] y [32. Sin embargo, esta Memoria contiene a su vez, algunos otros resultados no incluidos en estos artículos, dando además una visión unificada de la aplicación de la simetría de coálgebra a la formulación de nuevos sistemas hamiltonianos ND integrables.

\section{Capítulo 2. Sistemas integrables con simetría de coálgebra}

\subsection{Sistemas hamiltonianos definidos sobre coálgebras de Poisson}

En esta Sección se recapitula brevemente la construcción de sistemas hamiltonianos integrables con simetría de coálgebra. Partimos de un álgebra $A$, que junto con un homomorfismo llamado coproducto $\Delta$ y definido como

$$
\begin{gathered}
\Delta: A \rightarrow A \otimes A, \\
(\Delta \otimes i d) \circ \Delta=(i d \otimes \Delta) \circ \Delta
\end{gathered}
$$

hace que la construcción sea coasociativa. Es decir, se verifica el siguiente diagrama conmutativo

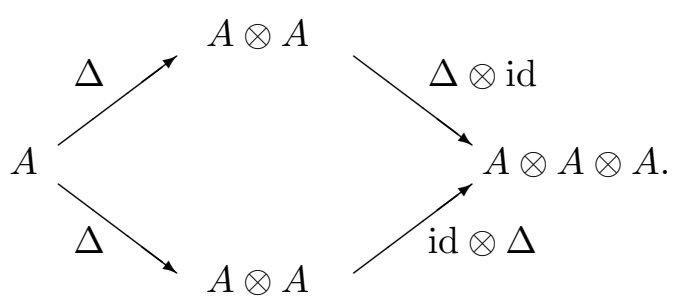


El coproducto $\Delta$ puede iterarse hasta un número arbitrario $N$ de copias del álgebra.

Un hamiltoniano con $N$ grados de libertad se dirá que tiene simetría de coálgebra si se construye como una función cualquiera del coproducto $N$-ésimo de los generadores de la coálgebra, es decir,

$$
\mathcal{H}^{(N)}:=\Delta^{(N)}\left(\mathcal{H}\left(X_{1}, \ldots, X_{l}\right)\right)=\mathcal{H}\left(\Delta^{(N)}\left(X_{1}\right), \ldots, \Delta^{(N)}\left(X_{l}\right)\right) .
$$

La integrabilidad completa de este tipo de sistema proviene de que, por construcción, la aplicación del coproducto a los $(r)$ operadores de Casimir $\left(\mathcal{C}_{j}\right)$ del álgebra utilizada

$$
\mathcal{C}_{j}^{(m)}:=\Delta^{(m)}\left(\mathcal{C}_{j}\left(X_{1}, \ldots, X_{l}\right)\right)=\mathcal{C}_{j}\left(\Delta^{(m)}\left(X_{1}\right), \ldots, \Delta^{(m)}\left(X_{l}\right)\right)
$$

proporciona siempre constantes del movimiento en involución con $\mathcal{H}^{(N)}$ :

$$
\left\{\mathcal{C}_{j}^{(m)}, \mathcal{H}^{N}\right\}_{A \otimes A \otimes \ldots{ }^{N)} \otimes A}=0 \quad m=1, \ldots, N .
$$

Además las constantes así obtenidas están en involución entre ellas

$$
\left\{\mathcal{C}_{i}^{(m)}, \mathcal{C}_{j}^{(n)}\right\}_{A \otimes A \otimes \ldots N) \otimes A}=0, \quad m, n=1, \ldots, N, \quad i, j=1, \ldots, r .
$$

Esta Memoria está basada en el hecho de que toda álgebra de Lie-Poisson $g^{*}$ con generadores $X_{i}(i=1, \ldots, l)$ y funciones de Casimir $\mathcal{C}_{j}\left(X_{1}, \ldots, X_{l}\right)(j=1, \ldots, r)$, tiene la estructura de coálgebra siguiente

$$
\Delta\left(X_{i}\right)=X_{i} \otimes 1+1 \otimes X_{i}
$$

y puede dar origen a hamiltonianos completamente integrables.

El método de la simetría de coálgebra ha sido aplicado anteriormente para la construcción de diferentes sistemas integrables basados en álgebras de dimensión 3 y una única función de Casimir no lineal, tomando siempre realizaciones simplécticas de los generadores en función de un único par de variables canónicas. En esta Sección se realiza un estudio sistemático de las condiciones que deben cumplir las realizaciones simplécticas arbitrarias

$$
D: x \rightarrow x\left(q_{1}, p_{1}, q_{2}, p_{2}, \ldots, q_{s}, p_{s}\right)
$$

de un álgebra cualquiera, para poder generar la integrabilidad completa del hamiltoniano $\mathcal{H}^{(N)}$.

Teniendo en cuenta que los invariantes o integrales del sistema serán los operadores de Casimir no lineales, para una coálgebra con dimensión $l$ y $R$ casimires no lineales 
xiv

con $s$ pares de variables canónicas en la realización simpléctica elegida, encontramos que debe cumplirse la siguiente condición necesaria de integrabilidad

$$
s \leq R-\frac{R-1}{N} .
$$

La expresión 12 implica que $s=1$ para coálgebras con $R=1$ y que $s<R$ para coálgebras con $R>1$. Nuestro posterior estudio sistemático de las álgebras de dimensiones 3, 4, 5, 6 (nilpotentes), se centrará en aquéllas que verifiquen este criterio. A partir de la fórmula anterior queda claro, que aquellas álgebras con un operador de Casimir no lineal $(R=1)$ deberán ser parametrizadas mediante una única pareja de variables canónicas para dar lugar a sistemas integrables. Ésta va a ser nuestra elección en todos los casos propuestos en este Capítulo y en el siguiente.

Considerando además la realización simpléctica genérica, cuya dimensión viene dada por

$$
s_{m}=\frac{l-r}{2}
$$

encontramos que la condición de integrabilidad que debe cumplirse es

$$
l \leq(2 R+r)-\frac{2}{N}(R-1) .
$$

Esta relación original, liga los parámetros $l, r, R$ y $N$, y será básica en todo el desarrollo posterior. En ella vemos que cualquier álgebra con representación $s_{m}=1$ y que tenga $R \geq 1$ verificará la condición de integrabilidad.

A continuación, también recordamos que la construcción de coálgebra puede dar lugar, en principio, a sistemas superintegrables, ya que el formalismo puede proporcionar hasta (2N-3) integrales del movimiento, cuya independencia funcional debe de ser comprobada a posteriori. En el caso más favorable, nuestros sistemas estarían a una sola integral del alcanzar el número máximo de integrales posibles (caso maximalmente superintegrable), integral que de existir, no puede ser aportada por este formalismo y debe obtenerse aparte.

\subsection{La coálgebra de Lie-Poisson $s l(2, \mathbb{R})$}

En este apartado, se muestra como ejemplo concreto del funcionamiento del esquema de simetría de coálgebra, la construcción de sistemas completamente integrables basados en $\operatorname{sl}(2, \mathbb{R})$. Este tipo de sistemas han sido ya descritos ampliamente en la literatura. A partir de los corchetes de Poisson:

$$
\left\{J_{3}, J_{+}\right\}=2 J_{+} \quad\left\{J_{3}, J_{-}\right\}=-2 J_{-} \quad\left\{J_{-}, J_{+}\right\}=4 J_{3}
$$


la función de Casimir es

$$
\mathcal{C}=J_{-} J_{+}-J_{3}^{2}
$$

y la realización simpléctica genérica viene dada por

$$
D\left(J_{-}\right)=q_{1}^{2} \quad D\left(J_{+}\right)=p_{1}^{2}+\frac{b_{1}}{q_{1}^{2}} \quad D\left(J_{3}\right)=q_{1} p_{1} .
$$

Con estos ingredientes, se obtienen los sistemas integrables definidos mediante

$$
\mathcal{H}^{(N)}=\mathcal{H}\left(\sum_{i=1}^{N}\left(p_{i}^{2}+\frac{b_{i}}{q_{i}^{2}}\right), \sum_{i=1}^{N} q_{i}^{2}, \sum_{i=1}^{N} q_{i} p_{i}\right) \quad b_{i} \in \mathbb{R}
$$

donde $\mathcal{H}$ es una función genérica con tres variables. Esta construcción será retomada en el Capítulo final, como parte integrante de un esquema algebraico más amplio, que permitirá la generalización axial ND de sistemas integrables 2D.

\subsection{Sistemas ND integrables a partir de coálgebras de Lie en 3D}

En esta Sección, se procede a la construcción exhaustiva de las realizaciones simplécticas genéricas de las 9 álgebras de Lie reales de dimensión 3 (ver Tabla 3). Igualmente, se presentan los sistemas hamiltonianos integrables a los que dan lugar estas álgebras junto con sus integrales del movimiento. En algunos casos, se aporta más de una posible parametrización para los generadores del álgebra. Como ejemplo de los nuevos hamiltonianos integrables encontrados en este Capítulo mostramos la siguiente construcción que proviene del álgebra $A_{3,3}$. A partir de los corchetes de Poisson no nulos

$$
\left\{J_{1}, J_{3}\right\}=J_{1} \quad\left\{J_{2}, J_{3}\right\}=J_{2}
$$

se puede formular el siguiente hamiltoniano,

$$
\mathcal{H}^{(N)}=\mathcal{H}\left(\sum_{i=1}^{N} \frac{p_{i}^{2}}{2 k_{i}}, \sum_{i=1}^{N} \frac{p_{i}^{2}}{2},-\sum_{i=1}^{N} \frac{p_{i} q_{i}}{2}\right)
$$

cuyas constantes del movimiento son

$$
\mathcal{C}^{(m)}=\frac{\left(\sum_{i=1}^{m} p_{i}^{2}\right)}{\left(\sum_{i=1}^{m} \frac{p_{i}^{2}}{k_{i}}\right)} \quad m=2, \ldots, N .
$$

Nótese que si tomamos la misma realización simpléctica en todas las copias del álgebra (esto es, si $k_{1}=k_{2}=\cdots=k_{N}$ ) todas las constantes del movimiento colapsan. Este hecho resalta la importancia de las realizaciones simplécticas elegidas. 
xvi

\subsection{Deformaciones integrables a partir de $q$-coálgebras de Poisson}

En esta Sección final, se recuerda cómo el formalismo de coálgebra puede ser aplicado para introducir de forma natural deformaciones integrables de sistemas hamiltonianos. Para ello, se utilizan las denominadas $q$-coálgebras de Poisson. Se presentan así los sistemas integrables obtenidos mediante la deformación $s l_{z}(2, \mathbb{R})$, que modifica la coálgebra $\operatorname{sl}(2, \mathbb{R})$ de la siguiente manera:

$$
\left\{J_{3}, J_{+}\right\}=2 J_{+} \cosh z J_{-} \quad\left\{J_{3}, J_{-}\right\}=-2 \frac{\sinh z J_{-}}{z} \quad\left\{J_{-}, J_{+}\right\}=4 J_{3} .
$$

El coproducto deformado es

$$
\begin{aligned}
& \Delta_{z}(1)=1 \otimes 1 \quad \Delta_{z}\left(J_{-}\right)=J_{-} \otimes 1+1 \otimes J_{-} \\
& \Delta_{z}\left(J_{i}\right)=J_{i} \otimes \mathrm{e}^{z J_{-}}+\mathrm{e}^{-z J_{-}} \otimes J_{i} \quad(i=+, 3) .
\end{aligned}
$$

La función de Casimir deformada se debe tomar como

$$
\mathcal{C}_{z}=\frac{\sinh z J_{-}}{z} J_{+}-J_{3}^{2}
$$

y la realización simpléctica correspondiente sería

$$
D_{z}\left(J_{-}\right)=q_{1}^{2} \quad D_{z}\left(J_{+}\right)=\frac{\sinh z q_{1}^{2}}{z q_{1}^{2}} p_{1}^{2}+\frac{z b_{1}}{\sinh z q_{1}^{2}} \quad D_{z}\left(J_{3}\right)=\frac{\sinh z q_{1}^{2}}{z q_{1}^{2}} q_{1} p_{1} .
$$

A partir de todo ello, se obtienen sistemas completamente integrables que deforman en términos del parámetro $z$ los ya obtenidos para $s l(2, \mathbb{R})$. Finalmente, se mencionan algunas de las aplicaciones físicas de los mismos.

\section{Capítulo 3.}

\section{Coálgebras en dimensiones más altas}

En este Capítulo se procede al estudio sistemático de todas las álgebras de Lie reales de dimensiones 4,5 y las nilpotentes de grado 6 . Se presentan todas aquellas que cumplen la condición de integrabilidad descrita en el Capítulo anterior (12 y 14), y para ellas, se construyen las familias de sistemas hamiltonianos integrables con simetría de coálgebra a los que dan lugar. 


\subsection{Sistemas integrables a partir de coálgebras 4D}

Se encuentran las realizaciones simplécticas de las 12 álgebras de Lie reales de dimensión 4 y se construyen los sistemas dinámicos que surgen de ellos, así como sus invariantes. El material se presenta de acuerdo con el número $R$ de casimires no lineales de cada una de las álgebras.

\section{Álgebras con $R=1$}

En la Tabla 4, se presentan dentro de esta Sección las álgebras $A_{4,1}, A_{4,3}, A_{4,8}$ y $A_{4,10}$. Como ejemplo de sistema dinámico interesante presentamos

$$
\mathcal{H}^{(N)}=\sum_{i=1}^{N} \frac{p_{i}^{2}+k_{1, i}^{2} q_{i}^{2}-k_{2, i}}{2 k_{1, i}}+\mathcal{F}\left(\sum_{i=1}^{N} k_{1, i} q_{i}\right)
$$

obtenido desde el álgebra $A_{4,10}$.

\section{Álgebras con $R=2$}

Siguiendo con el esquema anterior, la Tabla 5, muestra las álgebras $4 \mathrm{D}\left(A_{4,2}^{\alpha}, A_{4,4}, A_{4,5}^{a, b}\right.$ y $\left.A_{4,6}^{a, b}\right)$ que cuentan con dos funciones de Casimir no lineales. Desde un punto vista dinámico los sistemas aquí encontrados son menos interesantes. Como muestra de uno de ellos, presentamos el ejemplo de sistema formulado a partir de $A_{4,2}^{\alpha}$

$$
\mathcal{H}^{(N)}=\mathcal{H}\left(\sum_{i=1}^{N} \frac{k_{1, i}^{\alpha}}{k_{2, i}} e^{p_{i}}, \sum_{i=1}^{N} k_{1, i} e^{p_{i}}, \sum_{i=1}^{N} k_{1, i} p_{i} e^{p_{i}},-\sum_{i=1}^{N} q_{i}\right)
$$

donde, de nuevo, $\mathcal{H}$ es una función genérica de cuatro variables.

\subsection{Sistemas integrables a partir de coálgebras 5D}

En el mismo estilo que la Sección anterior, ésta presenta los sistemas que se formulan a partir de las 40 álgebras de Lie reales de dimensión 5, ordenados según el número de Casimires no lineales que aparecen en ellas. Una vez más, en la Memoria sólo se presentan los resultados que verifican la condición necesaria de integrabilidad (12). 
xviii

\section{Álgebras con $R=1$}

La Tabla 6 muestra las parametrizaciones simplécticas de las álgebras $A_{5,1}, A_{5,3}$. Como ejemplo más interesante podemos citar

$$
\mathcal{H}^{(N)}=\sum_{i=1}^{N} \frac{p_{i}^{2}}{2 k_{2, i}}+\sum_{i=1}^{N} k_{1, i} q_{i}+\mathcal{G}\left(\sum_{i=1}^{N} k_{2, i} q_{i}+\sum_{i=1}^{N} \frac{k_{3, i}}{k_{1, i}}\right)
$$

obtenido para el álgebra $A_{5,3}$. Nótese el papel destacado que en toda la formulación de la coálgebra desempeñan las constantes $k_{j, i}$, que indexan la realización simpléctica tomada en la copia $i$-ésima del álgebra.

\section{Álgebras con $R=2$}

La Tabla 7 presenta las realizaciones simplécticas de las álgebras $A_{5,2}, A_{5,8}^{c}, A_{5,10} \mathrm{y}$ $A_{5,14}^{\alpha}$. Un ejemplo de sistema hamiltoniano integrable sería

$$
\mathcal{H}^{(N)}=\mathcal{H}\left(\sum_{i=1}^{N} k_{1, i}, \sum_{i=1}^{N} k_{1, i} p_{i}, \sum_{i=1}^{N}\left(\frac{k_{1, i}}{2} p_{i}^{2}-\frac{k_{2, i}}{2 k_{1, i}}\right), \sum_{i=1}^{N} k_{3, i} e^{p_{i}},-\sum_{i=1}^{N} q_{i}\right) .
$$

Finalmente el caso $R=3$ se presenta en el Suplemento 3, ya que su interés dinámico es limitado. Sin embargo, sirve para ejemplificar la complejidad de las realizaciones simplécticas conforme se va subiendo de dimensión.

\subsection{Sistemas integrables a partir de coálgebras 6D nilpotentes}

Se han encontrado las realizaciones simplécticas de las 22 álgebras nilpotentes de dimensión 6, así como de las 12 solubles que contienen un nilradical abeliano. Del primer grupo, solamente tres de todas ellas verifican la condición necesaria de integrabilidad (12). Por este motivo, se presentan únicamente las álgebras $A_{6,3}, A_{6,1}$ y $A_{6,2}$, junto con los sistemas integrables a que dan lugar.

Del resto de álgebras de ese grupo, no se presentan explícitamente las parametrizaciones en esta Memoria, ya que aunque algebraicamente importantes, no dan lugar a sistemas dinámicos interesantes desde un punto de vista físico.

\subsection{Una familia de álgebras con dimensión arbitraria}

En la parte final del Capítulo, se presenta como resultado original la caracterización de la familia de álgebras de Lie denominada $\mathfrak{g}_{M}$ y definida por los corchetes de Poisson no 
nulos

$$
\left\{J_{i}, J_{M}\right\}=J_{i-1} \quad \forall i=2, \ldots, M-1 .
$$

Esta familia incluye como casos particulares las álgebras $A_{3,1}, A_{4,1}, A_{5,2}, \mathrm{y} A_{6,2}$.

Hemos encontrado la fórmula genérica para sus $(M-2)$ funciones de Casimir, que vienen dadas por

$\mathcal{C}_{\mathfrak{g}_{M}}\left\{\begin{array}{l}\mathcal{C}_{1}=J_{1} \\ \mathcal{C}_{2}=\frac{-J_{2}^{2}+2 J_{1} J_{3}}{2 J_{1}} \\ \vdots \quad \vdots \\ \mathcal{C}_{i}=\frac{(-1)^{i+1} J_{2}^{i}+\sum_{j=1}^{i-2} a_{j, i} J_{1}^{j} J_{2}^{(i-1-j)} J_{j+2}+i(i-2) ! J_{1}^{i-1} J_{i+1}}{i(i-2) ! J_{1}^{i-1}} \quad i=3, \ldots, M-2\end{array}\right.$

donde $a_{j}$ son ciertas constantes. Por tanto, esta familia cumple la condición de integrabilidad para todo $M>3$. La realización simpléctica de $\mathfrak{g}_{M}$ genérica tiene las siguientes expresiones para los generadores:

$$
\begin{aligned}
& J_{1}=k_{1} \\
& J_{2}=k_{1} p \\
& \vdots \quad \quad \quad \vdots \\
& J_{j}=k_{1} \frac{p^{j-1}}{(j-1) !}+\sum_{i=1}^{j-2} k_{i+1} \frac{p^{j-2-i}}{(j-2-i) !} \quad j=3,4, \ldots,(M-1) \\
& J_{M}=-q
\end{aligned}
$$

a partir de la cual, pueden escribirse los correspondientes hamiltonianos completamente integrables con un número arbitrario de grados de libertad dados por

$$
\mathcal{H}^{(N)}=\mathcal{H}\left(J_{1}, J_{2}, \ldots, J_{M}\right) .
$$

\section{Capítulo 4.}

\section{Integrabilidad ND a partir de la coálgebra 'two-photon'}

En este Capítulo se aplica el formalismo de la simetría de coálgebra para una cierta realización simpléctica (no genérica) de un álgebra de Lie de dimensión 6 denominada álgebra 'two-photon'. Los nuevos sistemas hamiltonianos clásicos integrables que se 
obtienen dependen de $N$ parámetros y de varias funciones arbitrarias. Igualmente dentro de este marco, se presentan todas sus integrales del movimiento. Como se verá en la serie de ejemplos presentados, el álgebra $h_{6}$ dará lugar a numerosos sistemas completamente integrables de gran interés físico.

\subsection{El álgebra $h_{6}$ o 'two-photon'}

Los corchetes de Poisson de este álgebra son

$$
\begin{array}{lll}
\left\{K, A_{+}\right\}=A_{+} & \left\{K, A_{-}\right\}=-A_{-} & \left\{A_{-}, A_{+}\right\}=M \\
\left\{K, B_{+}\right\}=2 B_{+} & \left\{K, B_{-}\right\}=-2 B_{-} & \left\{B_{-}, B_{+}\right\}=4 K+2 M \\
\left\{A_{+}, B_{-}\right\}=-2 A_{-} & \left\{A_{+}, B_{+}\right\}=0 & \{M, \cdot\}=0 \\
\left\{A_{-}, B_{+}\right\}=2 A_{+} & \left\{A_{-}, B_{-}\right\}=0 . &
\end{array}
$$

Sus dos casimires son el generador central $M$ y la función no lineal

$$
\mathcal{C}=\left(M B_{+}-A_{+}^{2}\right)\left(M B_{-}-A_{-}^{2}\right)-\left(M K-A_{-} A_{+}+M^{2} / 2\right)^{2} .
$$

Una realización simpléctica a una partícula de este álgebra, viene dada por

$$
\begin{aligned}
& A_{+}=\lambda_{1} p_{1} \quad A_{-}=\lambda_{1} q_{1} \quad K=q_{1} p_{1}-\frac{\lambda_{1}^{2}}{2} \\
& B_{+}=p_{1}^{2} \quad B_{-}=q_{1}^{2} \quad M=\lambda_{1}^{2} .
\end{aligned}
$$

A pesar de que este álgebra no verifica la condición de integrabilidad (12), es posible formular a partir de ella sistemas que están a falta de una única constante del movimiento para alcanzar la integrabilidad completa, tal y como analizamos en la Sección 4.2.

Desde un punto de vista físico, este álgebra contiene a $\operatorname{sl}(2, \mathbb{R})$ como subálgebra, lo cual supone que $h_{6}$ permite romper la simetría esférica a partir de la inclusión del término $A_{-}=\lambda_{1} q$. Igualmente, enfatizamos que la realización simpléctica (38) que se obtiene del coproducto, contiene $N$ parámetros libres $\lambda_{i}$. Este hecho va a proporcionar una gran abanico de posibilidades para los nuevos hamiltonianos presentados.

\subsection{Una familia infinita de sistemas cuasi-integrables}

El resultado fundamental de este capítulo es que cualquier hamiltoniano construido como una función

$$
\mathcal{H}=\mathcal{H}\left(K, B_{+}, B_{-}, A_{+}, A_{-}, M\right)
$$

donde

$$
A_{+}=\sum_{i=1}^{N} \lambda_{i} p_{i} \quad A_{-}=\sum_{i=1}^{N} \lambda_{i} q_{i} \quad K=\sum_{i=1}^{N}\left(q_{i} p_{i}-\frac{\lambda_{i}^{2}}{2}\right)
$$




$$
B_{+}=\sum_{i=1}^{N} p_{i}^{2} \quad B_{-}=\sum_{i=1}^{N} q_{i}^{2} \quad M=\sum_{i=1}^{N} \lambda_{i}^{2}
$$

es cuasi integrable, ya que posee $(N-2)$ integrales del movimiento dadas por

$$
\mathcal{C}^{(m)}=\sum_{1 \leq i<j<k}^{m}\left(\lambda_{i}\left(p_{j} q_{k}-p_{k} q_{j}\right)+\lambda_{j}\left(p_{k} q_{i}-p_{i} q_{k}\right)+\lambda_{k}\left(p_{i} q_{j}-p_{j} q_{i}\right)\right)^{2}
$$

donde $m=3, \ldots, N$. Nótese que el coproducto para $m=2$ da lugar a una integral trivial. Este hecho genera la ausencia de una integral del movimiento con respecto a todos los casos tratados hasta ahora, y refleja que la realización simpléctica elegida no cumple la condición de integrabilidad.

Se recapitula a continuación la forma general de algunos sistemas hamiltonianos cuasi-integrables que pueden formularse dentro de este marco, y cuyo estudio particular se desarrollará más adelante. De esta manera, se demuestra la cuasi-integrabilidad para cualquier $N$ de:

- Sistemas naturales.

$$
\mathcal{H}^{(N)}=\sum_{i=1}^{N} \frac{p_{i}^{2}}{2}+\mathcal{F}\left(\sum_{i=1}^{N} \lambda_{i} q_{i}, \sum_{i=1}^{N} q_{i}^{2}\right)
$$

- Hamiltonianos electromagnéticos. Los sistemas $h_{6}$ que contienen términos lineales en los momentos tienen la forma general siguiente:

$$
\begin{aligned}
\mathcal{H}^{(N)}= & \sum_{i=1}^{N} \frac{p_{i}^{2}}{2}+\left(\sum_{i=1}^{N}\left(q_{i} p_{i}-\frac{\lambda_{i}^{2}}{2}\right)\right) \mathcal{F}\left(\sum_{i=1}^{N} \lambda_{i} q_{i}, \sum_{i=1}^{N} q_{i}^{2}\right) \\
& +\left(\sum_{i=1}^{N} \lambda_{i} p_{i}\right) \mathcal{G}\left(\sum_{i=1}^{N} \lambda_{i} q_{i}, \sum_{i=1}^{N} q_{i}^{2}\right)+\mathcal{R}\left(\sum_{i=1}^{N} \lambda_{i} q_{i}, \sum_{i=1}^{N} q_{i}^{2}\right) .
\end{aligned}
$$

Comparando (para $N=3$ ) con un hamiltoniano electromagnético estático genérico

$$
\mathcal{H}_{e m}=\frac{1}{2}(\vec{p}-e \vec{A})^{2}+e \psi
$$

donde $e$ es la carga eléctrica, $\vec{A}$ es el potencial vector y $\psi$ el escalar, obtendríamos

$$
A_{i}=-\frac{q_{i}}{e} \mathcal{F}\left(\sum_{i=1}^{N} \lambda_{i} q_{i}, \sum_{i=1}^{N} q_{i}^{2}\right)-\frac{\lambda_{i}}{e} \mathcal{G}\left(\sum_{i=1}^{N} \lambda_{i} q_{i}, \sum_{i=1}^{N} q_{i}^{2}\right) \quad i=1,2,3
$$


xxii

$$
\begin{aligned}
\psi= & \frac{1}{e} \mathcal{R}\left(\sum_{i=1}^{N} \lambda_{i} q_{i}, \sum_{i=1}^{N} q_{i}^{2}\right)-\frac{1}{2 e}\left(\sum_{i=1}^{N} \lambda_{i}^{2}\right) \mathcal{F}\left(\sum_{i=1}^{N} \lambda_{i} q_{i}, \sum_{i=1}^{N} q_{i}^{2}\right) \\
& -\frac{1}{2 e}\left(\sum_{i=1}^{N} q_{i}^{2}\right)\left\{\mathcal{F}\left(\sum_{i=1}^{N} \lambda_{i} q_{i}, \sum_{i=1}^{N} q_{i}^{2}\right)\right\}^{2} \\
& -\frac{1}{e}\left(\sum_{i=1}^{N} \lambda_{i} q_{i}\right) \mathcal{F}\left(\sum_{i=1}^{N} \lambda_{i} q_{i}, \sum_{i=1}^{N} q_{i}^{2}\right) \mathcal{G}\left(\sum_{i=1}^{N} \lambda_{i} q_{i}, \sum_{i=1}^{N} q_{i}^{2}\right) \\
& -\frac{1}{2 e}\left(\sum_{i=1}^{N} \lambda_{i}^{2}\right)\left\{\mathcal{G}\left(\sum_{i=1}^{N} \lambda_{i} q_{i}, \sum_{i=1}^{N} q_{i}^{2}\right)\right\}^{2}
\end{aligned}
$$

siendo $\mathcal{F}, \mathcal{G}, \mathcal{R}$ funciones arbitrarias.

- Flujos geodésicos hamiltonianos. Recordemos la forma general de estos sistemas

$$
\mathcal{H}^{(N)}=\sum_{i, j=1}^{N} g^{i j}\left(q_{1}, \ldots, q_{N}\right) p_{i} p_{j}
$$

donde la métrica del espacio subyacente va a venir descrita por $g^{i j}\left(q_{1}, \ldots, q_{N}\right)$. Se prueba que el hamiltoniano $h_{6}$ invariante (y por tanto, cuasi-integrable) más general de este tipo que podemos escribir es

$$
\begin{aligned}
\mathcal{H}^{(N)}= & \left(\sum_{i=1}^{N} \frac{p_{i}^{2}}{2}\right) \mathcal{F}\left(\sum_{i=1}^{N} \lambda_{i} q_{i}, \sum_{i=1}^{N} q_{i}^{2}\right)+\left(\sum_{i=1}^{N} \lambda_{i} p_{i}\right)^{2} \mathcal{G}\left(\sum_{i=1}^{N} \lambda_{i} q_{i}, \sum_{i=1}^{N} q_{i}^{2}\right) \\
& +\left(\sum_{i=1}^{N} q_{i} p_{i}\right)^{2} \mathcal{R}\left(\sum_{i=1}^{N} \lambda_{i} q_{i}, \sum_{i=1}^{N} q_{i}^{2}\right) \\
& +\left(\sum_{i=1}^{N} q_{i} p_{i}\right)\left(\sum_{i=1}^{N} \lambda_{i} p_{i}\right) \mathcal{S}\left(\sum_{i=1}^{N} \lambda_{i} q_{i}, \sum_{i=1}^{N} q_{i}^{2}\right) .
\end{aligned}
$$

\subsection{Integrabilidad completa}

En todos los ejemplos descritos en la Sección anterior disponemos de $(N-2)$ integrales funcionalmente independientes y en involución. Por ello, es necesario encontrar para qué formas concretas del hamiltonano existe una integral adicional independiente que pueda escribirse en función de los generadores de $h_{6}$. A continuación se presentan tres posibilidades distintas para abordar este problema. 


\subsection{Integrabilidad a partir de las subálgebras}

Un aspecto importante del álgebra $h_{6}$ es su rica estructura de subálgebras. Teniendo en cuenta este hecho, es inmediato probar que si un hamiltoniano se define en función de los generadores de una de las subálgebras de $h_{6}$, podemos entonces completar el conjunto de integrales del movimiento con el coproducto $N$-ésimo del Casimir de la subálgebra correspondiente. Por tanto, se consigue demostrar la integrabilidad completa de los siguientes hamiltonianos:

$$
\begin{aligned}
& \mathcal{H}_{\mathcal{D}_{+}}=\mathcal{H}_{\mathcal{D}_{+}}\left(K, A_{+}, B_{+}\right) \\
& \mathcal{H}_{\mathcal{D}_{-}}=\mathcal{H}_{\mathcal{D}_{-}}\left(K, A_{-}, B_{-}\right) \\
& \mathcal{H}_{h_{4}}=\mathcal{H}_{h_{4}}\left(K, A_{-}, A_{+}, M\right) \\
& \mathcal{H}_{\overline{\mathcal{G}}_{+}}=\mathcal{H}_{\overline{\mathcal{G}}_{+}}\left(B_{+}, A_{-}, A_{+}, M\right) \\
& \mathcal{H}_{\overline{\mathcal{G}}_{-}}=\mathcal{H}_{\overline{\mathcal{G}}_{-}}\left(B_{-}, A_{-}, A_{+}, M\right) \\
& \mathcal{H}_{\overline{\mathcal{E}}}=\mathcal{H}_{\overline{\mathcal{E}}}\left(\mu B_{+}+\nu B_{-}, A_{-}, A_{+}, M\right) \\
& \mathcal{H}_{g l(2)}=\mathcal{H}_{g l(2)}\left(K, B_{-}, B_{+}, M\right) .
\end{aligned}
$$

La subálgebra a que corresponde cada caso se describe detalladamente en esta Sección, así como la integral adicional que proporciona.

\subsection{Integrabilidad a través de un generador}

Proponemos aquí una segunda estrategia para conseguir sistemas completamente integrables: elegimos un generador $X$ de $h_{6} \mathrm{y}$, posteriormente, buscamos todos aquellos generadores $X_{j}(j=1, \ldots, l)$ que conmutan con $X$ y todas las subálgebras $g_{k}(k=1, \ldots, t)$ que contienen a $X$ como generador. De esta manera, el hamiltoniano construido como sigue

$$
\mathcal{H}_{X}=\mathcal{H}_{X}\left(\mathcal{C}_{g_{1}}, \ldots, \mathcal{C}_{g_{t}}, X, X_{1}, \ldots, X_{l}\right),
$$

donde $\mathcal{C}_{g_{k}}$ es el operador de Casimir de la subálgebra $g_{k}$, verifica

$$
\left\{\mathcal{H}_{X}, X\right\}=0 \text {. }
$$

Utilizando el esquema anterior, vamos a poder construir sistemas de diferentes tipos cuya integral adicional será $X^{(N)}$. La integrabilidad completa de este tipo de hamiltonianos se alcanza mediante el conjunto de integrales

$$
\left\{\mathcal{C}_{h_{6}}^{(3)}, \ldots, \mathcal{C}_{h_{6}}^{(N)}, X^{(N)}, \mathcal{H}\right\}
$$


xxiv

Algunos ejemplos significativos de esta construcción son los siguientes:

- Hamiltonianos en involución con $K$. La forma general de estos sistemas será la siguiente:

$$
\mathcal{H}_{K}=\mathcal{H}_{K}\left(\mathcal{C}_{D_{+}}, \mathcal{C}_{D_{-}}, \mathcal{C}_{h_{4}}, \mathcal{C}_{g l(2)}, K, M\right)
$$

En este caso, sólo pueden formularse flujos geodésicos hamiltonianos. La expresión más general de estos sistemas integrables es

$$
\begin{aligned}
\mathcal{H}_{K}^{(N)}= & \left(\sum_{1 \leq i<j}^{N}\left(q_{j} p_{i}-q_{i} p_{j}\right)^{2}\right) \mathcal{F}\left(\frac{\left(\sum_{i=1}^{N} \lambda_{i} q_{i}\right)^{2}}{\sum_{i=1}^{N} q_{i}^{2}}\right)+\left(\sum_{i=1}^{N} q_{i} p_{i}\right)^{2} \mathcal{G}\left(\frac{\left(\sum_{i=1}^{N} \lambda_{i} q_{i}\right)^{2}}{\sum_{i=1}^{N} q_{i}^{2}}\right) \\
& +\left(\sum_{1 \leq i<j}^{N}\left(\lambda_{j} p_{i}-\lambda_{i} p_{j}\right)\left(\lambda_{j} q_{i}-\lambda_{i} q_{j}\right)\right)^{2} \mathcal{R}\left(\frac{\left(\sum_{i=1}^{N} \lambda_{i} q_{i}\right)^{2}}{\sum_{i=1}^{N} q_{i}^{2}}\right) \\
& +\left(\sum_{1 \leq i<j}^{N}\left(\lambda_{j} p_{i}-\lambda_{i} p_{j}\right)\left(\lambda_{j} q_{i}-\lambda_{i} q_{j}\right)\right)^{N}\left(\sum_{i=1}^{N} q_{i} p_{i}\right) \mathcal{S}\left(\frac{\left(\sum_{i=1}^{N} \lambda_{i} q_{i}\right)^{2}}{\sum_{i=1}^{N} q_{i}^{2}}\right)
\end{aligned}
$$

donde $\mathcal{F}, \mathcal{G}, \mathcal{R}, \mathcal{S}$ son funciones arbitrarias.

- Hamiltonianos en involución con $A_{+}$. Ésta es la familia de hamiltonianos que admite mayor variedad dentro de este esquema. Los sistemas tienen como invariante al generador $A_{+}^{(N)}=\sum_{i=1}^{N} \lambda_{i} p_{i}$, que en esencia representa una generalización de la simetría traslacional. Entre la variedad de sistemas que pueden así construirse presentamos hamiltonianos naturales

$$
\mathcal{H}_{A_{+}}^{(N)}=\sum_{i=1}^{N} \frac{p_{i}^{2}}{2}+\mathcal{F}\left(\sum_{1 \leq i<j}^{N}\left(\lambda_{j} q_{i}-\lambda_{i} q_{j}\right)^{2}\right)
$$


sistemas electromagnéticos de la forma

$$
\begin{aligned}
\mathcal{H}_{A_{+}}^{(N)}= & \sum_{i=1}^{N} \frac{p_{i}^{2}}{2}+\left(\sum_{1 \leq i<j}^{N}\left(\lambda_{j} p_{i}-\lambda_{i} p_{j}\right)\left(\lambda_{j} q_{i}-\lambda_{i} q_{j}\right)\right) \mathcal{G}\left(\sum_{1 \leq i<j}^{N}\left(\lambda_{j} q_{i}-\lambda_{i} q_{j}\right)^{2}\right) \\
& +\left(\sum_{i=1}^{N} \lambda_{i} p_{i}\right) \mathcal{R}\left(\sum_{1 \leq i<j}^{N}\left(\lambda_{j} q_{i}-\lambda_{i} q_{j}\right)^{2}\right)+\mathcal{F}\left(\sum_{1 \leq i<j}^{N}\left(\lambda_{j} q_{i}-\lambda_{i} q_{j}\right)^{2}\right)
\end{aligned}
$$

y, finalmente, flujos geodésicos del tipo

$$
\begin{aligned}
\mathcal{H}_{A_{+}}^{(N)}= & \left(\sum_{1 \leq i<j}^{N}\left(\lambda_{j} p_{i}-\lambda_{i} p_{j}\right)\left(\lambda_{j} q_{i}-\lambda_{i} q_{j}\right)\right)^{2} \mathcal{F}\left(\sum_{1 \leq i<j}^{N}\left(\lambda_{j} q_{i}-\lambda_{i} q_{j}\right)^{2}\right) \\
& +\left(\sum_{1 \leq i<j}^{N}\left(\lambda_{j} p_{i}-\lambda_{i} p_{j}\right)^{2}\right) \mathcal{G}\left(\sum_{1 \leq i<j}^{N}\left(\lambda_{j} q_{i}-\lambda_{i} q_{j}\right)^{2}\right) \\
& +\left(\sum_{i=1}^{N} p_{i}^{2}\right) \mathcal{R}\left(\sum_{1 \leq i<j}^{N}\left(\lambda_{j} q_{i}-\lambda_{i} q_{j}\right)^{2}\right)+\left(\sum_{i=1}^{N} \lambda_{i} p_{i}\right)^{2} \mathcal{S}\left(\sum_{1 \leq i<j}^{N}\left(\lambda_{j} q_{i}-\lambda_{i} q_{j}\right)^{2}\right) \\
& +\left(\sum_{i=1}^{N} \lambda_{i} p_{i}\right)\left(\sum_{1 \leq i<j}^{N}\left(\lambda_{j} p_{i}-\lambda_{i} p_{j}\right)\left(\lambda_{j} q_{i}-\lambda_{i} q_{j}\right)\right) \mathcal{T}\left(\sum_{1 \leq i<j}^{N}\left(\lambda_{j} q_{i}-\lambda_{i} q_{j}\right)^{2}\right) .
\end{aligned}
$$

- Hamiltonianos en involución con $A_{-}, B_{-}$ó $B_{+}$. En este apartado final dedicado a la integrabilidad conseguida a partir de un generador se muestran los sistemas que conmutan con cada uno de los restantes generadores no triviales de $h_{6}$. Los sistemas que se generan son todos ellos flujos geodésicos completamente integrables que se describen explícitamente en la Memoria.

\subsection{Búsqueda directa de hamiltonianos integrables}

La tercera posibilidad para conseguir la integral adicional $(\mathcal{I})$ de un sistema cuasiintegrable definido sobre $h_{6}$, consiste en realizar su búsqueda mediante cálculo directo, una vez que se realiza una cierta hipótesis bastante restrictiva sobre la forma del hamiltoniano. En esta Sección se presentan los resultados originales obtenidos mediante este tipo de búsqueda. Recogemos a continuación algunos de los más significativos. 
xxvi

\section{Sistemas naturales: el hamiltoniano de Garnier}

Si consideramos el siguiente hamiltoniano

$$
\mathcal{H}=\frac{1}{2} B_{+}+\delta_{1} B_{-}+\delta_{2} A_{-}^{2}+\delta_{3} B_{-}^{2}
$$

donde $\delta_{1}, \delta_{2}, \delta_{3}$ son constantes arbitrarias, probamos que la función

$$
\mathcal{I}=\delta_{3} C_{g l(2)}-\delta_{2}\left(A_{+}^{2}+2 A_{-}^{2}\left(M \delta_{2}+\delta_{1}+\delta_{3} B_{-}\right)\right)
$$

conmuta con $\mathcal{H}$. Como caso particular de este sistema, se obtiene justamente el hamil-

toniano de Garnier con dos frecuencias de oscilador distintas. En 2D, si tomamos $\lambda_{1}=1, \lambda_{2}=0$, tenemos

$$
\mathcal{H}^{(2)}=\frac{1}{2}\left(p_{1}^{2}+p_{2}^{2}\right)+A q_{1}^{2}+B q_{2}^{2}+\delta_{3}\left(q_{1}^{2}+q_{2}^{2}\right)^{2}
$$

donde $A=\delta_{1}+\delta_{2}$, y $B=\delta_{1}$. En tres dimensiones tomando $\lambda_{1}=1, \lambda_{2}=\lambda_{3}=0$ obtenemos

$$
\mathcal{H}^{(3)}=\frac{1}{2}\left(p_{1}^{2}+p_{2}^{2}+p_{3}^{2}\right)+\left(\delta_{1}+\delta_{2}\right) q_{1}^{2}+\delta_{1} q_{2}^{2}+\delta_{1} q_{3}^{2}+\delta_{3}\left(q_{1}^{2}+q_{2}^{2}+q_{3}^{2}\right)^{2}
$$

que sería la generalización axialmente simétrica de (58).

\section{Hamiltonianos electromagnéticos.}

Un ejemplo de sistema integrable tridimensional y lineal en los momentos con campo magnético no nulo y variable, encontrado mediante búsqueda directa, es el siguiente:

$$
\mathcal{H}=\frac{1}{2} \sum_{i=1}^{3} p_{i}^{2}+\delta_{5}\left\{\sum_{i=1}^{3} q_{i} p_{i}-\frac{\lambda_{i}^{2}}{2}\right\}\left(\sum_{i=1}^{3} \lambda_{i} q_{i}\right)+\delta_{6} \sum_{i=1}^{3} \lambda_{i} p_{i}
$$

\section{Flujos geodésicos hamiltonianos}

Son varios los flujos geodésicos interesantes cuya integrabilidad completa puede demostrarse mediante este método. En particular, el hamiltoniano

$$
\mathcal{H}=B_{+}\left(\alpha_{1} A_{-}+\alpha_{2} B_{-}+\alpha_{3}\right)
$$

o, lo que es lo mismo

$$
\mathcal{H}^{(N)}=\left(\sum_{i=1}^{N} p_{i}^{2}\right)\left\{\alpha_{1} \sum_{i=1}^{N} \lambda_{i} q_{i}+\alpha_{2} \sum_{i=1}^{N} q_{i}^{2}+\alpha_{3}\right\}
$$


donde $\alpha_{1}, \alpha_{2}, \alpha_{3}$ son constantes, es uno de ellos, ya que la siguiente integral, en involución con (61), puede encontrarse por cálculo directo:

$$
\mathcal{I}=4 \alpha_{1} \alpha_{2} A_{+}\left(K+\frac{M}{2}\right)+4 \alpha_{2} \alpha_{3} B_{+}+4 \alpha_{2}^{2} K(K+M)-\alpha_{1}^{2} \mathcal{C}_{\overline{\mathcal{G}}_{+}} .
$$

La curvatura gaussiana del espacio 2D definido por este flujo es

$$
\mathcal{K}=\frac{4 \alpha_{2} \alpha_{3}-\alpha_{1}^{2}\left(\lambda_{1}^{2}+\lambda_{2}^{2}\right)}{2\left[\alpha_{2}\left(q_{1}^{2}+q_{2}^{2}\right)+\alpha_{3}+\alpha_{1}\left(\lambda_{1} q_{1}+\lambda_{2} q_{2}\right)\right]}
$$

lo que significa que estamos ante variedades integrables con curvatura no constante. El resto de nuevos flujos geodésicos encontrados presentan esta misma propiedad.

\section{Capítulo 5.}

\section{Perturbaciones integrables del oscilador armónico en ND}

En este Capítulo se presentan dos familias de perturbaciones ND integrables del sistema hamiltoniano integrable por antonomasia: el oscilador armónico. Al igual que en el Capítulo anterior, la construcción algebraica está basada en $h_{6}$. Nótese que, aunque las perturbaciones integrables 2D y 3D del oscilador armónico han sido estudiadas con cierto detalle, el número de aquellas que son integrables en ND es realmente escaso.

\subsection{Un nuevo hamiltoniano ND integrable}

En esta Sección introducimos la siguiente familia de hamiltonianos

$$
\mathcal{H}^{(N)}=\frac{1}{2} \sum_{i=1}^{N} p_{i}^{2}+\delta_{1} \sum_{i=1}^{N} q_{i}^{2}+\mathcal{F}\left(\sum_{i<j}^{N}\left(\lambda_{j} q_{i}-\lambda_{i} q_{j}\right)^{2}\right)+\mathcal{G}\left(\sum_{i=1}^{N} \lambda_{i} q_{i}\right)
$$

y probamos su integrabilidad completa. Es interesante recalcar que sus invariantes son las siguientes expresiones

$$
\mathcal{C}^{(m)}=\sum_{1 \leq i<j<k}^{m}\left(\lambda_{i}\left(p_{j} q_{k}-p_{k} q_{j}\right)+\lambda_{j}\left(p_{k} q_{i}-p_{i} q_{k}\right)+\lambda_{k}\left(p_{i} q_{j}-p_{j} q_{i}\right)\right)^{2} \quad m=3, \ldots, N
$$

junto con

$$
\mathcal{I}^{(N)}=\left(\sum_{i=1}^{N} \lambda_{i} p_{i}\right)^{2}+2 \delta_{1}\left(\sum_{i=1}^{N} \lambda_{i} q_{i}\right)^{2}+2\left(\sum_{i=1}^{N} \lambda_{i}^{2}\right) \mathcal{G}\left(\sum_{i=1}^{N} \lambda_{i} q_{i}\right)
$$


xxviii

El aspecto más llamativo de este resultado radica en el hecho de que la integral (67) no depende de la función $\mathcal{F}$.

Como caso particular, eligiendo $\mathcal{F}(x)=\alpha / x$, llegamos al siguiente hamiltoniano

$$
\mathcal{H}^{(N)}=\frac{1}{2} \sum_{i=1}^{N} p_{i}^{2}+\delta_{1} \sum_{i=1}^{N} q_{i}^{2}+\frac{\alpha}{\sum_{1 \leq i<j}^{N}\left(\lambda_{j} q_{i}-\lambda_{i} q_{j}\right)^{2}}+\mathcal{G}\left(\sum_{i=1}^{N} \lambda_{i} q_{i}\right)
$$

Este sistema, sólo en dos dimensiones reproduce el sistema de Calogero-Moser

$$
\mathcal{H}^{(2)}=\frac{1}{2}\left(p_{1}^{2}+p_{2}^{2}\right)+\delta_{1}\left(q_{1}^{2}+q_{2}^{2}\right)+\frac{\alpha}{\left(\lambda_{2} q_{1}-\lambda_{1} q_{2}\right)^{2}}+\mathcal{G}\left(\lambda_{1} q_{1}+\lambda_{2} q_{2}\right) .
$$

Por el contrario, el hamiltoniano anterior, aun no siendo el modelo de Calogero-Moser en dimensión arbitraria, sigue manteniendo su integrabilidad completa.

\section{El problema de la isotropía}

A la vista de la familia de hamiltonianos anteriormente introducida (65), se estudia el problema de la posible anisotropía en las frecuencias que podría surgir a partir de la elección de las funciones arbitrarias $\mathcal{F}$ y $\mathcal{G}$.

Con el fin de aclarar este aspecto, partiendo del siguiente hamiltoniano

$$
\begin{aligned}
\mathcal{H}^{(N)}= & \frac{1}{2} \sum_{i=1}^{N} p_{i}^{2}+\delta_{1} \sum_{i=1}^{N} q_{i}^{2}+\alpha_{1}\left(\sum_{i<j}^{N}\left(\lambda_{j} q_{i}-\lambda_{i} q_{j}\right)^{2}\right)+\beta_{1}\left(\sum_{i=1}^{N} \lambda_{i} q_{i}\right)^{2} \\
& +f\left(\sum_{i<j}^{N}\left(\lambda_{j} q_{i}-\lambda_{i} q_{j}\right)^{2}\right)+g\left(\sum_{i=1}^{N} \lambda_{i} q_{i}\right)
\end{aligned}
$$

encontramos sólo dos posibilidades de anulación de los términos cruzados de tipo $q_{i} q_{j}$ :

- A) $\alpha_{1}=\beta_{1}$. Que conduce al caso isótropo dado por

$$
\mathcal{H}^{(N)}=\frac{1}{2} \sum_{i=1}^{N} p_{i}^{2}+\omega^{2} \sum_{i=1}^{N} q_{i}^{2}+f\left(\sum_{i<j}^{N}\left(\lambda_{j} q_{i}-\lambda_{i} q_{j}\right)^{2}\right)+g\left(\sum_{i=1}^{N} \lambda_{i} q_{i}\right)
$$

$\operatorname{con} \omega^{2}=\delta_{1}+\alpha_{1} \sum_{i=1}^{N} \lambda_{i}^{2}$ 
xxix

- B) Para un $i$ fijado, otra solución emerge de $\lambda_{i}=\lambda$ y $\lambda_{j}=0$ para $j \neq i$. Tomando por ejemplo $\lambda_{1}=\lambda$ el sistema hamiltoniano integrable deviene en la siguiente forma

$$
\mathcal{H}^{(N)}=\frac{1}{2} p_{1}^{2}+\omega_{1}^{2} q_{1}^{2}+g\left(\lambda q_{1}\right)+\frac{1}{2} \sum_{i=2}^{N} p_{i}^{2}+\omega_{2}^{2} \sum_{i=2}^{N} q_{i}^{2}+f\left(\lambda^{2} \sum_{i=2}^{N} q_{i}^{2}\right)
$$

con $\omega_{1}^{2}=\lambda^{2} \beta_{1}+\delta_{1}$ y $\omega_{2}^{2}=\lambda^{2} \alpha_{1}+\delta_{1}$. Por tanto, esta solución anisótropa resulta trivialmente separable, y en lo que sigue se considera tan sólo el caso isótropo (70).

\subsection{Osciladores no lineales acoplados en ND}

Como casos particulares de la familia de perturbaciones anteriormente introducida, consideramos las funciones $\mathcal{F}$ y $\mathcal{G}$, que dan lugar a osciladores acoplados de grados cuatro y seis.

\section{Perturbaciones cuárticas homogéneas}

La perturbación más general de este tipo viene dada por:

$$
\mathcal{H}^{(N)}=\frac{1}{2} \sum_{i=1}^{N} p_{i}^{2}+\delta_{1} \sum_{i=1}^{N} q_{i}^{2}+\alpha_{2}\left(\sum_{i<j}^{N}\left(\lambda_{j} q_{i}-\lambda_{i} q_{j}\right)^{2}\right)^{2}+\beta_{3}\left(\sum_{i=1}^{N} \lambda_{i} q_{i}\right)^{4} .
$$

Si elegimos para el caso bidimensional $\lambda_{1}=1, \lambda_{2}=0$ obtenemos

$$
\mathcal{H}^{(2)}=\frac{1}{2}\left(p_{1}^{2}+p_{2}^{2}\right)+\delta_{1}\left(q_{1}^{2}+q_{2}^{2}\right)+\beta_{3} q_{1}^{4}+\alpha_{2} q_{2}^{4}
$$

que es un sistema separable, siendo su integral la siguiente expresión:

$$
\mathcal{I}^{(2)}=p_{1}^{2}+2\left(\delta_{1} q_{1}^{2}+\beta_{3} q_{1}^{4}\right) .
$$

En 3 dimensiones tomando $\lambda_{1}=1, \lambda_{2}=\lambda_{3}=0$ obtenemos

$$
\mathcal{H}^{(3)}=\frac{1}{2}\left(p_{1}^{2}+p_{2}^{2}+p_{3}^{2}\right)+\delta_{1}\left(q_{1}^{2}+q_{2}^{2}+q_{3}^{2}\right)+\alpha_{2}\left(q_{2}^{2}+q_{3}^{2}\right)^{2}+\beta_{3} q_{1}^{4}
$$

Por otra parte, una elección diferente de las $\lambda$ como por ejemplo $\lambda_{1}=1, \lambda_{2}=1, \alpha_{2}=$ $\beta_{3}=\epsilon / 2$ nos hace recuperar un sistema integrable ya conocido

$$
\mathcal{H}^{(2)}=\frac{1}{2}\left(p_{1}^{2}+p_{2}^{2}\right)+\delta_{1}\left(q_{1}^{2}+q_{2}^{2}\right)+\epsilon\left(q_{1}^{4}+q_{2}^{4}+6 q_{1}^{2} q_{2}^{2}\right) .
$$


$\mathrm{XXX}$

En tres dimensiones, si elegimos $\lambda_{1}=\lambda_{2}=\lambda_{3}=1$ se llega a

$$
\begin{aligned}
\mathcal{H}^{(3)}= & \frac{1}{2}\left(p_{1}^{2}+p_{2}^{2}+p_{3}^{2}\right)+\delta_{1}\left(q_{1}^{2}+q_{2}^{2}+q_{3}^{2}\right) \\
& +2 \alpha_{2}\left(\left(q_{2}-q_{1}\right)^{4}+\left(q_{3}-q_{1}\right)^{4}+\left(q_{3}-q_{2}\right)^{4}\right)+\beta_{3}\left(q_{1}+q_{2}+q_{3}\right)^{4}
\end{aligned}
$$

sistema que generaliza el potencial de Chudnovsky.

\section{Perturbaciones séxticas homogéneas}

Estas perturbaciones se generan a partir de la elección $f(x)=\alpha_{3} x^{3}$ y $g(y)=\beta_{5} y^{6}$, lo cual conduce a una perturbación del tipo:

$$
f+g=\alpha_{3}\left(\sum_{i<j}^{N}\left(\lambda_{j} q_{i}-\lambda_{i} q_{j}\right)^{2}\right)^{3}+\beta_{5}\left(\sum_{i=1}^{N} \lambda_{i} q_{i}\right)^{6} .
$$

Para el caso 3D con, $\lambda_{1}=\lambda_{2}=1$ y $\alpha_{2}=\beta_{5}=\frac{b}{2}$ se recobra un conocido sistema integrable de osciladores de grado seis acoplados:

$$
\mathcal{H}^{(2)}=\frac{1}{2}\left(p_{1}^{2}+p_{2}^{2}\right)+\delta_{1}\left(q_{1}^{2}+q_{2}^{2}\right)+b\left(q_{1}^{6}+q_{2}^{6}+15 q_{1}^{2} q_{2}^{2}\left(q_{1}^{2}+q_{2}^{2}\right)\right) .
$$

El cálculo del invariante adicional en todos estos casos se basa en la sustitución directa de la fórmula general (67).

\subsection{Otras perturbaciones integrables en ND}

Como segundo resultado importante de este Capítulo presentamos otra familia de perturbaciones integrables, que incluye una función homogénea de grado -2 en las coordenadas, junto con otra función radial arbitraria:

$$
\begin{aligned}
\mathcal{H}_{r} & =\frac{1}{2} B_{+}+\delta_{1} B_{-}+\mathcal{V}_{-2}\left(A_{-}, B_{-}\right)+\mathcal{J}\left(B_{-}\right) \\
& =\frac{1}{2} \sum_{i=1}^{N} p_{i}^{2}+\delta_{1} \sum_{i=1}^{N} q_{i}^{2}+\mathcal{V}_{-2}\left(\sum_{i=1}^{N} \lambda_{i} q_{i}, \sum_{i=1}^{N} q_{i}^{2}\right)+\mathcal{J}\left(\sum_{i=1}^{N} q_{i}^{2}\right)
\end{aligned}
$$

donde $\delta_{1}, \lambda_{i}(i=1, \ldots, N)$ son parámetros libres.

Demostramos que la integral adicional de este sistema es

$$
\mathcal{I}_{r}^{(N)}=\sum_{1 \leq i<j}^{N}\left(q_{j} p_{i}-q_{i} p_{j}\right)^{2}+2\left(\sum_{i=1}^{N} q_{i}^{2}\right) \mathcal{V}_{-2}\left(\sum_{i=1}^{N} \lambda_{i} q_{i}, \sum_{i=1}^{N} q_{i}^{2}\right)
$$


Una vez más, el aspecto más importante del sistema anterior recae en la libertad de elección de ambas funciones arbitrarias.

\section{Un nuevo modelo ND integrable}

Es muy interesante destacar que si tomamos en el sistema anterior todos $\operatorname{los} \lambda_{i}=1$ junto con

$$
\mathcal{V}_{-2}\left(A_{-}, B_{-}\right)=\varepsilon \frac{A_{-}^{2}-B_{-}}{B_{-}\left(M B_{-}-A_{-}^{2}\right)}
$$

se llega al nuevo sistema integrable

$$
\mathcal{H}_{r}^{(N)}=\frac{1}{2} \sum_{i=1}^{N} p_{i}^{2}+\delta_{1} \sum_{i=1}^{N} q_{i}^{2}+\varepsilon \frac{2 \sum_{1 \leq i<j}^{N} q_{i} q_{j}}{\left(\sum_{i=1}^{N} q_{i}^{2}\right) \sum_{1 \leq i<j}^{N}\left(q_{i}-q_{j}\right)^{2}}+\mathcal{J}\left(\sum_{i=1}^{N} q_{i}^{2}\right)
$$

que es la generalización clásica ND de un sistema cuántico exactamente soluble recientemente introducido como generalización 2D del hamiltoniano de Calogero-Moser.

\section{Capítulo 6.}

\section{Extendiendo la integrabilidad de 2D a ND}

En este último Capítulo se aborda la generalización ND con simetría axial de potenciales integrables 2D. Para ello, se mostrará en la Memoria el esquema algebraico utilizado de una manera pormenorizada. Es importante señalar, que no sólo se van a reobtener las expresiones conocidas de sistemas hamiltonianos integrables en un marco elegante como el de la simetría de coálgebra, sino que también este último hará posible la adición de términos centrífugos de la forma $b_{i} / q_{i}^{2}$ a los potenciales ND así obtenidos.

\subsection{Desde 2D a ND a través de la simetría axial}

En esta Sección se retoma la idea conocida de extensión de ciertos potenciales integrables $2 \mathrm{D}$ de la forma $\mathcal{V}\left(x^{2}, y\right)$, siempre que admitan un término centrífugo del tipo $1 / x^{2}$, a sistemas ND integrables mediante una generalización axial del tipo

$$
\mathcal{H}^{(N)}=\sum_{i=1}^{N-1} \frac{1}{2} p_{x_{i}}^{2}+\frac{1}{2} p_{y}^{2}+\mathcal{V}\left(\sqrt{\sum_{i=1}^{N-1} x_{i}^{2}}, y\right) .
$$


xxxii

\subsection{Sistemas hamiltonianos con simetría $\operatorname{sl}(2, \mathbb{R}) \oplus h_{6}$}

En esta Sección presentamos el fundamento algebraico de la construcción mencionada en 6.1, que permitirá la generalización ND. La idea básica es que las $(N-1)$ primeras coordenadas canónicas de los hamiltonianos provienen de una coálgebra $\operatorname{sl}(2, \mathbb{R})$, mientras que la coordenada $N$-ésima proviene de la realización a una partícula de $h_{6}$.

$$
\begin{aligned}
& J_{+}=\sum_{i=1}^{N-1} p_{i}^{2} \quad J_{-}=\sum_{i=1}^{N-1} q_{i}^{2} \quad J_{3}=\sum_{i=1}^{N-1} q_{i} p_{i} \\
& A_{+}=p_{N} \quad A_{-}=q_{N} \quad K=q_{N} p_{N}-\frac{1}{2} \\
& B_{+}=p_{N}^{2} \quad B_{-}=q_{N}^{2} \quad M=1
\end{aligned}
$$

En este esquema, es importante remarcar que $(N-2)$ integrales van a provenir de $s l(2, \mathbb{R})$, mientras que la integral adicional se calcula de manera constructiva a partir de la integral del sistema $2 \mathrm{D}$ en su traducción adecuada al marco de $\operatorname{sl}(2, \mathbb{R}) \oplus h_{6}$.

\subsection{Integrabilidad completa}

En esta Sección, se demuestra que cualquier hamiltoniano integrable 2D de la forma

$$
\mathcal{H}^{(2)}=\frac{1}{2}\left(p_{x}^{2}+p_{y}^{2}\right)+\mathcal{V}\left(x^{2}, y\right)
$$

cuya integral a dos cuerpos se escribe como

$$
\mathcal{I}^{(2)}=\mathcal{I}^{(2)}\left(p_{x}^{2}, x^{2}, x p_{x}, y p_{y}, p_{y}^{2}, y^{2}, p_{y}, y\right)
$$

donde $x=q_{1}$ e $y=q_{N}=q_{2}$ es generalizable a ND, ya que puede escribirse como

$$
\mathcal{H}=\mathcal{H}\left(J_{+}, J_{-}, J_{3}, K, B_{+}, B_{-}, A_{+}, A_{-}, M\right) .
$$

\subsection{Sistemas ND de Hénon-Heiles}

Como ejemplos importantes de esta construcción se generalizan a ND los tres potenciales conocidos integrables de tipo Hénon-Heiles en 2D: El sistema de Sawada-Kotera, el sistema KdV y el sistema de Kaup-Kuperschdmit.

Por ejemplo, el hamiltoniano de Sawada-Kotera en 2D tiene la siguiente expresión

$$
\mathcal{H}^{(2)}=\frac{1}{2}\left(p_{1}^{2}+p_{2}^{2}\right)+\delta\left(q_{1}^{2}+q_{2}^{2}\right)+\alpha\left(q_{1}^{2} q_{2}+\frac{1}{3} q_{2}^{3}\right)
$$


y en términos de $s l(2, \mathbb{R}) \oplus h_{6}$ se escribe como

$$
\mathcal{H}=\frac{1}{2}\left(J_{+}+B_{+}\right)+\delta\left(J_{-}+A_{-}^{2}\right)+\alpha\left(J_{-} A_{-}+\frac{1}{3} A_{-}^{3}\right)
$$

Utilizando el formalismo anteriormente descrito, la integral adicional del movimiento para (91) tiene la siguiente expresión

$$
\begin{aligned}
\mathcal{I}= & -2 \alpha A_{-} J_{3}^{2}-3 \delta A_{+}^{2} A_{-}^{2}-\alpha A_{+}^{2} A_{-}^{3}-3 \delta^{2} A_{-}^{4}-2 \alpha \delta A_{-}^{5}-\frac{\alpha^{2}}{3} A_{-}^{6} \\
& -3 \delta A_{+}^{2} J_{-}-3 \alpha A_{+}^{2} A_{-} J_{-}-2 \alpha \delta A_{-}^{3} J_{-}-\frac{\alpha^{2}}{2} A_{-}^{4} J_{-} \\
& -3 \delta^{2} J_{-}^{2}-4 \alpha \delta A_{-} J_{-}^{2}-2 \alpha^{2} A_{-}^{2} J_{-}^{2}+\frac{\alpha^{2}}{6} J_{-}^{3} \\
& +6 \delta A_{+} A_{-} J_{3}+3 \alpha A_{+} A_{-}^{2} J_{3}+\alpha A_{+} J_{-} J_{3} \\
& -J_{+}\left(A_{-}^{2}+J_{-}\right)\left(3 \delta+\alpha A_{-}\right)-\frac{3}{4} J_{+}^{2}-\frac{3}{4} A_{+}^{4} .
\end{aligned}
$$

La generalización ND de este sistema junto con su integral adicional tienen la siguiente forma

$$
\begin{aligned}
\mathcal{H}^{(N)}=\sum_{i=1}^{N} \frac{1}{2} p_{i}^{2}+\delta \sum_{i=1}^{N} q_{i}^{2}+\alpha\left(q_{N} \sum_{i=1}^{N-1} q_{i}^{2}+\frac{1}{3} q_{N}^{3}\right) \\
\mathcal{I}^{(N)=}-2 \alpha q_{N}\left(\sum_{i=1}^{N-1} p_{i} q_{i}\right)^{2}-p_{N}^{2} q_{N}^{2}\left(3 \delta+\alpha q_{N}\right)-q_{N}^{4}\left(3 \delta^{2}+2 \alpha \delta q_{N}\right) \\
-\frac{\alpha^{2}}{3} q_{N}^{6}-3 \delta p_{N}^{2}\left(\sum_{i=1}^{N-1} q_{i}^{2}\right)-3 \alpha p_{N}^{2} q_{N}\left(\sum_{i=1}^{N-1} q_{i}^{2}\right) \\
-2 \alpha \delta q_{N}^{3}\left(\sum_{i=1}^{N-1} q_{i}^{2}\right)^{-} \frac{\alpha^{2}}{2} q_{N}^{4}\left(\sum_{i=1}^{N-1} q_{i}^{2}\right)-3 \delta^{2}\left(\sum_{i=1}^{N-1} q_{i}^{2}\right)^{2} \\
-4 \alpha \delta q_{N}\left(\sum_{i=1}^{N-1} q_{i}^{2}\right)^{2}-2 \alpha^{2} q_{N}^{2}\left(\sum_{i=1}^{N-1} q_{i}^{2}\right)^{2}+\frac{\alpha^{2}}{6}\left(\sum_{i=1}^{N-1} q_{i}^{2}\right)^{3} \\
-\left(\sum_{i=1}^{N-1} p_{i}^{2}\left(3 \delta+\alpha q_{N}\right)\left[q_{N}^{2}+\left(\sum_{i=1}^{N-1} q_{i}^{2}\right)\right]-\frac{3}{4}\left(\sum_{i=1}^{N-1} p_{i}^{2}\right)^{2}-\frac{3}{4} p_{N}^{4} .\right.
\end{aligned}
$$


xxxiv

\subsection{Potenciales de Ramani ND}

Otro caso muy interesante es el de los conocidos potenciales de Ramani en 2D, dados por

$$
\mathcal{H}^{(2)}=\frac{1}{2}\left(p_{1}^{2}+p_{2}^{2}\right)+\mathcal{V}_{M}\left(q_{1}, q_{2}\right)=\frac{1}{2}\left(p_{1}^{2}+p_{2}^{2}\right)+\sum_{k=0}^{\left[\frac{M}{2}\right]} 2^{M-2 k}\left(\begin{array}{c}
M-k \\
k
\end{array}\right) q_{1}^{2 k} q_{2}^{M-2 k}
$$

La integral del movimiento para el caso 2D tiene la siguiente expresión

$$
\mathcal{I}^{(2)}=-q_{2} p_{1}^{2}+q_{1} p_{1} p_{2}+q_{1}^{2} \mathcal{V}_{M-1}
$$

Mediante la aplicación del formalismo anterior hemos conseguido la generalización ND de la superposición de toda la serie de potenciales de la serie dando lugar al siguiente sistema integrable:

$$
\mathcal{H}_{R}^{(N)}=\frac{1}{2} \sum_{i=1}^{N} p_{i}^{2}+\sum_{i=2}^{R} \sum_{k=0}^{\left[\frac{i}{2}\right]} \alpha_{i} 2^{i-2 k}\left(\begin{array}{c}
i-k \\
k
\end{array}\right)\left(\sum_{j=1}^{N-1} q_{j}^{2}\right)^{k} q_{N}^{i-2 k}
$$

cuya integral adicional es

$$
\begin{aligned}
\mathcal{I}_{R}^{(N)} & =-q_{N}\left(\sum_{i=1}^{N-1} p_{i}^{2}\right)+p_{N}\left(\sum_{i=1}^{N-1} p_{i} q_{i}\right) \\
& +\left(\sum_{l=1}^{N-1} q_{l}^{2}\right) \sum_{i=2}^{R} \sum_{k=0}^{\left[\frac{i-1}{2}\right]} \alpha_{i} 2^{i-1-2 k}\left(\begin{array}{c}
i-1-k \\
k
\end{array}\right)\left(\sum_{j=1}^{N-1} q_{j}^{2}\right)^{k} q_{N}^{i-1-2 k}
\end{aligned}
$$

\subsection{Añadiendo términos centrífugos}

Debido a la estructura algebraica subyacente a los modelos anteriores, todos ellos van a ser susceptibles de ser modificados mediante la inclusión de términos centrífugos. En este caso las $(N-2)$ integrales provenientes de la simetría de coálgebra van a escribirse en la forma:

$$
\mathcal{C}^{(m)}=\sum_{i<j}^{m}\left(q_{i} p_{j}-q_{j} p_{i}\right)^{2}+\sum_{i<j}^{m}\left(b_{i} \frac{q_{j}^{2}}{q_{i}^{2}}+b_{j} \frac{q_{i}^{2}}{q_{j}^{2}}\right) \quad m=2, \ldots, N-1 .
$$

Como ejemplo, vamos a mostrar algunos de estos casos, como por ejemplo el hamiltoniano generalizado de tipo Sawada-Kotera, que resulta ser

$$
\mathcal{H}_{b}^{(N)}=\sum_{i=1}^{N-1} \frac{1}{2}\left(p_{i}^{2}+\frac{b_{i}}{q_{i}^{2}}\right)+\frac{1}{2} p_{N}^{2}+\delta \sum_{i=1}^{N} q_{i}^{2}+\alpha\left(q_{N} \sum_{i=1}^{N-1} q_{i}^{2}+\frac{1}{3} q_{N}^{3}\right)
$$


donde demostramos que la integral adicional tiene la siguiente forma:

$$
\begin{aligned}
& \mathcal{I}^{(N)}=-2 \alpha q_{N}\left(\sum_{i=1}^{N-1} p_{i} q_{i}\right)^{2}-p_{N}^{2} q_{N}^{2}\left(3 \delta+\alpha q_{N}\right)-q_{N}^{4}\left(3 \delta^{2}+2 \alpha \delta q_{N}\right) \\
& -\frac{\alpha^{2}}{3} q_{N}^{6}-3 \delta p_{N}^{2}\left(\sum_{i=1}^{N-1} q_{i}^{2}\right)-3 \alpha p_{N}^{2} q_{N}\left(\sum_{i=1}^{N-1} q_{i}^{2}\right) \\
& -2 \alpha \delta q_{N}^{3}\left(\sum_{i=1}^{N-1} q_{i}^{2}\right)-\frac{\alpha^{2}}{2} q_{N}^{4}\left(\sum_{i=1}^{N-1} q_{i}^{2}\right)-3 \delta^{2}\left(\sum_{i=1}^{N-1} q_{i}^{2}\right)^{2} \\
& -4 \alpha \delta q_{N}\left(\sum_{i=1}^{N-1} q_{i}^{2}\right)^{2}-2 \alpha^{2} q_{N}^{2}\left(\sum_{i=1}^{N-1} q_{i}^{2}\right)^{2}+\frac{\alpha^{2}}{6}\left(\sum_{i=1}^{N-1} q_{i}^{2}\right)^{3} \\
& -\left[\sum_{i=1}^{N-1}\left(p_{i}^{2}+\frac{b_{i}}{q_{i}^{2}}\right)\left(3 \delta+\alpha q_{N}\right)\right]\left[q_{N}^{2}+\left(\sum_{i=1}^{N-1} q_{i}^{2}\right)\right] \\
& -\frac{3}{4}\left[\sum_{i=1}^{N-1}\left(p_{i}^{2}+\frac{b_{i}}{q_{i}^{2}}\right)\left(3 \delta+\alpha q_{N}\right)\right]^{2}-\frac{3}{4} p_{N}^{4} .
\end{aligned}
$$

Igualmente presentamos el ejemplo de sistema integrable de los potenciales de Ramani anterior, al que se le han añadido los correspondientes términos centrífugos:

$$
\mathcal{H}_{R}^{(N)}=\sum_{i=1}^{N-1} \frac{1}{2}\left(p_{i}^{2}+\frac{b_{i}}{q_{i}^{2}}\right)+\frac{1}{2} p_{N}^{2}+\sum_{i=2}^{R} \sum_{k=0}^{\left[\frac{i}{2}\right]} \alpha_{i} 2^{i-2 k}\left(\begin{array}{c}
i-k \\
k
\end{array}\right)\left(\sum_{j=1}^{N-1} q_{j}^{2}\right)^{k} q_{N}^{i-2 k}
$$

y cuyas integrales del movimiento se proporcionan explícitamente.

\subsection{La construcción $\operatorname{sl}(2, \mathbb{R}) \oplus \operatorname{sl}(2, \mathbb{R})$}

Al igual que en la Sección anterior se procede a generalizar en ND los sistemas hamiltonianos $2 \mathrm{D}$ de la forma

$$
\mathcal{H}^{(2)}=\frac{1}{2}\left(p_{x}^{2}+p_{x}^{2}\right)+\mathcal{V}\left(x^{2}, y^{2}\right)
$$

Para ello se utilizan dos copias del álgebra $s l(2, \mathbb{R})$ de manera que la primera copia se realiza en términos de los $M$ primeros cuerpos y la segunda copia del álgebra $\operatorname{sl}(2, \mathbb{R})$ proporciona desde $M+1$ hasta $N$. Una vez más, lo más novedoso de los resultados obtenidos es la posibilidad de inclusión de términos centrífugos manteniendo la integrabilidad. 
xxxvi

Como ejemplo de esta construcción, presentamos el siguiente hamiltoniano integrable que representa $N$ osciladores no lineales con acoplamiento de orden cuatro y $N$ términos centrífugos:

$$
\begin{aligned}
\mathcal{H}_{b}^{(N)}= & \frac{1}{2} \sum_{i=1}^{M}\left(p_{i}^{2}+\frac{b_{i}}{q_{i}^{2}}\right)+\frac{1}{2} \sum_{i=M+1}^{N}\left(p_{i}^{2}+\frac{b_{i}}{q_{i}^{2}}\right) \\
& +\left(\sum_{i=1}^{M} q_{i}^{2}\right)^{2}+6\left(\sum_{i=1}^{M} q_{i}^{2}\right)\left(\sum_{i=M+1}^{N} q_{i}^{2}\right)+8\left(\sum_{i=M+1}^{N} q_{i}^{2}\right)^{2} \\
& +a\left(\sum_{i=1}^{M} q_{i}^{2}+4 \sum_{i=M+1}^{N} q_{i}^{2}\right)+\frac{\lambda}{\left(\sum_{i=1}^{M} q_{i}^{2}\right)}+\frac{\mu}{\left(\sum_{i=M+1}^{N} q_{i}^{2}\right)} .
\end{aligned}
$$

\section{Capítulo 7. Suplementos}

Al final de esta Memoria se incluyen una serie de apéndices a modo de Suplementos, en los que se presentan brevemente algunas de las nociones matemáticas necesarias para los desarrollos realizados, así como algunos resultados originales complementarios a los ya presentados en Capítulos anteriores.

El primer Suplemento se dedica a los conceptos fundamentales sobre álgebras de Lie, Poisson y funciones de Casimir.

El segundo Suplemento resume el test de integrabilidad de Yoshida-Ziglin para potenciales homogéneos ND. El test da una condición suficiente de la no integrabilidad de estos sistemas. Igualmente, se presentan dos ejemplos concretos de su aplicación.

El tercer Suplemento recoge otras realizaciones simplécticas para álgebras $5 \mathrm{D}$ con $R=3$. Finalmente, el último de ellos se dedica al álgebra $h_{9}$, extensión del álgebra $h_{6}$ generada por los Casimires de las subálgebras $\mathcal{C}_{h_{4}}, \mathcal{C}_{\overline{\mathcal{G}}_{+}}$y $\mathcal{C}_{\overline{\mathcal{G}}_{-}}$.

\section{Bibliografía}

La Memoria finaliza con una amplia Bibliografía que incluye todas las referencias que están directamente relacionadas con el trabajo aquí presentado, así como las páginas del texto en inglés en las que aparecen cada una de ellas. Por otra parte, somos conscientes de la extensa bibliografía existente sobre integrabilidad de sistemas hamil- 
xxxvii

tonianos, aunque nuestro intento ha sido ser exhaustivos con los trabajos existentes que hemos considerado conectados con nuestros resultados.

\section{Conclusiones y problemas abiertos}

Los resultados originales más importantes de la presente Tesis Doctoral pueden resumirse de la siguiente manera:

- Se ha introducido la condición necesaria para la realización simpléctica genérica de un álgebra de Poisson, de manera que se asegure la integrabilidad de los hamiltonianos ND que puedan ser obtenidos a partir de ella mediante el formalismo de coálgebra.

- Se han obtenido explícitamente las representaciones simplécticas genéricas para las diferentes coálgebras de Lie-Poisson de dimensiones $3,4,5$ y 6 , introduciendo además, una familia infinita de álgebras para la cual se mantiene el criterio de integrabilidad. En todos los casos estudiados se han presentado los correspondientes sistemas hamiltonianos ND junto con sus integrales de movimiento explícitas.

- Se ha probado cómo el hamiltoniano ND genérico definido a partir de la realización simpléctica de la coálgebra $h_{6}$ o 'two-photon', da lugar a sistemas cuasi-integrables, cuya integral adicional debe de encontrarse mediante métodos alternativos, para alcanzar la integrabilidad completa del sistema.

- Mediante la utilización de diferentes técnicas algebraicas, se han identificado algunas familias infinitas de hamiltonianos provenientes de la coálgebra 'two-photon', para las cuales dicha integral adicional existe. Además, esta integral ha sido encontrada de forma explícita. Entre estos sistemas se han propuesto nuevas familias de sistemas integrables naturales, de hamiltonianos electromagnéticos y de flujos geodésicos que definen espacios ND de curvatura no constante.

- Se han encontrado además dos nuevas familias de perturbaciones integrables no lineales del oscilador isótropo en ND. La primera depende de $N$ parámetros y de dos funciones arbitrarias. Además esta familia incluye como casos particulares acoplamientos no lineales entre osciladores de grados cuatro y seis. La segunda familia de perturbaciones integrables, incluye funciones homogéneas de grado menos dos en las coordenadas y una función arbitraria radial. Como un ejemplo concreto de este tipo, se ha propuesto una generalización ND de un modelo 2D de tipo Calogero-Moser.

- Se ha demostrado cómo la generalización ND de muchos sistemas integrables 2D conocidos puede realizarse haciendo uso de la suma directa de algunas coálgebras. En particular, se ha probado que cualquier potencial integrable bidimensional del tipo $\mathcal{V}\left(x^{2}, y\right)$ puede ser generalizado a ND preservando la integrabilidad completa del mode- 
xxxviii

lo. De forma similar, se ha obtenido un resultado análogo para potenciales de la forma $\mathcal{V}\left(x^{2}, y^{2}\right)$. Además, el formalismo permite la adición de términos centrífugos que preservan la integrabilidad. Como caso particular, se han encontrado en ND versiones generalizadas de los tres potenciales integrables de tipo Hénon-Heiles, de la serie de potenciales de Ramani, y se han obtenido nuevos sistemas ND de osciladores acoplados no lineales.

\section{Problemas abiertos}

Finalmente, se presentan varios problemas surgidos del presente trabajo, y que a nuestro juicio merecerán un estudio pormenorizado en el futuro.

- En general, las condiciones de integrabilidad presentadas en el Capítulo 2 pueden ser generalizadas en el caso en el que se utilicen realizaciones simplécticas de dimensiones diferentes en cada una de las copias del álgebra. Esta elección conduciría a sistemas hamiltonianos aparentemente distintos de los aquí presentados.

- Otra posibilidad abierta es la búsqueda de coálgebras de dimensión mayor de manera que, bajo la representación simpléctica adecuada, pudieran dar lugar a nuevos sistemas hamiltonianos integrables.

- Igualmente, sería interesante realizar un análisis pormenorizado de algunos de los nuevos hamiltonianos introducidos en esta Memoria, resolviendo de forma explícita sus ecuaciones de movimiento. Recordemos que este problema puede ser abordado mediante la técnica de las cluster variables [19]. Esta técnica hace uso de la simetría de coálgebra de cara a definir unas variables dinámicas colectivas adecuadas.

- En esta dirección, nos gustaría señalar que los sistemas hamiltonianos electromagnéticos y de flujos geodésicos presentados en esta Memoria merecen, en nuestra opinión, un estudio detallado en el futuro. Igualmente, la generalización del modelo de tipo Calogero-Moser introducido en el Capítulo 5 también deberá tratarse en mayor profundidad.

- Para la mayoría de los hamiltonianos presentados en esta Memoria, existen dos conjuntos diferentes de integrales del movimiento cuadráticas en los momentos. Este hecho pone de manifiesto la cuestión abierta concerniente a la separabilidad de todos estos modelos en al menos dos sistemas de coordenadas.

- Es claro que la construcción de coálgebra $h_{6}$ nos permite escribir muchos otros hamiltonianos a través de sus generadores. En cada caso, y por construcción, siempre se tendrían $(N-2)$ 'integrales universales', de manera que la única tarea a realizar para alcanzar la integrabilidad completa de este tipo de sistemas es calcular la integral adicional, en caso de que ésta exista. 
- Es igualmente conocido que la existencia de simetría de coálgebra permite la introducción natural de deformaciones a través de las $q$-deformaciones de la estructura de Poisson subyacente. En el caso de la coálgebra $h_{6}$, su versión cuántica es conocida [10, 11], de manera que sus análogos en términos de Poisson pudieran ser utilizados para construir deformaciones integrables de algunos de los sistemas aquí presentados.

- Otra posibilidad interesante podría ser la construcción en espacios de curvatura constante de los sistemas ND aquí presentados sobre espacios Euclídeos. Esto ha sido posible mediante la utilización de $s l(2, \mathbb{R})[24,26,29$, y lo sería para los sistemas aquí estudiados mediante la correspondiente construcción basada en $h_{6}$.

- Finalmente, podría resultar ciertamente interesante el estudio de la versión cuántica de algunos de los modelos clásicos aquí presentados. 


\section{Índice de la versión inglesa}

$\begin{array}{ll}1 \text { Introducción } & 7\end{array}$

2 Sistemas integrables con simetría de coálgebra $\quad 13$

2.1 Sistemas hamiltonianos sobre coálgebras de Poisson ................... 14

2.2 Realizaciones simplécticas e integrabilidad completa ................... 18

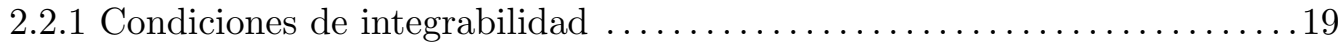

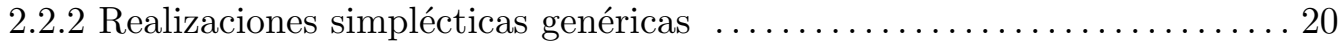

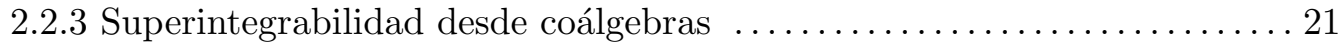

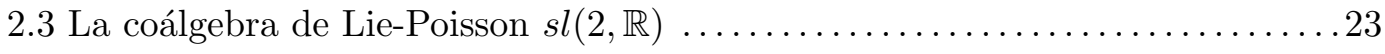

2.4 Sistemas integrables ND a partir de coálgebras $3 \mathrm{D} \ldots \ldots \ldots \ldots \ldots \ldots \ldots 24$

2.5 Deformaciones integrables a partir de $q$-Poisson coálgebras $\ldots \ldots \ldots \ldots \ldots . . .29$

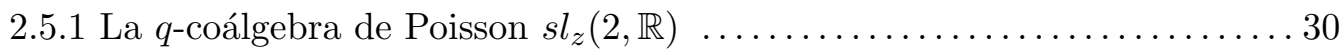

3 Coálgebras en dimensiones más altas 33

3.1 Sistemas integrables a partir de coálgebras de Lie 4D $\ldots \ldots \ldots \ldots \ldots \ldots 33$

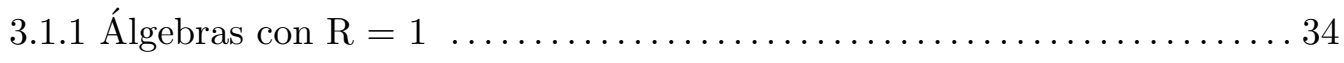

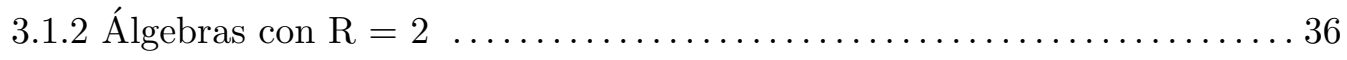

3.2 Sistemas integrables a partir de coálgebras de Lie $5 \mathrm{D} \ldots \ldots \ldots \ldots \ldots$

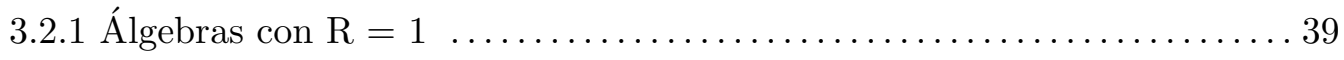

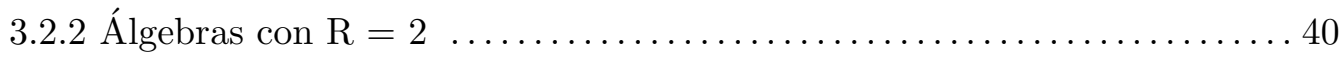

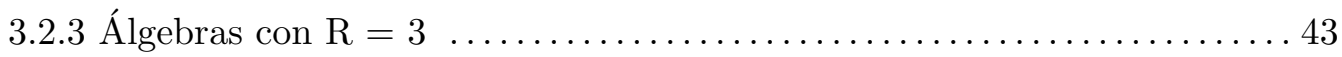

3.3 Sistemas integrables a partir de coálgebras de Lie $6 \mathrm{D}$ nilpotentes . ....... 46

3.4 Una familia de álgebras con dimensión arbitraria $\ldots \ldots \ldots \ldots \ldots \ldots \ldots \ldots$ 
4.1 El álgebra Two-Photon o álgebra de Schrödinger $h_{6} \ldots \ldots \ldots \ldots \ldots \ldots . \ldots 4$

4.2 Una familia infinita de sistemas cuasi-integrables $\ldots \ldots \ldots \ldots \ldots \ldots \ldots \ldots 6$

4.2.1 Algunos hamiltonianos cuasi-integrables relevantes . ................59

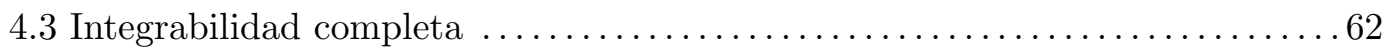

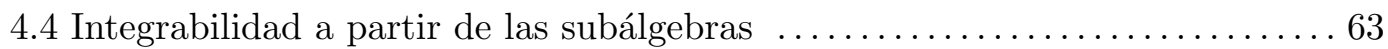

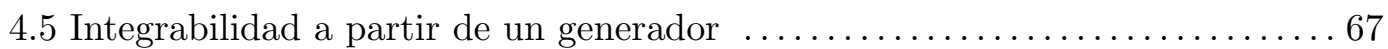

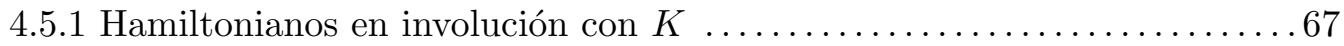

4.5.2 Hamiltonianos en involución con $A_{+} \ldots \ldots \ldots \ldots \ldots \ldots . \ldots \ldots$

4.5.3 Hamiltonianos en involución con $A_{-}, B_{-}$o $B_{+} \ldots \ldots \ldots \ldots \ldots \ldots \ldots$

4.6 Búsqueda directa de sistemas hamiltonianos integrables $\ldots \ldots \ldots \ldots \ldots \ldots 71$

4.6.1 Sistemas naturales: el hamiltoniano de Garnier $\ldots \ldots \ldots \ldots \ldots \ldots \ldots . \ldots 71$

4.6.2 Un hamiltoniano electromagnético .......................... 73

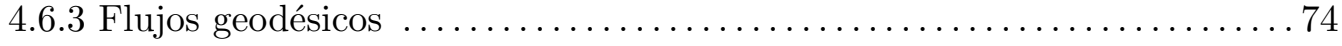

5 Perturbaciones integrables del oscilador en ND 77

5.1 Un nuevo hamiltoniano ND integrable $\ldots \ldots \ldots \ldots \ldots \ldots \ldots \ldots \ldots \ldots \ldots$

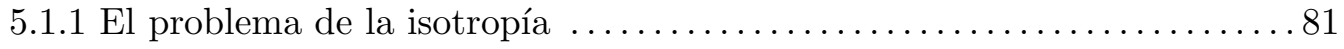

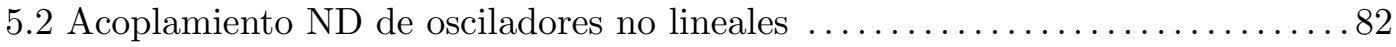

5.2 .1 Peturbaciones homogéneas de grado $4 \ldots \ldots \ldots \ldots \ldots \ldots . \ldots \ldots$

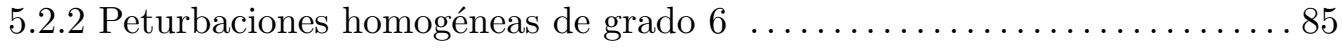

5.3 Otra perturbación integrable en ND $\ldots \ldots \ldots \ldots \ldots \ldots \ldots \ldots \ldots \ldots$

5.3 .1 Un nuevo modelo integrable en $\mathrm{ND} \ldots \ldots \ldots \ldots \ldots \ldots \ldots \ldots$

6 Extendiendo la integrabilidad desde 2D a ND 91

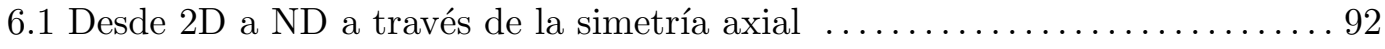

6.2 Sistemas hamiltonianos con simetría $s l(2, \mathbb{R}) \oplus h_{6} \ldots \ldots \ldots \ldots \ldots \ldots$

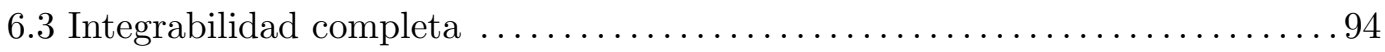

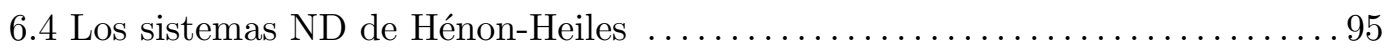

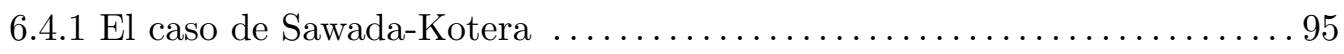

$6.4 .2 \mathrm{El}$ caso $\mathrm{KdV}$........................................ 97 
6.4.3 El caso de Kaup-Kuperschdmit ........................... 98

6.5. Potenciales de Ramani en ND ................................... 99

6.5.1 El hamiltoniano ND de Ramani $\mathcal{H}_{6} \ldots \ldots \ldots \ldots \ldots \ldots \ldots \ldots \ldots \ldots \ldots \ldots$

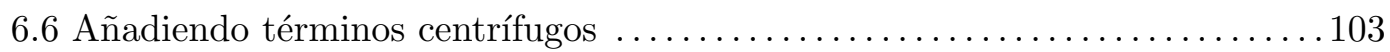

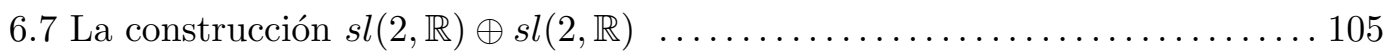

6.7.1 Osciladores no lineales ND con acoplamiento cuártico ..............107

7 Conclusiones y problemas abiertos $\quad 111$

8 Suplementos $\quad \mathbf{1 1 5}$

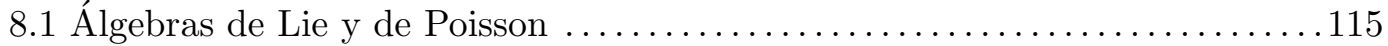

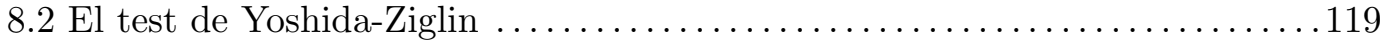

8.4 Realizaciones simplécticas para álgebras $5 \mathrm{D}$ con $\mathrm{R}=3 \ldots \ldots \ldots \ldots \ldots \ldots \ldots$

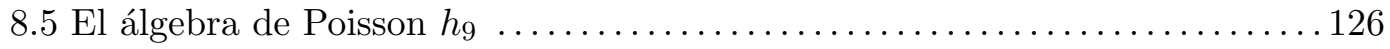

$\begin{array}{lr}\text { Bibliografía } & 127\end{array}$ 


\section{Integrability of nonlinear Hamiltonian systems with $\mathrm{N}$ degrees of freedom}




\section{Contents}

\begin{tabular}{lll}
\hline 1 & Introduction & 7 \\
\hline
\end{tabular}

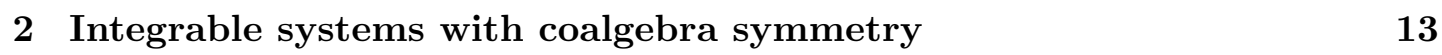

2.1 Hamiltonian systems on Poisson coalgebras . . . . . . . . . . . . . . . . 14

$2.2 \quad$ Symplectic realizations and complete integrability . . . . . . . . . . . . 18

$2.2 .1 \quad$ Integrability conditions . . . . . . . . . . . . . . . . . . 19

2.2 .2 Generic symplectic realizations . . . . . . . . . . . . . 20

2.2 .3 Coalgebra superintegrability . . . . . . . . . . . . . . . . 21

2.3 The $s l(2, \mathbb{R})$ Lie-Poisson coalgebra $\ldots \ldots \ldots \ldots$. . . . . . . . . 23

2.4 ND integrable systems from 3D Lie coalgebras . . . . . . . . . . . . . 24

2.5 Integrable deformations from $q$-Poisson coalgebras $\ldots . . . . . . . .29$

2.5 .1 The $q$-Poisson coalgebra $s_{z}(2, \mathbb{R}) \ldots \ldots$. . . . . . . 30

$\begin{array}{|ll|}3 & \text { Higher dimensional coalgebras }\end{array}$

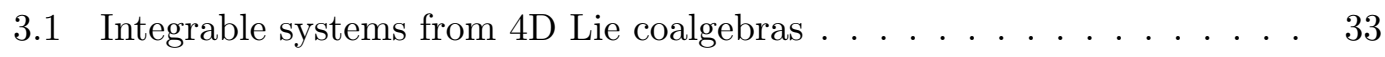

$3.1 .1 \quad$ Algebras with $R=1 \ldots \ldots \ldots$. . . . . . . . . . . . 34

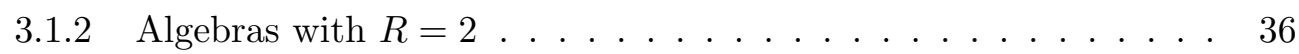

3.2 Integrable systems from $5 \mathrm{D}$ Lie coalgebras . . . . . . . . . . . . . . . . 39

$3.2 .1 \quad$ Algebras with $R=1 \ldots \ldots \ldots$. . . . . . . . . . . . . 39

3.2 .2 Algebras with $R=2 \ldots \ldots \ldots$. . . . . . . . . . 40

$3.2 .3 \quad$ Algebras with $R=3 \ldots \ldots \ldots$. . . . . . . . . . . 43

3.3 Integrable systems from $6 \mathrm{D}$ nilpotent coalgebras $\ldots \ldots . . . . . . .46$ 
3.4 A family of algebras with arbitrary dimension . . . . . . . . . . . . . 49

4 ND integrability from two-photon coalgebra

4.1 The two-photon/Schrödinger algebra $h_{6} \ldots \ldots \ldots \ldots$. . . . . . 54

4.2 An infinite family of quasi-integrable systems . . . . . . . . . . . . . . . 56

4.2 .1 Some relevant quasi-integrable Hamiltonians . . . . . . . . . . . 59

4.3 Complete integrability . . . . . . . . . . . . . . . . . . 62

4.4 Subalgebra integrability $\ldots \ldots \ldots \ldots$. . . . . . . . . . . . 63

4.5 Generator integrability $\ldots \ldots \ldots \ldots$. . . . . . . . . . . . . 67

4.5 .1 Hamiltonians in involution with $K \ldots \ldots$. . . . . . . 67

4.5 .2 Hamiltonians in involution with $A_{+} \ldots \ldots \ldots 6$

4.5.3 Hamiltonians in involution with either $A_{-}, B_{-}$or $B_{+} \ldots 70$

4.6 Direct search of integrable Hamiltonians $\ldots \ldots \ldots \ldots$. . . . . . . . . 71

4.6 .1 Natural systems: the Garnier Hamiltonian. . . . . . . . . . . . 71

4.6 .2 An electromagnetic Hamiltonian . . . . . . . . . . . . 73

4.6 .3 Geodesic flows $\ldots \ldots \ldots \ldots$. . . . . . . . . . . . . . . . . 74

\begin{tabular}{|lll}
5 & Integrable perturbations of the ND oscillator & 77
\end{tabular}

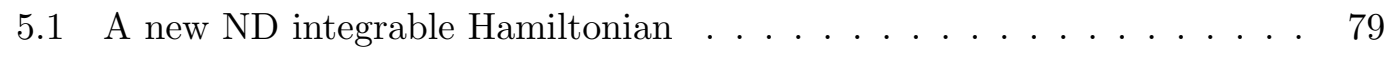

5.1 .1 The isotropy problem . . . . . . . . . . . . . . . 81

5.2 ND coupled nonlinear oscillators $\ldots \ldots \ldots \ldots$. . . . . . . . . 82

5.2 .1 Homogeneous quartic perturbations . . . . . . . . . . . . 83

5.2 .2 Homogeneous sextic perturbations . . . . . . . . . . . . 85

$5.3 \quad$ Another ND integrable perturbation $\ldots \ldots \ldots$. . . . . . . . 88

$5.3 .1 \quad$ A new ND integrable model . . . . . . . . . . . . . . . . . 89

$6 \quad$ Propagating integrability from 2D to ND 91

6.1 From 2D to ND through axial symmetry . . . . . . . . . . . . . . . . . . 92

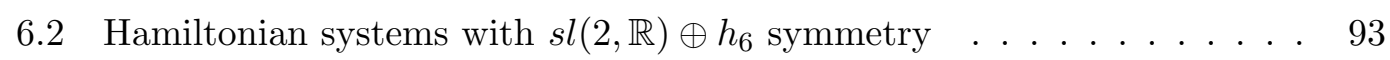

6.3 Complete integrability . . . . . . . . . . . . . . . 94

6.4 ND Hénon-Heiles systems $\ldots \ldots \ldots$. . . . . . . . . . . . . 95 
6.4 .1 The Sawada-Kotera case . . . . . . . . . . . . . . . . . 95

6.4 .2 The $\mathrm{KdV}$ case $\ldots \ldots \ldots$. . . . . . . . . . . . . . . . 97

6.4 .3 The Kaup-Kuperschdmit case . . . . . . . . . . . . . . . . . . 98

6.5 ND Ramani potentials . . . . . . . . . . . . . . . . . . . . 99

6.5 .1 The ND Ramani Hamiltonian $\mathcal{H}_{6} \ldots \ldots$. . . . . . . . . 101

6.6 Adding centrifugal terms . . . . . . . . . . . . . . . . . 103

6.7 The $s l(2, \mathbb{R}) \oplus \operatorname{sl}(2, \mathbb{R})$ construction . . . . . . . . . . . . 105

6.7 .1 ND nonlinear oscillators with quartic coupling . . . . . . . . . 107

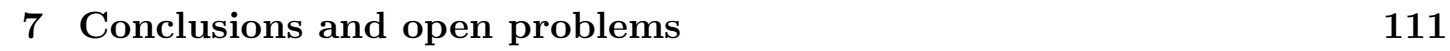

$\begin{array}{lll}8 & \text { Supplements } & 115\end{array}$

8.1 Lie and Poisson algebras . . . . . . . . . . . . . . . . . . 115

8.2 The Yoshida-Ziglin test . . . . . . . . . . . . . . . . . . . . . . . . 119

8.3 Symplectic realizations for 5D algebras with $R=3$. . . . . . . . . . 123

8.4 The $h_{9}$ Poisson algebra $\ldots \ldots \ldots \ldots \ldots \ldots$

\begin{tabular}{lr}
\hline Bibliography & 127
\end{tabular} 


\section{Chapter 1}

\section{Introduction}

"The mathematician

plays a role the rules of which he creates himself, as opposed to the physicist who enacts a role the rules of which are determinated by nature. Having said though, it is undeniable that as time goes by the rules the mathematician has primarily deemed as appropriate will eventually end up matching those provided by nature."

P. A. M. Dirac

Certainly, the Hamiltonian formalism is the fundamental framework for our description of both Classical and Quantum dynamics. As a consequence, the most usual physical approach of a given system consists in providing either the Hamiltonian function (if the system is classical) or the corresponding Hamiltonian operator (if quantum) for it. On the other hand, from the mathematical viewpoint, the Hamiltonian formalism is based on Lie-algebraic structures which give the unified symmetry approach to Classical and Quantum Mechanics. In fact, although in this work we will concentrate on Classical Mechanical systems, the Lie approach that we adopt would indeed make possible the quantum generalization of all the results here presented.

Therefore, let us consider a system of classical particles with $N$ degrees of freedom. Once the Hamiltonian $\mathcal{H}^{(N)}\left(q_{1}, q_{2}, \ldots, q_{N}, p_{1}, p_{2}, \ldots, p_{N}\right)$ for such system is given as a function depending on $N$ pairs of canonical variables, Hamilton's equations

$$
\dot{q}_{i}=\frac{\partial \mathcal{H}}{\partial p_{i}} \quad \dot{p}_{i}=-\frac{\partial \mathcal{H}}{\partial q_{i}} \quad i=1, \ldots, N
$$


will provide the dynamics of the system. In order to investigate it, the actual problem is to find the exact solutions of such differential equations that, in most of the physically interesting cases, are nonlinear and coupled.

This is the reason why, among all possible Hamiltonian systems, a distinguished subset called "exactly solvable systems" is frequently identified: they are those physical models for which Hamilton's equations can be exactly solved. But the number of known exactly solvable Hamiltonians is very small, and usually the existence of exact solutions is deeply connected with the existence of underlying symmetries (in some sense) of the model under study [98, 135, 184].

This work deals with the construction of new exactly solvable Hamiltonians, and the cornerstone of our approach is the following fact: if for a given Hamiltonian we have enough number of independent constants of the motion, then Hamilton's equations for such system can be integrated "by quadratures". This means that (quoting [147]), "its solutions can be obtained by finitely many algebraic operations (including inverting functions) and "quadratures", i.e., evaluating integrals of given functions". In a more precise language, the following founding result holds (for a more technical discussion see [147, Chapter 1):

Let $\mathbb{R}^{2 N}=\left\{q_{1}, \ldots, q_{N}, p_{1}, \ldots, p_{N}\right\}$ be the phase space of a Hamiltonian system $\mathcal{H}^{(N)}\left(q_{1}, q_{2}, \ldots, q_{N}, p_{1}, p_{2}, \ldots, p_{N}\right)$ endowed with the standard Poisson bracket

$$
\{f, g\}=\sum_{i=1}^{N}\left(\frac{\partial f}{\partial q_{i}} \frac{\partial g}{\partial p_{i}}-\frac{\partial g}{\partial q_{i}} \frac{\partial f}{\partial p_{i}}\right) .
$$

Then, if the system has $(N-1)$ functionally independent integrals of the motion in involution $\left\{F_{1}, \ldots, F_{N-1}\right\}$

$$
\left\{\mathcal{H}, F_{j}\right\}=0 \quad\left\{F_{i}, F_{j}\right\}=0 \quad i, j=1, \ldots,(N-1)
$$

the solutions of Hamilton's equations for $\mathcal{H}^{(N)}$ can be obtained by quadratures.

Therefore, a Hamiltonian system $\mathcal{H}^{(N)}$ with a (finite) number $N$ of degrees of freedom is called completely integrable (in the abovementioned Liouville sense) if such set of $(N-1)$ functionally independent (and globally defined) constants of the motion $\mathcal{F}_{k}$ $(k=1, \ldots, N-1)$ does exist [162]. In this sense, complete integrability implies that we would be able to solve explicitly the dynamical behaviour of the system. As a consequence, integrable systems are the paradigm of regular motion, and can be interpreted as the opposite to chaotic systems. Anyhow, it is important to stress that integrability is not the rule but clearly the exception among dynamical systems.

Moreover, there exist some exceptional systems which have more than $(N-1)$ functionally independent integrals in involution with $\mathcal{H}^{(N)}$ : these are the so-called superintegrable ones (obviously, only $(N-1)$ of these integrals can be mutually in involution) 
[75, 80, 99, 123. Moreover, a N-dimensional (hereafter ND) Hamiltonian $\mathcal{H}^{(N)}$ will be called maximally superintegrable (MS) if there exists a set of $(2 N-2)$ globally defined functionally independent constants of the motion Poisson-commuting with $\mathcal{H}^{(N)}$; among them, at least two different subsets of $(N-1)$ constants in involution can be found. Finally, a Hamiltonian system will be called quasi-maximally superintegrable (QMS) if it has $(2 N-3)$ independent integrals with the abovementioned properties.

Only a small number of systems are MS in any dimension. The two outstanding examples of this class of systems are the harmonic oscillator and the Kepler potential. Superintegrability has deep geometrical consecuences [64, 82, as for the abovementioned examples, in its classical version, all bounded trajectories are periodic. Thus, MS systems would be the paradigm of absolutely non-chaotic motion.

As a consequence of the abovementioned properties, the construction of finitedimensional integrable Hamiltonian systems, has focused an intense research activity that makes use of many different approaches and techniques (see, for instance, [5, 6, 40, 52, 96, 106, 107, 117, 147, 162, 179, 180, 181]).

Nevertheless, a main problem in this field is the lack of general sufficient criterion and/or systematic methods in order to determine whether a given Hamiltonian system is integrable (or not). Several approaches to the characterization of necessary conditions for integrability have been developed (like the Painlevé test [166] or the Yoshida-Ziglin approach [119, 120, 125, 136, 151, 154, 182, 183, 184]) but the actual approach to integrable systems is mainly constructive, because finally one has to find the integrals of motion.

Moreover, even for 2D and 3D Hamiltonians the classification of integrable Hamiltonians is not trivial at all [51, 52, 73, 109, 135, 184, and in higher dimensions difficulties grow exponentially. Therefore, the number of known integrable systems (in the Liouville sense) that can be generalized for an arbitrary number $N$ of degrees of freedom is very scarce. In most of the known cases, such a ND integrability is based on some underlying symmetry that allows for the appropriate propagation of the integrability properties to arbitrary dimension (see the systems described in $[26,37,53,54,55,81,90,111,112,113,117,127,137,157,158,160,165,169,175,180]$ and references therein).

The aim of this Ph.D. Thesis is to construct new ND integrable Hamiltonian systems with nonlinear interactions, obtaining explicitly their sets of funtionally independent integrals of the motion. To face this problem we will use the coalgebra symmetry approach (see [9, 12, 13, 17, 18, 19, 21, 27, 31]) that has been recently introduced as a new symmetry framework that underlies the integrability properties of many systems, and that also allows for the construction of integrable deformations of many of such systems by making use of the theory of quantum groups and algebras [8, 36, 69, 168]. We 
stress that in this scheme Casimir functions for the underlying coalgebra are essential in order to provide the integrals of the motion.

The coalgebra symmetry formalism is reviewed in Chapter 2. As a new contribution, the role of the dimensionality of the symplectic realization of a given Poisson coalgebra is analysed in order to propose a necessary condition for the complete integrability of the ND Hamiltonian systems that can be constructed from it. We also point out how the coalgebra symmetry is always providing a certain degree of superintegrability. A systematic study of the symplectic realizations of the 9 real 3D Lie coalgebras [150] is presented, and also some examples of $q$-Poisson coalgebras are recalled.

In Chapter 3 the full study of the symplectic realizations of all $4 \mathrm{D}$ and $5 \mathrm{D}$ real Lie coalgebras (see the algebra classification [59, 145]) is given. Afterwards, the completely integrable ND Hamiltonians that can be obtained from those symplectic realizations that fulfill the integrability criteria are presented. The analysis is completed by studying the same problem for all $6 \mathrm{D}$ nilpotent Lie coalgebras, and also for a infinite family of Lie coalgebras whose complete set of Casimir functions is found.

In the next Chapter the coalgebra formalism is used to construct new families of completely integrable ND systems which are defined on the 6D two-photon/Schrödinger coalgebra $h_{6}$. In general, these Hamiltonians depend on several arbitrary functions and $N$ free parameters. In particular, integrable natural systems, electromagnetic Hamiltonians and geodesic flows in arbitrary dimensions are presented. In order to prove the complete integrability of all these systems, we present different strategies which are mainly based on the rich subalgebra structure of $h_{6}$.

In the fifth Chapter we further apply the $h_{6}$ coalgebra construction in order to introduce two different types of integrable perturbations/deformations of the ND isotropic harmonic oscillator Hamiltonian. The first one is a family of integrable perturbations depending on $N$ parameters and two arbitrary functions. Afterwards, we discuss several examples of quartic and sextic coupled nonlinear oscillators that can be found as particular cases. The second family of ND perturbations includes homogeneous functions with degree -2 in the coordinates and a radial arbitrary function. Both families of systems can be considered as ND generalizations of certain subclasses of 3D integrable Hamiltonians that were proposed for the first time in [179].

The last chapter is devoted to show how the ND generalization of many known 2D integrable Hamiltonians can be achieved by making use the direct sum coalgebras $\operatorname{sl}(2, \mathbb{R}) \oplus h_{6}$ and $\operatorname{sl}(2, \mathbb{R}) \oplus \operatorname{sl}(2, \mathbb{R})$. The former is used to show that any $2 \mathrm{D}$ integrable potential of the type $\mathcal{V}\left(x^{2}, y\right)$ can be generalized to ND by preserving its complete integrability, and by making use of the second coalgebra, a similar result is obtained for potentials of the type $\mathcal{V}\left(x^{2}, y^{2}\right)$. Moreover, the $\operatorname{sl}(2, \mathbb{R})$ sector of the symmetry allows the systematic introduction of centrifugal terms, and the corresponding gener- 
alized integrals of the motion are explicitly found. As outstanding examples of this construction, we present for the first time ND generalized versions of the three integrable Hénon-Heiles systems, as well as of the Ramani series of potentials and other ND systems of coupled nonlinear oscillators.

Finally, in a closing Chapter, the main conclusions obtained from our research program are summarized, together with a list of open problems for further investigation.

This work is completed with a Supplements Chapter in which several mathematical tools are reviewed. We also include there some original complementary results that we have decided to present separately from the main body of the text. Concerning the bibliography, we have tried to include all the references that are directly related to the results here presented, although we are aware of the extensive bibliography on integrable systems that can be found.

A significant part of the original results presented in this Ph.D. Thesis has been already included in the works [20, 23, 27, 28, 30, 31] and [32]. Nevertheles, this manuscript includes new results that are not contained in such papers, and also provides a unified approach to the application of coalgebra symmetries in order to construct new physically meaningful ND integrable systems. 


\section{Chapter 2}

\section{Integrable systems with coalgebra symmetry}

"A system of differential equations is only more or less integrable."

H. Poincaré

Coalgebras are either Poisson (commutative) or commutator algebras (non commutative) endowed with a compatible comultiplication structure, and have been recently shown to be the 'hidden' symmetries underlying the integrability properties of a wide class of ND (super)integrable classical and quantum Hamiltonian systems (see [12, 13, 14, 16, 19, 21, 22, 24, 25] and references therein). In this construction, once a symplectic (resp. operatorial) realization of the coalgebra is given, their generators play the role of dynamical symmetries of the Hamiltonian, while the coproduct map of the coalgebra is used to 'propagate' the integrability to arbitrary dimension, and to give the explicit form of the integrals of motion as the coproducts of the Casimirs of the initial algebra.

From this coalgebra approach, several well-known (super)integrable systems have been recovered. Also some integrable deformations for them, as well as new integrable systems, have been obtained. In particular, this integrability-preserving coalgebra deformation procedure has been used to introduce integrable free motions on spaces with either constant or variable curvature, and (super)integrable potentials can also be defined on such spaces through the coalgebra approach [22, 24, 25, 26, 29].

Although we shall concentrate on classical mechanical systems obtained from (commutative) Poisson coalgebras, we stress that all the (super)integrability properties of the coalgebra symmetric systems that we are going to describe are preserved at the 
quantum mechanical level by using the corresponding (noncommutative) operator coalgebras. In this way, the coalgebra approach has also been used, for instance, to solve in [132, 133] the quantum Calogero-Gaudin system [56], as well as supersymmetric generalizations of this model and of its $q$-deformations, which have been constructed by starting from the underlying supersymmetric coalgebra structures [45, 134]. Finally we recall that a comodule algebra generalization of the coalgebra symmetry has been introduced in [18].

In this Chapter we review from a more systematic viewpoint this algebraic approach to Hamiltonian integrability, and the role of symplectic realizations of Poisson coalgebras in the formalism will be emphasized. In this way we present a more global perspective on both the possibilities and limitations of the coalgebra symmetry approach. In particular, we perform a detailed analysis of 3-dimensional Lie coalgebras that admit symplectic realizations that lead to new infinite families of completely integrable (in fact, superintegrable) Hamiltonian systems with $N$ degrees of freedom. Such systems are fully constructed, together with the explicit form of their integrals of the motion. In the final Section, we present some examples of $q$-Poisson coalgebras in order to show how they can be used, in order to construct integrable deformations of ND Hamiltonian systems.

\subsection{Hamiltonian systems on Poisson coalgebras}

We recall that a coalgebra $(A, \Delta)$ is a (unital, associative) algebra $A$ endowed with a coproduct map [79]:

$$
\Delta: A \rightarrow A \otimes A
$$

which is coassociative

$$
(\Delta \otimes i d) \circ \Delta=(i d \otimes \Delta) \circ \Delta
$$

that is, the following diagram is commutative:

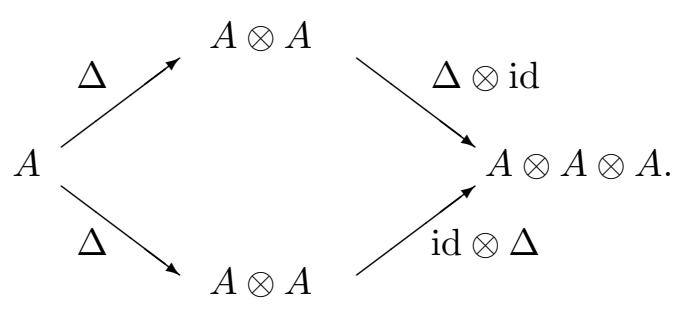


Due to the coassociativity property, the comultiplication $\Delta$ provides a 'two-fold way' for the definition of the objects on $A \otimes A \otimes A$ that, as we shall explain in Section (2.2.3), will be deeply connected with superintegrability properties.

In addition, $\Delta$ has to be an algebra homomorphism from $A$ to $A \otimes A$ :

$$
\Delta(a b)=\Delta(a) \Delta(b) \quad \forall a, b \in A .
$$

Moreover, if $A$ is a Poisson algebra and

$$
\Delta\left(\{a, b\}_{A}\right)=\{\Delta(a), \Delta(b)\}_{A \otimes A} \quad \forall a, b \in A,
$$

we shall say that $(A, \Delta)$ is a Poisson coalgebra.

Let us summarize the general construction of ref. [12. Let $(A, \Delta)$ be a Poisson coalgebra with $l$ generators $X_{i}(i=1, \ldots, l)$, and $r$ is the the number of functionally independent Casimir functions $\mathcal{C}_{j}\left(X_{1}, \ldots, X_{l}\right)$ (with $\left.j=1, \ldots, r\right)$. Among them, a certain subset of $R$ Casimir funtions will be non-linear functions of the generators of the coalgebra, and will be the relevant ones as far as integrability is concerned.

The coassociative coproduct $\Delta \equiv \Delta^{(2)}$ has to be a Poisson map with respect to the usual Poisson bracket on $A \otimes A$ :

$$
\left\{X_{i} \otimes X_{j}, X_{r} \otimes X_{s}\right\}_{A \otimes A}=\left\{X_{i}, X_{r}\right\}_{A} \otimes X_{j} X_{s}+X_{i} X_{r} \otimes\left\{X_{j}, X_{s}\right\}_{A}
$$

Then, the $m$-th coproduct map $\Delta^{(m)}\left(X_{i}\right)$

$$
\Delta^{(m)}: A \rightarrow A \otimes A \otimes \ldots{ }^{m)} \otimes A
$$

can be defined by applying recursively the coproduct $\Delta^{(2)}$ in the form

$$
\Delta^{(m)}:=\left(i d \otimes i d \otimes \ldots^{m-2)} \otimes i d \otimes \Delta^{(2)}\right) \circ \Delta^{(m-1)} .
$$

Such an induction ensures that $\Delta^{(m)}$ is also a Poisson map.

Table 1. Functions obtained by applying the coproduct map.

\begin{tabular}{|cccc|c|c|c|c|}
\hline$X_{1}$ & $X_{2}$ & $\ldots$ & $X_{l}$ & $\mathcal{C}_{1}$ & $\mathcal{C}_{2}$ & $\ldots$ & $\mathcal{C}_{r}$ \\
\hline$\Delta^{(2)}\left(X_{1}\right)$ & $\Delta^{(2)}\left(X_{2}\right)$ & $\ldots$ & $\Delta^{(2)}\left(X_{l}\right)$ & $\Delta^{(2)}\left(\mathcal{C}_{1}\right)$ & $\Delta^{(2)}\left(\mathcal{C}_{2}\right)$ & $\ldots$ & $\Delta^{(2)}\left(\mathcal{C}_{r}\right)$ \\
$\Delta^{(3)}\left(X_{1}\right)$ & $\Delta^{(3)}\left(X_{2}\right)$ & $\ldots$ & $\Delta^{(3)}\left(X_{l}\right)$ & $\Delta^{(3)}\left(\mathcal{C}_{1}\right)$ & $\Delta^{(3)}\left(\mathcal{C}_{2}\right)$ & $\ldots$ & $\Delta^{(3)}\left(\mathcal{C}_{r}\right)$ \\
$\vdots$ & $\vdots$ & & $\vdots$ & $\vdots$ & $\vdots$ & $\vdots$ & $\vdots$ \\
\hline$\Delta^{(N)}\left(X_{1}\right)$ & $\Delta^{(N)}\left(X_{2}\right)$ & $\ldots$ & $\Delta^{(N)}\left(X_{l}\right)$ & $\Delta^{(N)}\left(\mathcal{C}_{1}\right)$ & $\Delta^{(N)}\left(\mathcal{C}_{2}\right)$ & $\ldots$ & $\Delta^{(N)}\left(\mathcal{C}_{r}\right)$ \\
\hline
\end{tabular}


In this way, we can construct the set of functions shown in Table 1. From them, given a smooth function $\mathcal{H}\left(X_{1}, \ldots, X_{l}\right)$, the $N$-sites Hamiltonian is defined as the $N$-th coproduct of $\mathcal{H}$ :

$$
\mathcal{H}^{(N)}:=\Delta^{(N)}\left(\mathcal{H}\left(X_{1}, \ldots, X_{l}\right)\right)=\mathcal{H}\left(\Delta^{(N)}\left(X_{1}\right), \ldots, \Delta^{(N)}\left(X_{l}\right)\right) .
$$

From [12] it can be proven that the set of $r \cdot N$ functions $(m=1, \ldots, N ; j=1, \ldots, r)$

$$
\mathcal{C}_{j}^{(m)}:=\Delta^{(m)}\left(\mathcal{C}_{j}\left(X_{1}, \ldots, X_{l}\right)\right)=\mathcal{C}_{j}\left(\Delta^{(m)}\left(X_{1}\right), \ldots, \Delta^{(m)}\left(X_{l}\right)\right)
$$

Poisson-commute with the Hamiltonian

$$
\left\{\mathcal{C}_{j}^{(m)}, \mathcal{H}^{(N)}\right\}_{A \otimes A \otimes \ldots N) \otimes A}=0
$$

and, is in involution:

$$
\left\{\mathcal{C}_{i}^{(m)}, \mathcal{C}_{j}^{(n)}\right\}_{A \otimes A \otimes \ldots N) \otimes A}=0 \quad m, n=1, \ldots, N \quad i, j=1, \ldots, r .
$$

This construction is completely general, and holds when the Poisson bracket is replaced by the commutator, thus providing an immediate generalization of this approach to the case of quantum mechanical systems, for which the usual ordering prescriptions are taken into account.

There are two main classes of coalgebras to be used to generate ND integrable systems through this procedure. The first one are Lie-Poisson algebras $g^{*}$ with generators $X_{i}(i=1, \ldots, l)$ and Casimir functions $\mathcal{C}_{j}\left(X_{1}, \ldots, X_{l}\right)(j=1, \ldots, r)$, which are always endowed with the (primitive) coalgebra structure

$$
\Delta\left(X_{i}\right)=X_{i} \otimes 1+1 \otimes X_{i} .
$$

Then, a very natural choice is to consider Hamiltonians $\mathcal{H}\left(X_{1}, \ldots, X_{l}\right)$ that, under the iterated application of the coproduct map, will generate dynamical systems on $g^{*} \otimes g^{*} \otimes \ldots{ }^{N)} \otimes g^{*}$ with constants of the motion in involution coming from the nonlinear Casimir functions. These will be the kind of systems that will be sistematically explored in the two following Chapters.

The second one are the Poisson analogues of quantum algebras and groups [69, 79, 168], (the so-called $q$-Poisson algebras) which are also (deformed) coalgebras $\left(A_{z}, \Delta_{z}\right)$ (where $z$ is the deformation parameter). Consequently, any function of the generators of a given 'quantum' Poisson algebra (with deformed Casimir elements $\mathcal{C}_{z, j}$ ) will provide a deformation of the Hamiltonian constructed in terms of the undeformed Lie-Poisson coalgebra. Some of this systems have been already explored in the previous literature 
(for instance, in [12, 13, 15, 22]), and we stress that all the systems here presented can be deformed without altering their integrability properties provided that appropriate coalgebra deformations are constructed. In this respect we stress that the problem of the classification of quantum deformations is only fully solved for all 3D Lie algebras and for some isolated cases in slightly higher dimensions (see [14] and references therein). For a deeper insight into coalgebras, Hopf algebras and quantum group theory, we refer to $[8,36,69$, , 79, 168. In the final Section of this Chapter, we will explicitly present an example of the coalgebra construction for a $q$-Poisson coalgebra.

Some remarks are in order.

- In general, we cannot say a priori that $\mathcal{H}^{(N)}$ is a completely integrable Hamiltonian system because [27]: (i) We have to determine the number of degrees of freedom of $\mathcal{H}^{(N)}$ by choosing a explicit symplectic realization of the coalgebra $(A, \Delta)$. (ii) Once this number is fixed, we have to check whether the number of independent invariants extracted from $\mathcal{C}_{j}^{(m)}$ (under such a specific symplectic realization) is enough to guarantee complete integrability.

- However, if the coalgebra symmetry provides the complete integrability for $\mathcal{H}^{(N)}$, the integrals of the motion can always be obtained in arbitrary dimension $N$ in an explicit form. Hence the coalgebra symmetry arises as a unified approach to integrability since we obtain families of $N D$ systems that share a very large common set of integrals of the motion. Furthermore, in this case $\mathcal{H}^{(N)}$ will probably be superintegrable (to some extent) [21].

- In the case of $q$-deformations of Poisson coalgebras, the Hamiltonians obtained through the coalgebra approach are integrable deformations of the $z=0(q=1)$ cases in such a manner that different quantum algebras give rise to different integrable deformations. Moreover, this fact can provide some relevant information concerning the geometric/physical interpretation of the deformation parameter.

- This construction holds for noncommutative coalgebras as well. Thus, quantum mechanical systems can also be constructed (although ordering problems have to be fixed).

- From the point of view of the Poisson algebra of the constants of the motion (see [75]), the coalgebra approach is also relevant: once the coalgebra $A$ is fixed, the $\left\{\mathcal{C}_{i}^{(m)}, \mathcal{C}_{j}^{(n)}\right\}$ brackets are fixed for any $\mathcal{H}$ defined on $A$. The only brackets depending on the specific choice of the Hamiltonian are $\left\{\mathcal{H}, \mathcal{C}_{j}^{(m)}\right\} \quad \forall j$ and $\forall m$. These are the only brackets that would distinguish two different systems $\mathcal{H}_{1}$ and $\mathcal{H}_{2}$ with the same coalgebra symmetry. 
Before entering into explicit examples of the coalgebra construction, two important and general aspects have to be more deeply analysed in order to provide a global overview on the subject: they are, the role of the symplectic realizations [65] (which has been thoroughly studied in [27]) and the superintegrability features of the coalgebra symmetry (which were presented for the first time in [21]).

\subsection{Symplectic realizations and complete integrability}

For any $l$-dimensional Poisson coalgebra $(A, \Delta)$ and for any smooth Hamiltonian function $\mathcal{H}$ depending on $l$ variables, we can construct a Hamiltonian system on the Poisson manifold $A^{\otimes N}$ constructed as $N$-tensor copies of $A$. This is a 'cluster-type' dynamical system [19] with $l \cdot N$ dynamical variables whose evolution equations are

$$
\dot{X}_{(i, m)}=\left\{X_{(i, m)}, \mathcal{H}^{(N)}\right\} \quad i=1, \ldots, l \quad m=1, \ldots, N
$$

where $X_{(i, m)}$ denotes the generator $X_{i}$ living on the $m$-th copy of $A$. The $r$ Casimir functions of $A$ generate a maximum number of $r \cdot N$ integrals of the motion for $\mathcal{H}^{(N)}$ (see Table 1 ) but since, in general, $l-r \geq 2$ we have always less than $l \cdot N-1$ integrals and, therefore, complete integrability for $\mathcal{H}$ cannot be reached in terms of the 'algebraic' dynamical variables $X_{(i, m)}$.

However, we can get a specialization of the coalgebra formalism by working on the symplectic leaves of the initial Poisson coalgebra $A$, that can be parametrized through suitable symplectic realizations. If $A$ has $r$ independent Casimir functions, a symplectic leaf of $A$ (always even dimensional) will be denoted by $A_{\left(k_{1}, k_{2}, \ldots, k_{r}\right)}$, where the leaf is characterized by a given set of constant values $\left(k_{1}, k_{2}, \ldots, k_{r}\right)$ for the Casimir functions.

An $s$-dimensional symplectic realization $D$ for $A_{\left(k_{1}, k_{2}, \ldots, k_{r}\right)}$ is given (locally) in terms of $s$ pairs $\left(q_{i}, p_{i}\right)$ of canonical Darboux variables

$$
D: x \rightarrow x\left(q_{1}, p_{1}, q_{2}, p_{2}, \ldots, q_{s}, p_{s}\right)
$$

where $x$ is any point on $A_{\left(k_{1}, k_{2}, \ldots, k_{r}\right)}$. Different symplectic leaves $A_{\left(k_{1, i}, k_{2, i}, \ldots, k_{r, i}\right)}$ can be chosen for the different copies of $A$ within $A^{\otimes N}$. In this way $\mathcal{H}^{(N)}$ is defined on the $N$-th tensor product of the symplectic leaves

$$
A_{\left(k_{1,1}, k_{2,1}, \ldots, k_{r, 1}\right)} \otimes A_{\left(k_{1,2}, k_{2,2}, \ldots, k_{r, 2}\right)} \otimes \cdots \otimes A_{\left(k_{1, N}, k_{2, N}, \ldots, k_{r, N}\right)}
$$

where $k_{i, m}$ is the value of the $i$-th Casimir for the $m$-th symplectic leaf.

If we consider symplectic realizations with the same dimension $s$ for all the sites in the tensor product chain, $\mathcal{H}^{(N)}$ given by 2.8 turns out to be a function of $N \cdot s$ pairs of 
canonical variables, i.e., it defines a Hamiltonian system with $N \cdot s$ degrees of freedom. Therefore, we need a number of $(N \cdot s-1)$ independent and globally defined constants of the motion in involution to state that such Hamiltonian defines a completely integrable system.

\subsubsection{Integrability conditions}

At this point, we have to characterize the number of integrals that the coalgebra formalism provides. First of all, note that under the symplectic realizations that we are going to consider, the coproducts of linear Casimirs give just a sum of numerical constants with no dynamical information. Thus, as far as integrability properties are concerned, we have to consider only non-linear Casimirs, and for each of them we get $(N-1)$ integrals coming from the $2, \ldots, N$-th coproducts (the one-site evaluation of such Casimirs gives, by construction, constants). Since we have $R$ non-linear Casimirs (hereafter we will assume that $R \geq 1$, since coalgebras without any non-linear Casimir will be excluded) we get a maximum possible number of integrals in involution given by

$$
(N-1) \cdot R
$$

In order to get complete integrability we should have enough number of integrals, which means that

$$
N \cdot s-1 \leq(N-1) \cdot R
$$

thus, we need that the chosen symplectic realization $D$ of $A$ fulfils

$$
s \leq R-\frac{R-1}{N}
$$

Therefore the necessary condition for complete integrability is:

- The symplectic realization has to be of the type $s=1$ for coalgebras with $R=1$.

- The symplectic realization has to be of the type $s<R$ for coalgebras with $R>1$.

Obviously, this condition is not sufficient since the functional independence of a $(N \cdot s-1)$ dimensional subset of integrals has to be explicitly checked in each case. Note that this condition does not depend explicitly of the dimension $l$ of the coalgebra and that low values of $s$ are certainly preferred from the integrability viewpoint. 


\subsubsection{Generic symplectic realizations}

Now let us consider a particular type of symplectic realizations whose $s$ is always fixed by the dimension $l$ and the number $r$ of independent Casimirs of the coalgebra. We shall call "generic" to the symplectic realization with dimension $s=s_{m}$ given by

$$
s_{m}=\frac{l-r}{2} .
$$

This symplectic realization is "generic" in the sense that will incorporate as many parameters $\left(k_{1}, \ldots, k_{r}\right)$ as the number of Casimir functions of the coalgebra. Certainly, symplectic realizations with $s<s_{m}$ could exist, but they are not "generic" in the sense that can give rise to degeneracies in the Casimir functions (for an explicit example, see [16]).

The sufficient condition for integrability on the generic symplectic realization leads to

$$
s_{m}=\frac{l-r}{2} \leq R-\frac{R-1}{N}
$$

which leads to the final expression

$$
l \leq(2 R+r)-\frac{2}{N}(R-1) .
$$

The former expression (2.21), gives us the integrability condition in terms of the dimension $l$ and the number $R$. Thus, we get that the complete integrability for the generic symplectic realization is achieved provided that:

- The dimension $l \leq 2 R+r=2+r$ in the case of $R=1$ coalgebras.

- The dimension $l<2 R+r$ in the case of $R>1$ coalgebras.

In this work we will systematically consider all the Lie coalgebras with $l \leq 5$ for which their generic symplectic realizations fulfill the integrability condition, and we will construct all the completely integrable systems associated with them. Through this work, we shall follow the Lie algebra classifications and notation summarized in [145].

Two remarks are in order:

- For the classical simple Lie algebras, $R=r$ so we have that for $R=1$ coalgebras the condition is $l \leq 3$ and for $R>1$ coalgebras we should have that $l<3 R$. Therefore, apart from the $r=1$ cases, this result excludes all simple Lie algebras to provide complete integrable systems in the generic symplectic realization. 
- Let us consider any Lie coalgebra in which the generic symplectic realization has $s_{m}=1$. In that case, provided that $R \geq 1$, the coalgebra fulfills always the integrability condition under that symplectic realization and integrable systems can be always constructed.

\subsubsection{Coalgebra superintegrability}

Instead of (2.7), another recursion relation for the $m$-th coproduct map can be defined as [21]:

$$
\Delta_{R}^{(m)}:=\left(\Delta^{(2)} \otimes \mathrm{id} \otimes \ldots{ }^{m-2)} \otimes \mathrm{id}\right) \circ \Delta_{R}^{(m-1)} .
$$

Due to the coassociativity property of the coproduct, this new expression will provide exactly the same expressions for the $N$-th coproduct of any generator of $A$ :

$$
\Delta^{(N)}\left(X_{i}\right) \equiv \Delta_{R}^{(N)}\left(X_{i}\right)
$$

However, if we label from 1 to $N$ the sites of the chain $A \otimes A \otimes{ }^{N)} \otimes A$, lower dimensional $m$ th-coproducts (with $2<m<N$ ) will be 'different' in the sense that the 'left' coproducts $\Delta^{(m)}$ 2.7) will contain objects living on the tensor product space $1 \otimes 2 \otimes \cdots \otimes m$, whilst the 'right' coproducts $\Delta_{R}^{(m)}$ will be defined on the sites $(N-$ $m+1) \otimes(N-m+2) \otimes \cdots \otimes N$.

Therefore, the coalgebra symmetry of a given Hamiltonian gives rise to two 'pyramidal' sets of $r \cdot N$ integrals of the motion in involution that Poisson-commute with $\mathcal{H}^{(N)}$ [21], under the corresponding symplectic realization $D$ 2.14. Namely, both sets are just the 'left' integrals above considered $\mathcal{C}_{j}^{(m)} 2.9$ together with the 'right' ones given by

$$
\mathcal{C}_{j,(m)}:=\Delta_{R}^{(m)}\left(\mathcal{C}_{j}\left(X_{1}, \ldots, X_{l}\right)\right)=\mathcal{C}_{j}\left(\Delta_{R}^{(m)}\left(X_{1}\right), \ldots, \Delta_{R}^{(m)}\left(X_{l}\right)\right)
$$

such that $\mathcal{C}_{j}^{(N)} \equiv \mathcal{C}_{j,(N)}$, while both $\mathcal{C}_{j}^{(1)}$ and $\mathcal{C}_{j,(1)}$ are constants.

The very same arguments discussed in Section 2.2 on the connection between integrability and the dimensionality of the chosen symplectic realizations can be applied to the additional set of 'right' integrals $\mathcal{C}_{j,(m)}$. In this way, a completely integrable Hamiltonian $\mathcal{H}^{(N)}$ with coalgebra symmetry will be, in principle, superintegrable.

For the sake of symplicity let us assume that we are dealing with a Poisson coalgebra with $R=1$, that is, with $N$ degrees of freedom and with a single nonlinear Casimir. Therefore if we take a symplectic realization with $s=1$ the necessary condition for integrability $(2.18)$ is fulfilled. In this case, the coalgebra approach gives rise to $(2 N-3)$ functionally independent integrals, which are displayed in Table 2 , and 
Table 2. Coalgebra symmetry and quasi-maximal syperintegrability

\begin{tabular}{cl}
\hline 'Left' set of $(N-1)$ integrals $\mathcal{C}^{(m)}$ in involution & Tensor product space \\
$\mathcal{C}^{(2)} \equiv \Delta^{(2)}(\mathcal{C})$ & $1 \otimes 2$ \\
$\mathcal{C}^{(3)} \equiv \Delta^{(3)}(\mathcal{C})$ & $1 \otimes 2 \otimes 3$ \\
$\vdots$ & $\vdots$ \\
$\mathcal{C}^{(m)} \equiv \Delta^{(m)}(\mathcal{C})$ & $1 \otimes 2 \otimes \cdots \otimes m$ \\
$\vdots$ & $1 \otimes 2 \otimes \cdots \otimes(N-1) \otimes N$ \\
$\mathcal{C}^{(N)} \equiv \Delta^{(N)}(\mathcal{C})$ & Tensor product space \\
'Right' set of $(N-1)$ integrals $\mathcal{C}^{(m)}$ in involution & $(N-1) \otimes N$ \\
$\mathcal{C}_{(2)} \equiv \Delta_{R}^{(2)}(\mathcal{C})$ & $(N-2) \otimes(N-1) \otimes N$ \\
$\mathcal{C}_{(3)} \equiv \Delta_{R}^{(3)}(\mathcal{C})$ & $\vdots$ \\
$\vdots$ & $(N-m+1) \otimes(N-m+2) \otimes \cdots \otimes N$ \\
$\mathcal{C}_{(m)} \equiv \Delta_{R}^{(m)}(\mathcal{C})$ & $\vdots$ \\
$\vdots$ & $1 \otimes 2 \otimes \cdots \otimes(N-1) \otimes N$ \\
$\mathcal{C}_{(N)}=\mathcal{C}^{(N)} \equiv \Delta_{R}^{(N)}(\mathcal{C})$ & \\
\hline
\end{tabular}

with $\Delta_{L}^{(N)}(\mathcal{C}) \equiv \Delta_{R}^{(N)}(\mathcal{C})$ being a common 'left-right' integral. Then each set of 'left' and 'right' integrals is then formed by $(N-1)$ functions in involution. Therefore there is only one missing integral in order to ensure the maximal superintegrability of the system, which means that $\mathcal{H}^{(N)}$ is always, at least, QMS. Such a 'remaining' integral, in case it does exist, will not be provided by the coalgebra symmetry and it will have to be found by alternative methods. Hence, we can conclude that the coalgebra symmetry for this class of Hamiltonian systems with $N$ degrees of freedom implies the following integrability hierarchy:

- $N=2$. The Hamiltonian is only integrable with a single constant of motion $\mathcal{C}^{(2)}=\mathcal{C}_{(2)}$.

- $N=3$. The Hamiltonian is minimally (or weakly) superintegrable with three integrals given by $\left\{\mathcal{C}^{(2)}, \mathcal{C}^{(3)}=\mathcal{C}_{(3)}, \mathcal{C}_{(2)}\right\}$.

- $N>3$. The Hamiltonian is $Q M S$ with $(2 N-3)$ integrals $\left\{\mathcal{C}^{(m)}, \mathcal{C}^{(N)}=\mathcal{C}_{(N)}, \mathcal{C}_{(m)}\right\}$ for $m=2, \ldots, N-1$. 


\subsection{The $\operatorname{sl}(2, \mathbb{R})$ Lie-Poisson coalgebra}

We stress that the coalgebra approach to complete integrability is completely general and constructive for any Poisson coalgebra endowed with a suitable symplectic realization. In order to illustrate the above ideas, we will firstly consider the coalgebra construction for the $s l(2, \mathbb{R})[178]$ Lie-Poisson algebra.

This coalgebra is defined by the following Lie-Poisson brackets and comultiplication map:

$$
\begin{aligned}
& \left\{J_{3}, J_{+}\right\}=2 J_{+} \quad\left\{J_{3}, J_{-}\right\}=-2 J_{-} \quad\left\{J_{-}, J_{+}\right\}=4 J_{3} \\
& \Delta(1)=1 \otimes 1 \quad \Delta\left(J_{i}\right)=J_{i} \otimes 1+1 \otimes J_{i} \quad i=+,-, 3 .
\end{aligned}
$$

The Casimir function for $\operatorname{sl}(2, \mathbb{R})$ reads

$$
\mathcal{C}=J_{-} J_{+}-J_{3}^{2}
$$

A one-particle symplectic realization of this coalgebra is given by

$$
D\left(J_{-}\right)=q_{1}^{2} \quad D\left(J_{+}\right)=p_{1}^{2}+\frac{b_{1}}{q_{1}^{2}} \quad D\left(J_{3}\right)=q_{1} p_{1}
$$

where $\left\{q_{1}, p_{1}\right\}=1$, with the standard Poisson-bracket. Note that, under this realization, $\mathcal{C}^{(1)}=D(\mathcal{C})=b_{1}$. Hence, according to the notation and results presented in Section 2.1 we are dealing with a Poisson coalgebra with dimension $l=3$ and with a single nonlinear Casimir. Thus $r=R=1$ and this implies that (2.28) is the generic symplectic realization with $s \equiv s_{m}=(l-r) / 2=1$. The corresponding $N$-particle symplectic realization of $\operatorname{sl}(2, \mathbb{R})$, living on $\operatorname{sl}(2, \mathbb{R}) \otimes \ldots{ }^{N)} \otimes \operatorname{sl}(2, \mathbb{R})$, is obtained by applying

$$
J_{i}^{(N)}=\left(D \otimes D \otimes \ldots{ }^{N)} \otimes D\right)\left(\Delta^{(N)}\left(J_{i}\right)\right)
$$

which gives [13, 24]

$$
\begin{aligned}
& J_{-}^{(N)}=\sum_{i=1}^{N} q_{i}^{2} \equiv \mathbf{q}^{2} \quad J_{3}^{(N)}=\sum_{i=1}^{N} q_{i} p_{i} \equiv \mathbf{q} \cdot \mathbf{p} \\
& J_{+}^{(N)}=\sum_{i=1}^{N}\left(p_{i}^{2}+\frac{b_{i}}{q_{i}^{2}}\right) \equiv \mathbf{p}^{2}+\sum_{i=1}^{N} \frac{b_{i}}{q_{i}^{2}}
\end{aligned}
$$

where $b_{i}$, are $N$ arbitrary real parameters. This means that the $N$-particle generators (2.29) fulfil the commutation rules 2.25 with respect to the ND canonical Poisson bracket. 
Next, since $s_{m}=1$ and $R=1$ we are in the case of a Poisson coalgebra endowed with the $(2 N-3)$ integrals displayed in Table 2 ; these turn out to be [21, 24]:

$$
\mathcal{C}^{(m)}=\sum_{1 \leq i<j}^{m} I_{i j}+\sum_{i=1}^{m} b_{i} \quad \mathcal{C}_{(m)}=\sum_{N-m+1 \leq i<j}^{N} I_{i j}+\sum_{i=N-m+1}^{N} b_{i}
$$

where $m=2, \ldots, N$ and

$$
\mathcal{I}_{i j}=\left(q_{i} p_{j}-q_{j} p_{i}\right)^{2}+\left(b_{i} \frac{q_{j}^{2}}{q_{i}^{2}}+b_{j} \frac{q_{i}^{2}}{q_{j}^{2}}\right)
$$

are the $b_{i}$-generalization of the square of the 'angular momentum' generators $J_{i j}=$ $\left(q_{i} p_{j}-q_{j} p_{i}\right)$ which span an $s o(N)$ Lie-Poisson algebra. As a consequence of the coalgebra symmetry, the generators (2.29) Poisson commute with these $(2 N-3)$ functions. Therefore, any arbitrary function $\mathcal{H}$ defined as

$$
\mathcal{H}^{(N)}=\mathcal{H}\left(J_{-}^{(N)}, J_{+}^{(N)}, J_{3}^{(N)}\right)=\mathcal{H}\left(\mathbf{q}^{2}, \mathbf{p}^{2}+\sum_{i=1}^{N} \frac{b_{i}}{q_{i}^{2}}, \mathbf{q} \cdot \mathbf{p}\right)
$$

gives rise to an ND QMS Hamiltonian system which is always endowed, at least, with the $(2 N-3)$ integrals $(2.30)$.

Therefore, the following Hamiltonian

$$
\mathcal{H}^{(N)}=\frac{1}{2} \sum_{i=1}^{N}\left(p_{i}^{2}+\frac{b_{i}}{q_{i}^{2}}\right)+\mathcal{F}\left(\sum_{i=1}^{N} q_{i}^{2}\right)=\frac{1}{2} J_{+}+\mathcal{F}\left(J_{-}\right),
$$

represents the motion of a particle on the $N D$ Euclidean space under the action of $N$ 'centrifugal barriers' determined by the $b_{i}$-terms and an arbitrary central potential given by the function $\mathcal{F}$. As particular cases, this Hamiltonian reproduces the SmorodinskyWinternitz system [89] for $\mathcal{F}=\omega J_{-}$and provides, a $N D$ generalization of the Kepler potential when $\mathcal{F}=\frac{\gamma}{\sqrt{J_{-}}}$. In fact, this coalgebra has been recently shown to underlie the integrability of the oscillator and Kepler potentials on the ND spaces with constant curvature 24] and also of the ND spherically symmetric generalization of certain spaces with non-constant curvature [25, 26, 29].

\subsection{ND integrable systems from 3D Lie coalgebras}

After the previous generic presentation of the coalgebra formalism, we are going to analyse in detail, the generic symplectic realizations for 3D real Lie algebras (in this 
Chapter) and for some 4D, 5D and 6D real Lie algebras (in the following chapter) fulfilling the integrability condition. In this way, we shall illustrate the type of ND integrable systems that can be associated to these Lie-coalgebras symmetries.

By following the known classifications summarized in [145] we firstly consider the set of 9 non-isomorphic 3D $(l=3)$ real Lie algebras, all of them with $r=1$ (note that the generators $e_{i}$ in [145] are now written as $J_{i}$ ). Their generic symplectic realizations have been computed and are given in Table 3.

Only one of these algebras (namely, the Heisenberg algebra $A_{3,1}$ ) has $R=0$ (only one linear Casimir). This will be the only case in which the construction does not provide any dynamically relevant constant of the motion, since the Casimir coincides with the central generator $J_{1}$ and its $m$-th coproducts are just numerical constants.

Table 3. Generic symplectic realizations and Casimirs for 3D algebras.

\begin{tabular}{|c|c|c|c|c|c|}
\hline & $J_{1}$ & $J_{2}$ & $J_{3}$ & $\mathcal{C}$ & \\
\hline \hline$A_{3,1}$ & $k$ & $p$ & $-k q$ & $J_{1}$ & $k \neq 0$ \\
\hline$A_{3,2}$ & $k e^{\frac{p}{k}}$ & $p e^{\frac{p}{k}}$ & $-k q$ & $J_{1} e^{-\frac{J_{2}}{J_{1}}}$ & $k \neq 0$ \\
\hline$A_{3,3}$ & $\frac{p^{2}}{2 k}$ & $\frac{p^{2}}{2}$ & $-\frac{p q}{2}$ & $\frac{J_{2}}{J_{1}}$ & $k \neq 0$ \\
\hline$A_{3,4}$ & $k e^{p}$ & $e^{-p}$ & $-q$ & $J_{1} J_{2}$ & $k \neq 0$ \\
\hline$A_{3,5}^{\alpha}$ & $e^{\frac{p}{\alpha}}$ & $k e^{p}$ & $-\alpha q$ & $J_{2} J_{1}^{-\alpha}$ & $k \neq 0$ \\
\hline$A_{3,6}$ & $\sqrt{k} \cos p$ & $\sqrt{k} \sin p$ & $-q$ & $J_{1}^{2}+J_{2}^{2}$ & $k>0$ \\
\hline$A_{3,7}^{\alpha}$ & $\sqrt{k} e^{\alpha p} \cos p$ & $\sqrt{k} e^{\alpha p} \sin p$ & $-q$ & $\left(J_{1}^{2}+J_{2}^{2}\right) e^{-2 \alpha \arctan \left(\frac{J_{2}}{J_{1}}\right)}$ & $k>0$ \\
\hline$A_{3,8}$ & $\frac{e^{q}}{2}\left(k-2 p^{2}\right)$ & $p$ & $e^{-q}$ & $2 J_{2}^{2}+J_{1} J_{3}+J_{3} J_{1}$ & $\forall k$ \\
\hline$(* * *)$ & $\frac{q^{2}}{2}$ & $\frac{p q}{2}$ & $-\frac{p^{2}}{2}+\frac{k}{q^{2}}$ & & $\forall k, q \neq 0$ \\
\hline$(* *)$ & $-p q^{2}+\sqrt{2 k} q$ & $p q-\sqrt{\frac{k}{2}}$ & $p$ & & $k \geq 0$ \\
\hline$(*)$ & $p \sin q+p$ & $p \cos q$ & $p \sin q-p$ & & $k=0$ \\
\hline$A_{3,9}$ & $p$ & $\sqrt{k-p^{2}} \cos q$ & $\sqrt{k-p^{2}} \sin q$ & $J_{1}^{2}+J_{2}^{2}+J_{3}^{2}$ & $k>0$ \\
\hline
\end{tabular}

The rest of the 3D Lie coalgebras have $R=1$ and, since $s_{m}=(3-1) / 2=1$, we do have complete integrability for all the latter cases. Therefore, the 'one-particle' symplectic realizations given in Table 3 provide automatically infinite families of ND completely integrable (and in this case, quasi-maximally superintegrable) systems. In Table 3, the constant $k$ is just the value that the Casimir $\mathcal{C}$ takes under the given symplectic realization. Note that, in many cases, if $k=0$ we would get a lower dimensional algebra, a case that we do not consider. We also point out that two symplectic realizations with the same value for $k$ can always be related through a canonical transformation. This is the case of the $A_{3,8}^{\alpha}$ algebra, for which four different 
symplectic realizations are explicitly provided in order to illustrate the multiplicity of apparently different systems that share the same underlying coalgebra symmetry. In order to get classical Hamiltonian systems defined through real symplectic realizations, we will also restrict the values of the constant $k$, if needed.

To shorten the presentation of the results, for each Lie coalgebra we will give:

a) The explicit non-vanishing commutation rules (that have to be understood as Poisson brackets) that are fulfilled by the given symplectic realization.

b) The most general integrable Hamiltonian $\mathcal{H}^{(N)}$ that can be constructed as an arbitrary function of the $N$-th coproduct of the three generators.

c) The explicit form of the constants of the motion $\mathcal{C}^{(m)}(m=2, \ldots, N)$ coming from the Casimir function.

The 'right' set of constants of the motion 21] that gives rise to the quasi-maximal superintegrability of all these systems can be obtained from a given set $\mathcal{C}^{(m)}$ by performing the appropriate permutation of indices, as explained in [21, and we will not write them explicitly. Note that for each Lie coalgebra we obtain an infinite family of superintegrable $N D$ Hamiltonians (the function $\mathcal{H}$ is arbitrary) depending on $N$ arbitrary constants $k_{i}$ that label the specific symplectic realization that we have chosen on each of the $N$ copies of the Lie algebra.

- $A_{3,2}$ integrable systems

$$
\begin{gathered}
\left\{J_{1}, J_{3}\right\}=J_{1} \quad\left\{J_{2}, J_{3}\right\}=J_{1}+J_{2} \\
\mathcal{H}^{(N)}=\mathcal{H}\left(\sum_{i=1}^{N} k_{i} e^{\frac{p_{i}}{k_{i}}}, \sum_{i=1}^{N} p_{i} e^{\frac{p_{i}}{k_{i}}},-\sum_{i=1}^{N} k_{i} q_{i}\right) \\
\mathcal{C}^{(m)}=\left(\sum_{i=1}^{m} k_{i} e^{\frac{p_{i}}{k_{i}}}\right) e^{-\left(\frac{\sum_{i=1}^{m} p_{i} e^{\frac{p_{i}}{k_{i}}}}{\sum_{i=1}^{m} k_{i} e^{\frac{p_{i}}{k_{i}}}}\right)} .
\end{gathered}
$$

Note that in this case (and in some of the remaining examples) the integrals do not depend on the canonical coordinates $q_{i}$. Therefore, by taking into account the $\mathcal{C}^{(m)}$ and the $\mathcal{C}_{(m)}$ constants, we could obtain at most $N$ functionally independents integrals of motion in involution with $\mathcal{H}^{(N)}$.

- $A_{3,3}$ integrable systems

$$
\left\{J_{1}, J_{3}\right\}=J_{1} \quad\left\{J_{2}, J_{3}\right\}=J_{2}
$$




$$
\begin{gathered}
\mathcal{H}^{(N)}=\mathcal{H}\left(\sum_{i=1}^{N} \frac{p_{i}^{2}}{2 k_{i}}, \sum_{i=1}^{N} \frac{p_{i}^{2}}{2},-\sum_{i=1}^{N} \frac{p_{i} q_{i}}{2}\right) \\
\mathcal{C}^{(m)}=\frac{\left(\sum_{i=1}^{m} p_{i}^{2}\right)}{\left(\sum_{i=1}^{m} \frac{p_{i}^{2}}{k_{i}}\right)} .
\end{gathered}
$$

Surprisingly enough, in this case we lose the integrability if we take the same symplectic realization on all the copies of the $A$ algebra (i.e., if $k_{1}=k_{2}=\cdots=k_{N}$ ), since all the integrals are transformed into constants. This fact, emphasizes the role of symplectic representations throughout the formalism.

- $A_{3,4}$ integrable systems

$$
\begin{gathered}
\left\{J_{1}, J_{3}\right\}=J_{1} \quad\left\{J_{2}, J_{3}\right\}=-J_{2} \\
\mathcal{H}^{(N)}=\mathcal{H}\left(\sum_{i=1}^{N} k_{i} e^{p_{i}}, \sum_{i=1}^{N} e^{-p_{i}},-\sum_{i=1}^{N} q_{i}\right) \\
\mathcal{C}^{(m)}=\sum_{i=1}^{m} k_{i}+\sum_{\substack{i, j=1 \\
i \neq j}}^{m} k_{i} e^{p_{i}-p_{j}} .
\end{gathered}
$$

This algebra is just the $(1+1)$ Poincaré algebra. An analogue of the RuijsenaarsSchneider Hamiltonian [160] was obtained in [12] by using a quantum deformation of this realization, and will be presented in the next Section.

- $A_{3,5}^{\alpha}$ integrable systems $\quad(0<|\alpha|<1)$

$$
\begin{gathered}
\left\{J_{1}, J_{3}\right\}=J_{1} \quad\left\{J_{2}, J_{3}\right\}=\alpha J_{2} \\
\mathcal{H}^{(N)}=\mathcal{H}\left(\sum_{i=1}^{N} e^{\frac{p_{i}}{\alpha}}, \sum_{i=1}^{N} k_{i} e^{p_{i}},-\sum_{i=1}^{N} \alpha q_{i}\right) \\
\mathcal{C}^{(m)}=\frac{\sum_{i=1}^{m} k_{i} e^{p_{i}}}{\left(\sum_{i=1}^{m} e^{\frac{p_{i}}{\alpha}}\right)^{\alpha}}
\end{gathered}
$$

- $A_{3,6}$ integrable systems

$$
\left\{J_{1}, J_{3}\right\}=-J_{2} \quad\left\{J_{2}, J_{3}\right\}=J_{1}
$$




$$
\begin{gathered}
\mathcal{H}^{(N)}=\mathcal{H}\left(\sum_{i=1}^{N} \sqrt{k_{i}} \cos p_{i}, \sum_{i=1}^{N} \sqrt{k_{i}} \sin p_{i},-\sum_{i=1}^{N} q_{i}\right) \\
\mathcal{C}^{(m)}=\sum_{i=1}^{m} k_{i}+\sum_{\substack{i, j=1 \\
i \neq j}}^{m} \sqrt{k_{i} k_{j}} \cos \left(p_{i}-p_{j}\right) .
\end{gathered}
$$

Note that, this algebra is the two dimensional Euclidean algebra.

- $A_{3,7}^{\alpha}$ integrable systems $(\alpha>0)$

$$
\begin{aligned}
& \left\{J_{1}, J_{3}\right\}=\alpha J_{1}-J_{2} \quad\left\{J_{2}, J_{3}\right\}=J_{1}+\alpha J_{2} \\
& \mathcal{H}^{(N)}=\mathcal{H}\left(\sum_{i=1}^{N} \sqrt{k_{i}} e^{\alpha p_{i}} \cos p_{i}, \sum_{i=1}^{N} \sqrt{k_{i}} e^{\alpha p_{i}} \sin p_{i},-\sum_{i=1}^{N} q_{i}\right) \\
& \mathcal{C}^{(m)}=\left(\sum_{i=1}^{m} k_{i} e^{2 \alpha p_{i}}+\sum_{\substack{i, j=1 \\
i \neq j}}^{m} \sqrt{k_{i} k_{j}} e^{\alpha\left(p_{i}+p_{j}\right)} \cos \left(p_{i}-p_{j}\right)\right) e^{-2 \alpha \arctan \left(\frac{\sum_{i=1}^{m} \sqrt{k_{i}} e^{\alpha p_{i} \sin p_{i}}}{\sum_{i=1}^{m} \sqrt{k_{i}} e^{\alpha p_{i} \sin p_{i}}}\right)} .
\end{aligned}
$$

- $A_{3,8}$ integrable systems

$$
\begin{gathered}
\left\{J_{1}, J_{2}\right\}=J_{1} \quad\left\{J_{1}, J_{3}\right\}=-2 J_{2} \quad\left\{J_{2}, J_{3}\right\}=J_{3} \\
\mathcal{H}^{(N)}=\mathcal{H}\left(\sum_{i=1}^{N} \frac{e^{q_{i}}}{2}\left(k_{i}-2 p_{i}^{2}\right), \sum_{i=1}^{N} p_{i}, \sum_{i=1}^{N} e^{-q_{i}}\right) \\
\mathcal{C}^{(m)}=\sum_{i=1}^{m} k_{i}+\sum_{\substack{i, j=1 \\
i \neq j}}^{m} e^{q_{j}-q_{i}}\left(k_{j}-2 p_{j}^{2}\right)+2 \sum_{\substack{i, j=1 \\
i \neq j}}^{m} p_{i} p_{j} .
\end{gathered}
$$

This is the $s l(2, \mathbb{R}) \simeq s o(2,1)$ Lie coalgebra, and many different and important integrable systems can be obtained as $\mathcal{H}^{(N)}$ by making use of different symplectic realizations. For instance, the Calogero-Gaudin Hamiltonian [55, 91, 112, 113]

$$
\mathcal{H}^{(N)}=\sum_{i<j}^{N} 2 p_{i} p_{j}\left(1-\cos \left(q_{i}-q_{j}\right)\right),
$$

comes from the $k=0$ symplectic realization $(*)$ of $A_{3,8}$ (the $\operatorname{sl}(2)$ algebra) by taking as the Hamiltonian the Casimir operator $\mathcal{C}$ (see [12, 113] for a detailed discussion of this 
system and its integrable deformations, and the papers [132, 133] for its $q$-deformed quantum mechanical version). In general, note that the choice of the symplectic realization drastically changes the 'shape'of the Hamiltonian. For example, by using the Gel'fand-Dyson symplectic map (**) with $k=0$ the very same Calogero-Gaudin system reads

$$
\mathcal{H}^{(N)}=-\sum_{i<j}^{N} p_{i} p_{j}\left(q_{i}-q_{j}\right)^{2} .
$$

Finally, the symplectic realization $(* * *)$ has been fully analysed in the previous Section.

- $A_{3,9}$ integrable systems

$$
\begin{gathered}
\left\{J_{1}, J_{2}\right\}=J_{3} \quad\left\{J_{1}, J_{3}\right\}=-J_{2} \quad\left[J_{2}, J_{3}\right]=J_{1} \\
\mathcal{H}^{(N)}=\mathcal{H}\left(\sum_{i=1}^{N} p_{i}, \sum_{i=1}^{N} \sqrt{k_{i}-p_{i}^{2}} \cos q_{i}, \sum_{i=1}^{N} \sqrt{k_{i}-p_{i}^{2}} \sin q_{i}\right) \\
\mathcal{C}^{(m)}=-\sum_{i=1}^{m} k_{i}+2 \sum_{i=1}^{m} p_{i}^{2}+\sum_{\substack{i, j, i \neq j}}^{m} p_{i} p_{j}+\sum_{\substack{i, j, i \neq j}}^{m} \cos \left(q_{i}-q_{j}\right) \sqrt{p_{i}^{2}-k_{i}} \sqrt{p_{j}^{2}-k_{j}} .
\end{gathered}
$$

These would be the classical integrable systems provided by $N$ copies of the $s o(3)$ algebra.

\subsection{Integrable deformations from $q$-Poisson coalgebras}

The Poisson analogues of quantum algebras and groups [66, 67, 69, 79] are also (deformed) coalgebras $\left(A_{z}, \Delta_{z}\right)\left(q=\mathrm{e}^{z}\right)$, which means that any function of the generators of a given 'quantum' Poisson algebra (with deformed Casimir elements $\mathcal{C}_{z, j}$ ) will provide a deformation of the Hamiltonian generated by the undeformed structure. Such a $q$-coalgebraic deformation will preserve, by construction, the (super)integrability properties of the system defined on the undeformed Lie-Poisson coalgebra.

Therefore, $q$-deformations can be understood in this context as the algebraic machinery suitable for generating integrable deformations of Hamiltonian systems. This was explicitly shown for the first time by constructing the following deformed CG system [9]:

$$
\mathcal{H}_{z}^{(N)}=\sum_{1 \leq i<j}^{N} 2 \pi_{i} \pi_{j}\left(1-\cos \left(q_{i}-q_{j}\right)\right)
$$


where the non-local deformations of the momenta are

$$
\pi_{k}=2 \frac{\sinh \left(\frac{z}{2} p_{k}\right)}{z} \prod_{i=1}^{k-1} \mathrm{e}^{-\frac{z}{2} p_{i}} \prod_{j=k+1}^{N} \mathrm{e}^{\frac{z}{2} p_{j}}
$$

The corresponding constants of the motion come from the (deformed) coproduct of the (deformed) Casimir of $s_{z}(2,1)$ (the standard deformation of $\left.s o(2,1)\right)$ and, as expected, in the limit $z \rightarrow 0$ we recover the 'classical' CG system given in (2.55). We remark that the quantum mechanical version of this deformed CG system has been explicitly solved [132, 133 .

Another interesting example of coalgebra-invariant system is the following analogue [12] of the Ruijsenaars-Schneider model [160]:

$$
\mathcal{H}_{z}^{(N)}=\sum_{i=1}^{N} \cosh \theta_{i} \exp \left(-\frac{z}{2}\left(\sum_{j=1}^{i-1} q_{j}\right)+\frac{z}{2}\left(\sum_{k=i+1}^{N} q_{k}\right)\right)
$$

where $\left(q_{i}, \theta_{i}\right)$ are canonically conjugate variables such that $\left\{q_{i}, \theta_{j}\right\}=\delta_{i j}$. This completely integrable Hamiltonian was obtained by using the Poisson analogue of the quantum deformation of the $(1+1)$ D Poincaré algebra introduced in [173].

\subsubsection{The $q$-Poisson coalgebra $s l_{z}(2, \mathbb{R})$}

In order to illustrate explicitly this construction, let us focus on the non-standard $s l_{z}(2, \mathbb{R})$ Poisson coalgebra, which is defined by the following (deformed) Poisson brackets and coproduct map (see [13, 142]):

$$
\begin{gathered}
\left\{J_{3}, J_{+}\right\}=2 J_{+} \cosh z J_{-} \quad\left\{J_{3}, J_{-}\right\}=-2 \frac{\sinh z J_{-}}{z} \quad\left\{J_{-}, J_{+}\right\}=4 J_{3} \\
\Delta_{z}(1)=1 \otimes 1 \quad \Delta_{z}\left(J_{-}\right)=J_{-} \otimes 1+1 \otimes J_{-} \\
\Delta_{z}\left(J_{i}\right)=J_{i} \otimes \mathrm{e}^{z J_{-}}+\mathrm{e}^{-z J_{-}} \otimes J_{i} \quad(i=+, 3) .
\end{gathered}
$$

The Casimir function for $s l_{z}(2, \mathbb{R})$ reads

$$
\mathcal{C}_{z}=\frac{\sinh z J_{-}}{z} J_{+}-J_{3}^{2} .
$$

A one-particle (deformed) symplectic realization of $s l_{z}(2, \mathbb{R})$ is:

$$
D_{z}\left(J_{-}\right)=q_{1}^{2} \quad D_{z}\left(J_{+}\right)=\frac{\sinh z q_{1}^{2}}{z q_{1}^{2}} p_{1}^{2}+\frac{z b_{1}}{\sinh z q_{1}^{2}} \quad D_{z}\left(J_{3}\right)=\frac{\sinh z q_{1}^{2}}{z q_{1}^{2}} q_{1} p_{1}
$$


such that $\mathcal{C}_{z}^{(1)}=D_{z}\left(\mathcal{C}_{z}\right)=b_{1}$. Hence we are dealing again with a coalgebra with $l=3, r=R=1$ and $s_{m}=1$. The $N$ th-coproduct of $(2.63)$ through the one-particle representation 2.65 gives rise to an $N$-particle symplectic realization on $s_{z}(2, \mathbb{R}) \otimes$ $\ldots^{N)} \otimes s l_{z}(2, \mathbb{R})$ through

$$
J_{i}^{(N)}=\left(D_{z} \otimes D_{z} \otimes \ldots^{N)} \otimes D_{z}\right)\left(\Delta_{z}^{(N)}\left(J_{i}\right)\right),
$$

namely

$$
\begin{aligned}
& J_{-}^{(N)}=\sum_{i=1}^{N} q_{i}^{2} \equiv \mathbf{q}^{2} \quad J_{3}^{(N)}=\sum_{i=1}^{N} \frac{\sinh z q_{i}^{2}}{z q_{i}^{2}} q_{i} p_{i} \exp \left\{-z \sum_{k=1}^{i-1} q_{k}^{2}+z \sum_{l=i+1}^{N} q_{l}^{2}\right\} \equiv(\mathbf{q} \cdot \mathbf{p})_{z} \\
& J_{+}^{(N)}=\sum_{i=1}^{N}\left(\frac{\sinh z q_{i}^{2}}{z q_{i}^{2}} p_{i}^{2}+\frac{z b_{i}}{\sinh z q_{i}^{2}}\right) \exp \left\{-z \sum_{k=1}^{i-1} q_{k}^{2}+z \sum_{l=i+1}^{N} q_{l}^{2}\right\} \equiv \tilde{\mathbf{p}}_{z}^{2}
\end{aligned}
$$

where the $b_{i}$ 's are again $N$ arbitrary real parameters that label the representation on each 'lattice' site.

In this case the $(2 N-3)$ functions written in Table 2 are expliciltly given by [13, 21]:

$$
\begin{aligned}
\mathcal{C}_{z}^{(m)}= & \sum_{1 \leq i<j}^{m} I_{i j}^{z} \exp \left\{-2 z \sum_{k=1}^{i-1} q_{k}^{2}-z q_{i}^{2}+z q_{j}^{2}+2 z \sum_{l=j+1}^{m} q_{l}^{2}\right\} \\
& +\sum_{i=1}^{m} b_{i} \exp \left\{-2 z \sum_{k=1}^{i-1} q_{k}^{2}+2 z \sum_{l=i+1}^{m} q_{l}^{2}\right\} \\
\mathcal{C}_{z,(m)}= & \sum_{N-m+1 \leq i<j}^{N} I_{i j}^{z} \exp \left\{-2 z \sum_{k=N-m+1}^{i-1} q_{k}^{2}-z q_{i}^{2}+z q_{j}^{2}+2 z \sum_{l=j+1}^{N} q_{l}^{2}\right\} \\
& +\sum_{i=N-m+1}^{N} b_{i} \exp \left\{-2 z \sum_{k=N-m+1}^{i-1} q_{k}^{2}+2 z \sum_{l=i+1}^{N} q_{l}^{2}\right\}
\end{aligned}
$$

where $m=2, \ldots, N$ and

$$
\mathcal{I}_{i j}^{z}=\frac{\sinh z q_{i}^{2}}{z q_{i}^{2}} \frac{\sinh z q_{j}^{2}}{z q_{j}^{2}}\left(q_{i} p_{j}-q_{j} p_{i}\right)^{2}+\left(b_{i} \frac{\sinh z q_{j}^{2}}{\sinh z q_{i}^{2}}+b_{j} \frac{\sinh z q_{i}^{2}}{\sinh z q_{j}^{2}}\right) .
$$

Consequently, any smooth function $\mathcal{H}_{z}$ defined on the $N$-particle symplectic realization (2.66) of the generators of $s l_{z}(2, \mathbb{R})$ in the form

$$
\mathcal{H}_{z}^{(N)}=\mathcal{H}_{z}\left(J_{-}^{(N)}, J_{+}^{(N)}, J_{3}^{(N)}\right)=\mathcal{H}_{z}\left(\mathbf{q}^{2}, \tilde{\mathbf{p}}_{z}^{2},(\mathbf{q} \cdot \mathbf{p})_{z}\right)
$$


defines a QMS Hamiltonian system. We stress that all the choices for $\mathcal{H}_{z}$ share the 'universal' set of $(2 N-3)$ constants of motion given by (2.67).

Clearly, the non-deformed limit $z \rightarrow 0$ of all the above expressions gives rise to the ones corresponding to the $s l(2, \mathbb{R})$-coalgebra presented in Section 2.3, which shows that quantum algebras may provide (super)integrable generalizations of non-deformed Hamiltonian systems.

We also remark that this quantum deformation has been interpreted in [13] as an algebraic way to introduce long-range interactions in the underlying underformed systems due to the exponentials of the type $\exp \left(z \sum_{j} q_{j}^{2}\right)$ coming from the deformed symplectic realization (2.66) (compare with (2.29) and (2.32)). Another physically meaningful application has been presented in [22, where the geodesic flow hamiltonians defined as certain functions of the generators of $s l_{z}(2, \mathbb{R})$ have been shown to generate different curved spaces. In all of them, the deformation parameter can be interpreted as a curvature constant. 


\title{
Chapter 3
}

\section{Higher dimensional coalgebras}

\author{
"Don't worry about your difficulties in mathematics, \\ I can assure you that mine are still greater."
}

A. Einstein

In this Chapter, we continue with the systematic construction of generic symplectic realizations for low-dimensional real Lie-Poisson coalgebras. The four and five dimensional cases will be fully given, but we recall that in dimensions higher than five, classifications of real Lie algebras and their Casimir invariants are partial and restricted to certain simple, solvable or nilpotent subclasses, although a significant number of the latter are known (see, for instance, [44, 57, 61, 63, 148, 164, 171]). Thus, can be generated many new families of integrable systems provided that, for a given Lie coalgebra with known Casimir invariants, the integrability criterion is checked in order to determine a prior $i$ which are the symplectic realizations that can lead to integrable systems. Nevertheless, this analysis shows that, most of these systems have integrals of motion depending only on the momenta, thus restricting its potential dynamical interest.

\subsection{Integrable systems from 4D Lie coalgebras}

In this case the classification [145] provide a set of 12 non-isomorphic $4 \mathrm{D}(l=4)$ real Lie algebras. Among them, 4 algebras have $R=0$, and will not give rise to integrable systems under our approach. 


\subsubsection{Algebras with $R=1$}

We have four Lie algebras with $r=2$ and $R=1$ (two Casimirs, one of them linear). In all these cases $s_{m}=(4-2) / 2=1$ and the integrability condition is fulfilled. The explicit generic symr of these four algebras, together with the explicit form of the non-linear Casimir, are given in Table 4.

Table 4. Symplectic realizations for 4D Lie-Poisson algebras with $(R=1)$.

\begin{tabular}{|c|c|c|c|c|}
\hline & $A_{4,1}$ & $A_{4,3}$ & $A_{4,8}$ & $A_{4,10}$ \\
\hline \hline$J_{1}$ & $k_{1}$ & $e^{p}$ & $k_{1}$ & $k_{1}$ \\
\hline$J_{2}$ & $p$ & $k_{1}$ & $\sqrt{p} e^{q}$ & $k_{1} q$ \\
\hline$J_{3}$ & $\frac{p^{2}-k_{2}}{2 k_{1}}$ & $k_{1}\left(p-\log k_{2}\right)$ & $k_{1} \sqrt{p} e^{-q}$ & $p$ \\
\hline$J_{4}$ & $-k_{1} q$ & $-q$ & $-\frac{k_{2}}{2 k_{1}}+p$ & $\frac{-p^{2}-k_{1}^{2} q_{1}^{2}+k_{2}}{2 k_{1}}$ \\
\hline $\mathcal{C}_{2}$ & $J_{2}^{2}-2 J_{1} J_{3}$ & $J_{1} e^{-\frac{J_{3}}{J_{2}}}$ & $J_{2} J_{3}+J_{3} J_{2}-2 J_{1} J_{4}$ & $2 J_{1} J_{4}+J_{2}^{2}+J_{3}^{2}$ \\
\hline & $k_{1} \neq 0$ & $k_{1} \neq 0, k_{2}>0$ & $k_{1} \neq 0$ & $k_{1} \neq 0$ \\
\hline
\end{tabular}

- $A_{4,1}$ integrable systems

$$
\begin{gathered}
\left\{J_{2}, J_{4}\right\}=J_{1} \quad\left\{J_{3}, J_{4}\right\}=J_{2} \\
\mathcal{H}^{(N)}=\mathcal{H}\left(\sum_{i=1}^{N} k_{1, i}, \sum_{i=1}^{N} p_{i}, \sum_{i=1}^{N} \frac{p_{i}^{2}-k_{2, i}}{2 k_{1, i}},-\sum_{i=1}^{N} k_{1, i} q_{i}\right) \\
\mathcal{C}^{(m)}=\sum_{i=1}^{m} k_{2, i}+\sum_{\substack{i, j=1 \\
i \neq j}}^{m} p_{i} p_{j}+\sum_{\substack{i, j=1 \\
i \neq j}}^{m} k_{1, i} \frac{k_{2, j}}{k_{1, j}}-\sum_{\substack{i, j=1 \\
i \neq j}}^{m} \frac{p_{i}^{2}}{k_{1, i}} k_{1, j} .
\end{gathered}
$$

The algebra $A_{4,1}$ is the $(1+1)$ extended Galilei Lie algebra, and their associated integrable systems have been constructed in [14], as well as their integrable deformations.

- $A_{4,3}$ integrable systems

$$
\begin{gathered}
\left\{J_{1}, J_{4}\right\}=J_{1} \quad\left\{J_{3}, J_{4}\right\}=J_{2} \\
\mathcal{H}^{(N)}=\mathcal{H}\left(\sum_{i=1}^{N} e^{p_{i}}, \sum_{i=1}^{N} k_{1, i}, \sum_{i=1}^{N} k_{1, i}\left(p_{i}-\log k_{2, i}\right),-\sum_{i=1}^{N} q_{i}\right)
\end{gathered}
$$




$$
\mathcal{C}^{(m)}=\left(\sum_{i=1}^{m} e^{p_{i}}\right) e^{-\frac{\sum_{i=1}^{m} k_{1, i}\left(p_{i}-\log k_{2, i}\right)}{\sum_{i=1}^{m} k_{1, i}}}
$$

- $A_{4,8}$ integrable systems

$$
\begin{gathered}
\left\{J_{2}, J_{3}\right\}=J_{1} \quad\left\{J_{2}, J_{4}\right\}=J_{2} \quad\left\{J_{3}, J_{4}\right\}=-J_{3} \\
\mathcal{H}^{(N)}=\mathcal{H}\left(\sum_{i=1}^{N} k_{1, i}, \sum_{i=1}^{N} \sqrt{p_{i}} e^{q_{i}}, \sum_{i=1}^{N} k_{1, i} \sqrt{p_{i}} e^{-q_{i}}, \sum_{i=1}^{N}\left(-\frac{k_{2, i}}{2 k_{1, i}}+p_{i}\right)\right) \\
\mathcal{C}^{(m)}=\sum_{i=1}^{m} k_{2, i}+\sum_{\substack{i, j=1 \\
i \neq j}}^{m} \frac{k_{2, i}}{k_{1, i}} k_{1, j}-2 \sum_{\substack{i, j=1 \\
i \neq j}}^{m} p_{i} k_{1, j}+\sum_{\substack{i, j=1 \\
i \neq j}}^{m} e^{-q_{i}+q_{j}} k_{1, i} \sqrt{p_{i} p_{j}}
\end{gathered}
$$

The algebra $A_{4,8}$ is also known as the oscillator algebra $h_{4}$. If we take the $\mathcal{H}$ function

$$
\mathcal{H}=\lambda J_{4}+\mu J_{2} J_{3}
$$

under the realization with $\left(k_{1, i}=1\right)$ and $\left(k_{2, i}=0\right)$ we get the following integrable Hamiltonian

$$
\mathcal{H}^{(N)}=(\lambda+\mu) \sum_{i=1}^{N} p_{i}+2 \mu \sum_{i<j}^{N} \sqrt{p_{i} p_{j}} \cosh \left(q_{i}-q_{j}\right),
$$

whose quantum mechanical version was introduced in [56]. The integrals of the motion in involution in the chosen realization read:

$$
\mathcal{C}^{(m)}=-2 \sum_{i=1}^{m} p_{i}+2 \sum_{i, j=1}^{m} \sqrt{p_{i} p_{j}} \cosh \left(q_{i}-q_{j}\right)=2 \sum_{\substack{i, j=1 \\ i \neq j}}^{m} \sqrt{p_{i} p_{j}} \cosh \left(q_{i}-q_{j}\right) .
$$

- $A_{4,10}$ integrable systems

$$
\begin{array}{r}
\left\{J_{2}, J_{3}\right\}=J_{1} \quad\left\{J_{2}, J_{4}\right\}=-J_{3} \quad\left\{J_{3}, J_{4}\right\}=J_{2} \\
\mathcal{H}^{(N)}=\mathcal{H}\left(\sum_{i=1}^{N} k_{1, i}, \sum_{i=1}^{N} k_{1, i} q_{i}, \sum_{i=1}^{N} p_{i},-\sum_{i=1}^{N} \frac{p_{i}^{2}+k_{1, i}^{2} q_{i}^{2}-k_{2, i}}{2 k_{1, i}}\right)
\end{array}
$$




$$
\mathcal{C}^{(m)}=\sum_{i, j=1}^{m} \frac{k_{2, i} k_{1, j}}{k_{1, i}}-\sum_{\substack{i, j=1 \\ i \neq j}}^{m} \frac{p_{i}^{2} k_{1, j}}{k_{1, i}}+\sum_{\substack{i, j=1 \\ i \neq j}}^{m} k_{1, i} k_{1, j} q_{i} q_{j}+\sum_{\substack{i, j=1 \\ i \neq j}}^{m} p_{i} p_{j}-\sum_{\substack{i, j=1 \\ i \neq j}}^{m} q_{i}^{2} k_{1, i} k_{1, j} .
$$

In particular, the $N$-particle Hamiltonian given by $\mathcal{H}=-J_{4}+\mathcal{F}\left(J_{2}\right)$ gives

$$
\mathcal{H}^{(N)}=\sum_{i=1}^{N} \frac{p_{i}^{2}+k_{1, i}^{2} q_{i}^{2}-k_{2, i}}{2 k_{1, i}}+\mathcal{F}\left(\sum_{i=1}^{N} k_{1, i} q_{i}\right)
$$

which is a completely integrable Hamiltonian for any choice of the function $\mathcal{F}$, with integrals of the motion independent of $\mathcal{F}$ and given by (3.15). This system, is just an anisotropic ND oscillator plus an arbitrary function $\mathcal{F}\left(J_{2}\right)$.

\subsubsection{Algebras with $R=2$}

We have four more $4 \mathrm{D}$ algebras with $R=2$. Again, $s_{m}=(4-2) / 2=1$ and the integrability condition is fulfilled. The generic symplectic realizations of these four algebras are given in Table 5.

It is important to stress that, since we have two non-linear Casimirs, we obtain two sets $\left\{\mathcal{C}_{1}^{(m)}\right\}$ and $\left\{\mathcal{C}_{2}^{(m)}\right\}$ of $(N-1)$ constants of the motion in involution with the Hamiltonian, besides the two additional sets given by the 'right' coproducts. However, in all these cases the Casimir function $\left\{\mathcal{C}_{j}^{(m)}\right\}$ depends only on the momenta $\left(p_{1}, p_{2}, \ldots, p_{m}\right)$. Therefore, we can find at most $N$ functionally independent objects among the full set of $\left\{C_{j}^{(m)}\right\}$ functions.

- $A_{4,2}^{\alpha}$ integrable systems $\quad(\alpha \neq 0)$

$$
\begin{aligned}
& \left\{J_{1}, J_{4}\right\}=\alpha J_{1} \quad\left\{J_{2}, J_{4}\right\}=J_{2} \quad\left\{J_{3}, J_{4}\right\}=J_{2}+J_{3} \\
& \mathcal{H}^{(N)}=\mathcal{H}\left(\sum_{i=1}^{N} \frac{k_{1, i}^{\alpha}}{k_{2, i}} e^{p_{i}}, \sum_{i=1}^{N} k_{1, i} e^{p_{i}}, \sum_{i=1}^{N} k_{1, i} p_{i} e^{p_{i}},-\sum_{i=1}^{N} q_{i}\right) \\
& \mathcal{C}_{1}^{(m)}=\left(\sum_{i=1}^{m} k_{1, i} e^{p_{i}}\right) e^{-\left(\frac{\sum_{i=1}^{m} k_{1, i} p_{i} e^{p_{i}}}{\sum_{i=1}^{m} k_{1, i} e^{p_{i}}}\right)} \quad \mathcal{C}_{2}^{(m)}=\frac{\left(\sum_{i=1}^{m} k_{1, i} e^{p_{i}}\right)^{\alpha}}{\left(\sum_{i=1}^{m} \frac{k_{1, i}^{\alpha}}{k_{2, i}} e^{p_{i}}\right)} .
\end{aligned}
$$


Table 5. Symplectic realizations for 4D Lie-Poisson algebras with $R=2$.

\begin{tabular}{|c|c|c|c|c|}
\hline & $A_{4,2}^{\alpha}$ & $A_{4,4}$ & $A_{4,5}^{a, b}$ & $A_{4,6}^{a, b}$ \\
\hline \hline$J_{1}$ & $\frac{k_{1}^{\alpha} e^{p}}{k_{2}}$ & $k_{1} e^{p}$ & $\left(k_{1} a\right)^{\frac{1}{a}} e^{p}$ & $\left(k_{1} k_{2} e^{\frac{b \pi}{2}}\right)^{\frac{a}{2 b}} e^{a p}$ \\
\hline$J_{2}$ & $k_{1} e^{p}$ & $k_{1} p e^{p}$ & $a e^{a p}$ & $\sqrt{\frac{e^{\frac{b \pi}{2}}}{2} k_{2}} e^{b p} f(p)$ \\
\hline$J_{3}$ & $k_{1} p e^{p}$ & $\frac{k_{1} e^{p}}{2}\left(p^{2}+k_{2}\right)$ & $\frac{\left(k_{1} a\right)^{\frac{b}{a}}}{k_{2}} e^{b p}$ & $\sqrt{\frac{e^{\frac{b \pi}{2}}}{2} k_{2}} e^{b p} g(p)$ \\
\hline$J_{4}$ & $-q$ & $-q$ & $-q$ & $-q$ \\
\hline $\mathcal{C}_{1}$ & $J_{2} e^{-\frac{J_{3}}{J_{2}}}$ & $J_{1} e^{-\frac{J_{2}}{J_{1}}}$ & $\frac{J_{1}^{\alpha}}{J_{2}}$ & $\frac{J_{1}^{\frac{2 b}{a}}}{J_{2}^{2}+J_{3}^{2}}$ \\
\hline $\mathcal{C}_{2}$ & $\frac{J_{2}^{\alpha}}{J_{1}}$ & $\frac{2 J_{1} J_{3}-J_{2}^{2}}{J_{1}^{2}}$ & $\frac{J_{1}^{b}}{J_{3}}$ & $\left(J_{2}^{2}+J_{3}^{2}\right) e^{-2 b \arctan \left(\frac{J_{3}}{J_{2}}\right)}$ \\
\hline & $k_{1} \neq 0$ & $k_{1} \neq 0$ & $k_{1} \neq 0$ & $k_{1} \neq 0, k_{2}>0$ \\
\hline
\end{tabular}

where

$$
f(p)=(\cos p-\sin p), \quad g(p)=(\cos p+\sin p)
$$

are the functions involved in $A_{4,6}^{a, b}$.

- $A_{4,4}$ integrable systems

$$
\begin{aligned}
&\left\{J_{1}, J_{4}\right\}=J_{1} \quad\left\{J_{2}, J_{4}\right\}=J_{1}+J_{2} \quad\left\{J_{3}, J_{4}\right\}=J_{2}+J_{3} \\
& \mathcal{H}^{(N)}=\mathcal{H}\left(\sum_{i=1}^{N} k_{1, i} e^{p_{i}}, \sum_{i=1}^{N} k_{1, i} p_{i} e^{p_{i}}, \sum_{i=1}^{N} \frac{k_{1, i} e^{p_{i}}}{2}\left(p_{i}^{2}+k_{2, i}\right),-\sum_{i=1}^{N} q_{i}\right) \\
& \mathcal{C}_{1}^{(m)}=\left(\sum_{i=1}^{m} k_{1, i} e^{p_{i}}\right) e^{-\left(\frac{\sum_{i=1}^{m} k_{1, i} p_{i} e^{p_{i}}}{\sum_{i=1}^{m} k_{1, i} e^{p_{i}}}\right)} \\
& \mathcal{C}_{2}^{(m)}= \frac{2\left(\sum_{i=1}^{m} k_{1, i} e^{p_{i}}\right)\left(\sum_{i=1}^{m} \frac{k_{1, i} e^{p_{i}}}{2}\left(p_{i}^{2}+k_{2, i}\right)\right)-\left(\sum_{i=1}^{m} k_{1, i} p_{i} e^{p_{i}}\right)^{2}}{\left(\sum_{i=1}^{m} k_{1, i} e^{p_{i}}\right)^{2}} .
\end{aligned}
$$


- $A_{4,5}^{a, b}$ integrable systems $\quad(a b \neq 0) \quad(-1 \leq a \leq b \leq 1)$

$$
\begin{gathered}
\left\{J_{1}, J_{4}\right\}=J_{1} \quad\left\{J_{2}, J_{4}\right\}=a J_{2} \quad\left\{J_{3}, J_{4}\right\}=b J_{3} \\
\mathcal{H}^{(N)}=\mathcal{H}\left(\sum_{i=1}^{N}\left(k_{1, i} a\right)^{\frac{1}{a}} e^{p_{i}}, \sum_{i=1}^{N} a e^{a p_{i}}, \sum_{i=1}^{N} \frac{\left(k_{1, i} a\right)^{\frac{b}{a}}}{k_{2, i}} e^{b p_{i}},-\sum_{i=1}^{N} q_{i}\right) \\
\mathcal{C}_{1}^{(m)}=\frac{\left(\sum_{i=1}^{m}\left(k_{1, i} a\right)^{\frac{1}{a}} e^{p_{i}}\right)^{a}}{\left(a \sum_{i=1}^{m} e^{a p_{i}}\right)} \quad \mathcal{C}_{2}^{(m)}=\frac{\left(\sum_{i=1}^{m}\left(k_{1, i} a\right)^{\frac{1}{a}} e^{p_{i}}\right)^{b}}{\left(\sum_{i=1}^{m} \frac{\left(k_{1, i} a\right)^{\frac{b}{a}}}{k_{2, i}} e^{b p_{i}}\right)} .
\end{gathered}
$$

- $A_{4,6}^{a, b}$ integrable systems $\quad(a \neq 0, \quad b \geq 0)$

$$
\begin{aligned}
& \left\{J_{1}, J_{4}\right\}=a J_{1} \quad\left\{J_{2}, J_{4}\right\}=b J_{2}-J_{3} \quad\left\{J_{3}, J_{4}\right\}=J_{2}+b J_{3} \\
& J_{1}^{(N)}=\sum_{i=1}^{N}\left(k_{1, i} k_{2, i} e^{\frac{b \pi}{2}}\right)^{\frac{a}{2 b}} e^{a p_{i}} \quad J_{2}^{(N)}=\sum_{i=1}^{N} \sqrt{\frac{e^{\frac{b \pi}{2}} k_{2, i}}{2}} e^{b p_{i}}\left(\cos p_{i}-\sin p_{i}\right) \\
& J_{3}^{(N)}=\sum_{i=1}^{N} \sqrt{\frac{e^{\frac{b \pi}{2}} k_{2, i}}{2}} e^{b p_{i}}\left(\cos p_{i}+\sin p_{i}\right) \quad J_{4}^{(N)}=-\sum_{i=1}^{N} q_{i} \\
& \mathcal{H}^{(N)}=\mathcal{H}\left(J_{1}^{(N)}, J_{2}^{(N)}, J_{3}^{(N)}, J_{4}^{(N)}\right) \\
& \mathcal{C}_{1}^{(m)}=\frac{\sum_{i=1}^{m}\left(k_{1, i} k_{2, i}\right) e^{2 b p_{i}}}{\left(\sum_{i=1}^{m} k_{2, i} e^{2 b p_{i}}+\sum_{\substack{i, j=1, i \neq j}}^{m} \sqrt{k_{2, i} k_{2, j}} e^{b\left(p_{i}+p_{j}\right)} \cos \left(p_{i}-p_{j}\right)\right)} \\
& \mathcal{C}_{2}^{(m)}=e^{\frac{b \pi}{2}}\left(\sum_{i=1}^{m} k_{2, i} e^{2 b p_{i}}+\sum_{\substack{i, j=1, i \neq j}}^{m} \sqrt{k_{2, i} k_{2, j}} e^{b\left(p_{i}+p_{j}\right)} \cos \left(p_{i}-p_{j}\right)\right) e^{-2 b \arctan \left(\mathcal{F}\left(p_{1}, p_{2}, \ldots, p_{m}\right)\right)}
\end{aligned}
$$

being

$$
\mathcal{F}\left(p_{1}, p_{2}, \ldots, p_{m}\right)=\left(\frac{\sum_{i=1}^{m} \sqrt{\frac{e^{\frac{b \pi}{2}} k_{2, i}}{2}} e^{b p_{i}}\left(\cos p_{i}+\sin p_{i}\right)}{\sum_{i=1}^{m} \sqrt{\frac{e^{\frac{b \pi}{2}} k_{2, i}}{2}} e^{b p_{i}}\left(\cos p_{i}-\sin p_{i}\right)}\right)
$$


As it can be easily appreciated, the complexity of the symplectic realizations increases with the number of non-linear Casimirs that constrain the realization.

\subsection{Integrable systems from 5D Lie coalgebras}

Non-isomorphic real Lie algebras of dimension 5 are also fully classified (we use the notation given in [145] for Mubarakzyanov [128, 129, 130, 131] results). In fact, there are 40 different $5 \mathrm{D}$ Lie algebras with $r=1,3$.

It is easy to check that all the $r=1$ cases do not fulfill the integrability condition. This is obvious for the 7 cases in which $R=0$. There are also 18 cases with $R=r=1$, but for them $s_{m}=(5-1) / 2=2>R$.

So, we are left with the 15 cases with $r=3$. For all of them the integrability condition holds, since $R=1,2,3$ and $s_{m}=(5-3) / 2=1$. Hereafter, as far as, constants are concerned and so as to shorten the presentation in the tables, expressions like $\left(k_{1}, k_{2} \neq 0\right)$, must be understood as $\left(k_{1} \neq 0, k_{2} \neq 0\right)$. For the sake of making the presentation more readable, we postpone some of the cases to the Supplement 8.3.

\subsubsection{Algebras with $R=1$}

Table 6. Symplectic realizations for 5D Lie-Poisson algebras with $R=1$.

\begin{tabular}{|c|c|c|c|c|c|c|c|}
\hline & $J_{1}$ & $J_{2}$ & $J_{3}$ & $J_{4}$ & $J_{5}$ & $\mathcal{C}_{3}$ & \\
\hline \hline$A_{5,1}$ & $k_{1}$ & $k_{2}$ & $k_{1} p+\frac{k_{3}}{k_{2}}$ & $k_{2} p$ & $-q$ & $J_{2} J_{3}-J_{1} J_{4}$ & $k_{1}, k_{2} \neq 0$ \\
\hline$A_{5,3}$ & $k_{1}$ & $k_{2}$ & $p$ & $-k_{2} q-\frac{k_{3}}{2 k_{1}}$ & $-k_{1} q-\frac{p^{2}}{2 k_{2}}$ & $J_{3}^{2}+2 J_{2} J_{5}-2 J_{1} J_{4}$ & $k_{1}, k_{2} \neq 0$ \\
\hline
\end{tabular}

- $A_{5,1}$ integrable systems

$$
\begin{gathered}
\left\{J_{3}, J_{5}\right\}=J_{1} \quad\left\{J_{4}, J_{5}\right\}=J_{2} \\
\mathcal{H}^{(N)}=\mathcal{H}\left(\sum_{i=1}^{N} k_{1, i}, \sum_{i=1}^{N} k_{2, i}, \sum_{i=1}^{N}\left(k_{1, i} p_{i}+\frac{k_{3, i}}{k_{2, i}}\right), \sum_{i=1}^{N} k_{2, i} p_{i},-\sum_{i=1}^{N} q_{i}\right) \\
\mathcal{C}_{3}^{(m)}=\sum_{i=i}^{m} k_{3, i}+\sum_{\substack{i, j=1 \\
i \neq j}}^{m} \frac{k_{3, i} k_{2, j}}{k_{2, i}}-\sum_{\substack{i, j=1 \\
i \neq j}}^{m} k_{2, i} k_{1, j} p_{i}+\sum_{\substack{i, j=1 \\
i \neq j}}^{m} k_{1, i} k_{2, j} p_{i} .
\end{gathered}
$$

- $A_{5,3}$ integrable systems

$$
\left\{J_{3}, J_{4}\right\}=J_{2} \quad\left\{J_{3}, J_{5}\right\}=J_{1} \quad\left\{J_{4}, J_{5}\right\}=J_{3}
$$




$$
\begin{aligned}
& \mathcal{H}^{(N)}=\mathcal{H}\left(\sum_{i=1}^{N} k_{1, i}, \sum_{i=1}^{N} k_{2, i}, \sum_{i=1}^{N} p_{i},-\sum_{i=1}^{N}\left(k_{2, i} q_{i}+\frac{k_{3}}{2 k_{1, i}}\right),-\sum_{i=1}^{N}\left(k_{1, i} q_{i}+\frac{p^{2}}{2 k_{2, i}}\right)\right) \\
& \mathcal{C}_{3}^{(m)}=\sum_{i=i}^{m} k_{3, i}+\sum_{\substack{i, j=1 \\
i \neq j}}^{m} p_{i} p_{j}+\sum_{\substack{i, j=1 \\
i \neq j}}^{m} \frac{k_{3, i} k_{1, j}}{k_{1, i}}-\sum_{\substack{i, j=1 \\
i \neq j}}^{m} \frac{k_{2, j}}{k_{2, i}} p_{i}^{2}+2 \sum_{i, j=1}^{m} k_{1, i} k_{2, j}\left(q_{j}-q_{i}\right) .
\end{aligned}
$$

The $N$-particle Hamiltonian $\mathcal{H}=-J_{5}+\mathcal{G}\left(-J_{4}\right)$ leads to

$$
\mathcal{H}^{(N)}=\sum_{i=1}^{N} \frac{p_{i}^{2}}{2 k_{2, i}}+\sum_{i=1}^{N} k_{1, i} q_{i}+\mathcal{G}\left(\sum_{i=1}^{N} k_{2, i} q_{i}+\sum_{i=1}^{N} \frac{k_{3, i}}{k_{1, i}}\right)
$$

which is completely integrable for any choice of the function $\mathcal{G}$. In particular, a large family of $N D$ integrable non-homogeneous polynomial potentials are included in this family.

\subsubsection{Algebras with $R=2$}

Table 7. Symplectic realizations for 5D Lie-Poisson algebras with $R=2$.

\begin{tabular}{|c|c|c|c|c|}
\hline & $A_{5,2}$ & $A_{5,8}^{c}$ & $A_{5,10}$ & $A_{5,14}^{\alpha}$ \\
\hline \hline$J_{1}$ & $k_{1}$ & $k_{1}$ & $k_{1}$ & $k_{1}$ \\
\hline$J_{2}$ & $p$ & $k_{1} p$ & $k_{1} p$ & $k_{1} p+\frac{k_{1}}{2 \alpha} \log \left(\frac{k_{2}}{k_{3}}\right)$ \\
\hline$J_{3}$ & $\frac{1}{2 k_{1}}\left(p^{2}-k_{2}\right)$ & $k_{3} e^{p}$ & $\frac{k_{1}}{2} p^{2}-\frac{k_{2}}{2 k_{1}}$ & $\sqrt{k_{2}} e^{\alpha p} \cos p$ \\
\hline$J_{4}$ & $\frac{1}{6 k_{1}^{2}}\left(p^{3}-3 k_{2} p+2 k_{3}\right)$ & $\frac{k_{3}^{c}}{k_{2}} e^{c p}$ & $k_{3} e^{p}$ & $\sqrt{k_{2}} e^{\alpha p} \sin p$ \\
\hline$J_{5}$ & $-k_{1} q$ & $-q$ & $-q$ & $-q$ \\
\hline $\mathcal{C}_{2}$ & $J_{2}^{2}-2 J_{1} J_{3}$ & $\frac{J_{3}^{c}}{J_{4}}$ & $J_{2}^{2}-2 J_{1} J_{3}$ & $\left(J_{3}^{2}+J_{4}^{2}\right) e^{-2 \alpha \arctan \left(\frac{J_{4}}{J_{3}}\right)}$ \\
\hline $\mathcal{C}_{3}$ & $J_{2}^{3}+3 J_{1}^{2} J_{4}-J_{1} J_{2} J_{3}$ & $J_{3} e^{-\frac{J_{2}}{J_{1}}}$ & $J_{4} e^{-\frac{J_{2}}{J_{1}}}$ & $\left(J_{3}^{2}+J_{4}^{2}\right) e^{-2 \alpha \frac{J_{2}}{J_{1}}}$ \\
\hline & $k_{1} \neq 0$ & $k_{1}, k_{2}, k_{3} \neq 0$ & $k_{1}, k_{3} \neq 0$ & $k_{1} \neq 0, k_{2}, k_{3}>0$ \\
\hline
\end{tabular}

- $A_{5,2}$ Integrable systems

$$
\begin{gathered}
\left\{J_{2}, J_{5}\right\}=J_{1} \quad\left\{J_{3}, J_{5}\right\}=J_{2} \quad\left\{J_{4}, J_{5}\right\}=J_{3} \\
\mathcal{H}^{(N)}=\mathcal{H}\left(J_{1}^{(N)}, J_{2}^{(N)}, J_{3}^{(N)}, J_{4}^{(N)}, J_{5}^{(N)}\right)
\end{gathered}
$$




$$
\begin{aligned}
& J_{1}^{(N)}=\sum_{i=1}^{N} k_{1, i} J_{2}^{(N)}=\sum_{i=1}^{N} p_{i} \\
& J_{3}^{(N)}=\sum_{i=1}^{N} \frac{1}{2 k_{1, i}}\left(p_{i}^{2}-k_{2, i}\right) J_{4}^{(N)}=\sum_{i=1}^{N} \frac{1}{6 k_{1, i}^{2}}\left(p_{i}^{3}-3 k_{2, i} p_{i}+2 k_{3, i}\right) \\
& J_{5}^{(N)}=-\sum_{i=1}^{N} k_{1, i} q_{i} \\
& \mathcal{C}_{2}^{(m)}=\sum_{i=1}^{m} k_{2, i}+\sum_{\substack{i, j=1 \\
i \neq j}}^{m} p_{i} p_{j}-\sum_{\substack{i, j=1 \\
i \neq j}}^{m} \frac{k_{1, j}}{k_{1, i}}\left(p_{i}^{2}-k_{2, i}\right) \\
& \mathcal{C}_{3}^{(m)}=\left(\sum_{i=1}^{m} p_{i}\right)^{3}+3\left(\sum_{i=1}^{m} k_{1, i}\right)^{2}\left(\sum_{i=1}^{m} \frac{1}{6 k_{1, i}^{2}}\left(p_{i}^{3}-3 k_{2, i} p_{i}+2 k_{3, i}\right)\right) \\
& \quad-3\left(\sum_{i=1}^{m} k_{1, i}\right)\left(\sum_{i=1}^{m} p_{i}\right)\left(\sum_{i=1}^{m} \frac{1}{2 k_{1, i}}\left(p_{i}^{2}-k_{2, i}\right)\right) .
\end{aligned}
$$

- $A_{5,8}^{c}$ integrable systems $(0<|c| \leq 1)$

$$
\begin{gathered}
\left\{J_{2}, J_{5}\right\}=J_{1} \quad\left\{J_{3}, J_{5}\right\}=J_{3} \quad\left\{J_{4}, J_{5}\right\}=c J_{4} \\
\mathcal{H}^{(N)}=\mathcal{H}\left(\sum_{i=1}^{N} k_{1, i}, \sum_{i=1}^{N} k_{1, i} p_{i}, \sum_{i=1}^{N} k_{3, i} e^{p_{i}}, \sum_{i=1}^{N} \frac{k_{3, i}^{c}}{k_{2, i}} e^{c p_{i}},-\sum_{i=1}^{N} q_{i}\right) \\
\mathcal{C}_{2}^{(m)}=\frac{\left(\sum_{i=1}^{m} k_{3, i} e^{p_{i}}\right)^{c}}{\left(\sum_{i=1}^{m} \frac{k_{3, i}^{c}}{k_{2, i}} e^{c p_{i}}\right)} \quad \mathcal{C}_{3}^{(m)}=\left(\sum_{i=1}^{m} k_{3, i} e^{p_{i}}\right) e^{-\frac{\left(\sum_{i=1}^{m} k_{1, i} p_{i}\right)}{\left(\sum_{i=1}^{m} k_{1, i}\right)}} .
\end{gathered}
$$

- $A_{5,10}$ integrable systems

$$
\begin{array}{rlrl}
\left\{J_{2}, J_{5}\right\} & =J_{1} \quad\left\{J_{3}, J_{5}\right\}=J_{2} \quad\left\{J_{4}, J_{5}\right\}=J_{4} \\
\mathcal{H} & =\mathcal{H}\left(J_{1}^{(N)}, J_{2}^{(N)}, J_{3}^{(N)}, J_{4}^{(N)}, J_{5}^{(N)}\right) \\
J_{1}^{(N)}=\sum_{i=1}^{N} k_{1, i} & J_{2}^{(N)}=\sum_{i=1}^{N} k_{1, i} p_{i} \\
J_{3}^{(N)}=\sum_{i=1}^{N}\left(\frac{k_{1, i}}{2} p_{i}^{2}-\frac{k_{2, i}}{2 k_{1, i}}\right) & J_{4}^{(N)}=\sum_{i=1}^{N} k_{3, i} e^{p_{i}} \\
J_{5}^{(N)}=-\sum_{i=1}^{N} q_{i} & &
\end{array}
$$




$$
\begin{aligned}
& \mathcal{C}_{2}^{(m)}=\sum_{i=1}^{m} k_{2, i}+\sum_{\substack{i, j=1 \\
i \neq j}}^{m}\left(\frac{k_{2, i}}{k_{1, i}}-k_{1, i} p_{i}^{2}\right) k_{1, j}+\sum_{\substack{i, j=1 \\
i \neq j}}^{m} k_{1, i} k_{1, j} p_{i} p_{j} \\
& \mathcal{C}_{3}^{(m)}=\left(\sum_{i=1}^{m} k_{3, i} e^{p_{i}}\right) e^{-\frac{\left(\sum_{i=1}^{m} k_{1, i} p_{i}\right)}{\left(\sum_{i=1}^{m} k_{1, i}\right)}} .
\end{aligned}
$$

- $A_{5,14}^{\alpha}$ integrable systems

$$
\begin{aligned}
& \left\{J_{2}, J_{5}\right\}=J_{1} \quad\left\{J_{3}, J_{5}\right\}=\alpha J_{3}-J_{4} \quad\left\{J_{4}, J_{5}\right\}=J_{3}+\alpha J_{4} \\
& \mathcal{H}^{(N)}=\left(J_{1}^{(N)}, J_{2}^{(N)}, J_{3}^{(N)}, J_{4}^{(N)}, J_{5}^{(N)}\right) \\
& J_{1}^{(N)}=\sum_{i=1}^{N} k_{1, i} \quad J_{2}^{(N)}=\sum_{i=1}^{N}\left(k_{1, i} p_{i}+\frac{k_{1, i}}{2 \alpha} \log \frac{k_{2, i}}{k_{3, i}}\right) \\
& J_{3}^{(N)}=\sum_{i=1}^{N} \sqrt{k_{2, i}} e^{\alpha p_{i}} \cos p_{i} \quad J_{4}^{(N)}=\sum_{i=1}^{N} \sqrt{k_{2, i}} e^{\alpha p_{i}} \sin p_{i} \\
& J_{5}^{(N)}=-\sum_{i=1}^{N} q_{i} \\
& \mathcal{C}_{2}^{(m)}=\left(\sum_{i=1}^{m} k_{2, i} e^{2 \alpha p_{i}}+2 \sum_{\substack{i, j=1 \\
i \neq j}}^{m} \sqrt{k_{2, i} k_{2, j}} e^{\alpha\left(p_{i}+p_{j}\right)} \cos \left(p_{i}-p_{j}\right)\right) e^{-2 \alpha \arctan \left(\mathcal{F}\left(p_{1}, \ldots, p_{m}\right)\right)} \\
& \mathcal{C}_{3}^{(m)}=\left(\sum_{i=1}^{m} k_{2, i} e^{2 \alpha p_{i}}+2 \sum_{\substack{i, j=1 \\
i \neq j}}^{m} \sqrt{k_{2, i} k_{2, j}} e^{\alpha\left(p_{i}+p_{j}\right)} \cos \left(p_{i}-p_{j}\right)\right) e^{-2 \alpha\left(\mathcal{G}\left(p_{1}, \ldots, p_{m}\right)\right)}
\end{aligned}
$$

Where the functions $\mathcal{F}$ and $\mathcal{G}$ have the following expressions

$$
\mathcal{F}\left(p_{1}, \ldots, p_{m}\right)=\frac{\sum_{i=1}^{m} \sqrt{k_{2, i}} e^{\alpha p_{i} \sin p_{i}}}{\sum_{i=1}^{m} \sqrt{k_{2, i}} e^{\alpha p_{i} \cos p_{i}}} \quad \mathcal{G}\left(p_{1}, \ldots, p_{m}\right)=\frac{\sum_{i=1}^{m}\left(k_{1, i} p_{i}+\frac{k_{1, i}}{2 \alpha} \log \frac{k_{2, i}}{k_{3, i}}\right)}{\sum_{i=1}^{m} k_{1, i}} .
$$




\subsubsection{Algebras with $R=3$}

Table 8. Symplectic realizations for 5D Lie-Poisson algebras with $R=3$.

\begin{tabular}{|c|c|c|c|c|c|}
\hline & $A_{5,7}^{a, b, c}$ & $A_{5,9}^{b, c}$ & $A_{5,11}^{c}$ & $A_{5,12}^{c}$ & $A_{5,15}^{\alpha}$ \\
\hline \hline$J_{1}$ & $e^{p}$ & $k_{3} e^{p}$ & $k_{2} e^{p}$ & $k_{1} e^{p}$ & $e^{-p}$ \\
\hline$J_{2}$ & $\frac{e^{\alpha p}}{k_{1}}$ & $k_{3} p e^{p}$ & $k_{2} p e^{p}$ & $k_{1} p e^{p}$ & $\left(p-\log k_{2}\right) e^{p}$ \\
\hline$J_{3}$ & $\frac{e^{b p}}{k_{2}}$ & $\frac{k_{3}^{b}}{k_{1}} e^{b p}$ & $\frac{k_{2}}{2} e^{b p}\left(p^{2}+k_{3}\right)$ & $\frac{k_{1}}{2} e^{p}\left(p^{2}+k_{2}\right)$ & $\frac{e^{\alpha p}}{k_{1}}$ \\
\hline$J_{4}$ & $\frac{e^{c p}}{k_{3}}$ & $\frac{k_{3}^{c}}{k_{2}} e^{c p}$ & $\frac{k_{2}^{c}}{k_{1}} e^{c p}$ & $\frac{k_{1} e^{p}}{6}\left(2 k_{3}+3 k_{2} p+p^{3}\right)$ & $\frac{e^{\alpha p}}{\alpha k_{1}}\left(\alpha p-\log k_{1} k_{3}\right)$ \\
\hline$J_{5}$ & $-q$ & $-q$ & $-q$ & $-q$ & $-q$ \\
\hline & $k_{1}, k_{2}, k_{3} \neq 0$ & $k_{3} \neq 0$ & $k_{2} \neq 0$ & $k_{1} \neq 0$ & $k_{2}>0, \frac{k_{1}}{k_{3}}>0$ \\
\hline
\end{tabular}

- $A_{5,7}^{a, b, c}$ integrable systems $(a b c \neq 0) \quad(-1 \leq c \leq b \leq a \leq 1)$

$$
\begin{array}{cl}
\left\{J_{1}, J_{5}\right\}=J_{1} & \left\{J_{2}, J_{5}\right\}=a J_{2} \\
\left\{J_{3}, J_{5}\right\}=b J_{3} & \left\{J_{4}, J_{5}\right\}=c J_{4} \\
\mathcal{H}^{(N)}=\mathcal{H}\left(\sum_{i=1}^{N} e^{p_{i}}, \sum_{i=1}^{N} \frac{e^{a p_{i}}}{k_{1, i}}, \sum_{i=1}^{N} \frac{e^{b p_{i}}}{k_{2, i}}, \sum_{i=1}^{N} \frac{e^{c p_{i}}}{k_{3, i}},-\sum_{i=1}^{N} q_{i}\right) .
\end{array}
$$

The non-linear Casimirs for this algebra are

$$
\begin{gathered}
\mathcal{C}_{1}=\frac{J_{1}{ }^{a}}{J_{2}} \quad \mathcal{C}_{2}=\frac{J_{1}{ }^{b}}{J_{3}} \quad \mathcal{C}_{3}=\frac{J_{1}{ }^{c}}{J_{4}} \\
\mathcal{C}_{1}^{(m)}=\frac{\left(\sum_{i=1}^{m} e^{p_{i}}\right)^{a}}{\left(\sum_{i=1}^{m} \frac{e^{a p_{i}}}{k_{1, i}}\right)} \quad \mathcal{C}_{2}^{(m)}=\frac{\left(\sum_{i=1}^{m} e^{p_{i}}\right)^{b}}{\left(\sum_{i=1}^{m} \frac{e^{b p_{i}}}{k_{2, i}} e^{p_{i}}\right)^{c}} \quad \mathcal{C}_{3}^{(m)}=\frac{\left(\sum_{i=1}^{m} \frac{e^{c p_{i}}}{k_{3, i}}\right)^{c}}{}
\end{gathered}
$$

- $A_{5,9}^{b, c}$ integrable systems $\quad(0 \neq c \leq b)$

$$
\begin{aligned}
& \left\{J_{1}, J_{5}\right\}=J_{1} \quad\left\{J_{2}, J_{5}\right\}=J_{1}+J_{2} \\
& \left\{J_{3}, J_{5}\right\}=b J_{3} \quad\left\{J_{4}, J_{5}\right\}=c J_{4} \\
& \mathcal{H}^{(N)}=\mathcal{H}\left(\sum_{i=1}^{N} k_{3, i} e^{p_{i}}, \sum_{i=1}^{N} k_{3, i} p_{i} e^{p_{i}}, \sum_{i=1}^{N} \frac{k_{3, i}^{b}}{k_{1, i}} e^{b p_{i}}, \sum_{i=1}^{N} \frac{k_{3, i}^{c}}{k_{2, i}} e^{c p_{i}},-\sum_{i=1}^{N} q_{i}\right) .
\end{aligned}
$$


The non-linear Casimirs are

$$
\begin{gathered}
\mathcal{C}_{1}=\frac{J_{1}^{b}}{J_{3}} \quad \mathcal{C}_{2}=\frac{J_{1}^{c}}{J_{4}} \quad \mathcal{C}_{3}=J_{1} e^{-\frac{J_{2}}{J_{1}}} \\
\mathcal{C}_{1}^{(m)}=\frac{\left(\sum_{i=1}^{m} k_{3, i} e^{p_{i}}\right)^{b}}{\left(\sum_{i=1}^{m} \frac{k_{3, i}^{b}}{k_{1, i}} e^{b p_{i}}\right)} \quad \mathcal{C}_{2}^{(m)}=\frac{\left(\sum_{i=1}^{m} k_{3, i} e^{p_{i}}\right)^{c}}{\left(\sum_{i=1}^{m} \frac{k_{3, i}^{c}}{k_{2, i}} e^{c p_{i}}\right)} \\
\mathcal{C}_{3}^{(m)}=\left(\sum_{i=1}^{m} k_{3, i} e^{p_{i}}\right) e^{-\frac{\left(\sum_{i=1}^{m} k_{3, i} p_{i} e^{p_{i}}\right)}{\left(\sum_{i=1}^{m} k_{3, i} e^{p_{i}}\right)}} .
\end{gathered}
$$

- $A_{5,11}^{c}$ integrable systems $\quad(c \neq 0)$

$$
\begin{aligned}
& \left\{J_{1}, J_{5}\right\}=J_{1} \quad\left\{J_{2}, J_{5}\right\}=J_{1}+J_{2} \\
& \left\{J_{3}, J_{5}\right\}=J_{2}+J_{3} \quad\left\{J_{4}, J_{5}\right\}=c J_{4} \\
& \mathcal{H}^{(N)}=\mathcal{H}\left(\sum_{i=1}^{N} k_{2, i} e^{p_{i}}, \sum_{i=1}^{N} k_{2, i} p_{i} e^{p_{i}}, \sum_{i=1}^{N} \frac{k_{2, i}}{2} e^{p_{i}}\left(p_{i}^{2}+k_{3, i}\right), \sum_{i=1}^{N} \frac{k_{2, i}^{c}}{k_{1, i}} e^{c p_{i}},-\sum_{i=1}^{N} q_{i}\right) .
\end{aligned}
$$

Again, from the following non-linear Casimirs we get the constants of the motion for this system:

$$
\begin{gathered}
\mathcal{C}_{1}=\frac{J_{1}^{c}}{J_{4}} \quad \mathcal{C}_{2}=J_{1} e^{-\frac{J_{2}}{J_{1}}} \quad \mathcal{C}_{3}=\frac{2 J_{3}}{J_{1}}-\frac{J_{2}^{2}}{J_{1}^{2}} \\
\mathcal{C}_{1}^{(m)}=\frac{\left(\sum_{i=1}^{m} k_{2, i} e^{p_{i}}\right)^{c}}{\left(\sum_{i=1}^{m} \frac{k_{2, i}^{c}}{k_{1, i}} e^{c p_{i}}\right)} \mathcal{C}_{2}^{(m)}=\left(\sum_{i=1}^{m} k_{2, i} e^{p_{i}}\right) e^{-\frac{\left(\sum_{i=1}^{m} k_{2, i} p_{i} e^{p_{i}}\right.}{\left(\sum_{i=1}^{m} k_{2, i} e^{p_{i}}\right)}} \\
\mathcal{C}_{3}^{(m)}=\frac{\left(\sum_{i=1}^{m} k_{2, i} e^{p_{i}}\left(p_{i}^{2}+k_{3, i}\right)\right)}{\left(\sum_{i=1}^{m} k_{2, i} e^{p_{i}}\right)}-\frac{\left(\sum_{i=1}^{m} k_{2, i} p_{i} e^{p_{i}}\right)^{2}}{\left(\sum_{i=1}^{m} k_{2, i} e^{p_{i}}\right)^{2}} .
\end{gathered}
$$


- $A_{5,12}$ integrable systems

$$
\begin{aligned}
& \left\{J_{1}, J_{5}\right\}=J_{1} \quad\left\{J_{2}, J_{5}\right\}=J_{1}+J_{2} \\
& \left\{J_{3}, J_{5}\right\}=J_{2}+J_{3} \quad\left\{J_{4}, J_{5}\right\}=J_{3}+J_{4} \\
& \mathcal{H}^{(N)}=\mathcal{H}\left(J_{1}^{(N}, J_{2}^{(N)}, J_{3}^{(N)}, J_{4}^{(N)}, J_{5}^{(N)}\right) \\
& J_{1}^{(N)}=\sum_{i=1}^{N} k_{1, i} e^{p_{i}} \quad J_{2}^{(N)}=\sum_{i=1}^{N} k_{1, i} p_{i} e^{p_{i}} \\
& J_{3}^{(N)}=\sum_{i=1}^{N} \frac{k_{1, i}}{2} e^{p_{i}}\left(p_{i}^{2}+k_{2, i}\right) \quad J_{4}^{(N)}=\sum_{i=1}^{N} \frac{k_{1, i} e^{p_{i}}}{6}\left(2 k_{3, i}+3 k_{2, i} p_{i}+p_{i}^{3}\right) \\
& J_{5}^{(N)}=-\sum_{i=1}^{N} q_{i} .
\end{aligned}
$$

The associated constants of the motion will be given by the $m$-th symplectic realizations of the non-linear Casimir functions for $A_{5,12}$, namely

$$
\begin{aligned}
\mathcal{C}_{1}= & J_{1} e^{-\frac{J_{2}}{J_{1}}} \quad \mathcal{C}_{2}=\frac{2 J_{3}}{J_{1}}-\frac{J_{2}^{2}}{J_{1}^{2}} \quad \mathcal{C}_{3}=\frac{3 J_{4}}{J_{1}}-\frac{3 J_{2} J_{3}}{J 1^{2}}+\frac{J_{2}^{3}}{J_{1}^{3}} \\
\mathcal{C}_{1}^{(m)}= & \left(\sum_{i=1}^{m} k_{1, i} e^{p_{i}}\right) e^{-\frac{\left(\sum_{i=1}^{m} k_{1, i} p_{i} e^{p_{i}}\right)}{\left(\sum_{i=1}^{m} k_{1, i} e^{p_{i}}\right)}} \\
\mathcal{C}_{2}^{(m)}= & \frac{\left(\sum_{i=1}^{m} k_{1, i} e^{p_{i}}\left(p_{i}^{2}+k_{2, i}\right)\right)}{\left(\sum_{i=1}^{m} k_{1, i} e^{p_{i}}\right)}-\frac{\left(\sum_{i=1}^{m} k_{1, i} p_{i} e^{p_{i}}\right)^{2}}{\left(\sum_{i=1}^{m} k_{1, i} e^{p_{i}}\right)^{2}} \\
\mathcal{C}_{3}^{(m)}= & \frac{1}{2} \frac{\left(\sum_{i=1}^{m} k_{1, i} e^{p_{i}}\left(2 k_{3, i}+3 k_{2, i} p_{i}+p_{i}^{3}\right)\right)}{\left(\sum_{i=1}^{m} k_{1, i} e^{p_{i}}\right)} \\
& -\frac{3}{2} \frac{\left(\sum_{i=1}^{m} k_{1, i} p_{i} e^{p_{i}}\right)\left(\sum_{i=1}^{m} k_{1, i} e^{p_{i}}\left(p_{i}^{2}+k_{2, i}\right)\right.}{\left(\sum_{i=1}^{m} k_{1, i} e^{p_{i}}\right)^{2}}+\frac{\left(\sum_{i=1}^{m} k_{2, i} p_{i} e^{p_{i}}\right)^{3}}{\left(\sum_{i=1}^{m} k_{1, i} e^{p_{i}}\right)^{3}} .
\end{aligned}
$$


- $A_{5,15}^{\alpha}$ integrable systems $\quad(|\alpha| \leq 1)$

$$
\begin{array}{ccc}
\left\{J_{1}, J_{5}\right\}=J_{1} & \left\{J_{2}, J_{5}\right\}=J_{1}+J_{2} \\
\left\{J_{4}, J_{5}\right\}=J_{3}+\alpha J_{4} \quad & \left\{J_{3}, J_{5}\right\}=\alpha J_{3} \\
\mathcal{H}^{(N)}=\mathcal{H}\left(J_{1}^{(N)}, J_{2}^{(N)}, J_{3}^{(N)}, J_{4}^{(N)}, J_{5}^{(N)}\right) & \\
J_{1}^{(N)}=\sum_{i=1}^{N} e^{p_{i}} \quad J_{2}^{(N)}=\sum_{i=1}^{N}\left(p_{i}-\log k_{2, i}\right) e^{p_{i}} \\
J_{3}^{(N)}=\sum_{i=1}^{N} \frac{e^{\alpha p_{i}}}{k_{1, i}} \quad J_{4}^{(N)}=\sum_{i=1}^{N} \frac{e^{\alpha p_{i}}}{\alpha k_{1, i}}\left(\alpha p_{i}-\log k_{1, i} k_{3, i}\right) \\
J_{5}^{(N)}=-\sum_{i=1}^{N} q_{i} .
\end{array}
$$

Finally, the complete integrability is given again by the $N$-particle symplectic realizations of the following non-linear Casimirs:

$$
\begin{gathered}
\mathcal{C}_{1}=\frac{J_{1}^{\alpha}}{J_{3}} \quad \mathcal{C}_{2}=J_{1} e^{-\frac{J_{2}}{J_{1}}} \quad \mathcal{C}_{3}=J_{3} e^{-\alpha \frac{J_{4}}{J_{3}}} \\
\mathcal{C}_{1}^{(m)}=\frac{\left(\sum_{i=1}^{m} e^{p_{i}}\right)^{\alpha}}{\left(\sum_{i=1}^{m} \frac{e^{\alpha p_{i}}}{k_{1, i}}\right)} \mathcal{C}_{2}^{(m)}=\left(\sum_{i=1}^{m} e^{p_{i}}\right) e^{-\frac{\left(\sum_{i=1}^{m}\left(p_{i}-\log k_{2, i}\right) e^{p_{i}}\right)}{\left(\sum_{i=1}^{m} e^{p_{i}}\right)}} \\
\mathcal{C}_{3}^{(m)}=\left(\sum_{i=1}^{m} \frac{e^{\alpha p_{i}}}{k_{1, i}}\right) e^{-\frac{\left(\sum_{i=1}^{m} \frac{e^{\alpha p_{i}}}{k_{1, i}}\left(\alpha p_{i}-\log k_{1, i} k_{3, i}\right)\right.}{\left(\sum_{i=1}^{m} \frac{e^{\alpha p_{i}}}{k_{1, i}}\right)}}
\end{gathered}
$$

\subsection{Integrable systems from 6D nilpotent coalgebras}

The same approach can be applied to the study of the 22 nilpotent $6 \mathrm{D}$ algebras classified in [145]. Among them, only three fulfill the necessary integrability condition for the generic symplectic realization presented in Chapter 2. They are those algebras in which $r=4$ and $R \geq 1$. Consequently,

$$
s_{m}=\frac{6-4}{2}=1
$$


and the existence of only one non-linear Casimir is enough to guaranteee the complete integrability of the ND systems coming from them. For the remining 19 nilpotent algebras, we have $r=2$ with $R=1$, so we have

$$
s_{m}=\frac{6-2}{2}=2
$$

and the integrability condition is not fulfilled.

In the sequel we present the coalgebra construction of the integrable systems arising from the three algebras with $r=4$. As usual, we give the symplectic realization, the generic form of the integrable Hamiltonian and the non-linear casimirs whose coproduct will provide the integrals of the motion.

- $A_{6,3}$ integrable systems $(R=1)$

$$
\begin{aligned}
&\left\{J_{1}, J_{2}\right\}=J_{6} \quad\left\{J_{1}, J_{3}\right\}=J_{4} \quad\left\{J_{2}, J_{3}\right\}=J_{5} \\
& J_{1}= k_{3} p \\
& J_{2}=-q-\frac{k_{4}}{k_{1}} \\
& J_{3}=-\frac{k_{1}}{k_{3}} q-k_{2} p \\
& J_{4}=k_{1} \\
& J_{5}=k_{2} \\
& J_{6}=k_{3} \quad\left(k_{1}, k_{2} \neq 0\right) \\
& k_{4, i}\left.,-\sum_{i=1}^{N}\left(\frac{k_{1, i}}{k_{3, i}} q_{i}+k_{2, i} p_{i}\right), \sum_{i=1}^{N} k_{1, i}, \sum_{i=1}^{N} k_{2, i}, \sum_{i=1}^{N} k_{3, i}\right) . \\
& \mathcal{H}^{(N)}=\mathcal{H}\left(\sum_{i=1}^{N} k_{3, i} p_{i},-\sum_{i=1}^{N}\left(q_{i}+\frac{13.79)}{k_{1, i}}\right)\right.
\end{aligned}
$$

The non-linear Casimir is

$$
\begin{gathered}
\mathcal{C}_{4}=J_{1} J_{5}+J_{3} J_{6}-J_{2} J_{4} \\
\mathcal{C}_{4}^{(m)}=\sum_{i=1}^{m} k_{4, i}+\sum_{\substack{i, j=1 \\
i \neq j}}^{m} \frac{k_{4, i}}{k_{1, i}} k_{1, j}+\sum_{\substack{i, j=1 \\
i \neq j}}^{m} k_{3, i} k_{2, j}\left(p_{i}-p_{j}\right)-\sum_{\substack{i, j=1 \\
i \neq j}}^{m} \frac{k_{1, i} q_{i}}{k_{3, i}} k_{3, j}+\sum_{\substack{i, j=1 \\
i \neq j}}^{m} k_{1, j} q_{i} .
\end{gathered}
$$

- $A_{6,1}$ integrable systems $(R=2)$

$$
\left\{J_{1}, J_{2}\right\}=J_{3} \quad\left\{J_{1}, J_{3}\right\}=J_{4} \quad\left\{J_{1}, J_{5}\right\}=J_{6}
$$




$$
\begin{aligned}
& J_{1}=q \\
& J_{2}=\frac{k_{1}}{2} p^{2}+\frac{k_{4}}{2 k_{1}} \\
& J_{3}=k_{1} p \\
& J_{4}=k_{1} \\
& J_{5}=k_{2} p-\frac{k_{3}}{k_{1}} \\
& J_{6}=k_{2} \quad\left(k_{1}, k_{2} \neq 0\right) \\
& \mathcal{H}^{(N)}=\mathcal{H}\left(\sum_{i=1}^{N} q_{i}, \sum_{i=1}^{N}\left(\frac{k_{1, i}}{2} p_{i}^{2}+\frac{k_{4, i}}{2 k_{1, i}}\right), \sum_{i=1}^{N} k_{1, i} p_{i}, \sum_{i=1}^{N} k_{1, i}, \sum_{i=1}^{N}\left(k_{2, i} p_{i}-\frac{k_{3, i}}{k_{1, i}}\right), \sum_{i=1}^{N} k_{2, i}\right) .
\end{aligned}
$$

The non-linear Casimirs are

$$
\begin{aligned}
& \mathcal{C}_{3}=J_{3} J_{6}-J_{4} J_{5} \\
& \mathcal{C}_{4}=2 J_{2} J_{4}-J_{3}^{2} .
\end{aligned}
$$

The constants of the motion will be given by the $m$-th coproducts of the two non-linear Casimir functions:

$$
\begin{aligned}
& \mathcal{C}_{3}^{(m)}=\sum_{i=1}^{m} k_{3, i}+\sum_{\substack{i, j=1 \\
i \neq j}}^{m} \frac{k_{3, i}}{k_{1, i}} k_{1, j}+\sum_{\substack{i, j=1 \\
i \neq j}}^{m} k_{1, i} k_{2, j}\left(p_{i}-p_{j}\right) \\
& \mathcal{C}_{4}^{(m)}=\sum_{i=1}^{m} k_{4, i}+\sum_{\substack{i, j=1 \\
i \neq j}}^{m} \frac{k_{4, i}}{k_{1, i}} k_{1, j}-\sum_{\substack{i, j=1 \\
i \neq j}}^{m} k_{1, i} k_{1, j} p_{i} p_{j}+\sum_{\substack{i, j=1 \\
i \neq j}}^{m} k_{1, i} k_{1, j} p_{i}^{2} .
\end{aligned}
$$

- $A_{6,2}$ integrable systems $(R=3)$

$$
\begin{aligned}
& \left\{J_{1}, J_{2}\right\}=J_{3} \quad\left\{J_{1}, J_{3}\right\}=J_{4} \\
& \left\{J_{1}, J_{4}\right\}=J_{5} \quad\left\{J_{1}, J_{5}\right\}=J_{6} \\
& J_{1}=k_{1} q \\
& J_{2}=\frac{p^{4}-6 k_{2} p^{2}-3 k_{2}^{2}+12 k_{1}^{2} k_{3}+8 k_{4} p}{24 k_{1}^{3}} \\
& J_{3}=\frac{p^{3}+3 k_{2} p+2 k_{4}}{6 k_{1}^{2}} \\
& J_{4}=\frac{p^{2}+k_{2}}{2 k_{1}} \\
& J_{5}=p \\
& J_{6}=k_{1} \quad\left(k_{1} \neq 0\right) .
\end{aligned}
$$


Therefore the generic ND integrable Hamiltonian would be:

$$
\mathcal{H}^{(N)}=\mathcal{H}\left(J_{1}^{(N)}, J_{2}^{(N)}, J_{3}^{(N)}, J_{4}^{(N)}, J_{5}^{(N)}, J_{6}^{(N)}\right)
$$

where

$$
\begin{aligned}
J_{1}^{(N)} & =\sum_{i=1}^{N} k_{1, i} q_{i} & J_{2}^{(N)} & =\sum_{i=1}^{N}\left(\frac{p_{i}^{4}-6 k_{2, i}}{6 k_{1, i}}\right) \\
J_{3}^{(N)} & =\sum_{i=1}^{N}\left(\frac{p_{i}^{3}+3 p_{i} k_{2, i}+2 k_{4, i}}{6 k^{2}}\right) & J_{4}^{(N)} & =\sum_{i=1}^{N} \frac{p_{i}^{2}+k_{2, i}}{2 k_{1, i}} \\
J_{5}^{(N)} & =\sum_{i=1}^{N} p_{i} & J_{6}^{(N)} & =\sum_{i=1}^{N} k_{1, i}
\end{aligned}
$$

and the coproducts of the three non-linear Casimir functions

$$
\begin{aligned}
& \mathcal{C}_{2}=2 J_{4} J_{6}-J_{5}^{2} \\
& \mathcal{C}_{3}=2 J_{2} J_{6}-2 J_{3} J_{5}+J_{4}^{2} \\
& \mathcal{C}_{4}=3 J_{3} J_{6}^{2}-3 J_{4} J_{5} J_{6}+J_{5}^{3}
\end{aligned}
$$

will give us the integrals of the motion by choosing once again, an appropriate set of $(N-1)$ functionally independet quantities

$$
\begin{aligned}
\mathcal{C}_{2}^{(m)}= & \frac{1}{2} \sum_{i=1}^{m}\left(k_{2, i}-p_{i}^{2}\right)+\frac{1}{2} \sum_{\substack{i, j=1 \\
i \neq j}}^{m}\left(\frac{k_{2, i}+p_{i}^{2}}{k_{1, i}}\right) k_{1, j}-\sum_{\substack{i, j=1 \\
i \neq j}}^{m} p_{i} p_{j} \\
\mathcal{C}_{3}^{(m)}= & 2\left(\sum_{i=1}^{m} \frac{p_{i}^{4}-6 k_{2, i} p_{i}^{2}-3 k_{2, i}^{2}+12 k_{1, i}^{2} k_{3, i}+8 p_{i} k_{4, i}}{24 k_{1, i}^{3}}\right)\left(\sum_{i=1}^{m} k_{1, i}\right) \\
& -2\left(\sum_{i=1}^{m} \frac{p_{i}^{3}+3 p_{i} k_{2, i}+2 k_{4, i}}{6 k_{1, i}^{2}}\right)\left(\sum_{i=1}^{m} p_{i}\right)+\left(\sum_{i=1}^{m} \frac{p_{i}^{2}+k_{2, i}}{2 k_{1, i}}\right)^{2} \\
\mathcal{C}_{4}^{(m)}= & 3\left(\sum_{i=1}^{m} \frac{p_{i}^{3}+3 p_{i} k_{2, i}+2 k_{4, i}}{6 k_{1, i}^{2}}\right)\left(\sum_{i=1}^{m} k_{1, i}\right)^{2} \\
& -3\left(\sum_{i=1}^{m} \frac{p_{i}^{2}+k_{2, i}}{2 k_{1, i}}\right)\left(\sum_{i=1}^{m} p_{i}\right)\left(\sum_{i=1}^{m} k_{1, i}\right)+\left(\sum_{i=1}^{m} p_{i}\right)^{3} .
\end{aligned}
$$

\subsection{A family of algebras with arbitrary dimension}

In view of the exhaustive description of the Lie algebras with dimensions 3, 4, 5, y 6 (the nilpotent ones) given in Chapters 2 and 3 , it seems natural to wonder whether we can 
identify some families of algebras that can be defined for any dimension and for which the integrability condition under the coalgebra approach holds. The answer to this question is affirmative, and in this Secion we are going to show that the $M$-dimensional Lie algebra $\mathfrak{g}_{M}$ defined by the non-vanishing Poisson brackets

$$
\left\{J_{i}, J_{M}\right\}=J_{i-1} \text { with } i=2, \ldots, M-1
$$

is a Lie algebra with $r=M-2$ and with $R=r-1=M-3$, thus fulfilling the interability criteria for $M \geq 4$, since in that case $s_{m}=(M-r) / 2=1$. Moreover, we will explicitly compute a closed formula for the $(M-2)$ Casimir functions for $\mathfrak{g}_{M}$, as well as its generic symplectic realization.

The key observation for the construction of $\mathfrak{g}_{M}$ is to realize that the following chain of inclusions among different algebras holds:

$$
A_{3,1} \subset A_{4,1} \subset A_{5,2} \subset A_{6,2} .
$$

In fact, the following isomorphisms of Lie algebras are easily proven through the appropriate changes of basis:

$$
\mathfrak{g}_{3} \equiv A_{3,1} \quad \mathfrak{g}_{4} \equiv A_{4,1} \quad \mathfrak{g}_{5} \equiv A_{5,2} \quad \mathfrak{g}_{6} \equiv A_{6,2} .
$$

Now, by making use of the expressions for the Casimirs of these four algebras given in this and the previous Chapter, we can obtain explicitly the Casimir functions for $\mathfrak{g}_{M}$ in the cases $M=3,4,5,6$, which read:

- $\mathfrak{g}_{3}: \mathcal{C}_{1}=J_{1}$

- $\mathfrak{g}_{4}:\left\{\begin{array}{l}\mathcal{C}_{1}=J_{1} \\ \mathcal{C}_{2}=\frac{-J_{2}^{2}+2 J_{1} J_{3}}{2 J_{1}}\end{array}\right.$

• $\mathfrak{g}_{5}:\left\{\begin{array}{l}\mathcal{C}_{1}=J_{1} \\ \mathcal{C}_{2}=\frac{-J_{2}^{2}+2 J_{1} J_{3}}{2 J_{1}} \\ \mathcal{C}_{3}=\frac{J_{2}^{3}-3 J_{1} J_{2} J_{3}+3 J_{1}^{2} J_{4}}{3 J_{1}^{2}}\end{array}\right.$

- $\mathfrak{g}_{6}:\left\{\begin{array}{l}\mathcal{C}_{1}=J_{1} \\ \mathcal{C}_{2}=\frac{-J_{2}^{2}+2 J_{1} J_{3}}{2 J_{1}} \\ \mathcal{C}_{3}=\frac{J_{2}^{3}-3 J_{1} J_{2} J_{3}+3 J_{1}^{2} J_{4}}{3 J_{1}^{2}} \\ \mathcal{C}_{4}=\frac{-J_{2}^{4}+4 J_{1} J_{2}^{2} J_{3}-8 J_{1}^{2} J_{2} J_{4}+8 J_{1}^{3} J_{5}}{8 J_{1}^{3}} .\end{array}\right.$ 
In these expressions we can easily appreciate how the chain of algebra embeddings is constructed: as far as we add another generator, one more Casimir function appears, and it contains the $J_{M-1}$ generator.

This construction can be generalized for the arbitrary $\mathfrak{g}_{M}$ algebra, since the $\mathcal{C}_{r}$ Casimir functions $(r=1, \ldots, M-2)$ must fulfill (see [1, 59, 145])

$$
\left\{J_{i}, \mathcal{C}_{r}\right\}=\sum_{j=1}^{M} \frac{\partial \mathcal{C}_{r}}{\partial J_{j}}\left\{J_{i}, J_{j}\right\}=0 \quad\left\{\begin{array}{l}
i=1,2, \ldots, M \\
r=1,2, \ldots,(M-2)
\end{array}\right.
$$

By taking into account the Poisson brackets (3.95), we get the following system of differential equations

$$
J_{i-1} \frac{\partial \mathcal{C}_{r}}{\partial J_{M}}=0 \quad\left\{\begin{array}{l}
i=2,3, \ldots, M \\
r=1,2, \ldots,(M-2) .
\end{array}\right.
$$

From this expression we see that

$$
\mathcal{C}_{M-2}=\mathcal{C}_{M-2}\left(J_{1}, J_{2}, \ldots, J_{M-1}\right)
$$

and the general solution of the system can be found. It reads,

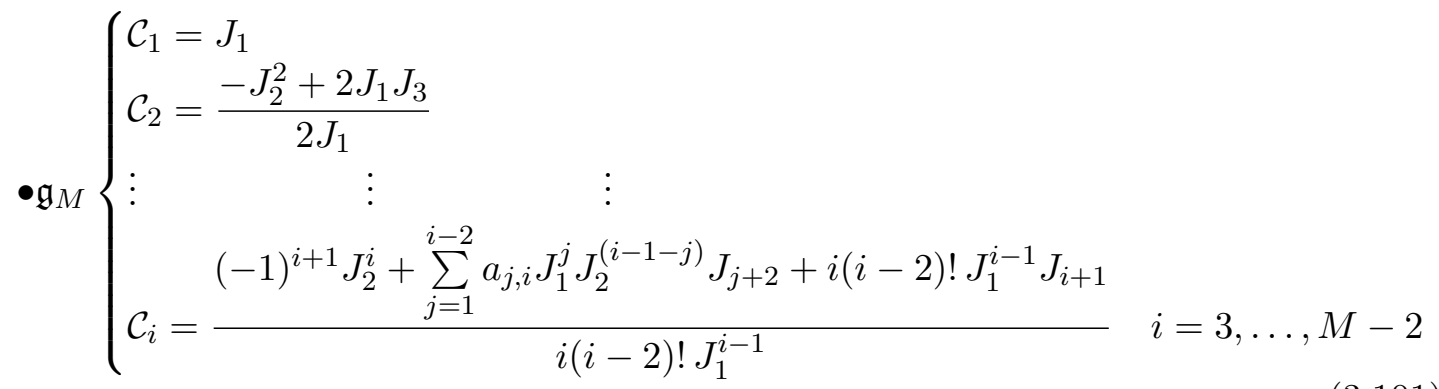

where the coefficients $a_{j}$ are given by:

$$
\left\{\begin{array}{l}
a_{1, i}=(-1)^{i} i \\
a_{2, i}=(-1)^{i+1} i \cdot(i-2) \\
a_{3, i}=(-1)^{i+2} i \cdot(i-2) \cdot(i-3) \\
\vdots \\
a_{i-2, i}=(-1)^{i+i-3} i \cdot(i-2) \ldots(i-(i-2)) .
\end{array}\right.
$$


Finally, the generic symplectic realization for $\mathfrak{g}_{M}$ can be found:

$$
\begin{aligned}
& J_{1}=k_{1} \\
& J_{2}=k_{1} p \\
& \vdots \quad \quad \quad \vdots \\
& J_{j}=k_{1} \frac{p^{j-1}}{(j-1) !}+\sum_{i=1}^{j-2} k_{i+1} \frac{p^{j-2-i}}{(j-2-i) !} \quad j=3,4, \ldots,(M-1) \\
& J_{M}=-q .
\end{aligned}
$$

Note that this realization can be easily derived by taking into account that the commutation rules (3.95) imply that the bracket of $J_{i}$ with $J_{M}$ gives $J_{i-1}$. If we take $J_{M}=-q$ and the rest of generators $J_{j}$ are taken as polynomials in $p$ with degree $j-1$, this implies that

$$
J_{j}=\int J_{j-1}(p) \mathrm{d} p+k_{j-1} \quad j=3, \ldots,(M-1) .
$$

With this symplectic realization at hand, the construction of completely integrable systems on the $\mathfrak{g}_{M}$ coalgebra is straightforward.

Finally, it is also interesting to stress that symplectic realizations that do not fulfill the integrability condition can also lead to interesting (but partially integrable) Hamiltonian models. This is the case of the 'two-photon' algebra $h_{6}$, a $6 \mathrm{D}$ Lie algebra with $r=2$ (therefore $s=1,2$ ) that admits an $s=1$ symplectic realization for which, among the $2 N$ integrals provided by the coalgebra, only $(2 N-5)$ of them are functionally independent and $(N-2)$ are in involution. Hence, any Hamiltonian $\mathcal{H}$ with $h_{6}$-coalgebra symmetry is "almost" integrable (only one constant is left) to get complete integrability, and such a remaining integral does exist for some special choices of $\mathcal{H}$. In fact, the study of the integrable systems coming from this coalgebra will be the subject of the next two Chapters. 


\section{Chapter 4}

\section{ND integrability from two-photon coalgebra}

"It is difficult to make a prediction, especially a future prediction."

N. Bohr

This Chapter is devoted to the application of the coalgebra symmetry method described in Chapter 2 to the Poisson version of the so-called two-photon/Schrödinger algebra $h_{6}$ [16, 46, 49, 50, 185. As we shall show in the sequel, the $h_{6}$-coalgebra symmetry turns out to be extremely powerful, since the $N$-particle framework provided by the coalgebra structure encompasses different $N$-body symmetries that underlie several useful and explicit integrability properties, leading to several families of new completely integrable Hamiltonians that will be further analysed in Chapter 5.

We stress, that in the coalgebra symmetry framework the dimension of the coalgebra and the number of its non-linear Casimirs are essential in order to elucidate whether the coproduct gives either complete or partial integrability under a chosen symplectic realization. This dimensionality problem is essential for coalgebras with dimension greater than three, and it has been fully analysed in [27]. In fact, the $h_{6}$-coalgebra provides an explicit case of the coalgebra construction for a six-dimensional coalgebra with two Casimir functions in which one of them is a linear one (the generator $M$ ). Therefore we have $l=6, r=2, R=1$ and $s_{m}=\frac{l-r}{2}=2$, and the necessary integrability condition for the generic symplectic realization is not fulfilled. Nevertheles, we shall consider a non-generic symplectic realization with $s=1$, and we shall see how 
in this case the coalgebra approach leads to quasi-integrability. This is an essential feature of the $h_{6}$-coalgebra that could not appear in any of the examples of the coalgebra construction considered so far (see, for instance, [9, 12, 14, 21, 24, 27, 93, 114]).

Therefore, as a consequence of the quasi-integrability of the $h_{6}$-coalgebra symmetry, it becomes important to develop some additional algebraic machinery in order to investigate for which choices of the generic Hamiltonian (4.6) the complete integrability can be restored. This is the aim of Sections 3,4 and 5 in which we present a novel algebraic completion of the coalgebra approach that provides a guide to obtain the additional independent integral of the motion $\mathcal{I}$ by exploiting the rich subalgebra structure of $h_{6}$. This approach is fully general and can be applied to any coalgebra with dimension greater than three. Moreover, having in mind further applications, particular choices for $\mathcal{H}$ leading to $N D$ natural systems, geodesic flows and static electromagnetic Hamiltonians will be explicitly identified.

In particular, in Section 3 we analyse two different possibilities in order to find an extra integral $\mathcal{I}$. We remark that, in both cases, $\mathcal{I}$ will be always defined as a function of the generators of $h_{6}$, since this guarantees its existence for any number of degrees of freedom. The first case arises if the chosen Hamiltonian can be defined on a subalgebra of $h_{6}$, since then the $N$-particle Casimir of such subalgebra can be directly identified with the additional constant of the motion $\mathcal{I}$. This possibility is discussed in Section 4 , where the rich subalgebra structure for $h_{6}$ is fully described. A second possibility is analysed in Section 5, where we introduce five new families of ND completely integrable systems that have one of the five non-central generators of $h_{6}$ as the remaining integral of motion $\mathcal{I}$. This latter construction turns out to be powerful, since all these systems depend on several arbitrary functions and provide a large number of new instances of interesting Hamiltonians, both from the mathematical and the physical viewpoints.

A third possibility is developed in Section 6, where the direct search of the remaining integral $\mathcal{I}$ is performed through Poisson-algebra computations. In this way, several classes of new interesting completely integrable systems are obtained.

\subsection{The two-photon/Schrödinger algebra $h_{6}$}

Let us recall that the $h_{6}$ Lie-Poisson algebra is spanned by the six abstract generators $\left\{K, A_{+}, A_{-}, B_{+}, B_{-}, M\right\}$, whose one-particle symplectic realization is given by

$$
\begin{array}{lll}
A_{+}=\lambda_{1} p_{1} & A_{-}=\lambda_{1} q_{1} & K=q_{1} p_{1}-\frac{\lambda_{1}^{2}}{2} \\
B_{+}=p_{1}^{2} & B_{-}=q_{1}^{2} & M=\lambda_{1}^{2}
\end{array}
$$


where $\lambda_{1}$ is a non-vanishing constant that labels the previous symplectic realization and where we have considered the usual Poisson bracket $\left\{q_{1}, p_{1}\right\}=1$. The abstract Poisson brackets defining $h_{6}$ read

$$
\begin{array}{lll}
\left\{K, A_{+}\right\}=A_{+} & \left\{K, A_{-}\right\}=-A_{-} & \left\{A_{-}, A_{+}\right\}=M \\
\left\{K, B_{+}\right\}=2 B_{+} & \left\{K, B_{-}\right\}=-2 B_{-} & \left\{B_{-}, B_{+}\right\}=4 K+2 M \\
\left\{A_{+}, B_{-}\right\}=-2 A_{-} & \left\{A_{+}, B_{+}\right\}=0 & \{M, \cdot\}=0 \\
\left\{A_{-}, B_{+}\right\}=2 A_{+} & \left\{A_{-}, B_{-}\right\}=0 . &
\end{array}
$$

A direct inspection of this algebra makes its rich subalgebra structure evident (for instance, the $g l(2)$ subalgebra $\left\{K, B_{+}, B_{-}, M\right\}$, the oscillator one $h_{4} \equiv\left\{K, A_{+}, A_{-}, M\right\}$ and the Heisenberg one $h_{3} \equiv\left\{A_{+}, A_{-}, M\right\}$ can be easily identified). This is one of the main features of $h_{6}$, since this algebra generalizes many lower dimensional Lie symmetries in a transparent way, a fact that will be relevant in order to find new and more general integrability structures, as we shall see in Section 4.

As a consequence of 4.1), any quadratic Hamiltonian with one degree of freedom can always be written as a linear combination of the $h_{6}$ generators in the above representation. This is indeed the origin of the quantum mechanical relevance of the $h_{6}$ Lie algebra as a dynamical symmetry, since the quantum counterpart of such a quadratic Hamiltonian can be interpreted as a single-mode radiation field Hamiltonian including the number operator $\hat{K}$, creation and annihilation operators $\hat{A}_{+}$and $\hat{A}_{-}$and twophoton creation and annihilation operators $\hat{B}_{+}$and $\hat{B}_{-}$(the generator $\hat{M}$ is a central one). In this context, different applications of the $h_{6}$ symmetry can be found in [46], and it is also interesting to recall that $h_{6}$ is isomorphic to the $(1+1) \mathrm{D}$ centrally extended Schrödinger Lie algebra [10]. In fact, this isomorphism provides the two Casimir functions for $h_{6}$, which are the central generator $M$ and the fourth-order Casimir [145]

$$
\mathcal{C}=\left(M B_{+}-A_{+}^{2}\right)\left(M B_{-}-A_{-}^{2}\right)-\left(M K-A_{-} A_{+}+M^{2} / 2\right)^{2}
$$

that will play a relevant role hereafter. The function $\mathcal{C}$ can be reduced to a third-order invariant by extracting $M$ as a common factor:

$$
\mathcal{C}_{h_{6}}=\mathcal{C} / M=M B_{+} B_{-}-B_{+} A_{-}^{2}-B_{-} A_{+}^{2}-M(K+M / 2)^{2}+2 A_{-} A_{+}(K+M / 2) .
$$

Note that if we substitute the symplectic realization (4.1) within the two Casimir functions, the former is characterized by the values $M=\lambda_{1}^{2}$ and $\mathcal{C}_{h_{6}}=0$.

Now, if we endow the $h_{6}$ Poisson algebra with a primitive coalgebra structure, i.e. with a two-body coproduct (which is a Poisson algebra homomorphism $\Delta: h_{6} \rightarrow h_{6} \otimes h_{6}$ [12, 16]) given by

$$
\Delta(X)=X \otimes 1+1 \otimes X \quad X \in\left\{K, A_{+}, A_{-}, B_{+}, B_{-}, M\right\}
$$


then the one-particle dynamical symmetry given by (4.1) can be generalized for any number of degrees of freedom. As we shall see in Section 2, this gives rise to an infinite family of $N$-particle Hamiltonians defined as any smooth function $\mathcal{H}$ of the generators of $h_{6}$

$$
\mathcal{H}=\mathcal{H}\left(K, B_{+}, B_{-}, A_{+}, A_{-}, M\right)
$$

and provided that $\mathcal{H}$ is realized in the $N$-particle symplectic realization coming from the coproduct structure.

\subsection{An infinite family of quasi-integrable systems}

The integrability properties of the generic $N$-particle Hamiltonians with $h_{6}$-coalgebra symmetry relies on the following result [28], which is based in the application of the coalgebra symmetry approach to a non-generic symplectic realization of the $h_{6}$ Poisson coalgebra.

In particular, let $\{\mathbf{q}, \mathbf{p}\}=\left\{\left(q_{1}, \ldots, q_{N}\right),\left(p_{1}, \ldots, p_{N}\right)\right\}$ be $N$ pairs of canonical variables. The ND Hamiltonian

$$
\mathcal{H}=\mathcal{H}\left(K, B_{+}, B_{-}, A_{+}, A_{-}, M\right)
$$

defined as any smooth function $\mathcal{H}: \mathbb{R}^{6} \rightarrow \mathbb{R}$ and

$$
\begin{array}{lll}
A_{+}=\sum_{i=1}^{N} \lambda_{i} p_{i} & A_{-}=\sum_{i=1}^{N} \lambda_{i} q_{i} & K=\sum_{i=1}^{N}\left(q_{i} p_{i}-\frac{\lambda_{i}^{2}}{2}\right) \\
B_{+}=\sum_{i=1}^{N} p_{i}^{2} & B_{-}=\sum_{i=1}^{N} q_{i}^{2} & M=\sum_{i=1}^{N} \lambda_{i}^{2}
\end{array}
$$

where $\lambda_{i}$, are $N$ arbitrary parameters, is quasi-integrable. The $(N-2)$ functionally independent integrals of the motion for $\mathcal{H}$ are

$$
\mathcal{C}^{(m)}=\sum_{1 \leq i<j<k}^{m}\left(\lambda_{i}\left(p_{j} q_{k}-p_{k} q_{j}\right)+\lambda_{j}\left(p_{k} q_{i}-p_{i} q_{k}\right)+\lambda_{k}\left(p_{i} q_{j}-p_{j} q_{i}\right)\right)^{2}
$$

where $m=3, \ldots, N$. These integrals are in involution and can be called 'universal' in the sense that they do not depend on the specific choice of the function $\mathcal{H}$.

The keystone to prove this result (see [28]) comes from the fact that (4.1) is a one-particle symplectic realization for the Poisson coalgebra $\left(h_{6}, \Delta\right)$, labelled by the $\lambda_{1}$ parameter. Moreover, it can be easily checked that (4.8) is just the $N$-particle 
symplectic realization of $\left(h_{6}, \Delta\right)$ that is obtained through the $N$-sites generalization of the coproduct 4.5):

$$
\begin{aligned}
\Delta^{(N)}(X)=X & \otimes 1 \otimes 1 \otimes \ldots{ }^{N-1)} \otimes 1 \\
+1 \otimes X & \otimes 1 \otimes \ldots{ }^{N-2)} \otimes 1+\ldots . \\
& +1 \otimes 1 \otimes \ldots{ }^{N-1)} \otimes 1 \otimes X .
\end{aligned}
$$

This means that the $N$-particle generators 4.8 fulfil the commutation rules 4.2 with respect to the canonical Poisson bracket $\{f, g\}=\sum_{i=1}^{N}\left(\frac{\partial f}{\partial q_{i}} \frac{\partial g}{\partial p_{i}}-\frac{\partial g}{\partial q_{i}} \frac{\partial f}{\partial p_{i}}\right)$.

Moreover, such a coalgebra symmetry expressed through the symplectic realization implies that each of the $N$-particle generators (4.8) Poisson-commute with the $(N-1)$ functions $\mathcal{C}^{(m)}$ given by the $m$-th coproducts of the Casimir 4.9 with $m=2,3, \ldots, N$ (see [12, 16] for details). However, in the case of the specific symplectic realization of $h_{6}$ given by (4.8), the $\mathcal{C}^{(2)}$ function vanishes (the two-body coproduct of the Casimir is zero [16]) and we are left with the set of $(N-2)$ integrals $(4.9)$ that, also by construction, are functionally independent and Poisson-commuting. Therefore, any function $\mathcal{H}$ (4.7) of the $N$-particle symplectic realization of the $h_{6}$ generators will be in involution with the set of integrals $\mathcal{C}^{(m)}$, which completes the proof.

This general result deserves the following remarks and comments:

- First of all, we have to characterize the symplectic realizations for $h_{6}$ in the framework of Chapter 2, by taking into account that $R=1, r=2, l=6$. According to (2.19), the generic representation for $h_{6}$ would have

$$
s_{m}=\frac{l-r}{2}=\frac{6-2}{2}=2
$$

pairs of canonical variables. This generic realization would be 'a Calogero-Moser' realization, namely.

$$
\begin{array}{ll}
\mathcal{D}\left(A_{+}\right)=\lambda_{1} p_{1}+\lambda_{2} p_{2} & \mathcal{D}\left(A_{-}\right)=\lambda_{1} q_{1}+\lambda_{2} q_{2} \\
\mathcal{D}(K)=q_{1} p_{1}+q_{2} p_{2}-\frac{\left(\lambda_{1}^{2}+\lambda_{2}^{2}\right)}{2} & \mathcal{D}\left(B_{+}\right)=p_{1}^{2}+p_{2}^{2}+\frac{b}{\left(\lambda_{1} q_{2}-\lambda_{2} q_{1}\right)^{2}} \\
\mathcal{D}\left(B_{-}\right)=q_{1}^{2}+q_{2}^{2} & \mathcal{D}(M)=\lambda_{1}^{2}+\lambda_{2}^{2}
\end{array}
$$

In this case, the value for the non trivial Casimir operator of $h_{6}$ is

$$
\mathcal{C}_{h_{6}}=b .
$$

And concerning the necessary integrability condiction expressed in 2.18 and (2.21) we would have that

$$
s \leq R-\frac{(R-1)}{N} \rightarrow 2 \leq 1
$$




$$
l \leq(2 R+r)-\frac{2}{N}(R-1) \rightarrow 6 \leq 4
$$

Obviously the former relations are not verified for the generic symplectic realization, and the construction of Hamiltonian systems from it does not lead to complete integrability. Moreover, the non-generic symplectic realization that we are using does fulfill the necessary integrability condition, but it shows that such condition is not sufficient: despite the dimensionality conditions are satisfied, the coalgebra framework does not provide complete integrability since one integral (the one coming from the first coproduct of the Casimir) vanishes.

- We can properly say that $\mathcal{H}$ is a quasi-integrable Hamiltonian, since for any dimension $N$ and any choice of $\mathcal{H}$ there is only one integral left in order to get its complete integrability. Obviously, some specific choices for $\mathcal{H}$ will lead to completely integrable Hamiltonians for which an additional integral does exist for any dimension $N$. The aim of this Chapter is just to find solutions to this problem.

- Within the coalgebra approach it is well-known that, in general, two different sets of integrals of the motion coming from 'left' and 'right' $m$-th coproducts of the Casimir can be obtained (see [21] for details). Indeed, this is also the case for the $\left(h_{6}, \Delta\right)$ coalgebra, where by making use of the 'right' $m$-th coproducts, the following alternative set of $(N-2)$ integrals in involution $\mathcal{C}_{(m)}$ is obtained:

$$
\mathcal{C}_{(m)}=\sum_{N-m+1 \leq i<j<k}^{N}\left(\lambda_{i}\left(p_{j} q_{k}-p_{k} q_{j}\right)+\lambda_{j}\left(p_{k} q_{i}-p_{i} q_{k}\right)+\lambda_{k}\left(p_{i} q_{j}-p_{j} q_{i}\right)\right)^{2}
$$

This means that if we label the $N$ sites on $h_{6} \otimes h_{6} \otimes{ }^{N)} \otimes h_{6}$ by $1 \otimes 2 \otimes \cdots \otimes N$, the 'left' Casimir $\mathcal{C}^{(m)}$ is defined on the sites $1 \otimes 2 \otimes \cdots \otimes m$, while the 'right' one $\mathcal{C}_{(m)}$ is defined on $(N-m+1) \otimes \cdots \otimes(N-1) \otimes N$. Moreover, it is straightforward to prove that the $(2 N-4)$ functions $\left\{\mathcal{C}^{(3)}, \mathcal{C}^{(4)}, \ldots, \mathcal{C}^{(N)} \equiv \mathcal{C}_{(N)}, \mathcal{C}_{(N-1)}, \ldots \mathcal{C}_{(3)}, \mathcal{H}\right\}$ are functionally independent (assuming that $\mathcal{H}$ is not a function of $\mathcal{C}$ only) and the coalgebra symmetry ensures that each of the two subsets $\left\{\mathcal{C}^{(3)}, \ldots, \mathcal{C}^{(N)}, \mathcal{H}\right\}$ or $\left\{\mathcal{C}_{(3)}, \ldots, \mathcal{C}_{(N)}, \mathcal{H}\right\}$ is formed by $(N-1)$ functions in involution [12, 21].

- As a consequence, in case that an additional integral $\mathcal{I}$ is found for a given $\mathcal{H}$, this Hamiltonian will be not only integrable, but also superintegrable provided that the $(N-3)$ 'right' constants $\mathcal{C}_{(m)}$ (with $m=3, \ldots, N-1$ ) commute with $\mathcal{I}$ (and this property will be ensured if $\mathcal{I}$ is a function of the $N$-particle symplectic realization of the $h_{6}$-coalgebra).

- The role of the $\lambda_{i}$ parameters is essential in this approach, since they provide an $N$-parameter freedom for the Hamiltonian. From a co-algebraic viewpoint 
these $\lambda_{i}$ parameters can be neatly interpreted: each of them fixes the one-particle symplectic realization that we are using on the $i$-th site of the underlying $h_{6}$ symmetry lattice $h_{6} \otimes h_{6} \otimes \ldots{ }^{N)} \otimes h_{6}$.

- We stress that the integrals (4.9) can be interpreted as sums of the squares of a linear combination (through the $\lambda_{i}$ parameters) of 'Euclidean angular momentum' components $J_{i j}$. In particular, the $N(N-1) / 2$ functions $J_{i j}=\left(q_{i} p_{j}-q_{j} p_{i}\right)$ with $i<j$ and $i, j=1, \ldots, N$ span an $s o(N)$ Lie-Poisson algebra so that $\mathcal{C}^{(m)}$ can be read as

$$
\mathcal{C}^{(m)}=\sum_{1 \leq i<j<k}^{m}\left(\lambda_{i} J_{j k}+\lambda_{j} J_{k i}+\lambda_{k} J_{i j}\right)^{2}
$$

where $J_{k i}=-J_{i k}$. Hence each term in $\mathcal{C}^{(m)}$ is the square of an element of the LiePoisson algebra $s o(3)=\left\{J_{i j}, J_{i k}, J_{j k}\right\}$ (and the same happens in $\mathcal{C}_{(m)}$ ). From this perspective, the $h_{6}$-coalgebra symmetry can be interpreted as a 'generalization' of the spherical symmetry, which will be fully recovered when the Hamiltonian is defined on the $g l(2)$ Poisson subalgebra of $h_{6}$.

- Although the central generator $M$ is also a Casimir for the two-photon coalgebra, its $N$-th coproduct gives rise to $N$ trivial integrals of the motion

$$
M^{(m)}=\sum_{i=1}^{m} \lambda_{i}^{2} \quad m=1, \ldots, N
$$

that, do not provide any dynamical information. In this sense, $M$ can be considered either as a generator on its own right or as a constant that depends on both the dimension $N$ and the chosen symplectic realizations through the $\lambda_{i}$ parameters.

Finally, is worth mentioning that the role of the $h_{6}$ algebra in the integrability properties of certain 3D Hamiltonian systems was already pointed out from a different viewpoint in [179]. Nevertheless, the introduction of a coalgebra structure in $h_{6}$ turns out to be essential in order to fully exploit its integrability information and to generalize it to arbitrary dimensions.

\subsubsection{Some relevant quasi-integrable Hamiltonians}

Among the bunch of ND quasi-integrable systems that are provided by (4.7), the following particular subclasses are physically outstanding. 


\section{Natural systems}

The Hamiltonian

$$
\mathcal{H}=\frac{1}{2} B_{+}+\mathcal{F}\left(A_{-}, B_{-}\right)
$$

where $\mathcal{F}$ is a function playing the role of a potential, gives rise to the following quasiintegrable system on the $N D$ Euclidean space $\mathbb{E}^{N}$ :

$$
\mathcal{H}^{(N)}=\sum_{i=1}^{N} \frac{p_{i}^{2}}{2}+\mathcal{F}\left(\sum_{i=1}^{N} \lambda_{i} q_{i}, \sum_{i=1}^{N} q_{i}^{2}\right)
$$

Notice that central potentials (endowed with spherical symmetry) directly arise whenever $\mathcal{F}$ does not depend on $A_{-}$, since the Hamiltonian is then defined on the $g l(2)$ subalgebra. Thus in the case with generic $\mathcal{F}\left(A_{-}, B_{-}\right)$, the spherical symmetry is broken and its associated (super)integrability is, in principle, reduced to quasi-integrability. Nevertheless, the $h_{6}$-coalgebra symmetry of 4.20 reduces the $N D$ integrability problem to the search for only one additional integral, whose existence and explicit form will depend on the particular choice of the function $\mathcal{F}$.

\section{Electromagnetic Hamiltonians}

The most general ND quasi-integrable Hamiltonian including linear terms in the momenta is given by

$$
\mathcal{H}=\frac{1}{2} B_{+}+K \mathcal{F}\left(A_{-}, B_{-}\right)+A_{+} \mathcal{G}\left(A_{-}, B_{-}\right)+\mathcal{R}\left(A_{-}, B_{-}\right)
$$

where $\mathcal{F}, \mathcal{G}$ and $\mathcal{R}$ are smooth functions. In terms of canonical variables, it reads

$$
\begin{aligned}
\mathcal{H}^{(N)}= & \sum_{i=1}^{N} \frac{p_{i}^{2}}{2}+\left(\sum_{i=1}^{N}\left(q_{i} p_{i}-\frac{\lambda_{i}^{2}}{2}\right)\right) \mathcal{F}\left(\sum_{i=1}^{N} \lambda_{i} q_{i}, \sum_{i=1}^{N} q_{i}^{2}\right) \\
& +\left(\sum_{i=1}^{N} \lambda_{i} p_{i}\right) \mathcal{G}\left(\sum_{i=1}^{N} \lambda_{i} q_{i}, \sum_{i=1}^{N} q_{i}^{2}\right)+\mathcal{R}\left(\sum_{i=1}^{N} \lambda_{i} q_{i}, \sum_{i=1}^{N} q_{i}^{2}\right) .
\end{aligned}
$$

In $3 \mathrm{D}$, this Hamiltonian describes the motion of a particle on $\mathbb{E}^{3}$ under the action of a static electromagnetic field which is determined by the functions $\mathcal{F}, \mathcal{G}$ and $\mathcal{R}$. Namely, if we compare 4.22 with the 3D electromagnetic Hamiltonian

$$
\mathcal{H}_{e m}=\frac{1}{2}(\vec{p}-e \vec{A})^{2}+e \psi
$$


where $e$ is the electric charge, $\vec{A}$ is the vector potential and $\psi$ is the scalar one, we get

$$
\begin{aligned}
A_{i}= & -\frac{q_{i}}{e} \mathcal{F}\left(A_{-}, B_{-}\right)-\frac{\lambda_{i}}{e} \mathcal{G}\left(A_{-}, B_{-}\right) \quad i=1,2,3 \\
\psi= & \frac{1}{e} \mathcal{R}\left(A_{-}, B_{-}\right)-\frac{1}{2 e} M \mathcal{F}\left(A_{-}, B_{-}\right) \\
& \quad-\frac{1}{2 e}\left[B_{-} \mathcal{F}\left(A_{-}, B_{-}\right)^{2}+2 A_{-} \mathcal{F}\left(A_{-}, B_{-}\right) \mathcal{G}\left(A_{-}, B_{-}\right)+M \mathcal{G}\left(A_{-}, B_{-}\right)^{2}\right] .
\end{aligned}
$$

Note the relevant role that the $\lambda_{i}$ parameters play in the definition of the electromagnetic field. Recall also that ND superintegrable electromagnetic systems have been recently obtained in $[24$ by making use of an $\operatorname{sl}(2, \mathbb{R})$-coalgebra symmetry. In fact, as we shall show in Section 4.4, the latter systems are a particular subfamily of 4.22 since $\operatorname{sl}(2, \mathbb{R})$ is a sub-coalgebra of $h_{6}$. We also recall that only low-dimensional integrable Euclidean Hamiltonians with velocity-dependent potentials have been previously studied in [35, 42, 78, 106, 108, 124, 152, 153, 167].

\section{Geodesic flow Hamiltonians}

A third family of relevant systems is the one given by ND quasi-integrable Hamiltonians of the type

$$
\mathcal{H}^{(N)}=\sum_{i, j=1}^{N} g^{i j}\left(q_{1}, \ldots, q_{N}\right) p_{i} p_{j}
$$

that are obtained by considering

$$
\begin{aligned}
\mathcal{H}= & B_{+} \mathcal{F}\left(A_{-}, B_{-}\right)+A_{+}^{2} \mathcal{G}\left(A_{-}, B_{-}\right)+\left(K+\frac{M}{2}\right)^{2} \mathcal{R}\left(A_{-}, B_{-}\right) \\
& +\left(K+\frac{M}{2}\right) A_{+} \mathcal{S}\left(A_{-}, B_{-}\right)
\end{aligned}
$$

since for any choice of the functions $\mathcal{F}, \mathcal{G}, \mathcal{R}$ and $\mathcal{S}$ we obtain a Hamiltonian which is a quadratic homogeneous function in the momenta. Explicitly,

$$
\begin{aligned}
\mathcal{H}^{(N)}= & \left(\sum_{i=1}^{N} \frac{p_{i}^{2}}{2}\right) \mathcal{F}\left(\sum_{i=1}^{N} \lambda_{i} q_{i}, \sum_{i=1}^{N} q_{i}^{2}\right)+\left(\sum_{i=1}^{N} \lambda_{i} p_{i}\right)^{2} \mathcal{G}\left(\sum_{i=1}^{N} \lambda_{i} q_{i}, \sum_{i=1}^{N} q_{i}^{2}\right) \\
& +\left(\sum_{i=1}^{N} q_{i} p_{i}\right)^{2} \mathcal{R}\left(\sum_{i=1}^{N} \lambda_{i} q_{i}, \sum_{i=1}^{N} q_{i}^{2}\right) \\
& +\left(\sum_{i=1}^{N} q_{i} p_{i}\right)\left(\sum_{i=1}^{N} \lambda_{i} p_{i}\right) \mathcal{S}\left(\sum_{i=1}^{N} \lambda_{i} q_{i}, \sum_{i=1}^{N} q_{i}^{2}\right) .
\end{aligned}
$$


We stress that the specific form of the metric $g^{i j}$ is determined by the $\mathcal{F}, \mathcal{G}, \mathcal{R}$ and $\mathcal{S}$ functions which, in general, gives rise to an ND space of nonconstant curvature. In any case, the set of constants of motion (4.9) is once again universal and does not depend on the specific choice of the functions in the Hamiltonian. Moreover, additional potentials on these $h_{6}$-coalgebra spaces can be naturally considered by adding functions such as, e.g., $\mathcal{U}\left(A_{-}, B_{-}\right)$to the free Hamiltonian (4.27). In this way the Euclidean natural systems 4.19) can be generalized to the curved spaces defined through (4.27) without breaking the quasi-integrability of the geodesic flow Hamiltonian.

In this respect, we recall that the complete integrability of a free Hamiltonian on a curved space is a rather nontrivial property which is connected with geometric and topological features of the underlying manifold [25, 110, 115, 146]. From the physical viewpoint, the study of integrable geodesic flows in arbitrary dimension is becoming increasingly popular in general relativity, supergravity and superstring theories, where the explicit knowledge of the Stäckel-Killing integrals of motion for the geodesic flows of $N D$ curved spaces provides very useful information (see, for instance, [70, 116, 143, 174]). Since integrable examples of such ND curved geodesic flows are quite scarce, the search of new completely integrable instances among the Hamiltonians (4.28) is thus meaningful.

\subsection{Complete integrability}

At this point the main problem to be faced is the characterization of those Hamiltonians $\mathcal{H}$ for which an additional integral $\mathcal{I}$ does exist for any dimension $N$, thus providing their complete $N D$ integrability.

In order to ensure the existence of $\mathcal{I}$ for any dimension $N$, we shall assume that this additional integral is also $h_{6}$-coalgebra invariant, which means that it can be written as a function

$$
\mathcal{I}=\mathcal{I}\left(K, B_{+}, B_{-}, A_{+}, A_{-}, M\right)
$$

where the $h_{6}$ generators are written in their $N$-particle symplectic realization (4.8). In this way, if $\mathcal{I}$ is functionally independent with respect to both the $h_{6}$ Casimir (4.4) and the Hamiltonian $\mathcal{H}$, the coalgebra symmetry ensures -by construction- the involutivity of $\mathcal{I}$ with respect to the $(N-2)$ 'left' integrals $\mathcal{C}^{(m)}(m=3, \ldots, N)$ and its functional independence with respect to them. And the very same result holds for the $(N-3)$ 'right' integrals $\mathcal{C}_{(m)}$ where $m=3, \ldots, N-1$ (we recall that $\mathcal{C}_{(N)}=\mathcal{C}^{(N)}$ ).

This means that if $\mathcal{I}$ does exist in the form (4.29), then $\mathcal{H}$ will be not only a completely integrable system but also a superintegrable one, since a total number of $(N-2)+(N-3)+1=(2 N-4)$ functionally independent constants of motion for 
$\mathcal{H}$ has been explicitly found. Nevertheless, even in this superintegrable case, $\mathcal{H}$ is not a maximally superintegrable Hamiltonian, since two more independent constants of the motion would be needed to get the maximum possible total number of $(2 N-2)$ independent integrals. Again, these two remaining integrals could exist for some very particular choices for $\mathcal{H}$, but in any case neither their existence nor their explicit form can be derived from the $h_{6}$-coalgebra symmetry.

The rest of this Chapter is devoted to show the search for the additional $\mathcal{I} 4.29$ by different algebraic strategies within $h_{6}$. In particular, we shall consider two different situations in which the existence of $\mathcal{I}$ is guaranteed by construction:

A) If the Hamiltonian $\mathcal{H}$ is defined within a subalgebra of $h_{6}$ that has a non-linear Casimir invariant, the $N$-particle realization of the Casimir of the subalgebra provides the integral $\mathcal{I}$. This subalgebra integrability approach will be analysed in the next Section (4.4), in which the subalgebra structure for $h_{6}$ will be fully described.

B) Let $X$ be a fixed generator of $h_{6}$. The $N$-particle symplectic realization of $X$ will Poisson commute with any $N$-particle Hamiltonian $\mathcal{H}_{X}$ defined as a function of all the remaining $h_{6}$ generators commuting with $X$ and of the Casimirs of all the subalgebras containing the given generator $X$. Under such hypotheses, $\mathcal{H}_{X}$ is completely integrable since the generator $X$ is just the additional constant of motion $\mathcal{I}$. We have five relevant generators $\left\{K, B_{+}, B_{-}, A_{+}, A_{-}\right\}$(the central generator $M$ would give no dynamical information), so this generator integrability procedure will give rise to five families of completely integrable systems that will be studied in detail in Section 4.5.

Finally, we stress that if a given Hamiltonian does not fit within the two previous approaches, the search for the remaining integral $\mathcal{I}$-in case it does exist- have to be performed by using direct methods. Indeed, some particular solutions can be found, and a several examples will be given in the final Section. This direct search method will be also the cornerstone for all the results presented in Chapter 5 .

\subsection{Subalgebra integrability}

The subalgebras of $h_{6}$ with a non-trivial (i.e. linear) Casimir function are summarized in Table 9 together with their 1D symplectic realization. They are:

- Two 'book' algebras $\mathcal{D}_{+}$and $\mathcal{D}_{-}$generated by a dilation plus two translations.

- The harmonic oscillator algebra $h_{4}$.

- Two centrally extended $(1+1)$ D Galilean algebras $\overline{\mathcal{G}}_{+}$and $\overline{\mathcal{G}}_{-}$. 
- A centrally extended 2D Euclidean algebra $\overline{\mathcal{E}}$ (where $\mu$ and $\nu$ are non-zero real parameters).

- The $g l(2)$ algebra.

More details on these subalgebras and on their associated Lie-Poisson structures can be found in [16]. Clearly the Heisenberg-Weyl algebra $h_{3}=\left\{A_{+}, A_{-}, M\right\}$ is a subalgebra of $h_{4}$, and $g l(2)$ contains an $s l(2, \mathbb{R})$ subalgebra (by mapping $K \rightarrow K+M / 2$ ), so we have the following subalgebra embeddings:

$$
h_{3} \subset h_{4} \subset h_{6} \quad \overline{\mathcal{G}}_{ \pm} \subset h_{6} \quad s l(2, \mathbb{R}) \subset g l(2) \subset h_{6} .
$$

Notice also that $\overline{\mathcal{E}}$ is a proper Euclidean subalgebra whenever $\mu$ and $\nu$ have the same sign; on the contrary, $\overline{\mathcal{E}}$ is in fact a centrally extended $(1+1) \mathrm{D}$ Poincaré subalgebra. In the sequel we do not distinguish the two real forms as the resulting expressions for $\overline{\mathcal{E}}$ will be globally parametrized through $\mu$ and $\nu$.

Table 9. Relevant subalgebras of $h_{6}$.

\begin{tabular}{clll}
\hline Subalgebra & Generators & Symplectic realization & Casimir function \\
\hline $\mathcal{D}_{+}$ & $K, A_{+}, B_{+}$ & $q p-\frac{\lambda^{2}}{2}, \lambda p, p^{2}$ & $A_{+}^{2} / B_{+}$ \\
$\mathcal{D}_{-}$ & $K, A_{-}, B_{-}$ & $q p-\frac{\lambda^{2}}{2}, \lambda q, q^{2}$ & $A_{-}^{2} / B_{-}$ \\
$h_{4}$ & $K, A_{-}, A_{+}, M$ & $q p-\frac{\lambda^{2}}{2}, \lambda q, \lambda p, \lambda^{2}$ & $M\left(K+\frac{1}{2} M\right)-A_{-} A_{+}$ \\
$\overline{\mathcal{G}}_{+}$ & $B_{+}, A_{-}, A_{+}, M$ & $p^{2}, \lambda q, \lambda p, \lambda^{2}$ & $M B_{+}-A_{+}^{2}$ \\
$\overline{\mathcal{G}}_{-}$ & $B_{-}, A_{-}, A_{+}, M$ & $q^{2}, \lambda q, \lambda p, \lambda^{2}$ & $M B_{-}-A_{-}^{2}$ \\
$\overline{\mathcal{E}}$ & $\mu B_{+}+\nu B_{-}$, & $\mu p^{2}+\nu q^{2}$, & $M\left(\mu B_{+}+\nu B_{-}\right)$ \\
& $A_{-}, A_{+}, M$ & $\lambda q, \lambda p, \lambda^{2}$ & $-\mu A_{+}^{2}-\nu A_{-}^{2}$ \\
$g l(2)$ & $K, B_{-}, B_{+}, M$ & $q p-\frac{\lambda^{2}}{2}, q^{2}, p^{2}, \lambda^{2}$ & $B_{-} B_{+}-\left(K+\frac{1}{2} M\right)^{2}$ \\
\hline
\end{tabular}

As we have pointed out in the previous Section, any Hamiltonian $\mathcal{H}_{g}$ defined on one of the abovementioned subalgebras $g$ is completely integrable by construction, since the $N$-th coproduct of the Casimir $\mathcal{C}_{g}$ provides the extra integral $\mathcal{I}$, which completes the set of $(N-2)$ left integrals $\mathcal{C}^{(m)}$ coming from the $h_{6}$-coalgebra. Note that $\mathcal{I}$ is a function of the $h_{6}$ generators and, as a consequence, is in involution with each of the $\mathcal{C}^{(m)}$ integrals. Therefore, we can state that the following ND Hamiltonians define 
Table 10. ND symplectic realization of the Casimir of each of the subcoalgebras of $\left(h_{6}, \Delta\right)$ given in Table 9.

\begin{tabular}{|c|c|}
\hline Sub-coalgebra & Integrals of motion \\
\hline$\left(\mathcal{D}_{+}, \Delta\right)$ & $\left.\sum_{-1}^{N} \lambda_{i} p_{i}\right)^{2} /\left(\sum_{i=1}^{N} p_{j}^{2}\right)$ \\
\hline$\left(\mathcal{D}_{-}, \Delta\right)$ & $\mathcal{C}_{\mathcal{D}_{-}}^{(N)}=\left(\sum_{i=1}^{N} \lambda_{i} q_{i}\right)^{2} /\left(\sum_{i=1}^{N} q_{j}^{2}\right)$ \\
\hline$\left(h_{4}, \Delta\right)$ & $\mathcal{C}_{h_{4}}^{(N)}=\sum_{1<i<j}^{N}\left(\lambda_{j} p_{i}-\lambda_{i} p_{j}\right)\left(\lambda_{j} q_{i}-\lambda_{i} q_{j}\right)$ \\
\hline$\left(\overline{\mathcal{G}}_{+}, \Delta\right)$ & $\mathcal{C}_{\overline{\mathcal{G}}_{+}}^{(N)}=\sum_{1 \leq i<j}^{N}\left(\lambda_{j} p_{i}-\lambda_{i} p_{j}\right)^{2}$ \\
\hline$\left(\overline{\mathcal{G}}_{-}, \Delta\right)$ & $\mathcal{C}_{\overline{\mathcal{G}}_{-}}^{(N)}=\sum_{\substack{1 \leq i<j \\
N}}^{N}\left(\lambda_{j} q_{i}-\lambda_{i} q_{j}\right)^{2}$ \\
\hline$(\overline{\mathcal{E}}, \Delta)$ & $\mathcal{C}_{\overline{\mathcal{E}}}^{(N)}=\sum_{1<i<i}^{N}\left\{\mu\left(\lambda_{j} p_{i}-\lambda_{i} p_{j}\right)^{2}+\nu\left(\lambda_{j} q_{i}-\lambda_{i} q_{j}\right)^{2}\right\}$ \\
\hline$(g l(2), \Delta)$ & $\mathcal{C}_{g l(2)}^{(N)}=\sum_{1 \leq i<j}^{N}\left(q_{j} p_{i}-q_{i} p_{j}\right)^{2}$ \\
\hline
\end{tabular}

completely integrable systems:

$$
\begin{aligned}
& \mathcal{H}_{\mathcal{D}_{+}}=\mathcal{H}_{\mathcal{D}_{+}}\left(K, A_{+}, B_{+}\right) \\
& \mathcal{H}_{\mathcal{D}_{-}}=\mathcal{H}_{\mathcal{D}_{-}}\left(K, A_{-}, B_{-}\right) \\
& \mathcal{H}_{h_{4}}=\mathcal{H}_{h_{4}}\left(K, A_{-}, A_{+}, M\right) \\
& \mathcal{H}_{\overline{\mathcal{G}}_{+}}=\mathcal{H}_{\overline{\mathcal{G}}_{+}}\left(B_{+}, A_{-}, A_{+}, M\right) \\
& \mathcal{H}_{\overline{\mathcal{G}}_{-}}=\mathcal{H}_{\overline{\mathcal{G}}_{-}}\left(B_{-}, A_{-}, A_{+}, M\right) \\
& \mathcal{H}_{\overline{\mathcal{E}}}=\mathcal{H}_{\overline{\mathcal{E}}}\left(\mu B_{+}+\nu B_{-}, A_{-}, A_{+}, M\right) \\
& \mathcal{H}_{g l(2)}=\mathcal{H}_{g l(2)}\left(K, B_{-}, B_{+}, M\right)
\end{aligned}
$$

where the $h_{6}$ generators are taken through their ND symplectic realization (4.8) and the Hamiltonian functions are any smooth functions of the corresponding arguments. Moreover, all these systems are superintegrable, since the $h_{6}$-coalgebra provides $(N-3)$ 
additional and functionally independent integrals of the motion given by the 'right' integrals $\mathcal{C}_{(m)}$.

The explicit form of the Casimir invariant $\mathcal{C}_{g} \equiv \mathcal{I}$ of each subalgebra $g$ is given in Table 10 in terms of the $N$-particle symplectic realization (4.8). It is interesting to remark that the two-photon Casimir (4.4) can be expressed in terms of the Casimirs of the four subalgebras $h_{3}, h_{4}, \overline{\mathcal{G}}_{+}, \overline{\mathcal{G}}_{-}$as

$$
\mathcal{C}_{h_{6}}=\frac{1}{\mathcal{C}_{h_{3}}}\left(\mathcal{C}_{\overline{\mathcal{G}}_{+}} \mathcal{C}_{\overline{\mathcal{G}}_{-}}-\mathcal{C}_{h_{4}}^{2}\right)
$$

Let us finally comment that all of these subalgebras are also sub-coalgebras since the same primitive coproduct (4.5) holds for all of them as Lie-Poisson algebras. In fact, an alternative approach to the integrability of the systems (4.31) would be to consider directly the coalgebra construction for the subalgebra in which $\mathcal{H}_{g}$ is defined, thus forgetting about the whole $h_{6}$ scheme. In that case, the integrals of motion would be given by the 'left' and 'right' $m$-th coproducts of the Casimir of the subalgebra $\mathcal{C}_{g}$, say $\mathcal{C}_{g}^{(m)}$ and $\mathcal{C}_{g,(m)}(m=2, \ldots, N)$, respectively.

In this way, by taking into account that $\mathcal{C}_{g}^{(2)}$ and $\mathcal{C}_{g,(2)}$ do not vanish in the subalgebra, we would obtain (in principle) a maximum number of $(2 N-3)$ independent constants of motion for $\mathcal{H}_{g}$, and each set of $N$ functions $\left\{\mathcal{C}_{g}^{(m)}, \mathcal{H}_{g}\right\}$ or $\left\{\mathcal{C}_{g,(m)}, \mathcal{H}_{g}\right\}$ would be in involution. However, in the case of $\mathcal{D}_{+}, \mathcal{D}_{-}$and the two centrally extended $(1+1) \mathrm{D}$ Galilean algebras $\overline{\mathcal{G}}_{+}$and $\overline{\mathcal{G}}_{-}$, the right integrals $\mathcal{C}_{g,(m)}$ turn out to be functionally dependent with respect to the left ones, and in these cases the superintegrability of the associated systems can be only derived by making use of the $h_{6}$-coalgebra construction.

Some of these subalgebras have been considered previously from the coalgebra method, so that we refer to the various papers on the subject [14, 24, 27]. Nevertheless it is worthy to point out that in the present $h_{6}$ framework the integrals of motion coming from $\mathrm{gl}(2)$ just provide the ones coming from the spherical symmetry (see Table 10). In terms of the $s o(N)$ generators $J_{i j}$, (see Section 4.2) these read

$$
\mathcal{C}_{g l(2)}^{(m)}=\sum_{1 \leq i<j}^{m} J_{i j}^{2} \quad \mathcal{C}_{(m), g l(2)}=\sum_{N-m+1 \leq i<j}^{m} J_{i j}^{2} .
$$

Therefore when a Hamiltonian of the type $\mathcal{H}_{g l(2)}$ is considered the spherical symmetry and its associated superintegrability is recovered as a particular case of the more general $h_{6}$-coalgebra setting. 


\subsection{Generator integrability}

Now, let us choose a given generator $X$ of $h_{6}$. If we look for all the generators $X_{j} \quad(j=$ $1, \ldots, l)$ commuting with $X$ and we look for all the subalgebras $g_{k}(k=1, \ldots, t)$ containing $X$ as generator, it becomes obvious that the Hamiltonian constructed through any function of the type

$$
\mathcal{H}_{X}=\mathcal{H}_{X}\left(\mathcal{C}_{g_{1}}, \ldots, \mathcal{C}_{g_{t}}, X, X_{1}, \ldots, X_{l}\right)
$$

where $\mathcal{C}_{g_{k}}$ is the Casimir function of the subalgebra $g_{k}$, verifies that

$$
\left\{\mathcal{H}_{X}, X\right\}=0 .
$$

Moreover, the $N$-th particle symplectic realization of both $X$ and $\mathcal{H}_{X}$ will Poissoncommute with the two sets of integrals $\mathcal{C}^{(m)} \sqrt{4.9}$ and $\mathcal{C}_{(m)} \sqrt{4.16}$. Therefore, the $N$-th symplectic realization of $\mathcal{H}_{X}$ is a completely integrable $N$ D Hamiltonian system (in fact, superintegrable with a total number of $(2 N-4)$ integrals of the motion).

As we shall see in the sequel, by taking into account the information concerning the $h_{6}$ subalgebras that is contained in Tables 9 and 10, this result provides in a straightforward way a bunch of new ND integrable systems. We stress that particular integrable systems belonging to the three classes of the generically quasi-integrable Hamiltonians (4.20), 4.22) and 4.28) can be straightforwardly identified.

\subsubsection{Hamiltonians in involution with $K$}

Let us start by considering $X \equiv K$. It is immediate to check that the only generator that Poisson-commutes with $K$ is $M$, the central one. On the other hand, $K$ is contained in the subalgebras $\mathcal{D}_{+}, \mathcal{D}_{-}, h_{4}$ and $g l(2)$. Therefore, the most general Hamiltonian with $h_{6}$-coalgebra symmetry and in involution with $K$ is

$$
\mathcal{H}_{K}=\mathcal{H}_{K}\left(\mathcal{C}_{D_{+}}, \mathcal{C}_{D_{-}}, \mathcal{C}_{h_{4}}, \mathcal{C}_{g l(2)}, K, M\right)
$$

where the smooth function $\mathcal{H}_{K}: \mathbb{R}^{6} \rightarrow \mathbb{R}$. Now, if we take the $N D$ symplectic realization of $\mathcal{H}_{K}$, we obtain an $N$ D integrable Hamiltonian with $(N-1)$ integrals of motion in involution given by 4.9 together with

$$
\mathcal{I} \equiv K=\sum_{i=1}^{N}\left(q_{i} p_{i}-\frac{\lambda_{i}^{2}}{2}\right) .
$$

Next, in order to classify the type of Hamiltonian systems that can be constructed from $\mathcal{H}_{K}$, we have to realize that the symplectic realization of $K$ and $\mathcal{C}_{h_{4}}$ are linear in 
the momenta, while $\mathcal{C}_{g l(2)}$ is quadratic in $p$. On the other hand, $\mathcal{C}_{D_{+}}$is rational in $p$ (for arbitrary $\lambda_{i}$ ) and $\mathcal{C}_{D_{-}}$is a rational function in the canonical coordinates $q$. With these ingredients in mind and by considering the three families of systems given in Section 4.2.1, a family of completely integrable geodesic flows on ND curved spaces is obtained through a choice of the Hamiltonian $\mathcal{H}_{K}$ leading to a quadratic homogeneous function in the momenta. Namely, the most general possibility of this type turns out to be

$$
\mathcal{H}_{K}=\mathcal{C}_{g l(2)} \mathcal{F}\left(\mathcal{C}_{D_{-}}\right)+\left(K+\frac{M}{2}\right)^{2} \mathcal{G}\left(\mathcal{C}_{D_{-}}\right)+\mathcal{C}_{h_{4}}^{2} \mathcal{R}\left(\mathcal{C}_{D_{-}}\right)+\left(K+\frac{M}{2}\right) \mathcal{C}_{h_{4}} \mathcal{S}\left(C_{D_{-}}\right)
$$

where $\mathcal{F}, \mathcal{G}, \mathcal{R}$ and $\mathcal{S}$ are smooth functions. When this Hamiltonian is written in terms of canonical coordinates we get

$$
\begin{aligned}
\mathcal{H}_{K}^{(N)}= & \left(\sum_{1 \leq i<j}^{N}\left(q_{j} p_{i}-q_{i} p_{j}\right)^{2}\right) \mathcal{F}\left(\frac{\left(\sum_{i=1}^{N} \lambda_{i} q_{i}\right)^{2}}{\sum_{i=1}^{N} q_{i}^{2}}\right)+\left(\sum_{i=1}^{N} q_{i} p_{i}\right)^{2} \mathcal{G}\left(\frac{\left(\sum_{i=1}^{N} \lambda_{i} q_{i}\right)^{2}}{\sum_{i=1}^{N} q_{i}^{2}}\right) \\
& \left.+\left(\sum_{1 \leq i<j}^{N}\left(\lambda_{j} p_{i}-\lambda_{i} p_{j}\right)\left(\lambda_{j} q_{i}-\lambda_{i} q_{j}\right)\right)^{2} \mathcal{R}\left(\frac{\left(\sum_{i=1}^{N} \lambda_{i} q_{i}\right)^{2}}{\sum_{i=1}^{N} q_{i}^{2}}\right)^{2}\right) \\
& +\left(\sum_{1 \leq i<j}^{N}\left(\lambda_{j} p_{i}-\lambda_{i} p_{j}\right)\left(\lambda_{j} q_{i}-\lambda_{i} q_{j}\right)\right)\left(\sum_{i=1}^{N} q_{i} p_{i}\right) \mathcal{S}\left(\frac{\left(\sum_{i=1}^{N} \lambda_{i} q_{i}\right)^{2}}{\sum_{i=1}^{N} q_{i}^{2}}\right)^{(4.38)}
\end{aligned}
$$

which is an ND integrable geodesic flow that depends on four smooth functions and $N$ free parameters $\lambda_{i}$.

\subsubsection{Hamiltonians in involution with $A_{+}$}

When the generator $A_{+}$is considered, we find that both $B_{+}$and $M$ commute with it. On the other hand, $A_{+}$belongs to the subalgebras $\mathcal{D}_{+}, h_{4}, \overline{\mathcal{G}}_{+}, \overline{\mathcal{G}}_{-}$and $\overline{\mathcal{E}}$. Both facts lead to the completely integrable Hamiltonian

$$
\mathcal{H}_{A_{+}}=\mathcal{H}_{A_{+}}\left(\mathcal{C}_{\mathcal{D}_{+}}, \mathcal{C}_{h_{4}}, \mathcal{C}_{\overline{\mathcal{G}}_{+}}, \mathcal{C}_{\overline{\mathcal{G}}_{-}}, \mathcal{C}_{\overline{\mathcal{E}}}, A_{+}, B_{+}, M\right)
$$

whatever the function $\mathcal{H}_{A_{+}}$be. In this case, the appearance of $B_{+}$(the Euclidean kinetic energy term) allows for a wider set of possibilities. In particular, all the following 
types of integrable Hamiltonians can be considered as specific cases of $\mathcal{H}_{A_{+}}$for which the remaining integral is $\mathcal{I} \equiv A_{+}=\sum_{i=1}^{N} \lambda_{i} p_{i}$. This integral can be interpreted as a $\lambda_{i}$-generalization of the translational symmetry.

- Natural Hamiltonians. The only possibility is

$$
\mathcal{H}_{A_{+}}=\frac{1}{2} B_{+}+\mathcal{F}\left(\mathcal{C}_{\overline{\mathcal{G}}_{-}}\right)=\sum_{i=1}^{N} \frac{p_{i}^{2}}{2}+\mathcal{F}\left(\sum_{1 \leq i<j}^{N}\left(\lambda_{j} q_{i}-\lambda_{i} q_{j}\right)^{2}\right)
$$

Note that this Hamiltonian is not defined within the $\overline{\mathcal{G}}_{-}$subalgebra. In the $N=2$ case, the Calogero-Moser systems [53, 127, 177] arise as particular choices for $\mathcal{F}$.

- Electromagnetic Hamiltonians. We can add linear terms in the momenta to the previous Hamiltonian leading to

$$
\begin{aligned}
\mathcal{H}_{A_{+}}= & \frac{1}{2} B_{+}+\mathcal{C}_{h_{4}} \mathcal{G}\left(\mathcal{C}_{\overline{\mathcal{G}}_{-}}\right)+A_{+} \mathcal{R}\left(\mathcal{C}_{\overline{\mathcal{G}}_{-}}\right)+\mathcal{F}\left(\mathcal{C}_{\overline{\mathcal{G}}_{-}}\right) \\
\mathcal{H}_{A_{+}}^{(N)}= & \sum_{i=1}^{N} \frac{p_{i}^{2}}{2}+\left(\sum_{1 \leq i<j}^{N}\left(\lambda_{j} p_{i}-\lambda_{i} p_{j}\right)\left(\lambda_{j} q_{i}-\lambda_{i} q_{j}\right)\right) \mathcal{G}\left(\sum_{1 \leq i<j}^{N}\left(\lambda_{j} q_{i}-\lambda_{i} q_{j}\right)^{2}\right) \\
& +\left(\sum_{i=1}^{N} \lambda_{i} p_{i}\right) \mathcal{R}\left(\sum_{1 \leq i<j}^{N}\left(\lambda_{j} q_{i}-\lambda_{i} q_{j}\right)^{2}\right)+\mathcal{F}\left(\sum_{1 \leq i<j}^{N}\left(\lambda_{j} q_{i}-\lambda_{i} q_{j}\right)^{2}\right) .
\end{aligned}
$$

- Geodesic flows. The most general expression coming from $\mathcal{H}_{A_{+}}$and with homogeneous quadratic dependence in the momenta is given by 


$$
\begin{aligned}
& \mathcal{H}_{A_{+}}=\mathcal{C}_{h_{4}}^{2} \mathcal{F}\left(\mathcal{C}_{\overline{\mathcal{G}}_{-}}\right)+\mathcal{C}_{\overline{\mathcal{G}}_{+}} \mathcal{G}\left(\mathcal{C}_{\overline{\mathcal{G}}_{-}}\right)+B_{+} \mathcal{R}\left(\mathcal{C}_{\overline{\mathcal{G}}_{-}}\right)+A_{+}^{2} \mathcal{S}\left(\mathcal{C}_{\overline{\mathcal{G}}_{-}}\right)+A_{+} \mathcal{C}_{h_{4}} \mathcal{T}\left(\mathcal{C}_{\overline{\mathcal{G}}_{-}}\right) \\
& \mathcal{H}_{A_{+}}^{(N)}=\left(\sum_{1 \leq i<j}^{N}\left(\lambda_{j} p_{i}-\lambda_{i} p_{j}\right)\left(\lambda_{j} q_{i}-\lambda_{i} q_{j}\right)\right)^{2} \mathcal{F}\left(\sum_{1 \leq i<j}^{N}\left(\lambda_{j} q_{i}-\lambda_{i} q_{j}\right)^{2}\right) \\
& +\left(\sum_{1 \leq i<j}^{N}\left(\lambda_{j} p_{i}-\lambda_{i} p_{j}\right)^{2}\right) \mathcal{G}\left(\sum_{1 \leq i<j}^{N}\left(\lambda_{j} q_{i}-\lambda_{i} q_{j}\right)^{2}\right) \\
& +\left(\sum_{i=1}^{N} p_{i}^{2}\right) \mathcal{R}\left(\sum_{1 \leq i<j}^{N}\left(\lambda_{j} q_{i}-\lambda_{i} q_{j}\right)^{2}\right)+\left(\sum_{i=1}^{N} \lambda_{i} p_{i}\right)^{2} \mathcal{S}\left(\sum_{1 \leq i<j}^{N}\left(\lambda_{j} q_{i}-\lambda_{i} q_{j}\right)^{2}\right) \\
& +\left(\sum_{i=1}^{N} \lambda_{i} p_{i}\right)\left(\sum_{1 \leq i<j}^{N}\left(\lambda_{j} p_{i}-\lambda_{i} p_{j}\right)\left(\lambda_{j} q_{i}-\lambda_{i} q_{j}\right)\right) \mathcal{T}\left(\sum_{1 \leq i<j}^{N}\left(\lambda_{j} q_{i}-\lambda_{i} q_{j}\right)^{2}\right) .
\end{aligned}
$$

\subsubsection{Hamiltonians in involution with either $A_{-}, B_{-}$or $B_{+}$}

To end with we present jointly these tree types of Hamiltonians, since all of them provide new examples of $N D$ geodesic flows.

- $A_{-}$-Hamiltonians. If we consider that $\mathcal{I} \equiv A_{-}=\sum_{i=1}^{N} \lambda_{i} q_{i}$, is straightforward to prove that the most general integrable $A_{-}$-Hamiltonian reads

$$
\mathcal{H}_{A_{-}}=\mathcal{H}_{A_{-}}\left(\mathcal{C}_{\mathcal{D}_{-}}, \mathcal{C}_{h_{4}}, \mathcal{C}_{\overline{\mathcal{G}}_{+}}, \mathcal{C}_{\overline{\mathcal{G}}_{-}}, \mathcal{C}_{\overline{\mathcal{E}}}, A_{-}, B_{-}, M\right)
$$

In this case, geodesic flow Hamiltonians are available through the particular choice

$$
\mathcal{H}_{\mathcal{A}_{-}}=\mathcal{C}_{h_{4}}^{2} \mathcal{F}\left(\mathcal{C}_{\mathcal{D}_{-}}, \mathcal{C}_{\overline{\mathcal{G}}_{-}}, A_{-}, B_{-}\right)+\mathcal{C}_{\overline{\mathcal{G}}_{+}} \mathcal{G}\left(\mathcal{C}_{\mathcal{D}_{-}}, \mathcal{C}_{\overline{\mathcal{G}}_{-}}, A_{-}, B_{-}\right)
$$

and its $N$-particle symplectic realization can be immediately obtained.

- B--Hamiltonians. A similar situation is encountered when $\mathcal{I} \equiv B_{-}=\sum_{i=1}^{N} q_{i}^{2}$ is considered. In this case we have that

$$
\mathcal{H}_{B_{-}}=\mathcal{H}_{B_{-}}\left(\mathcal{C}_{\mathcal{D}_{-}}, \mathcal{C}_{\overline{\mathcal{G}}_{-}}, \mathcal{C}_{g l(2)}, B_{-}, A_{-}, M\right)
$$

and since $\mathcal{C}_{g l(2)}$ is the only term quadratic in the momenta, we are led to the integrable geodesic flow given by

$$
\mathcal{H}_{B_{-}}=\mathcal{C}_{g l(2)} \mathcal{F}\left(\mathcal{C}_{\mathcal{D}_{-}}, \mathcal{C}_{\overline{\mathcal{G}}_{-}}, B_{-}, A_{-}\right)
$$


- $B_{+}$-Hamiltonians. Finally, the last possibility is given by $\mathcal{I} \equiv B_{+}=\sum_{i=1}^{N} p_{i}^{2}$. Now, the most general integrable Hamiltonian is given by

$$
\mathcal{H}_{B_{+}}=\mathcal{H}_{B_{+}}\left(\mathcal{C}_{\mathcal{D}_{+}}, \mathcal{C}_{\overline{\mathcal{G}}_{+}}, \mathcal{C}_{g l(2)}, B_{+}, A_{+}, M\right)
$$

All the variables fot $\mathcal{H}_{B_{+}}$(except $M$ ) depend on the momenta. Therefore, in this case the only integrable geodesic flow can be obtained through

$$
\mathcal{H}_{B_{+}}=\alpha B_{+}+\beta A_{+}^{2}+\gamma \mathcal{C}_{g l(2)}+\delta \mathcal{C}_{\overline{\mathcal{G}}_{+}}
$$

where $\alpha, \beta, \gamma$ and $\delta$ are constants.

\subsection{Direct search of integrable Hamiltonians}

As we mentioned in Section 4.3, a third possibility to show the complete integrability for a given Hamiltonian $\mathcal{H}$ (4.7) with $h_{6}$-coalgebra symmetry is the direct search for an additional integral $\mathcal{I}$, that can be assumed to be an unknown function of the $h_{6}$ generators. An example for this type of construction is given by the following examples of natural, electromagnetic and geodesic flow Hamiltonians, thus showing the versatility of the coalgebra construction.

\subsubsection{Natural systems: the Garnier Hamiltonian}

If we consider the following Hamiltonian

$$
\mathcal{H}=\frac{1}{2} B_{+}+\delta_{1} B_{-}+\delta_{2} A_{-}^{2}+\delta_{3} B_{-}^{2}
$$

where $\delta_{1}, \delta_{2}, \delta_{3}$ are arbitrary constants, a direct computation by making use of the Poisson algebra (4.2) shows that

$$
\mathcal{I}=\delta_{3} \mathcal{C}_{g l(2)}-\delta_{2}\left(A_{+}^{2}+2 A_{-}^{2}\left(M \delta_{2}+\delta_{1}+\delta_{3} B_{-}\right)\right)
$$

is in involution with $\mathcal{H}$. Here is worth mentioning that if $\delta_{2}=0$, we are falling into the $g l(2)$-subalgebra, and also the fact that the only allowed perturbation to the radial symmetry is coming from the term $A_{-}^{2}$. In this sense, the $h_{6}$ coalgebra can be again interpreted as the algebraic tool to express the spherical symmetry breaking of a given model. 
Let us consider the $2 \mathrm{D}$ and $3 \mathrm{D}$ symplectic realizations for 4.50. The general expresssion of our system in $2 \mathrm{D}$ reads

$$
\mathcal{H}^{(2)}=\frac{1}{2}\left(p_{1}^{2}+p_{2}^{2}\right)+\delta_{1}\left(q_{1}^{2}+q_{2}^{2}\right)+\delta_{2}\left(\lambda_{1}^{2} q_{1}^{2}+\lambda_{2}^{2} q_{2}^{2}+2 \lambda_{1} \lambda_{2} q_{1} q_{2}\right)+\delta_{3}\left(q_{1}^{4}+q_{2}^{4}+2 q_{1}^{2} q_{2}^{2}\right) .
$$

By taking $\lambda_{1}=1$ and $\lambda_{2}=0$ we get

$$
\mathcal{H}^{(2)}=\frac{1}{2}\left(p_{1}^{2}+p_{2}^{2}\right)+A q_{1}^{2}+B q_{2}^{2}+\delta_{3}\left(q_{1}^{2}+q_{2}^{2}\right)^{2}
$$

where

$$
A=\delta_{1}+\delta_{2} \quad B=\delta_{1}
$$

which is the 2D Garnier system. By substituting the previous values of the $\lambda$ parameters, the invariant becomes

$$
\mathcal{I}^{(2)}=\delta_{3}\left(p_{2} q_{1}-p_{1} q_{2}\right)^{2}-\delta_{2}\left(p_{1}^{2}+2 q_{1}^{2}\left(\delta_{1}+\delta_{2}+\delta_{3}\left(q_{1}^{2}+q_{2}^{2}\right)\right)\right)
$$

The $3 \mathrm{D}$ realization of 4.50 gives

$$
\begin{aligned}
\mathcal{H}^{(3)}= & \frac{1}{2}\left(p_{1}^{2}+p_{2}^{2}+p_{3}^{2}\right)+\delta_{1}\left(q_{1}^{2}+q_{2}^{2}+q_{3}^{2}\right)+\delta_{2}\left(\lambda_{1} q_{1}+\lambda_{2} q_{2}+\lambda_{3} q_{3}\right)^{2} \\
& +\delta_{3}\left(q_{1}^{2}+q_{2}^{2}+q_{3}^{2}\right)^{2}
\end{aligned}
$$

and if we choose $\lambda_{1}=1$ and $\lambda_{2}=\lambda_{3}=0$ we get

$$
\mathcal{H}^{(3)}=\frac{1}{2}\left(p_{1}^{2}+p_{2}^{2}+p_{3}^{2}\right)+\left(\delta_{1}+\delta_{2}\right) q_{1}^{2}+\delta_{1} q_{2}^{2}+\delta_{1} q_{3}^{2}+\delta_{3}\left(q_{1}^{2}+q_{2}^{2}+q_{3}^{2}\right)^{2}
$$

In this case the invariants have the following expressions:

$$
\begin{aligned}
\mathcal{C}_{h_{6}}^{(3)}= & \left(q_{2} p_{3}-q_{3} p_{2}\right)^{2} \\
\mathcal{I}^{(3)}= & \delta_{3}\left(p_{2}^{2} q_{1}^{2}+p_{3}^{2} q_{1}^{2}-2 p_{1} p_{2} q_{1} q_{2}+p_{1}^{2} q_{2}^{2}+p_{3}^{2} q_{2}^{2}-2 p_{1} p_{3} q_{1} q_{3}-2 p_{2} p_{3} q_{2} q_{3}+p_{1}^{2} q_{3}^{2}\right. \\
& \left.+p_{2}^{2} q_{3}^{2}-2 \delta_{2}\left(q_{1}^{4}+q_{1}^{2} q_{2}^{2}+q_{1}^{2} q_{3}^{2}\right)\right)-\delta_{2}\left(p_{1}^{2}+2 \delta_{1} q_{1}^{2}+2 \delta_{2} q_{1}^{2}\right) .
\end{aligned}
$$

Note that in the $3 \mathrm{D}$ case the oscillator term is non isotropic only in the $q_{1}$ coordinate, and this feature is preserved in any dimension. Again, if $\delta_{2}$ vanishes, the radial symmetry of the system is recovered and, from the algebraic viewpoint, the Hamiltonian is defined on $g l(2)$. 


\subsubsection{An electromagnetic Hamiltonian}

Now we consider the following Hamiltonian, which represents a isotropic oscillator plus linear terms in the momenta encoded within $K$ and $A_{+}$:

$$
\mathcal{H}=\frac{B_{+}}{2}+\delta_{1} B_{-}+\delta_{5} K A_{-}+\delta_{6} A_{+} .
$$

A long but straightforward computation shows that this Hamiltonian commutes with the following polynomial object defined on $h_{6}$ :

$$
\begin{aligned}
\mathcal{I}= & -6 \delta_{1}\left(A_{+}^{2}+2 \delta_{1} A_{-}^{2}\right)+2 \delta_{5} A_{+}\left(B_{+} M-A_{+}^{2}\right) \\
& +4 \delta_{1} \delta_{5}\left(-3 A_{+} A_{-}^{2}+K A_{-} M-A_{+} B_{-} M+2 A_{-} M^{2}\right) \\
& +\delta_{5}^{2}\left(-3 A_{+}^{2} A_{-}^{2}+3 A_{-}^{2} B_{+} M-A_{+}^{2} B_{-} M+B_{+} B_{-} M^{2}+A_{+} A_{-} M^{2}-K M^{3}\right) \\
& -4 \delta_{6}\left(3 \delta_{1} A_{+} M+\delta_{5} A_{+}^{2} M+2 \delta_{1} \delta_{5} B_{-} M^{2}+2 \delta_{5}^{2} K A_{-} M+2 \delta_{5} \delta_{6} A_{+} M^{2}\right) .
\end{aligned}
$$

Note that this integral is quadratic in the momenta.

In 3D the Hamiltonian (4.59) can be interpreted as the one describing an electromagnetic field, provided we write it in the form

$$
\mathcal{H}=\frac{1}{2}(\vec{p}-e \vec{A})^{2}+e \psi
$$

where $e$ is the electric charge, $\vec{A}$ is the vector potential, and $\psi$ the scalar one. Now, by considering the 3D symplectic realization of $h_{6}$ with arbitrary $\lambda$ parameters we get that 4.59 corresponds to the motion of a charged particle under the the following vector and scalar potentials:

$$
\begin{gathered}
A_{i}=-\frac{\delta_{5}}{e} q_{i}\left(\lambda_{1} q_{1}+\lambda_{2} q_{2}+\lambda_{3} q_{3}\right)-\frac{\delta_{6}}{e} \lambda_{i} \quad i=1,2,3 \\
\psi=-\frac{\delta_{5}}{2 e} M-\frac{e}{2} \sum_{i=1}^{3} A_{i}^{2}+\frac{\delta_{1}}{e} \sum_{i=1}^{3} q_{i}^{2} .
\end{gathered}
$$

From them, the magnetic $\left(\Omega_{1}, \Omega_{2}, \Omega_{3}\right)$ and electric field components $\left(E_{1}, E_{2}, E_{3}\right)$ would be

$$
\begin{aligned}
& \Omega_{1}=\frac{\delta_{5}}{e}\left(\lambda_{3} q_{2}-\lambda_{2} q_{3}\right) \\
& \Omega_{2}=\frac{\delta_{5}}{e}\left(\lambda_{1} q_{3}-\lambda_{3} q_{1}\right) \\
& \Omega_{3}=\frac{\delta_{5}}{e}\left(\lambda_{2} q_{1}-\lambda_{1} q_{2}\right)
\end{aligned}
$$




$$
E_{i}=-\partial_{q_{i}} \psi \quad i=1,2,3 .
$$

Therefore, we can say that this static electromagnetic field generates integrable motions in 3D. It is worth stressing that by switching off the harmonic oscillator term $\left(\delta_{1} \rightarrow\right.$ 0 ) the integral of the motion is significantly simplified, although the magnetic field components $\Omega_{i}$ do not change.

\subsubsection{Geodesic flows}

A third type of interesting examples is obtained by considering geodesic flow Hamiltonians. We will present here four examples for which the additional integral that guarantees the complete integrability of the associated ND geodesic flow can be explicitly found as a function of the $h_{6}$ coalgebra generators. These four examples do not exhaust the list of completely integrable geodesic flows that can be obtained in this approach through more complicated choices of the Hamiltonian function.

\section{Example I}

Let us consider the Hamiltonian

$$
\mathcal{H}=B_{+}\left(\alpha_{1} A_{-}+\alpha_{2} B_{-}+\alpha_{3}\right)
$$

where $\alpha_{1}, \alpha_{2}, \alpha_{3}$ are arbitrary constants. Despite its simplicity, this quadratic $h_{6}$ Hamiltonian neither lives in any $h_{6}$ subalgebra nor can be included within the cases studied in the previous Section. However, the following additional (and functionally independent) constant of motion can be found by direct computation

$$
\mathcal{I}=4 \alpha_{1} \alpha_{2} A_{+}\left(K+\frac{M}{2}\right)+4 \alpha_{2} \alpha_{3} B_{+}+4 \alpha_{2}^{2} K(K+M)-\alpha_{1}^{2} \mathcal{C}_{\overline{\mathcal{G}}_{+}} .
$$

This integral provides the complete integrability of the system 4.66 for any dimension $N$. Note that in the limit $\alpha_{2} \rightarrow 0$ the Hamiltonian (4.66) belongs to the subalgebra $\overline{\mathcal{G}}_{+}$, and in that case $\mathcal{I}$ is just the Casimir function for such a subalgebra, as it should be.

Although we will not study in detail here the geometric content of the spaces defined by the integrable geodesic flows (4.66), we can say that they are spaces with nonconstant curvature. This can be easily proven by taking the $2 \mathrm{D}$ symplectic realization of (4.66) and by computing the 2D Gaussian curvature $K$ of the associated metrics. A long but straightforward computation shows that

$$
\mathcal{K}=\frac{4 \alpha_{2} \alpha_{3}-\alpha_{1}^{2}\left(\lambda_{1}^{2}+\lambda_{2}^{2}\right)}{2\left[\alpha_{2}\left(q_{1}^{2}+q_{2}^{2}\right)+\alpha_{3}+\alpha_{1}\left(\lambda_{1} q_{1}+\lambda_{2} q_{2}\right)\right]} .
$$


Note that either if $\alpha_{1}=\alpha_{2}=0$ or $\alpha_{1}=\alpha_{3}=0$ the space is flat, but 2D spaces with constant (but non-vanishing) curvature are not included in 4.66).

\section{Example II}

Another interesting example is provided by the following Hamiltonian

$$
\mathcal{H}=B_{+}\left(\alpha_{1} A_{-}^{2}+\alpha_{2} B_{-}+\alpha_{3}\right) .
$$

A direct computation shows that the extra invariant is now given by

$$
\mathcal{I}=\alpha_{1} \alpha_{2} K M(K+M)+\alpha_{2}^{2}\left(K+\frac{M}{2}\right)^{2}+\alpha_{1} \alpha_{3} \mathcal{C}_{\overline{\mathcal{G}}_{+}}+\alpha_{2} \alpha_{3} B_{+} .
$$

In $2 \mathrm{D}$, the Gaussian curvature of the spaces defined through the flow $(4.69)$ is

$$
\mathcal{K}=-\frac{\alpha_{1} \sum_{i=1}^{2} \lambda_{i}^{2}\left(-\alpha_{3}+\alpha_{1}\left\{\sum_{i=1}^{2} \lambda_{i} q_{i}\right\}^{2}\right)+\alpha_{2}\left\{-2 \alpha_{3}+\alpha_{1}\left[\left(\sum_{i=1}^{2} \lambda_{i} q_{i}\right)^{2}-\left(\lambda_{2} q_{1}-\lambda_{2} q_{1}\right)^{2}\right]\right\}}{\left[\alpha_{2} \sum_{i=1}^{2} q_{i}^{2}+\alpha_{3}+\alpha_{1}\left(\sum_{i=1}^{2} \lambda_{i} q_{i}\right)^{2}\right]}
$$

and again we have obtained a family of integrable spaces with, in general, non-constant curvature. We also remark that the $\alpha_{1} \rightarrow 0$ limit of Examples I and II leads to the same system.

\section{Example III}

A third example would be

$$
\mathcal{H}=B_{+}\left(\alpha_{1} A_{-} B_{-}+\alpha_{2}\right)
$$

for which the extra invariant is

$$
\begin{aligned}
\mathcal{I}= & \alpha_{1}\left(-4 K^{2} A_{-}^{2}+4 K A_{+} A_{-} B_{-}-A_{+}^{2} B_{-}^{2}-4 K A_{-}^{2} M+2 A_{-} A_{+} B_{-} M+B_{+} B_{-}^{2} M\right) \\
& -\alpha_{1} A_{-}^{2} M^{2}+\alpha_{2}\left(8 K A_{+}-8 A_{-} B_{+}+4 A_{+} M\right)
\end{aligned}
$$

and the 2D Gaussian curvature reads

$$
\mathcal{K}=-\frac{\alpha_{1}\left[-8 \alpha_{2} \sum_{i=1}^{2} \lambda_{i} q_{i}+\alpha_{1}\left\{\sum_{i=1}^{2} q_{i}^{2}\right\}^{2}\left(\sum_{i=1}^{2} \lambda_{i}^{2}\right)\right]}{2\left(\alpha_{2}+\alpha_{1}\left\{\sum_{i=1}^{2} q_{i}^{2}\right\}\left(\sum_{i=1}^{2} \lambda_{i}^{2}\right)\right)}
$$

where again the flat limit is given by $\alpha_{1} \rightarrow 0$. 


\section{Example IV}

And finally we consider the geodesic flow defined by

$$
\mathcal{H}=B_{+}\left(\alpha_{1} A_{-}^{2}+\alpha_{2} B_{-}^{2}+\alpha_{3}\right)
$$

for which the extra invariant becomes much more complicated, namely

$$
\begin{aligned}
\mathcal{I}= & \alpha_{1}^{2}\left(-2 K A_{+} A_{-} M+A_{+}^{2} B_{-} M+K^{2} M^{2}-A_{+} A_{-} M^{2}-B_{+} B_{-} M^{2}+K M^{3}\right) \\
& +\alpha_{1} \alpha_{2}\left(-4 K^{2} A_{-}^{2}+4 K A_{+} A_{-} B_{-}-A_{+}^{2} B_{-}^{2}-4 K A_{-}^{2} M-A_{-}^{2} M^{2}\right) \\
& +2 \alpha_{1} \alpha_{2} A_{+} A_{-} B_{-} M-\alpha_{1} \alpha_{3} A_{+}^{2}-4 \alpha_{2} \alpha_{3}\left(K^{2}-B_{+} B_{-}+K M\right)
\end{aligned}
$$

In this case, the $2 \mathrm{D}$ gaussian curvature is

$$
\mathcal{K}=\frac{-\alpha_{1} \sum_{i=1}^{2} \lambda_{i}^{2}\left[-\alpha_{3}+\alpha_{1}\left(\sum_{i=1}^{2} \lambda_{i} q_{i}\right)^{2}\right]+\alpha_{2} \sum_{i=1}^{2} q_{i}^{2}\left\{8 \alpha_{3}+\alpha_{1}\left(\sum_{i=1}^{2} q_{i}^{2}\right)\left(\sum_{i=1}^{2} \lambda_{i}^{2}\right)\right\}}{\alpha_{2}\left(\sum_{i=1}^{2} q_{i}^{2}\right)^{2}+\alpha_{3}+\alpha_{1}\left(\sum_{i=1}^{2} \lambda_{i} q_{i}\right)^{2}} .
$$

Obviously, the $\alpha_{2} \rightarrow 0$ limit of Examples II and IV leads to the same system.

We stress that this direct search for the remaining integral can be indeed very useful, since it can be quite easily computerized. In fact, the integral $\mathcal{I}$ can be searched among $h_{6}$ functions with cubic or higher dependence on the momenta (note that all the integrals that we have presented so far are, at most, quadratic in the momenta).

Moreover, nothing prevents that, although for a certain $\mathcal{H}$ defined on $h_{6}$ the additional integral does exist, such $\mathcal{I}$ cannot be written as a function (4.29) of the $h_{6}$ generators (i.e., $\mathcal{I}$ would not be coalgebra-invariant). This implies that in this case all the previous methods are not applicable and the explicit form for $\mathcal{I}$ has to be found for each dimension $N$, which constitutes a much more cumbersome task. Nevertheless, we would like to emphasize that any $h_{6}$-coalgebra invariant Hamiltonian $\mathcal{H}$ of the form 4.7) is only one integral away from being completely integrable, and the search of the complete list of integrable choices for $\mathcal{H}$ is certainly interesting. 


\title{
Chapter 5
}

\section{Integrable perturbations of the ND oscillator}

\author{
"Rather than trust our own wisdom, \\ one should ultimately rely upon algebraic calculations."
}

L. Euler

The harmonic oscillator is indeed the paradigm of integrable Hamiltonian dynamics on the $N$-dimensional (ND) Euclidean space, and its superintegrability properties are very well established through group-theoretic methods (see, for instance, [4, 87, 147]). Therefore, the construction of non-trivial integrable perturbations/deformations of the ND harmonic oscillator (understood in a broad sense as the addition of any ND potential term -not necessarily small- that preserves the complete integrability of the system) are interesting from both physical and mathematical viewpoints.

In this respect, although certain $2 \mathrm{D}$ and $3 \mathrm{D}$ perturbations have been thoroughly studied (see, for instance [47, 78, 83, 95, 96, 100, 101, 105, 106, 121, 122, 144, 154, 176, 179] and references therein) the number of ND results is more limited. Among them we can quote the search for coupled polynomial perturbations [48, 72, 117, 97, 155], Garnier systems [90], the Smorodinski-Winternitz Hamiltonian [81, 89], Calogero-Moser systems [53, 127] and coupled oscillators coming from symmetric spaces [85]. In a more generic sense, integrable oscillators on ND curved spaces can also be considered as deformations of the ND Euclidean one in which the kinetic energy term is also perturbed through functions of the canonical coordinates containing a curvature parameter (see [24, 26, 29] and references therein).

In this Chapter we use the $h_{6}$ coalgebra machinery introduced in the previous 
Chapter, in order to demonstrate the complete integrability of the following $N$-dimensional natural Hamiltonian system

$$
\mathcal{H}^{(N)}=\frac{1}{2} \sum_{i=1}^{N} p_{i}^{2}+\delta_{1} \sum_{i=1}^{N} q_{i}^{2}+\mathcal{F}\left(\sum_{1 \leq i<j}^{N}\left(\lambda_{j} q_{i}-\lambda_{i} q_{j}\right)^{2}\right)+\mathcal{G}\left(\sum_{i=1}^{N} \lambda_{i} q_{i}\right)
$$

where $\mathcal{F}$ and $\mathcal{G}$ are arbitrary functions and $\delta_{1}$ and $\lambda_{i}(i=1, \ldots, N)$ are $(N+1)$ free parameters. Obviously, the first term in the potential is just the ND isotropic harmonic oscillator, and the second one $(\mathcal{F}+\mathcal{G})$ can be interpreted as two independent families of integrable deformations/perturbations whose superposition preserves the complete integrability of the whole system. Moreover, since the expressions for the integrals of the motion are analytic in $\delta_{1}$, the oscillator term can also be removed without altering the integrability properties of the system.

In Section 5.1 we shall prove the complete integrability of $\mathcal{H}$ by giving explicitly a set of $(N-1)$ functionally independent integrals of the motion for $\mathcal{H}$, which are obtained by making use of the underlying $h_{6}$-Poisson coalgebra symmetry of the Hamiltonian. In fact, such symmetry implies that this Hamiltonian has two different sets of $(N-1)$ independent integrals of the motion, and among both sets there will be a total number of $(2 N-4)$ independent constants of the motion in involution with $\mathcal{H}$, which implies that (5.1) is a superintegrable system (albeit not maximally superintegrable). We shall also prove that no oscillator anisotropies can be obtained by including quadratic terms in the canonical coordinates in either $\mathcal{F}$ or $\mathcal{G}$.

As a consequence, by considering appropriate specializations of the dimension $N$, the arbitrary functions $\mathcal{F}$ and $\mathcal{G}$ and the $(N+1)$ free parameters, we can obtain many different integrable systems. In particular, in Section 5.2 we shall present a number of integrable polynomial perturbations that can be easily obtained from $\mathcal{H}$.

Moreover, another family of integrable perturbations of the ND oscillator is introduced in Section 5.3, namely

$$
\mathcal{H}_{r}^{(N)}=\frac{1}{2} \sum_{i=1}^{N} p_{i}^{2}+\delta_{1} \sum_{i=1}^{N} q_{i}^{2}+\mathcal{V}_{-2}\left(\sum_{i=1}^{N} \lambda_{i} q_{i}, \sum_{i=1}^{N} q_{i}^{2}\right)+\mathcal{J}\left(\sum_{i=1}^{N} q_{i}^{2}\right)
$$

where $\mathcal{V}_{-2}$ is any homogeneous function of degree -2 in the canonical coordinates such that it can be written in terms of the variables $\sum_{i=1}^{N} \lambda_{i} q_{i}$ and $\sum_{i=1}^{N} q_{i}^{2}$. Moreover, $\mathcal{J}$ is an arbitrary radial perturbation and $\delta_{1}$ and $\lambda_{i}(i=1, \ldots, N)$ are again $(N+1)$ free parameters. The (super)integrability of this family of ND Hamiltonian systems will be proven by restorting to their $h_{6}$-Poisson coalgebra symmetry. 
We would like to mention that in the 3D case Hamiltonians (5.1) and (5.2) are subclasses of the systems considered in [179] through a 3D realization of a so-called 'extended' $s l(2, \mathbb{R})$ Poisson-Lie algebra (which is just isomorphic to $h_{6}$ ). However, the ND integrable generalization here presented is only possible by endowing $h_{6}$ with the appropriate underlying coalgebra structure and by imposing the full Hamiltonian to be $h_{6}$-coalgebra invariant.

\subsection{A new ND integrable Hamiltonian}

In order to prove the complete integrability of the ND Hamiltonian (5.1) we consider the functions

$$
\begin{array}{rlrl}
A_{+}=\sum_{i=1}^{N} \lambda_{i} p_{i} & A_{-}=\sum_{i=1}^{N} \lambda_{i} q_{i} & K=\sum_{i=1}^{N}\left(q_{i} p_{i}-\frac{\lambda_{i}^{2}}{2}\right) \\
B_{+}=\sum_{i=1}^{N} p_{i}^{2} & B_{-}=\sum_{i=1}^{N} q_{i}^{2} & M=\sum_{i=1}^{N} \lambda_{i}^{2}
\end{array}
$$

where $\lambda_{i}$ are arbitrary parameters and $N$ fixes the number of degrees of freedom. These functions provide a $N$-dimensional symplectic realization of the $h_{6}$-Poisson coalgebra with Lie-Poisson brackets given by [16, 28, 92 ]

$$
\begin{array}{lll}
\left\{K, A_{+}\right\}=A_{+} & \left\{K, A_{-}\right\}=-A_{-} & \left\{A_{-}, A_{+}\right\}=M \\
\left\{K, B_{+}\right\}=2 B_{+} & \left\{K, B_{-}\right\}=-2 B_{-} & \left\{B_{-}, B_{+}\right\}=4 K+2 M \\
\left\{A_{+}, B_{-}\right\}=-2 A_{-} & \left\{A_{+}, B_{+}\right\}=0 & \{M, \cdot\}=0 \\
\left\{A_{-}, B_{+}\right\}=2 A_{+} & \left\{A_{-}, B_{-}\right\}=0 . &
\end{array}
$$

The Casimir functions for this algebra [145] are given by the central generator $M$ and by

$$
\mathcal{C}=\left(M B_{+}-A_{+}^{2}\right)\left(M B_{-}-A_{-}^{2}\right)-\left(M K-A_{-} A_{+}+M^{2} / 2\right)^{2} .
$$

Thus, we can say that the Hamiltonian $\mathcal{H}(5.1)$ is $h_{6}$-coalgebra invariant, since it can be written as the following function of the $h_{6}$-coalgebra generators:

$$
\mathcal{H}=\frac{1}{2} B_{+}+\delta_{1} B_{-}+\mathcal{F}\left(\mathcal{C}_{\overline{\mathcal{G}}_{-}}\right)+\mathcal{G}\left(A_{-}\right)
$$

provided they are realized in the ND symplectic realization $(5.3)$ and where

$$
\mathcal{C}_{\overline{\mathcal{G}}_{-}}=M B_{-}-A_{-}^{2}=\sum_{i<j}^{N}\left(\lambda_{j} q_{i}-\lambda_{i} q_{j}\right)^{2}
$$


is just the Casimir for a $(1+1)$-Galilei subalgebra of $h_{6}$ spanned by $\left\{B_{-}, A_{-}, A_{+}, M\right\}$. This invariance implies that, the following $(N-2)$ functionally independent functions

$$
\mathcal{C}_{h_{6}}^{(m)}=\sum_{i<j<k}^{m}\left(\lambda_{i}\left(p_{j} q_{k}-p_{k} q_{j}\right)+\lambda_{j}\left(p_{k} q_{i}-p_{i} q_{k}\right)+\lambda_{k}\left(p_{i} q_{j}-p_{j} q_{i}\right)\right)^{2} \quad m=3,4, \ldots, N
$$

Poisson-commute with $\mathcal{H}$ and among themselves. In fact, a given integral $\mathcal{C}_{h_{6}}^{(m)}$ is just the Casimir function (5.5) divided by $M$ and expressed in terms of the $m$-particle realization of the $h_{6}$ algebra.

Thus there is only one integral left in order to prove the complete integrability of $\mathcal{H}$. Such an integral $\mathcal{I}$ can be also found in an $h_{6}$-invariant form through direct computation and by making use of the Poisson brackets (5.4), and reads:

$$
\mathcal{I}=A_{+}^{2}+2 \delta_{1} A_{-}^{2}+2 \mathcal{G}\left(A_{-}\right) M .
$$

In terms of the ND symplectic realization, this last integral is explicitly written as

$$
\mathcal{I}^{(N)}=\left(\sum_{i=1}^{N} \lambda_{i} p_{i}\right)^{2}+2 \delta_{1}\left(\sum_{i=1}^{N} \lambda_{i} q_{i}\right)^{2}+2\left(\sum_{i=1}^{N} \lambda_{i}^{2}\right) \mathcal{G}\left(\sum_{i=1}^{N} \lambda_{i} q_{i}\right)
$$

and note that, $\mathcal{I}$ does not depend on the choice of the function $\mathcal{F}$.

We stress that the $h_{6}$-coalgebra symmetry ensures that $\mathcal{I}$ Poisson-commutes with all the $\mathcal{C}_{h_{6}}^{(m)}$ integrals, and the fact that $\{\mathcal{H}, \mathcal{I}\}=0$ is easily proven by direct computation. The functional independence of $\mathcal{I}$ with respect to the remaining integrals is proven by taking $\delta_{1}=0$ and $\mathcal{G}=0$. In this case $\mathcal{I}=A_{+}^{2}$ depends only on the momenta, and is indeed functionally independent of $\mathcal{C}_{h_{6}}^{(m)}$ (that does not depend on $\delta_{1}, \mathcal{F}$ and $\mathcal{G})$ and of the Hamiltonian. This functional independence will be mantained under the 'deformations' $\delta_{1} \neq 0$ and $\mathcal{G} \neq 0$.

Moreover, the $h_{6}$-coalgebra symmetry implies that the Hamiltonian $\mathcal{H}$ is not only integrable but superintegrable, since the set of integrals (5.8) can be replaced by the alternative one

$$
\mathcal{C}_{h_{6},(m)}=\sum_{N-m+1 \leq i<j<k}^{N}\left(\lambda_{i}\left(p_{j} q_{k}-p_{k} q_{j}\right)+\lambda_{j}\left(p_{k} q_{i}-p_{i} q_{k}\right)+\lambda_{k}\left(p_{i} q_{j}-p_{j} q_{i}\right)\right)^{2}
$$

where $m=3, \ldots, N$. Note that $\mathcal{C}_{h_{6},(N)}=\mathcal{C}_{h_{6}}^{(N)}$, so $\mathcal{H}$ has a total number of $(2 N-4)$ functions in involution (including $\mathcal{I}$ ). We recall that the ND isotropic oscillator (without any perturbations) has a total number of $(2 N-2)$ independent integrals, that makes it 
a maximally superintegrable system. From this perspective, the perturbation given by $\mathcal{F}$ and $\mathcal{G}$ strongly preserves the integrability properties of the oscillator Hamiltonian, since only two integrals of the motion are lost under perturbation, which is certainly a consequence of imposing the $h_{6}$ invariance of the latter.

\section{Example}

If we consider $\mathcal{F}(x)=\alpha / x$ we get

$$
\mathcal{H}^{(N)}=\frac{1}{2} \sum_{i=1}^{N} p_{i}^{2}+\delta_{1} \sum_{i=1}^{N} q_{i}^{2}+\frac{\alpha}{\sum_{1 \leq i<j}^{N}\left(\lambda_{j} q_{i}-\lambda_{i} q_{j}\right)^{2}}+\mathcal{G}\left(\sum_{i=1}^{N} \lambda_{i} q_{i}\right)
$$

which in the case $N=2$ is just the rational Calogero-Moser (CM) system plus an arbitrary function $\mathcal{G}$ :

$$
\mathcal{H}^{(2)}=\frac{1}{2}\left(p_{1}^{2}+p_{2}^{2}\right)+\delta_{1}\left(q_{1}^{2}+q_{2}^{2}\right)+\frac{\alpha}{\left(\lambda_{2} q_{1}-\lambda_{1} q_{2}\right)^{2}}+\mathcal{G}\left(\lambda_{1} q_{1}+\lambda_{2} q_{2}\right) .
$$

The integral of the motion in this case is 5.10 with $N=2$, since the integrals (5.8) and (5.11) only exist from $N=3$. Note that $\mathcal{I}$ does not depend on the CM potential given by $\mathcal{F}$. We stress that the ND generalization $(5.12)$ obtained from $(5.1)$ is not the CM Hamiltonian, but it is indeed completely integrable in any dimension.

\subsubsection{The isotropy problem}

Before entering into more detailed examples, it is convenient to study whether anisotropic oscillators can be 'hidden' in the general result (5.1) through quadratic contributions coming from the perturbation term

$$
\phi=\mathcal{F}(x)+\mathcal{G}(y) .
$$

Since the only terms that can give rise to a homogeneous quadratic contribution in the canonical coordinates are $\alpha_{1} x$ and $\beta_{1} y^{2}$, we write such perturbations in the form

$$
\mathcal{F}(x)=\alpha_{1} x+f(x) \quad \mathcal{G}(y)=\beta_{1} y^{2}+g(y)
$$

where $f$ and $g$ are generic functions with no linear and quadratic term, respectively. In this way we rewrite the Hamiltonian as

$$
\mathcal{H}^{(N)}=\frac{1}{2} \sum_{i=1}^{N} p_{i}^{2}+\delta_{1} \sum_{i=1}^{N} q_{i}^{2}+\alpha_{1}\left(\sum_{i<j}^{N}\left(\lambda_{j} q_{i}-\lambda_{i} q_{j}\right)^{2}\right)+\beta_{1}\left(\sum_{i=1}^{N} \lambda_{i} q_{i}\right)^{2}
$$




$$
+f\left(\sum_{i<j}^{N}\left(\lambda_{j} q_{i}-\lambda_{i} q_{j}\right)^{2}\right)+g\left(\sum_{i=1}^{N} \lambda_{i} q_{i}\right) .
$$

Now, if we impose that all the coefficients of the crossed quadratic terms of the type $q_{i} q_{j}$ vanish, we get only two possible solutions:

- A) $\alpha_{1}=\beta_{1}$. In this case a straightforward computation shows that the Hamiltonian (5.15) is again a ND isotropic oscillator perturbation given by

$$
\mathcal{H}^{(N)}=\frac{1}{2} \sum_{i=1}^{N} p_{i}^{2}+\omega^{2} \sum_{i=1}^{N} q_{i}^{2}+f\left(\sum_{i<j}^{N}\left(\lambda_{j} q_{i}-\lambda_{i} q_{j}\right)^{2}\right)+g\left(\sum_{i=1}^{N} \lambda_{i} q_{i}\right)
$$

with $\omega^{2}=\delta_{1}+\alpha_{1} \sum_{i=1}^{N} \lambda_{i}^{2}$.

- B) For a fixed $i$, another solution is given by $\lambda_{i}=\lambda$ and $\lambda_{j}=0$ for any $j \neq i$. With no loss of generality, we thus consider the case $\lambda_{1}=\lambda$, and the Hamiltonian (5.15) reads

$$
\mathcal{H}^{(N)}=\frac{1}{2} p_{1}^{2}+\omega_{1}^{2} q_{1}^{2}+g\left(\lambda q_{1}\right)+\frac{1}{2} \sum_{i=2}^{N} p_{i}^{2}+\omega_{2}^{2} \sum_{i=2}^{N} q_{i}^{2}+f\left(\lambda^{2} \sum_{i=2}^{N} q_{i}^{2}\right)
$$

with $\omega_{1}^{2}=\lambda^{2} \beta_{1}+\delta_{1}$ and $\omega_{2}^{2}=\lambda^{2} \alpha_{1}+\delta_{1}$. This Hamiltonian is indeed separable as the sum of two Hamiltonians: the first one depends only on $q_{1}$ an the second one is a radial deformation of the $(N-1)$-dimensional isotropic oscillator with frequency $\omega_{2}$. In this case the integrals of the motion read

$$
\begin{gathered}
\mathcal{C}_{h_{6}}^{(m)}=\lambda^{2} \sum_{2 \leq j<k}^{m}\left(p_{j} q_{k}-p_{k} q_{j}\right)^{2} \quad m=3,4, \ldots, N \\
\mathcal{I}^{(N)}=\lambda^{2}\left(p_{1}^{2}+2 \omega_{1}^{2} q_{1}^{2}+2 g\left(\lambda q_{1}\right)\right) .
\end{gathered}
$$

In fact, the first set of integrals reflects the axial symmetry of the ND Hamiltonian, and the last one is directly related to the abovementioned separability.

As a consequence of this analysis, and with no loss of generality, in the rest of the Chapter we will only consider the ND isotropic case (5.16).

\subsection{ND coupled nonlinear oscillators}

As an immediate application of our general result, we will now consider in detail integrable polynomial perturbations of the ND isotropic oscillator given by the Hamiltonian 
(5.16). Based on the previous discussion, we put $\alpha_{1}=\beta_{1}=0$. Afterwards, if we write the perturbation functions $\mathcal{F} \equiv f$ and $\mathcal{G} \equiv g$ in the form

$$
f(x)=\sum_{j=2}^{k} \alpha_{j} x^{j} \quad g(y)=\sum_{j=3}^{l} \beta_{j-1} y^{j}
$$

we will obtain a superposition of a polynomial deformation of degree $2 k$ in the coordinates (the argument $x \equiv \mathcal{C}_{\mathcal{G}_{-}}$is quadratic in $q$ ) and another of degree $l$ (the argument $y \equiv A_{-}$is linear in $\left.q\right)$.

Since the integrability of the perturbation is preserved by the superposition of any of the monomials given in (5.20) (the only thing we have to do is to include the appropriate function $\mathcal{G}\left(A_{-}\right)=g\left(A_{-}\right)$in the invariant $\left.\mathcal{I}\right)$, we can analyse separately the homogeneous perturbations with a fixed degree $m$. Note that for odd $m$ only $g\left(A_{-}\right)$can contribute, which means that the richest cases will be obtained for $m$ even. Therefore, in the sequel we will analyse in detail the cases $m=4$ and $m=6$.

\subsubsection{Homogeneous quartic perturbations}

The homogeneous quartic case is obtained by taking

$$
\phi=f\left(\mathcal{C}_{\overline{\mathcal{G}}_{-}}\right)+g\left(A_{-}\right)=\alpha_{2} \mathcal{C}_{\overline{\mathcal{G}}_{-}}^{2}+\beta_{3} A_{-}^{4}=\alpha_{2}\left(\sum_{i<j}^{N}\left(\lambda_{j} q_{i}-\lambda_{i} q_{j}\right)^{2}\right)^{2}+\beta_{3}\left(\sum_{i=1}^{N} \lambda_{i} q_{i}\right)^{4} .
$$

Let us describe more explicitly the $2 \mathrm{D}$ and $3 \mathrm{D}$ cases.

\section{D examples}

The generic 2D Hamiltonian coming from (5.21) is

$$
\mathcal{H}^{(2)}=\frac{1}{2}\left(p_{1}^{2}+p_{2}^{2}\right)+\delta_{1}\left(q_{1}^{2}+q_{2}^{2}\right)+\alpha_{2}\left(\lambda_{2} q_{1}-\lambda_{1} q_{2}\right)^{4}+\beta_{3}\left(\lambda_{1} q_{1}+\lambda_{2} q_{2}\right)^{4}
$$

and the following cases can be distinguished.

- If $\lambda_{1}=1, \lambda_{2}=0$ we obtain the separable Hamiltonian

$$
\mathcal{H}^{(2)}=\frac{1}{2}\left(p_{1}^{2}+p_{2}^{2}\right)+\delta_{1}\left(q_{1}^{2}+q_{2}^{2}\right)+\beta_{3} q_{1}^{4}+\alpha_{2} q_{2}^{4}
$$

whose invariant 5.10 reflects such separability since $\mathcal{I}^{(2)}=p_{1}^{2}+2\left(\delta_{1} q_{1}^{2}+\beta_{3} q_{1}^{4}\right)$. Note that the separability of the generic 2D Hamiltonian (5.22) in terms of the $\left(\lambda_{2} q_{1}-\lambda_{1} q_{2}\right)$ and $\left(\lambda_{1} q_{1}+\lambda_{2} q_{2}\right)$ coordinates with $\lambda_{1}^{2}+\lambda_{2}^{2}=1$ is straightforward. 
- On the other hand, by taking $\lambda_{1}=1, \lambda_{2}=1, \alpha_{2}=\beta_{3}=\epsilon / 2$ we recover the well-known 1: $6: 1$ integrable quartic perturbation (case (4) 3 ' in [105] with $E=0$ )

$$
\mathcal{H}^{(2)}=\frac{1}{2}\left(p_{1}^{2}+p_{2}^{2}\right)+\delta_{1}\left(q_{1}^{2}+q_{2}^{2}\right)+\epsilon\left(q_{1}^{4}+6 q_{1}^{2} q_{2}^{2}+q_{2}^{4}\right)
$$

and the corresponding integral is obtained through direct substitution onto $\mathcal{I}$ :

$$
\mathcal{I}^{(2)}=\left(p_{1}+p_{2}\right)^{2}+2\left(q_{1}+q_{2}\right)^{2}\left(\delta_{1}+\epsilon\left(q_{1}+q_{2}\right)^{2}\right) .
$$

This system is known to be connected with the Hirota-Satsuma coupled KdV system (see [7]).

\section{$3 \mathrm{D}$ examples}

The $3 \mathrm{D}$ realization of $(5.21)$ for arbitrary values of the parameters reads:

$$
\begin{aligned}
\mathcal{H}^{(3)}= & \frac{1}{2}\left(p_{1}^{2}+p_{2}^{2}+p_{3}^{2}\right)+\delta_{1}\left(q_{1}^{2}+q_{2}^{2}+q_{3}^{2}\right)+\left(\beta_{3} \lambda_{1}^{4}+\alpha_{2} \lambda_{2}^{4}+2 \alpha_{2} \lambda_{2}^{2} \lambda_{3}^{2}+\alpha_{2} \lambda_{3}^{4}\right) q_{1}^{4} \\
& +\left(\alpha_{2} \lambda_{1}^{4}+\beta_{3} \lambda_{2}^{4}+2 \alpha_{2} \lambda_{1}^{2} \lambda_{3}^{2}+\alpha_{2} \lambda_{3}^{4}\right) q_{2}^{4}+\left(\alpha_{2} \lambda_{1}^{4}+2 \alpha_{2} \lambda_{1}^{2} \lambda_{2}^{2}+\alpha_{2} \lambda_{2}^{4}+\beta_{3} \lambda_{3}^{4}\right) q_{2}^{4} \\
& -4 \lambda_{1} \lambda_{3}\left(\alpha_{2}\left(\lambda_{1}^{2}+\lambda_{2}^{2}\right)-\beta_{3} \lambda_{3}^{2}\right) q_{1} q_{3}^{3}-4 \lambda_{1} \lambda_{2}\left(\alpha_{2}\left(\lambda_{1}^{2}+\lambda_{3}^{2}\right)-\beta_{3} \lambda_{2}^{2}\right) q_{1} q_{2}^{3} \\
& +4 \lambda_{1} \lambda_{2}\left(\beta_{3} \lambda_{1}^{2}-\alpha_{2}\left(\lambda_{2}^{2}+\lambda_{3}^{2}\right)\right) q_{1}^{3} q_{2}+4 \lambda_{1} \lambda_{3}\left(\beta_{3} \lambda_{1}^{2}-\alpha_{2}\left(\lambda_{2}^{2}+\lambda_{3}^{2}\right)\right) q_{1}^{3} q_{3} \\
& -4 \lambda_{2} \lambda_{3}\left(\alpha_{2}\left(\lambda_{1}^{2}+\lambda_{2}^{2}\right)-\beta_{3} \lambda_{3}^{2}\right) q_{2} q_{3}^{3}+4 \lambda_{2} \lambda_{3}\left(\beta_{3} \lambda_{2}^{2}-\alpha_{2}\left(\lambda_{1}^{2}+\lambda_{2}^{2}\right)\right) q_{2}^{3} q_{3} \\
& +2\left\{3 \beta_{3} \lambda_{1}^{2} \lambda_{2}^{2}+\alpha_{2}\left[\lambda_{3}^{2}\left(\lambda_{2}^{2}+\lambda_{3}^{2}\right)+\lambda_{1}^{2}\left(3 \lambda_{2}^{2}+\lambda_{3}^{2}\right)\right]\right\} q_{1}^{2} q_{2}^{2} \\
& +2\left\{3 \beta_{3} \lambda_{2}^{2} \lambda_{3}^{2}+\alpha_{2}\left[\lambda_{1}^{4}+3 \lambda_{2}^{2} \lambda_{3}^{2}+\lambda_{1}^{2}\left(\lambda_{2}^{2}+\lambda_{3}^{2}\right)\right]\right\} q_{2}^{2} q_{3}^{2} \\
& +2\left\{3 \beta_{3} \lambda_{1}^{2} \lambda_{2}^{2}+\alpha_{2}\left[\lambda_{2}^{2}\left(\lambda_{2}^{2}+\lambda_{3}^{2}\right)+\lambda_{1}^{2}\left(\lambda_{2}^{2}+3 \lambda_{3}^{2}\right)\right]\right\} q_{1}^{2} q_{3}^{2} \\
& -4 \lambda_{1} \lambda_{2}\left\{-3 \beta_{3} \lambda_{3}^{2}+\alpha_{2}\left(\lambda_{1}^{2}+\lambda_{2}^{2}-2 \lambda_{3}^{2}\right)\right\} q_{1} q_{2} q_{3}^{2} \\
& -4 \lambda_{1} \lambda_{3}\left\{-3 \beta_{3} \lambda_{2}^{2}+\alpha_{2}\left(\lambda_{1}^{2}-2 \lambda_{2}^{2}+\lambda_{3}^{2}\right)\right\} q_{1} q_{2}^{2} q_{3} \\
& -4 \lambda_{2} \lambda_{3}\left\{-3 \beta_{3} \lambda_{1}^{2}+\alpha_{2}\left(-2 \lambda_{1}^{2}+\lambda_{2}^{2}+\lambda_{3}^{2}\right)\right\} q_{1}^{2} q_{2} q_{3}
\end{aligned}
$$

and the two invariants for this Hamiltonian are (5.10) and the 'universal' integral

$$
\mathcal{C}_{h_{6}}^{(3)}=\left[\lambda_{1}\left(p_{2} q_{3}-p_{3} q_{2}\right)+\lambda_{2}\left(p_{3} q_{1}-p_{1} q_{3}\right)+\lambda_{3}\left(p_{1} q_{2}-p_{2} q_{1}\right)\right]^{2} .
$$


Two representative cases would be:

- $\lambda_{1}=1, \lambda_{2}=0, \lambda_{3}=0$, which again provides the separability of the $q_{1}$ coordinate

$$
\mathcal{H}^{(3)}=\frac{1}{2}\left(p_{1}^{2}+p_{2}^{2}+p_{3}^{2}\right)+\delta_{1}\left(q_{1}^{2}+q_{2}^{2}+q_{3}^{2}\right)+\alpha_{2}\left(q_{2}^{2}+q_{3}^{2}\right)^{2}+\beta_{3} q_{1}^{4}
$$

that is also reflected in the invariant $\mathcal{I}^{(3)}=p_{1}^{2}+2\left(\delta_{1} q_{1}^{2}+\beta_{3} q_{1}^{4}\right)$. Moreover, the second invariant reads $\mathcal{C}_{h_{6}}^{(3)}=\left(p_{2} q_{3}-p_{3} q_{2}\right)^{2}$, which indicates the axial symmetry with respect to the coordinates $\left(q_{2}, q_{3}\right)$. This is the case (1) of Table 1 in [78].

- If we take $\lambda_{1}=\lambda_{2}=\lambda_{3}=1$ we get

$$
\begin{aligned}
\mathcal{H}^{(3)}= & \frac{1}{2}\left(p_{1}^{2}+p_{2}^{2}+p_{3}^{2}\right)+\delta_{1}\left(q_{1}^{2}+q_{2}^{2}+q_{3}^{2}\right) \\
& +2 \alpha_{2}\left(\left(q_{2}-q_{1}\right)^{4}+\left(q_{3}-q_{1}\right)^{4}+\left(q_{3}-q_{2}\right)^{4}\right)+\beta_{3}\left(q_{1}+q_{2}+q_{3}\right)^{4}
\end{aligned}
$$

which is just the 3D Chudnowski potential plus an additional quartic term (see [71, [179]). The specific integral is

$$
\mathcal{I}^{(3)}=\left(p_{1}+p_{2}+p_{3}\right)^{2}+2\left(q_{1}+q_{2}+q_{3}\right)^{2}\left(\delta_{1}+3 \beta_{3}\left(q_{1}+q_{2}+q_{3}\right)^{2}\right) .
$$

\subsubsection{Homogeneous sextic perturbations}

In the same way, the generic homogeneous sextic case is obtained by taking

$$
\phi=f\left(\mathcal{C}_{\overline{\mathcal{G}}_{-}}\right)+g\left(A_{-}\right)=\alpha_{3} \mathcal{C}_{\overline{\mathcal{G}}_{-}}+\beta_{5} A_{-}^{6}=\alpha_{3}\left(\sum_{i<j}^{N}\left(\lambda_{j} q_{i}-\lambda_{i} q_{j}\right)^{2}\right)^{3}+\beta_{5}\left(\sum_{i=1}^{N} \lambda_{i} q_{i}\right)^{6} .
$$

Let us also analyse the $2 \mathrm{D}$ and $3 \mathrm{D}$ cases.

\section{D examples}

The generic $2 \mathrm{D}$ integrable sextic perturbation reads

$$
\mathcal{H}^{(2)}=\frac{1}{2}\left(p_{1}^{2}+p_{2}^{2}\right)+\delta_{1}\left(q_{1}^{2}+q_{2}^{2}\right)+\alpha_{3}\left(\lambda_{2} q_{1}-\lambda_{1} q_{2}\right)^{6}+\beta_{5}\left(\lambda_{1} q_{1}+\lambda_{2} q_{2}\right)^{6} .
$$

- Once again, the separability in terms of the $\left(\lambda_{2} q_{1}-\lambda_{1} q_{2}\right)$ and $\left(\lambda_{1} q_{1}+\lambda_{2} q_{2}\right)$ coordinates with $\lambda_{1}^{2}+\lambda_{2}^{2}=1$ is straightforward. In particular, if $\lambda_{1}=1, \lambda_{2}=0$ we have

$$
\mathcal{H}^{(2)}=\frac{1}{2}\left(p_{1}^{2}+p_{2}^{2}\right)+\delta_{1}\left(q_{1}^{2}+q_{2}^{2}\right)+\beta_{5} q_{1}^{6}+\alpha_{3} q_{2}^{6}
$$


and the integral is $\mathcal{I}^{(2)}=p_{1}^{2}+2\left(\delta_{1} q_{1}^{2}+\beta_{5} q_{1}^{6}\right)$.

- The case $\lambda_{1}=\lambda_{2}=1$ with $\alpha_{2}=\beta_{5}=\frac{b}{2}$ gives the known coupled sextic oscillator (see [117, case (i) of Table 5.3.):

$$
\mathcal{H}^{(2)}=\frac{1}{2}\left(p_{1}^{2}+p_{2}^{2}\right)+\delta_{1}\left(q_{1}^{2}+q_{2}^{2}\right)+b\left(q_{1}^{6}+q_{2}^{6}+15 q_{1}^{2} q_{2}^{2}\left(q_{1}^{2}+q_{2}^{2}\right)\right)
$$

and we also recover from $(5.10)$ the right expression for the invariant:

$$
\mathcal{I}^{(2)}=\left(p_{1}+p_{2}\right)^{2}+2\left(q_{1}+q_{2}\right)^{2}\left(\delta_{1}+b\left(q_{1}+q_{2}\right)^{4}\right) .
$$

\section{$3 \mathrm{D}$ examples}

In 3D the most general integrable homogeneous sextic perturbation coming from (5.1) reads

$$
\begin{aligned}
\mathcal{H}^{(3)}= & \frac{1}{2}\left(p_{1}^{2}+p_{2}^{2}+p_{3}^{2}\right)+\delta_{1}\left(q_{1}^{2}+q_{2}^{2}+q_{3}^{2}\right)+\beta_{5}\left(\lambda_{1} q_{1}+\lambda_{2} q_{2}+\lambda_{3} q_{3}\right)^{6} \\
& +\alpha_{3}\left[\left(\lambda_{2} q_{1}-\lambda_{1} q_{2}\right)^{2}+\left(\lambda_{3} q_{1}-\lambda_{1} q_{3}\right)^{2}+\left(\lambda_{3} q_{2}-\lambda_{2} q_{3}\right)^{2}\right]^{3}
\end{aligned}
$$

which, by construction, commutes the corresponding (5.10) and the 'universal' integral 5.27). Similarly to the quartic oscillator case we can mention two particular cases:

- The choice $\lambda_{1}=1, \lambda_{2}=0, \lambda_{3}=0$, which gives

$$
\mathcal{H}^{(3)}=\frac{1}{2}\left(p_{1}^{2}+p_{2}^{2}+p_{3}^{2}\right)+\delta_{1}\left(q_{1}^{2}+q_{2}^{2}+q_{3}^{3}\right)+\alpha_{3}\left(q_{2}^{2}+q_{3}^{2}\right)^{3}+\beta_{5} q_{1}^{6}
$$

which is again separable in $q_{1}$ with associated invariant $\mathcal{I}^{(3)}=p_{1}^{2}+2\left(\delta_{1} q_{1}^{2}+\beta_{5} q_{1}^{6}\right)$ and axial symmetry in $\left(q_{2}, q_{3}\right)$ is also recovered.

- An the case $\lambda_{1}=\lambda_{2}=\lambda_{3}=1$ in 5.36,

$$
\begin{aligned}
\mathcal{H}^{(3)}= & \frac{1}{2}\left(p_{1}^{2}+p_{2}^{2}+p_{3}^{2}\right)+\delta_{1}\left(q_{1}^{2}+q_{2}^{2}+q_{3}^{2}\right) \\
& +8 \alpha_{3}\left(q_{1}^{2}+q_{2}^{2}+q_{3}^{2}-q_{2} q_{3}-q_{1} q_{2}-q_{1} q_{3}\right)^{3}+\beta_{5}\left(q_{1}+q_{2}+q_{3}\right)^{6}
\end{aligned}
$$

whose invariant reads

$$
\mathcal{I}^{(3)}=\left(p_{1}+p_{2}+p_{3}\right)^{2}+2\left(q_{1}+q_{2}+q_{3}\right)^{2}\left(\delta_{1}+3 \beta_{5}\left(q_{1}+q_{2}+q_{3}\right)^{4}\right) .
$$


In order to show the complexity of this kind of systems we expand (5.36).

$$
\begin{aligned}
& \mathcal{H}^{(3)}=\frac{1}{2}\left(p_{1}^{2}+p_{2}^{2}+p_{3}^{2}\right)+\delta_{1}\left(q_{1}^{2}+q_{2}^{2}+q_{3}^{2}\right) \\
& +\left(\beta_{5} \lambda_{1}^{6}+\alpha_{3}\left\{\lambda_{2}^{2}+\lambda_{3}^{2}\right\}^{3}\right) q_{1}^{6}+\left(\beta_{5} \lambda_{2}^{6}+\alpha_{3}\left\{\lambda_{1}^{2}+\lambda_{3}^{2}\right\}^{3}\right) q_{2}^{6}+\left(\beta_{5} \lambda_{3}^{6}+\alpha_{3}\left\{\lambda_{1}^{2}+\lambda_{2}^{2}\right\}^{3}\right) q_{3}^{6} \\
& -6 \lambda_{1} \lambda_{2}\left(-\beta_{5} \lambda_{1}^{4}+\alpha_{3}\left\{\lambda_{2}^{2}+\lambda_{3}^{2}\right\}^{2}\right) q_{1}^{5} q_{2}-6 \lambda_{1} \lambda_{2}\left(-\beta_{5} \lambda_{2}^{4}+\alpha_{3}\left\{\lambda_{1}^{2}+\lambda_{3}^{2}\right\}^{2}\right) q_{1} q_{2}^{5} \\
& -6 \lambda_{2} \lambda_{3}\left(-\beta_{5} \lambda_{2}^{4}+\alpha_{3}\left\{\lambda_{1}^{2}+\lambda_{2}^{2}\right\}^{2}\right) q_{2}^{5} q_{3}-6 \lambda_{2} \lambda_{3}\left(-\beta_{5} \lambda_{3}^{4}+\alpha_{3}\left\{\lambda_{1}^{2}+\lambda_{2}^{2}\right\}^{2}\right) q_{2} q_{3}^{5} \\
& -6 \lambda_{1} \lambda_{3}\left(-\beta_{5} \lambda_{3}^{4}+\alpha_{3}\left\{\lambda_{1}^{2}+\lambda_{2}^{2}\right\}^{2}\right) q_{1} q_{3}^{5}-6 \lambda_{1} \lambda_{3}\left(-\beta_{5} \lambda_{1}^{4}+\alpha_{3}\left\{\lambda_{2}^{2}+\lambda_{3}^{2}\right\}^{2}\right) q_{1}^{5} q_{3} \\
& +3\left(5 \beta_{5} \lambda_{1}^{4} \lambda_{2}^{2}+\alpha_{3}\left\{\lambda_{2}^{2}+\lambda_{3}^{2}\right\}\left[\lambda_{3}^{2}\left(\lambda_{2}^{2}+\lambda_{3}^{2}\right)+\lambda_{1}^{2}\left(5 \lambda_{2}^{2}+\lambda_{3}^{2}\right)\right]\right) q_{1}^{4} q_{2}^{2} \\
& +3\left(5 \beta_{5} \lambda_{1}^{2} \lambda_{2}^{4}+\alpha_{3}\left\{\lambda_{1}^{2}+\lambda_{3}^{2}\right\}\left[\lambda_{3}^{2}\left(\lambda_{2}^{2}+\lambda_{3}^{2}\right)+\lambda_{1}^{2}\left(5 \lambda_{2}^{2}+\lambda_{3}^{2}\right)\right]\right) q_{1}^{2} q_{2}^{4} \\
& +3\left(5 \beta_{5} \lambda_{2}^{2} \lambda_{3}^{4}+\alpha_{3}\left\{\lambda_{1}^{2}+\lambda_{2}^{2}\right\}\left[\lambda_{1}^{2}\left(\lambda_{2}^{2}+\lambda_{3}^{2}\right)+\lambda_{1}^{4}+5 \lambda_{2}^{2} \lambda_{3}^{2}\right]\right) q_{2}^{2} q_{3}^{4} \\
& +3\left(5 \beta_{5} \lambda_{2}^{4} \lambda_{3}^{2}+\alpha_{3}\left\{\lambda_{1}^{2}+\lambda_{3}^{2}\right\}\left[\lambda_{1}^{2}\left(\lambda_{2}^{2}+\lambda_{3}^{2}\right)+\lambda_{1}^{4}+5 \lambda_{2}^{2} \lambda_{3}^{2}\right]\right) q_{2}^{4} q_{3}^{2} \\
& +3\left(5 \beta_{5} \lambda_{1}^{2} \lambda_{3}^{4}+\alpha_{3}\left\{\lambda_{1}^{2}+\lambda_{2}^{2}\right\}\left[\lambda_{2}^{2}\left(\lambda_{2}^{2}+\lambda_{3}^{2}\right)+\lambda_{1}^{2}\left(\lambda_{2}^{2}+5 \lambda_{3}^{2}\right)\right]\right) q_{1}^{2} q_{3}^{4} \\
& +3\left(5 \beta_{5} \lambda_{1}^{4} \lambda_{3}^{2}+\alpha_{3}\left\{\lambda_{2}^{2}+\lambda_{3}^{2}\right\}\left[\lambda_{2}^{2}\left(\lambda_{2}^{2}+\lambda_{3}^{2}\right)+\lambda_{1}^{2}\left(\lambda_{2}^{2}+5 \lambda_{3}^{2}\right)\right]\right) q_{1}^{4} q_{3}^{2} \\
& -4 \lambda_{2} \lambda_{3}\left(-5 \beta_{5} \lambda_{2}^{2} \lambda_{3}^{2}+\alpha_{3}\left[3 \lambda_{1}^{4}+5 \lambda_{2} \lambda_{3}^{2}+3 \lambda_{1}^{2}\left\{\lambda_{2}^{2}+\lambda_{3}^{2}\right\}\right]\right) q_{2}^{3} q_{3}^{3} \\
& -4 \lambda_{1} \lambda_{3}\left(-5 \beta_{5} \lambda_{1}^{2} \lambda_{3}^{2}+\alpha_{3}\left[3 \lambda_{2}^{2}\left(\lambda_{2}^{2}+\lambda_{3}^{2}\right)+\lambda_{1}^{2}\left\{3 \lambda_{2}^{2}+5 \lambda_{3}^{2}\right\}\right]\right) q_{1}^{3} q_{3}^{3} \\
& -4 \lambda_{1} \lambda_{2}\left(-5 \beta_{5} \lambda_{1}^{2} \lambda_{2}^{2}+\alpha_{3}\left[3 \lambda_{3}^{2}\left(\lambda_{2}^{2}+\lambda_{3}^{2}\right)+\lambda_{1}^{2}\left\{5 \lambda_{2}^{2}+3 \lambda_{3}^{2}\right\}\right]\right) q_{1}^{3} q_{2}^{3} \\
& -6 \lambda_{1} \lambda_{2}\left(-5 \beta_{5} \lambda_{3}^{4}+\alpha_{3}\left\{\lambda_{1}^{2}+\lambda_{2}^{2}\right\}\left[\lambda_{1}^{2}+\lambda_{2}^{2}-4 \lambda_{3}^{2}\right]\right) q_{1} q_{2} q_{3}^{4} \\
& -6 \lambda_{1} \lambda_{3}\left(-5 \beta_{5} \lambda_{2}^{4}+\alpha_{3}\left\{\lambda_{1}^{2}+\lambda_{3}^{2}\right\}\left[\lambda_{1}^{2}-4 \lambda_{2}^{2}+\lambda_{3}^{2}\right]\right) q_{1} q_{2}^{4} q_{3} \\
& -6 \lambda_{2} \lambda_{3}\left(-5 \beta_{5} \lambda_{1}^{4}-\alpha_{3}\left\{\lambda_{2}^{2}+\lambda_{3}^{2}\right\}\left[4 \lambda_{1}^{2}-\lambda_{2}^{2}-\lambda_{3}^{2}\right]\right) q_{1}^{4} q_{2} q_{3} \\
& -12 \lambda_{1} \lambda_{3}\left(-5 \beta_{5} \lambda_{2}^{2} \lambda_{3}^{2}+\alpha_{3}\left[\lambda_{1}^{4}-2 \lambda_{2}^{4}+3 \lambda_{2}^{2} \lambda_{3}^{2}+\lambda_{1}^{2}\left\{-\lambda_{2}^{2}+\lambda_{3}^{2}\right\}\right]\right) q_{1} q_{2}^{2} q_{3}^{3} \\
& -12 \lambda_{1} \lambda_{2}\left(-5 \beta_{5} \lambda_{2}^{2} \lambda_{3}^{2}+\alpha_{3}\left[\lambda_{1}^{4}+3 \lambda_{2}^{2} \lambda_{3}^{2}-2 \lambda_{3}^{4}+\lambda_{1}^{2}\left\{\lambda_{2}^{2}-\lambda_{3}^{2}\right\}\right]\right) q_{1} q_{2}^{3} q_{3}^{2} \\
& -12 \lambda_{1} \lambda_{2}\left(-5 \beta_{5} \lambda_{1}^{2} \lambda_{3}^{2}+\alpha_{3}\left[\lambda_{2}^{4}-\lambda_{2}^{2} \lambda_{3}^{2}-2 \lambda_{3}^{4}+\lambda_{1}^{2}\left\{\lambda_{2}^{2}+3 \lambda_{3}^{2}\right\}\right]\right) q_{1}^{3} q_{2} q_{3}^{2} \\
& 12 \lambda_{2} \lambda_{3}\left(5 \beta_{5} \lambda_{1}^{2} \lambda_{3}^{2}+\alpha_{3}\left[2 \lambda_{2}^{4}+\lambda_{1}^{2}\left\{\lambda_{2}^{2}-3 \lambda_{3}^{2}\right\}-\lambda_{2}^{2}\left\{\lambda_{2}^{2}+\lambda_{3}^{2}\right\}\right]\right) q_{1}^{2} q_{2} q_{3}^{3} \\
& 12 \lambda_{2} \lambda_{3}\left(5 \beta_{5} \lambda_{1}^{2} \lambda_{2}^{2}+\alpha_{3}\left[2 \lambda_{1}^{4}+\lambda_{1}^{2}\left\{-3 \lambda_{2}^{2}+\lambda_{3}^{2}\right\}-\lambda_{3}^{2}\left\{\lambda_{2}^{2}+\lambda_{3}^{2}\right\}\right]\right) q_{1}^{2} q_{2}^{3} q_{3} \\
& -12 \lambda_{1} \lambda_{3}\left(-5 \beta_{5} \lambda_{1}^{2} \lambda_{2}^{2}+\alpha_{3}\left[-2 \lambda_{2}^{4}-\lambda_{2}^{2} \lambda_{3}^{2}+\lambda_{3}^{4}+\lambda_{1}^{2}\left\{3 \lambda_{2}^{2}+\lambda_{3}^{2}\right\}\right]\right) q_{1}^{3} q_{2}^{2} q_{3} \\
& +18\left(5 \beta_{5} \lambda_{1}^{2} \lambda_{2}^{2} \lambda_{3}^{2}+\alpha_{3}\left[\lambda_{1}^{2}\left\{\lambda_{2}^{2}-\lambda_{3}^{2}\right\}^{2}+\lambda_{1}^{4}\left\{\lambda_{2}^{2}+\lambda_{3}^{2}\right\}+\lambda_{2}^{2} \lambda_{3}^{2}\left\{\lambda_{2}^{2}+\lambda_{3}^{2}\right\}\right]\right) q_{1}^{2} q_{2}^{2} q_{3}^{2}
\end{aligned}
$$




\subsection{Another ND integrable perturbation}

The second main result of this Chapter is the following. Let

$$
\mathcal{V}_{-2}\left(A_{-}, B_{-}\right)=\mathcal{V}_{-2}\left(\sum_{i=1}^{N} \lambda_{i} q_{i}, \sum_{i=1}^{N} q_{i}^{2}\right)
$$

be a homogeneous function of degree -2 in the canonical coordinates. Then the ND Hamiltonian

$$
\begin{aligned}
\mathcal{H}_{r} & =\frac{1}{2} B_{+}+\delta_{1} B_{-}+\mathcal{V}_{-2}\left(A_{-}, B_{-}\right)+\mathcal{J}\left(B_{-}\right) \\
& =\frac{1}{2} \sum_{i=1}^{N} p_{i}^{2}+\delta_{1} \sum_{i=1}^{N} q_{i}^{2}+\mathcal{V}_{-2}\left(\sum_{i=1}^{N} \lambda_{i} q_{i}, \sum_{i=1}^{N} q_{i}^{2}\right)+\mathcal{J}\left(\sum_{i=1}^{N} q_{i}^{2}\right)
\end{aligned}
$$

where $\mathcal{J}$ is an arbitrary radial function and $\delta_{1}, \lambda_{i}(i=1, \ldots, N)$ are free parameters, is completely integrable.

The $(N-1)$ functionally independent integrals of the motion in involution with $\mathcal{H}_{r}$ are the $(N-2)$ 'universal' ones coming from the $h_{6}$-coalgebra symmetry (5.8) and the additional integral

$$
\mathcal{I}_{r}=B_{-} B_{+}-\left(K+\frac{1}{2} M\right)^{2}+2 B_{-} \mathcal{V}_{-2}\left(A_{-}, B_{-}\right)
$$

that written in terms of the canonical coordinates reads:

$$
\mathcal{I}_{r}^{(N)}=\sum_{1 \leq i<j}^{N}\left(q_{j} p_{i}-q_{i} p_{j}\right)^{2}+2\left(\sum_{i=1}^{N} q_{i}^{2}\right) \mathcal{V}_{-2}\left(\sum_{i=1}^{N} \lambda_{i} q_{i}, \sum_{i=1}^{N} q_{i}^{2}\right) .
$$

Again, the involutivity of $\mathcal{H}_{r}$ and $\mathcal{I}_{r}$ with respect to the integrals (5.5) is a direct consequence of the $h_{6}$-coalgebra symmetry of both functions and the bracket $\left\{\mathcal{H}_{r}, \mathcal{I}_{r}\right\}=$ 0 is easily proven by direct computation. Finally, the functional independence of $\mathcal{I}_{r}$ can be easily proven in the harmonic oscillator case $\mathcal{J}=\mathcal{V}_{-2}=0$ with $\lambda_{i}=\delta_{i}^{j}$ for a given $j$. Therefore, it follows for the generic case with arbitrary $\lambda_{i}$ and non-vanishing $\mathcal{J}$ and $\mathcal{V}_{-2}$ functions.

Note that in $N=3$ the Hamiltonian $(5.42)$ is a particular subclass of the Hamiltonians presented in [179]. This is due to the fact that in our construction we have imposed $\mathcal{V}_{-2}$ to be $h_{6}$-coalgebra invariant, which is an additional constraint with respect to [179], where the only condition imposed on $\mathcal{V}_{-2}$ was to be a homogeneous function of degree -2 in the $3 \mathrm{D}$ canonical coordinates. 


\subsubsection{A new ND integrable model}

If we take

$$
\mathcal{V}_{-2}\left(A_{-}, B_{-}\right)=\varepsilon \frac{A_{-}^{2}-B_{-}}{B_{-}\left(M B_{-}-A_{-}^{2}\right)}
$$

and $\forall i, \lambda_{i}=1$ we obtain the Hamiltonian

$$
\mathcal{H}_{r}^{(N)}=\frac{1}{2} \sum_{i=1}^{N} p_{i}^{2}+\delta_{1} \sum_{i=1}^{N} q_{i}^{2}+\varepsilon \frac{2 \sum_{1 \leq i<j}^{N} q_{i} q_{j}}{\left(\sum_{i=1}^{N} q_{i}^{2}\right)\left(\sum_{1 \leq i<j}^{N}\left(q_{i}-q_{j}\right)^{2}\right)}+\mathcal{J}\left(\sum_{i=1}^{N} q_{i}^{2}\right)
$$

in which the function $\mathcal{V}_{-2}\left(A_{-}, B_{-}\right)$gives rise a homogeneous function of degree -2 in the canonical coordinates. In the $N=2$ case (and with the radial perturbation $\mathcal{J}=0$ ) the quantum mechanical analogue of (5.46) has been studied in [76] as an exactly solvable 'generalization' of the 2D CM model. Therefore, presumably 5.46 provides a good candidate for a new exactly solvable model in arbitrary dimension, whose exact solvability should be indeed algebraically related with its underlying $h_{6}$ coalgebra symmetry. 
90 CHAPTER 5. INTEGRABLE PERTURBATIONS OF THE ND OSCILLATOR 


\title{
Chapter 6
}

\section{Propagating integrability from $2 \mathrm{D}$ to $\mathrm{ND}$}

\author{
"The good Christian should beware the mathematician \\ and all those who make empty prophecies. \\ The danger already exists that the mathematicians \\ have made a covenant with the devil \\ to darken the spirit and to confine man in the bonds of hell."
}

St. Augustine

The aim of this Chapter is to present yet another application of coalgebra symmetry in order to introduce a general procedure that allows the construction of a ND completely integrable system from any $2 \mathrm{D}$ integrable potential of the form $\mathcal{V}\left(x^{2}, y\right)$. We show that such potentials can be always defined as a precise $N=2$ symplectic realization of the direct-sum Poisson algebra $s l(2, \mathbb{R}) \oplus h_{6}$. This implies that by using the coalgebra approach in the $s l(2, \mathbb{R})$ sector we can straightforwardly obtain a $N$-dimensional integrable generalization of all these systems. This construction can be interpreted as the proper Poisson-algebraic generalization for the procedure given in [97, 98] for natural systems, and the application of this method to electromagnetic systems and geodesic flows would follow the same lines. Moreover, this coalgebra symmetry opens the possibility to introduce integrable deformations of all the systems presented in this Chapter by making use, for instance, of the $q$-Poisson $s l(2, \mathbb{R})$ algebra presented in Chapter 2.

As outstanding examples of this construction we shall generalize the three integrable cases of the 2D Hénon-Heiles Hamiltonian, originally introduced in order to model 
the dynamics of a star when orbiting around an axially symmetric galaxy (see for instance [38, 39, 86, 100, 102]). Also, the Ramani series of 2D integrable polynomial perturbations of the harmonic oscillator [154] will be considered. As a consequence, we will obtain ND generalizations of all these systems, and the coupling between different orders in the polynomial perturbations will be studied. Moreover, we will show that all these results can be generalized by preserving their complete integrability through the addition of $(N-1)$ centrifugal terms, and the $\operatorname{sl}(2, \mathbb{R}) \oplus h_{6}$ symmetry will also give us automatically the extra contributions in the integrals of the motion coming from them.

Finally, we will also show that this approach can be generalized to consider those 2D integrable Hamiltonians with potentials of the form $\mathcal{V}\left(x^{2}, y^{2}\right)$. In this case, the underlying Poisson algebra that allows the construction of the ND integrable generalization of such systems is just $\operatorname{sl}(2, \mathbb{R}) \oplus \operatorname{sl}(2, \mathbb{R})$. In this case our construction will allow the introduction of $N$ centrifugal terms, and two examples of this type of systems will be explicitly given.

\subsection{From 2D to ND through axial symmetry}

Let us firstly recall the key observation given in [97]. Let us consider any 2D integrable natural Hamiltonian system in the form

$$
\mathcal{H}^{(2)}=\frac{1}{2}\left(p_{x}^{2}+p_{y}^{2}\right)+\mathcal{V}(x, y)+\frac{\lambda}{x^{2}}
$$

i.e., we select those $2 \mathrm{D}$ integrable potentials $\mathcal{V}(x, y)$ that can be perturbed through a centrifugal term in at least one of the variables without destroying its integrability. In that case, it is clear that $\mathcal{H}^{(2)}$ can be interpreted as the radial reduction of the following axially symmetric 3D Hamiltonian

$$
\mathcal{H}^{(3)}=\frac{1}{2}\left(p_{x_{1}}^{2}+p_{x_{2}}^{2}+p_{y}^{2}\right)+\mathcal{V}\left(\sqrt{x_{1}^{2}+x_{2}^{2}}, y\right)
$$

through the change of variables $x=\sqrt{x_{1}{ }^{2}+x_{2}{ }^{2}}$. The centrifugal term $\lambda / x^{2}$ is then the usual kinetic energy term coming from the conserved angular momentum $\lambda$ on the $\left(x_{1}, x_{2}\right)$ plane. Therefore, the authors of [97] stated that the ND Hamiltonian

$$
\mathcal{H}^{(N)}=\frac{1}{2} \sum_{i=1}^{N-1} p_{x_{i}}^{2}+\frac{1}{2} p_{y}^{2}+\mathcal{V}\left(\sqrt{\sum_{i=1}^{N-1} x_{i}^{2}}, y\right)
$$

is a completely integrable one, and gave explicitly its $(N-1)$ integrals of the motion: one of them is the ND generalization of the $2 \mathrm{D}$ integral in involution with (6.1), and the 
remaining ones arise from the spherical symmetry in the $\left(x_{1}, x_{2}, \ldots, x_{N-1}\right)$ variables. Surprisingly enough, in [106, all the potentials that admit a centrifugal term of the type 6.1) are functions of $x^{2}$. This observation opens the path to the algebraic formulation of this construction in terms of Poisson coalgebras, that we shall describe in the sequel.

\subsection{Hamiltonian systems with $\operatorname{sl}(2, \mathbb{R}) \oplus h_{6}$ symmetry}

The essential algebraic object for our construction will be the 9-dimensional Poisson algebra $\operatorname{sl}(2, \mathbb{R}) \oplus h_{6}$, with generators $\left\{J_{+}, J_{-}, J_{3}, K, A_{+}, A_{-}, B_{+}, B_{-}, M\right\}$ and Poisson brackets given by

$$
\begin{array}{lll}
\left\{J_{3}, J_{+}\right\}=2 J_{+} & \left\{J_{3}, J_{-}\right\}=-2 J_{-} & \left\{J_{-}, J_{+}\right\}=4 J_{3} \\
\left\{K, A_{+}\right\}=A_{+} & \left\{K, A_{-}\right\}=-A_{-} & \left\{A_{-}, A_{+}\right\}=M \\
\left\{K, B_{+}\right\}=2 B_{+} & \left\{K, B_{-}\right\}=-2 B_{-} & \left\{B_{-}, B_{+}\right\}=4 K+2 M \\
\left\{A_{+}, B_{-}\right\}=-2 A_{-} & \left\{A_{+}, B_{+}\right\}=0 & \{M, \cdot\}=0 \\
\left\{A_{-}, B_{+}\right\}=2 A_{+} & \left\{A_{-}, B_{-}\right\}=0 . &
\end{array}
$$

(all the brackets between generators of $\operatorname{sl}(2, \mathbb{R})$ and $h_{6}$ vanish). Obviously, this Poisson algebra has three Casimir functions: the $s l(2, \mathbb{R})$ Casimir 2.27) and the two $h_{6}$ ones (4.3) and $M$.

Now we consider the following ND symplectic realization of $\operatorname{sl}(2, \mathbb{R}) \oplus h_{6}$, in which the first set of $(N-1)$ degrees of freedom is associated to $\operatorname{sl}(2, \mathbb{R})$, while the last one is just the usual one-particle $h_{6}$ realization with $\lambda=1$ :

$$
\begin{aligned}
& J_{+}=\sum_{i=1}^{N-1} p_{i}^{2} \quad J_{-}=\sum_{i=1}^{N-1} q_{i}^{2} \quad J_{3}=\sum_{i=1}^{N-1} q_{i} p_{i} \\
& A_{+}=p_{N} \quad A_{-}=q_{N} \quad K=q_{N} p_{N}-\frac{1}{2} \\
& B_{+}=p_{N}^{2} \quad B_{-}=q_{N}^{2} \quad M=1 .
\end{aligned}
$$

Note that we can say that this is the $(0,0, \ldots, 0) \oplus(1,0)$ symplectic realization of $\operatorname{sl}(2, \mathbb{R}) \oplus h_{6}$.

Now, it is straightforward to realize that any ND Hamiltonian constructed through the previous symplectic realization as

$$
\mathcal{H}^{(N)}=\mathcal{H}\left(J_{+}, J_{-}, J_{3}, K, B_{+}, B_{-}, A_{+}, A_{-}, M\right)
$$

is quasi-integrable, since the following $(N-2)$ functions

$$
\mathcal{C}^{(m)}=\sum_{1 \leq i<j}^{m}\left(q_{i} p_{j}-q_{j} p_{i}\right)^{2} \quad m=2, \ldots, N-1
$$


are constants of the motion for $\mathcal{H}$. In fact $(6.9)$ are just the $s l(2, \mathbb{R})$-coalgebra integrals for the $\operatorname{sl}(2, \mathbb{R})$-sector of the Hamiltonian, and any contribution coming from the last degree of freedom $\left(q_{N}, p_{N}\right)$ will obviously Poisson-commute with them.

Therefore, in case that for a certain choice of $\mathcal{H}$ we are able to find just one additional integral of the form

$$
\mathcal{I}=\mathcal{I}\left(J_{+}, J_{-}, J_{3}, K, B_{+}, B_{-}, A_{+}, A_{-}, M\right)
$$

and we realize it under the ND symplectic realization (6.6) and (6.7), the complete integrability of $\mathcal{H}^{(N)}$ will be obtained. Moreover, the coalgebra symmetry of the $\operatorname{sl}(2, \mathbb{R})$ sector of the Hamiltonian will imply that there does exist an additional set of $(N-2)$ integrals $\mathcal{C}_{(m)}$ 2.30, $b_{i}=0$ ), thus making $\mathcal{H}^{(N)}$ a (non-maximally) superintegrable system.

As we shall see in the following Section, suitable candidates for completely integrable $\mathcal{H}$ are obtained from certain known 2D integrable Hamiltonians, since the additional integral $\mathcal{I}$ can be proposed by working out the $s l(2, \mathbb{R}) \oplus h_{6}$ symmetry of the $2 \mathrm{D}$ system.

\subsection{Complete integrability}

Let us consider any integrable 2D Hamiltonian of the form

$$
\mathcal{H}^{(2)}=\frac{1}{2}\left(p_{x}^{2}+p_{y}^{2}\right)+\mathcal{V}\left(x^{2}, y\right)
$$

whose integral of the motion $\mathcal{I}^{(2)}$ can be written as a function of the form

$$
\mathcal{I}^{(2)}=\mathcal{I}^{(2)}\left(p_{x}^{2}, x^{2}, x p_{x}, y p_{y}, p_{y}^{2}, y^{2}, p_{y}, y\right) .
$$

Under these hypotheses it becomes clear that $\mathcal{H}^{(2)}$ is $\operatorname{sl}(2, \mathbb{R}) \oplus h_{6}$ symmetric, since it would be just the $N=2$ case of the generic Hamiltonian

$$
\mathcal{H}=\frac{1}{2}\left(J_{+}+B_{+}\right)+\mathcal{V}\left(J_{-}, A_{-}\right)
$$

in which we have identified $x \equiv q_{1}$ and $y \equiv q_{N}=q_{2}$. This is tantamount to say that we have assigned the $x$ degree of freedom with $\operatorname{sl}(2, \mathbb{R})$ (note that $\mathcal{H}^{(2)}$ depends on $x^{2}$ ) and $y$ corresponds to the degree of freedom associated to $h_{6}$.

Moreover, the integral $\mathcal{I}^{(2)}$ gives rise to a generic $\operatorname{sl}(2, \mathbb{R}) \oplus h_{6}$ integral through the substitution

$$
\mathcal{I}^{(2)}\left(p_{x}^{2}, x^{2}, x p_{x}, y p_{y}, p_{y}^{2}, y^{2}, p_{y}, y\right) \rightarrow \mathcal{I}\left(J_{+}, J_{-}, J_{3}, K, B_{+}, B_{-}, A_{+}, A_{-}\right)
$$


As we shall see in practical examples, the substitution 6.14 could be performed in different ways. As a rule, the most general one has to be considered, and afterwards one has to check that the object so obtained does Poisson commutes with (6.13) by using the algebra $(6.4)-(6.5)$. In this way the true 'abstract' $s l(2, \mathbb{R}) \oplus h_{6}$ integral is obtained, and its ND realization provides the remaining constant of the motion.

\subsection{ND Hénon-Heiles systems}

In this Section, by using the abovementioned symmetry we will construct the ND generalization of the three integrable cases among the family of 2D Hénon-Heiles Hamiltonians

$$
\mathcal{H}^{(2)}=\frac{1}{2}\left(p_{1}^{2}+p_{2}^{2}\right)+\delta q_{1}^{2}+(\delta+\Omega) q_{2}^{2}+\alpha\left(q_{1}^{2} q_{2}+\beta q_{2}^{3}\right) .
$$

It is well-known [2, 41, 68, 95, 104, 156] that the only integrable members of this class of Hamiltonians are given by the following choices of the parameters, where we will use the terminology of [121] and the results given in [84, 138]:

- The Sawada-Kotera case: $\beta=1 / 3$ and $\Omega=0$.

- The KdV case: $\beta=2$ and $\Omega$ arbitrary.

- The Kaup-Kuperschdmit case: $\beta=16 / 3$ and $\Omega=15 \delta$.

We recall that in the $\mathrm{KdV}$ case the integral of the motion is quadratic in the momenta, while in the Sawada-Kotera and Kaup-Kuperschdmit case is a quartic one. Nevertheless, the separability of the latter Hamiltonian has been shown through a very involved canonical transformation in [161].

\subsubsection{The Sawada-Kotera case}

The 2D Hamiltonian is

$$
\mathcal{H}^{(2)}=\frac{1}{2}\left(p_{1}^{2}+p_{2}^{2}\right)+\delta\left(q_{1}^{2}+q_{2}^{2}\right)+\alpha\left(q_{1}^{2} q_{2}+\frac{1}{3} q_{2}^{3}\right)
$$

If we consider the $N=2$ realization $(6.6)$ and 6.7$)$ of the algebra $\operatorname{sl}(2, \mathbb{R}) \oplus h_{6}$ we can write:

$$
\mathcal{H}=\frac{1}{2}\left(J_{+}+B_{+}\right)+\delta\left(J_{-}+A_{-}^{2}\right)+\alpha\left(J_{-} A_{-}+\frac{1}{3} A_{-}^{3}\right) .
$$


On the other hand, the integral of the motion for 6.16 is given by [117]

$$
\begin{aligned}
\mathcal{I}^{(2)}= & -\frac{1}{4}\left(p_{1}^{4}+p_{2}^{4}\right)-\left(p_{1}^{2}+p_{2}^{2}\right)\left(\delta q_{1}^{2}+\delta q_{2}^{2}\right)-\delta^{2}\left(q_{1}^{4}+q_{2}^{4}\right) \\
& -\alpha q_{1}^{2} q_{2}\left(p_{1}^{2}+p_{2}^{2}\right)-\alpha \frac{1}{3} q_{2}^{3}\left(p_{1}^{2}+p_{2}^{2}\right)-\alpha \delta \frac{2}{3} q_{2}^{3}\left(q_{1}^{2}+q_{2}^{2}\right)-\alpha \delta \frac{4}{3} q_{1}^{4} q_{2} \\
& +\alpha^{2} \frac{1}{9}\left(\frac{1}{2} q_{1}^{6}-q_{2}^{6}\right)-\alpha^{2} q_{1}^{2} q_{2}^{2}\left(\frac{2}{3} q_{1}^{2}+\frac{1}{6} q_{2}^{2}\right)+2 \delta p_{1} p_{2} q_{1} q_{2} \\
& +\alpha p_{1} p_{2} q_{1}\left(\frac{1}{3} q_{1}^{2}+q_{2}^{2}\right)
\end{aligned}
$$

which can also be written in terms of the coalgebra generators as

$$
\begin{aligned}
\mathcal{I}= & -2 \alpha A_{-} J_{3}^{2}-3 \delta A_{+}^{2} A_{-}^{2}-\alpha A_{+}^{2} A_{-}^{3}-3 \delta^{2} A_{-}^{4}-2 \alpha \delta A_{-}^{5}-\frac{\alpha^{2}}{3} A_{-}^{6} \\
& -3 \delta A_{+}^{2} J_{-}-3 \alpha A_{+}^{2} A_{-} J_{-}-2 \alpha \delta A_{-}^{3} J_{-}-\frac{\alpha^{2}}{2} A_{-}^{4} J_{-} \\
& -3 \delta^{2} J_{-}^{2}-4 \alpha \delta A_{-} J_{-}^{2}-2 \alpha^{2} A_{-}^{2} J_{-}^{2}+\frac{\alpha^{2}}{6} J_{-}^{3} \\
& +6 \delta A_{+} A_{-} J_{3}+3 \alpha A_{+} A_{-}^{2} J_{3}+\alpha A_{+} J_{-} J_{3} \\
& -J_{+}\left(A_{-}^{2}+J_{-}\right)\left(3 \delta+\alpha A_{-}\right)-\frac{3}{4} J_{+}^{2}-\frac{3}{4} A_{+}^{4} .
\end{aligned}
$$

By making use of the Poisson algebra (6.4) and (6.5), a straightforward computation shows that 6.17$)$ and $(6.19)$ are in involution, and this will be true for any symplectic realization of the $\operatorname{sl}(2, \mathbb{R}) \oplus h_{6}$ Poisson algebra that we could consider. Therefore, we take 6.17) as the algebraic definition of the Sawada-Kotera Hamiltonian, and the specialization of (6.17) and 6.19) through the symplectic realization 6.6. 6 -6.7 will provide the explicit form of the ND generalization of this Hamiltonian.

Let us explicitly write the 3D and ND systems:

- The 3D case. By taking $N=3$ in 6.6 - 6.7 and, afterwards, by substituting these expressions into 6.17)-6.19) we get:

$$
\mathcal{H}^{(3)}=\frac{1}{2}\left(p_{1}^{2}+p_{2}^{2}+p_{3}^{2}\right)+\delta\left(q_{1}^{2}+q_{2}^{2}+q_{3}^{2}\right)+\alpha q_{3}\left(q_{1}^{2}+q_{2}^{2}\right)+\alpha \frac{1}{3} q_{3}^{3} .
$$

Note that (and this is a general fact in the formalism here presented) that we are obtaining a 'radial' generalization of the Sawada-Kotera potential in the $\left(q_{1}, q_{2}\right)$ subspace.

- The ND case. The same construction leads to the Hamiltonian

$$
\mathcal{H}^{(N)}=\sum_{i=1}^{N} \frac{1}{2} p_{i}^{2}+\delta \sum_{i=1}^{N} q_{i}^{2}+\alpha\left(q_{N} \sum_{i=1}^{N-1} q_{i}^{2}+\frac{1}{3} q_{N}^{3}\right)
$$


and to the following integral of the motion coming from 6.19 is now

$$
\begin{aligned}
\mathcal{I}^{(N)}= & -2 \alpha q_{N}\left(\sum_{i=1}^{N-1} p_{i} q_{i}\right)^{2}-p_{N}^{2} q_{N}^{2}\left(3 \delta+\alpha q_{N}\right)-q_{N}^{4}\left(3 \delta^{2}+2 \alpha \delta q_{N}\right) \\
& -\frac{\alpha^{2}}{3} q_{N}^{6}-3 \delta p_{N}^{2}\left(\sum_{i=1}^{N-1} q_{i}^{2}\right)-3 \alpha p_{N}^{2} q_{N}\left(\sum_{i=1}^{N-1} q_{i}^{2}\right) \\
& -2 \alpha \delta q_{N}^{3}\left(\sum_{i=1}^{N-1} q_{i}^{2}\right)-\frac{\alpha^{2}}{2} q_{N}^{4}\left(\sum_{i=1}^{N-1} q_{i}^{2}\right)-3 \delta^{2}\left(\sum_{i=1}^{N-1} q_{i}^{2}\right)^{2} \\
& -4 \alpha \delta q_{N}\left(\sum_{i=1}^{N-1} q_{i}^{2}\right)^{2}-2 \alpha^{2} q_{N}^{2}\left(\sum_{i=1}^{N-1} q_{i}^{2}\right)^{2}+\frac{\alpha^{2}}{6}\left(\sum_{i=1}^{N-1} q_{i}^{2}\right)^{3} \\
& -\left(\sum_{i=1}^{N-1} p_{i}^{2}\right)\left(3 \delta+\alpha q_{N}\right)\left[q_{N}^{2}+\left(\sum_{i=1}^{N-1} q_{i}^{2}\right)\right]-\frac{3}{4}\left(\sum_{i=1}^{N-1} p_{i}^{2}\right)^{2}-\frac{3}{4} p_{N}^{4} .
\end{aligned}
$$

\subsubsection{The KdV case}

In this case the Hénon-Heiles Hamiltonian is given by

$$
\mathcal{H}^{(2)}=\frac{1}{2}\left(p_{1}^{2}+p_{2}^{2}\right)+\delta q_{1}^{2}+(\delta+\Omega) q_{2}^{2}+\alpha\left(q_{1}^{2} q_{2}+2 q_{2}^{3}\right)
$$

and its integral of the motion is given by 117

$$
\mathcal{I}^{(2)}=p_{1}^{2}\left(\frac{3}{2} \delta-\frac{\Omega}{2}-\alpha q_{2}\right)+\alpha p_{2} p_{1} q_{1}+3 \delta^{2} q_{1}^{2}+\frac{\alpha^{2}}{4} q_{1}^{4}+2 \alpha \delta q_{2} q_{1}^{2}+\alpha^{2} q_{2}^{2} q_{1}^{2}-\delta \Omega q_{1}^{2}
$$

This system can be writen in a $s l(2) \otimes h_{6}$ invariant form as

$$
\mathcal{H}=\frac{1}{2}\left(J_{+}+B_{+}\right)+\delta\left(J_{-}+A_{-}^{2}\right)+\Omega A_{-}^{2}+\alpha\left(J_{-} A_{-}+2 A_{-}^{3}\right)
$$

together with the following integral of the motion

$$
\mathcal{I}=J_{+}\left(\frac{3}{2} \delta-\frac{\Omega}{2}-\alpha A_{-}\right)+\alpha J_{3} A_{+}+3 \delta^{2} J_{-}+\frac{\alpha^{2}}{4} J_{-}^{2}+2 \alpha \delta J_{-} A_{-}+\alpha^{2} J_{-} A_{-}^{2}-\delta \Omega J_{-}
$$

whose involutivity with respect to 6.25 is easily shown by using the abstract Poisson brackets for this algebra. 
Now, the symplectic realization 6.6 - 6.7 provides the expression for the ND system $(N \geq 2)$ :

$$
\mathcal{H}^{(N)}=\sum_{i=1}^{N-1}\left(\frac{p_{i}^{2}}{2}+\delta q_{i}^{2}\right)+\left(\frac{p_{N}^{2}}{2}+(\delta+\Omega) q_{N}^{2}\right)+\alpha\left(q_{N} \sum_{i=1}^{N-1} q_{i}^{2}+2 q_{N}^{3}\right)
$$

and the integral of the motion reads

$$
\begin{aligned}
\mathcal{I}^{(N)}= & \left(\sum_{i=1}^{N-1} p_{i}^{2}\right)\left(\frac{3}{2} \delta-\frac{\Omega}{2}-\alpha q_{N}\right)+\alpha p_{N} \sum_{i=1}^{N-1} p_{i} q_{i}+3 \delta^{2}\left(\sum_{i=1}^{N-1} q_{i}^{2}\right)+\frac{\alpha^{2}}{4}\left(\sum_{i=1}^{N-1} q_{i}^{2}\right)^{2} \\
& +2 \alpha \delta q_{N}\left(\sum_{i=1}^{N-1} q_{i}^{2}\right)+\alpha^{2} q_{N}^{2}\left(\sum_{i=1}^{N-1} q_{i}^{2}\right)-\delta \Omega\left(\sum_{i=1}^{N-1} q_{i}^{2}\right) .
\end{aligned}
$$

This, together with the coalgebra integrals $(6.9)$, prove the complete integrability of the system.

\subsubsection{The Kaup-Kuperschdmit case}

Finally, we consider the 2D Hamiltonian

$$
\mathcal{H}^{(2)}=\frac{1}{2}\left(p_{1}^{2}+p_{2}^{2}\right)+\delta q_{1}^{2}+16 \delta q_{2}^{2}+\alpha\left(q_{1}^{2} q_{2}+\frac{16}{3} q_{2}^{3}\right)
$$

whose invariant reads [117]

$$
\begin{aligned}
\mathcal{I}^{(2)}= & -\frac{3}{4} p_{1}^{4}-3 \delta p_{1}^{2} q_{1}^{2}+\alpha p_{1} p_{2} q_{1}^{3}-3 \delta^{2} q_{1}^{4}+\frac{\alpha^{2}}{6} q_{1}^{6}-3 \alpha p_{1}^{2} q_{1}^{2} q_{2} \\
& +2 \alpha \delta q_{1}^{4} q_{2}+\alpha^{2} q_{1}^{4} q_{2}^{2} .
\end{aligned}
$$

The very same procedure gives us the $\operatorname{sl}(2, \mathbb{R}) \oplus h_{6}$ invariant object:

$$
\mathcal{H}=\frac{1}{2}\left(J_{+}+B_{+}\right)+\delta\left(J_{-}+16 A_{-}^{2}\right)+\alpha\left(J_{-} A_{-}+\frac{16}{3} A_{-}^{3}\right)
$$

together with

$$
\begin{aligned}
\mathcal{I}= & -J_{+}\left(\frac{3}{4} J_{+}+3 \delta J_{-}+\alpha A_{-} J_{-}\right)+J_{-}^{2}\left(-3 \delta^{2}+2 \alpha \delta A_{-}+\alpha^{2} A_{-}^{2}\right) \\
& +\frac{\alpha^{2}}{6} J_{-}^{3}+\alpha J_{3}\left(A_{+} J_{-}-2 \alpha A_{-} J_{3}\right) .
\end{aligned}
$$


Starting from the latter expressions, the ND generalization of the KaupKuperschdmit Hamiltonian reads $(N \geq 2)$

$$
\begin{aligned}
\mathcal{H}^{(N)}= & \frac{1}{2} \sum_{i=1}^{N} p_{i}^{2}+\delta \sum_{i=1}^{N-1} q_{i}^{2}+16 \delta q_{N}^{2}+\left(\alpha q_{N} \sum_{i=1}^{N-1} q_{i}^{2}+\frac{16 \alpha}{3} q_{N}^{3}\right) \\
\mathcal{I}^{(N)}= & -\left(\sum_{i=1}^{N-1} p_{i}^{2}\right)\left\{\frac{3}{4} \sum_{i=1}^{N-1} p_{i}^{2}+3 \delta \sum_{i=1}^{N-1} q_{i}^{2}+\alpha q_{N} \sum_{i=1}^{N-1} q_{i}^{2}\right\} \\
+ & \left(\sum_{i=1}^{N-1} q_{i}^{2}\right)^{2}\left\{-3 \delta^{2}+2 \alpha \delta q_{N}+\alpha^{2} q_{N}^{2}\right\}+\frac{\alpha^{2}}{6}\left(\sum_{i=1}^{N-1} q_{i}^{2}\right)^{3} \\
+ & \alpha\left(\sum_{i=1}^{N-1} p_{i} q_{i}\right)\left\{p_{N} \sum_{i=1}^{N-1} q_{i}^{2}-2 q_{N} \sum_{i=1}^{N-1} p_{i} q_{i}\right\}
\end{aligned}
$$

\subsection{ND Ramani potentials}

An interesting family of examples is given by any of the Ramani potentials $\mathcal{V}_{M}\left(x^{2}, y\right)$, which are homogeneous polynomial potentials with degree $M$ and given by [106, 154]

$$
\mathcal{V}_{M}(x, y)=\sum_{k=0}^{\left[\frac{M}{2}\right]} 2^{M-2 k}\left(\begin{array}{c}
M-k \\
k
\end{array}\right) x^{2 k} y^{M-2 k}
$$

The first ones are

$$
\begin{aligned}
& \mathcal{V}_{1}=2 y \\
& \mathcal{V}_{2}=4 y^{2}+x^{2} \\
& \mathcal{V}_{3}=8 y^{3}+4 x^{2} y \\
& \mathcal{V}_{4}=16 y^{4}+12 x^{2} y^{2}+x^{4} \\
& \mathcal{V}_{5}=32 y^{5}+32 x^{2} y^{3}+6 x^{4} y \\
& \mathcal{V}_{6}=64 y^{6}+80 x^{2} y^{4}+24 x^{4} y^{2}+x^{6}
\end{aligned}
$$

Note that $\mathcal{V}_{2}$ is just the 2D harmonic oscillator with frequency ratio $1: 4$ and $\mathcal{V}_{3}$ is proportional to the KdV Hénon-Heiles potential. In fact, if we write the $\mathcal{V}_{M}$ Ramani Hamiltonian as

$$
\mathcal{H}^{(2)}=\frac{1}{2}\left(p_{1}^{2}+p_{2}^{2}\right)+\mathcal{V}_{M}\left(q_{1}^{2}, q_{2}\right)=\frac{1}{2}\left(p_{1}^{2}+p_{2}^{2}\right)+\sum_{k=0}^{\left[\frac{M}{2}\right]} 2^{M-2 k}\left(\begin{array}{c}
M-k \\
k
\end{array}\right) q_{1}^{2 k} q_{2}^{M-2 k}
$$


its integral of the motion (for $M \geq 2$ ) is given by [106]

$$
\mathcal{I}^{(2)}=-q_{2} p_{1}^{2}+q_{1} p_{1} p_{2}+q_{1}^{2} \mathcal{V}_{M-1}
$$

and for $M=1$ the Hamiltonian is directly separable in the $(x, y)$ coordinates. Moreover, it is well known all these potentials can be superposed freely without destroying their integrability (see [106]). In particular, it can be proven that the Hamiltonian with (non homogeneous) polynomial potential of degree $R$ given by

$$
\mathcal{H}_{R}^{(2)}=\frac{1}{2}\left(p_{1}^{2}+p_{2}^{2}\right)+\sum_{i=2}^{R} \alpha_{i} \mathcal{V}_{i}\left(q_{1}^{2}, q_{2}\right)
$$

with $\alpha_{i}$ being arbitrary constants, Poisson-commutes with

$$
\mathcal{I}_{R}^{(2)}=-q_{2} p_{1}^{2}+q_{1} p_{1} p_{2}+q_{1}^{2} \sum_{i=2}^{R} \alpha_{i} \mathcal{V}_{i-1}\left(q_{1}^{2}, q_{2}\right)
$$

The Hamiltonian $\mathcal{H}_{R}(6.44)$ can be immediately written in terms of $s l(2, \mathbb{R}) \oplus h_{6}$ as follows:

$$
\mathcal{H}_{R}=\frac{1}{2}\left(J_{+}+B_{+}\right)+\sum_{i=2}^{R} \sum_{k=0}^{\left[\frac{i}{2}\right]} \alpha_{i} 2^{i-2 k}\left(\begin{array}{c}
i-k \\
k
\end{array}\right) J_{-}^{k} A_{-}^{i-2 k} .
$$

and in terms of the algebra generators we will have the following integral

$$
\mathcal{I}_{R}=-A_{-} J_{+}+J_{3} A_{+}+J_{-} \sum_{i=2}^{R} \sum_{k=0}^{\left[\frac{i-1}{2}\right]} \alpha_{i} 2^{i-1-2 k}\left(\begin{array}{c}
i-1-k \\
k
\end{array}\right) J_{-}^{k} A_{-}^{i-1-2 k}
$$

whose Poisson involutivity with respect to 6.46 can be proven by direct computation.

Therefore, the ND generalization of the Ramani Hamiltonian will be given by taking the corresponding ND symplectic realization of (6.46), which reads

$$
\mathcal{H}_{R}^{(N)}=\frac{1}{2} \sum_{i=1}^{N} p_{i}^{2}+\sum_{i=2}^{R} \sum_{k=0}^{\left[\frac{i}{2}\right]} \alpha_{i} 2^{i-2 k}\left(\begin{array}{c}
i-k \\
k
\end{array}\right)\left(\sum_{j=1}^{N-1} q_{j}^{2}\right)^{k} q_{N}^{i-2 k} .
$$

This is indeed a new completely integrable system, since it commutes by construction with the $(N-2)$ integrals $(6.9)$ and with the ND realization of (6.47), namely

$$
\begin{aligned}
& \mathcal{I}_{R}^{(N)}=-q_{N}\left(\sum_{i=1}^{N-1} p_{i}^{2}\right)+p_{N}\left(\sum_{i=1}^{N-1} p_{i} q_{i}\right) \\
& +\left(\sum_{l=1}^{N-1} q_{l}^{2}\right)\left(\sum_{i=2}^{R} \sum_{k=0}^{\left[\frac{i-1}{2}\right]} \alpha_{i} 2^{i-1-2 k}\left(\begin{array}{c}
i-1-k \\
k
\end{array}\right)\left(\sum_{j=1}^{N-1} q_{j}^{2}\right)^{k} q_{N}^{i-1-2 k}\right) .
\end{aligned}
$$




\subsubsection{The ND Ramani Hamiltonian $\mathcal{H}_{6}$}

In order to illustrate the previous result, we shall consider in the sequel the $R=6$ case, that can be considered as an integrable sextic deformation of the KdV Hénon-Heiles system. In this case the initial 2D Ramani system (6.44) will be given by

$$
\begin{aligned}
\mathcal{H}_{6}^{(2)}= & \frac{1}{2}\left(p_{1}^{2}+p_{2}^{2}\right)+\alpha_{2}\left(q_{1}^{2}+4 q_{2}^{2}\right)+\alpha_{3}\left(4 q_{1}^{2} q_{2}+8 q_{2}^{3}\right) \\
& +\alpha_{4}\left(q_{1}^{4}+12 q_{1}^{2} q_{2}^{2}+16 q_{2}^{4}\right)+\alpha_{5}\left(6 q_{1}^{4} q_{2}+32 q_{1}^{2} q_{2}^{3}+32 q_{2}^{5}\right) \\
& +\alpha_{6}\left(q_{1}^{6}+24 q_{1}^{4} q_{2}^{2}+80 q_{1}^{2} q_{2}^{4}+64 q_{2}^{6}\right)
\end{aligned}
$$

and its invariant 6.45 is

$$
\begin{aligned}
\mathcal{I}^{(2)}= & p_{2} p_{1} q_{1}-q_{2}\left(p_{1}^{2}-2 \alpha_{2} q_{1}^{2}\right)+\alpha_{3} q_{1}^{4}+4 \alpha_{3} q_{1}^{2} q_{2}^{2}+4 \alpha_{4} q_{1}^{4} q_{2}+8 \alpha_{4} q_{1}^{2} q_{2}^{3} \\
& +\alpha_{5} q_{1}^{6}+12 \alpha_{5} q_{1}^{4} q_{2}^{2}+16 \alpha_{5} q_{1}^{2} q_{2}^{4}+6 \alpha_{6} q_{1}^{6} q_{2}+32 \alpha_{6} q_{1}^{4} q_{2}^{3}+32 \alpha_{6} q_{1}^{2} q_{2}^{5} .
\end{aligned}
$$

A straightforward computation shows that the corresponding algebraic expressions in terms of the $\operatorname{sl}(2, \mathbb{R}) \oplus h_{6}$ Poisson algebra generators read

$$
\begin{aligned}
\mathcal{H}_{6}= & \frac{1}{2}\left(J_{+}+B_{+}\right)+\alpha_{2}\left(J_{-}+4 A_{-}^{2}\right)+4 \alpha_{3}\left(J_{-} A_{-}+2 A_{-}^{3}\right) \\
& +\alpha_{4}\left(J_{-}^{2}+12 J_{-} A_{-}^{2}+16 A_{-}^{4}\right)+\alpha_{5}\left(6 J_{-}^{2} A_{-}+32 J_{-} A_{-}^{3}+32 A_{-}^{5}\right) \\
& +\alpha_{6}\left(J_{-}^{3}+24 J_{-}^{2} A_{-}^{2}+80 J_{-} A_{-}^{4}+64 A_{-}^{6}\right) \\
\mathcal{I}_{6}= & A_{+} J_{3}-A_{-} J_{+}+2 \alpha_{2} A_{-} J_{-}+\alpha_{3} J_{-}^{2}+4 \alpha_{3} J_{-} A_{-}^{2}+4 \alpha_{4} J_{-}^{2} A_{-} \\
& +8 \alpha_{4} J_{-} A_{-}^{3}+\alpha_{5} J_{-}^{3}+12 \alpha_{5} J_{-}^{2} A_{-}^{2}+16 \alpha_{5} J_{-} A_{-}^{4} \\
& +6 \alpha_{6} J_{-}^{3} A_{-}+32 \alpha_{6} J_{-}^{2} A_{-}^{3}+32 \alpha_{6} J_{-} A_{-}^{5} .
\end{aligned}
$$

By using these expressions it is immediate to write the $3 \mathrm{D}$ generalization of this system as

$$
\begin{aligned}
\mathcal{H}_{6}^{(3)}= & \frac{1}{2}\left(p_{1}^{2}+p_{2}^{2}+p_{3}^{2}\right)+\alpha_{2}\left(q_{1}^{2}+q_{2}^{2}+4 q_{3}^{2}\right) \\
& +4 \alpha_{3}\left(q_{3}\left(q_{1}^{2}+q_{2}^{2}\right)+2 q_{3}^{3}\right)+\alpha_{4}\left(q_{1}^{4}+2 q_{1}^{2} q_{2}^{2}+q_{2}^{4}+12 q_{1}^{2} q_{3}^{2}+12 q_{2}^{2} q_{3}^{2}+16 q_{3}^{4}\right) \\
& +\alpha_{5}\left(6 q_{1}^{4} q_{3}+12 q_{1}^{2} q_{2}^{2} q_{3}+6 q_{2}^{4} q_{3}+32 q_{1}^{2} q_{3}^{3}+32 q_{2}^{2} q_{3}^{3}+32 q_{3}^{5}\right) \\
& +\alpha_{6}\left(q_{1}^{6}+3 q_{1}^{4} q_{2}^{2}+3 q_{1}^{2} q_{2}^{4}+q_{2}^{6}+48 q_{1}^{2} q_{2}^{2} q_{3}^{2}+24 q_{2}^{4} q_{3}^{2}+24 q_{1}^{2} q_{3}^{2}\right) \\
& +\alpha_{6}\left(80 q_{1}^{2} q_{3}^{4}+80 q_{2}^{2} q_{3}^{4}+64 q_{3}^{6}\right)
\end{aligned}
$$




$$
\begin{aligned}
\mathcal{I}_{6}^{(3)}= & p_{3}\left(p_{1} q_{1}+p_{2} q_{2}\right)-q_{3}\left(p_{1}^{2}-2 \alpha_{2} q_{1}^{2}+p_{2}^{2}-2 \alpha_{2} q_{2}^{2}\right) \\
& +\alpha_{3}\left(q_{1}^{4}+q_{2}^{4}\right)+2 \alpha_{3} q_{1}^{2} q_{2}^{2}+4 \alpha_{3} q_{3}\left(q_{1}^{2}+q_{2}^{2}\right)+4 \alpha_{4} q_{3}\left(q_{1}^{4}+q_{2}^{4}\right) \\
& +8 \alpha_{4} q_{3}^{3}\left(q_{1}^{2}+q_{2}^{2}\right)+8 \alpha_{4} q_{1}^{2} q_{2}^{2} q_{3}+\alpha_{5}\left(q_{1}^{6}+q_{2}^{6}\right)+3 \alpha_{5} q_{1}^{4} q_{2}^{2}+3 \alpha_{5} q_{1}^{2} q_{2}^{4} \\
& +12 \alpha_{5} q_{3}^{2}\left(q_{1}^{4}+q_{2}^{4}\right)+16 \alpha_{5} q_{3}^{4}\left(q_{1}^{2}+q_{2}^{2}\right)+24 \alpha_{5} q_{1}^{2} q_{2}^{2} q_{3}^{2}+64 \alpha_{6} q_{1}^{2} q_{2}^{2} q_{3}^{3} \\
& +6 \alpha_{6} q_{3}\left(q_{1}^{6}+q_{2}^{6}\right)+18 \alpha_{6} q_{3}\left(q_{1}^{2} q_{2}^{4}+q_{1}^{4} q_{2}^{2}\right)+32 \alpha_{6} q_{3}^{3}\left(q_{1}^{4}+q_{2}^{4}\right) \\
& +32 \alpha_{6} q_{3}^{5}\left(q_{1}^{2}+q_{2}^{2}\right) .
\end{aligned}
$$

And the ND case would be

$$
\begin{aligned}
\mathcal{H}_{6}^{(N)}= & \frac{1}{2} \sum_{i=1}^{N} p_{i}^{2}+\alpha_{2}\left(\sum_{i=1}^{N-1} q_{i}^{2}+4 q_{N}^{2}\right)+4 \alpha_{3}\left(q_{N} \sum_{i=1}^{N-1} q_{i}^{2}+2 q_{N}^{3}\right) \\
& +\alpha_{4}\left(\left\{\sum_{i=1}^{N-1} q_{i}^{2}\right\}^{2}+12 q_{N}^{2} \sum_{i=1}^{N-1} q_{i}^{2}+16 q_{N}^{4}\right) \\
& +\alpha_{5}\left(6 q_{N}\left\{\sum_{i=1}^{N-1} q_{i}^{2}\right\}^{2}+32 q_{N}^{3} \sum_{i=1}^{N-1} q_{i}^{2}+32 q_{N}^{5}\right)^{2} \\
& +\alpha_{6}\left(\left\{\sum_{i=1}^{N-1} q_{i}^{2}\right\}^{3}+24 q_{N}^{2}\left\{\sum_{i=1}^{N-1} q_{i}^{2}\right\}^{2}+80 q_{N}^{4} \sum_{i=1}^{N-1} q_{i}^{2}+64 q_{N}^{6}\right)(6.56) \\
\mathcal{I}_{6}^{(N)}= & p_{N} \sum_{i=1}^{N-1} p_{i} q_{i}-q_{N} \sum_{i=1}^{N-1} p_{i}^{2}+2 \alpha_{2} q_{N} \sum_{i=1}^{N-1} q_{i}^{2}+\alpha_{3}\left(\sum_{i=1}^{N-1} q_{i}^{2}\right)^{2}+4 \alpha_{3} q_{N}^{2}\left(\sum_{i=1}^{N-1} q_{i}^{2}\right)^{2} \\
+ & 4 \alpha_{4} q_{N}\left(\sum_{i=1}^{N-1} q_{i}^{2}\right)^{2}+8 \alpha_{4} q_{N}^{3}\left(\sum_{i=1}^{N-1} q_{i}^{2}\right)^{2}+\alpha_{5}\left(\sum_{i=1}^{N-1} q_{i}^{2}\right)^{3}+12 \alpha_{5} q_{N}^{2}\left(\sum_{i=1}^{N-1} q_{i}^{2}\right)^{2} \\
+ & +16 \alpha_{5} q_{N}^{4}\left(\sum_{i=1}^{N-1} q_{i}^{2}\right)^{N-1}+6 \alpha_{6} q_{N}\left(\sum_{i=1}^{N} q_{i}^{2}\right)^{2}+32 \alpha_{6} q_{N}^{3}\left(\sum_{i=1}^{N-1} q_{i}^{2}\right)^{2} \\
+ & +32 \alpha_{6} q_{N}^{5}\left(\sum_{i=1}^{N-1} q_{i}^{2}\right) .
\end{aligned}
$$

As a conclusion, we can appreciate from the examples here shown that the $\operatorname{sl}(2, \mathbb{R}) \oplus$ $h_{6}$ symmetry allows for a systematic and straightforward construction of new integrable ND Hamiltonians starting from known 2D ones. 


\subsection{Adding centrifugal terms}

The previous construction in which a given 2D integrable Hamiltonian is written as a function of the generators of the Poisson algebra $s l(2, \mathbb{R}) \oplus h_{6}$ has also an interesting byproduct: the possibility of adding centrifugal terms to the corresponding ND Hamiltonian without breaking the integrability.

This can be achieved by considering the following ND symplectic realization of $s l(2, \mathbb{R}) \oplus h_{6}$ :

$$
\begin{aligned}
& J_{+}=\sum_{i=1}^{N-1}\left(p_{i}^{2}+\frac{b_{i}}{q_{i}^{2}}\right) \quad J_{-}=\sum_{i=1}^{N-1} q_{i}^{2} \quad J_{3}=\sum_{i=1}^{N-1} q_{i} p_{i} \\
& A_{+}=p_{N} \quad A_{-}=q_{N} \quad K=q_{N} p_{N}-\frac{1}{2} \\
& B_{+}=p_{N}^{2} \quad B_{-}=q_{N}^{2} \quad M=1 .
\end{aligned}
$$

This would be the $\left(b_{1}, b_{2}, \ldots, b_{N-1}\right) \oplus(1,0)$ symplectic realization of $s l(2, \mathbb{R}) \oplus h_{6}$, and its only difference with respect to (6.6) and 6.7) is the addition of $(N-1)$ centrifugal terms in the realization of the $J_{+}$generator.

We know that when these terms are included, the constants of the motion 6.9 coming from the $s l(2, \mathbb{R})$-sector of the Hamiltonian are converted into

$$
\mathcal{C}^{(m)}=\sum_{1 \leq i<j}^{m}\left(q_{i} p_{j}-q_{j} p_{i}\right)^{2}+\sum_{1 \leq i<j}^{m}\left(b_{i} \frac{q_{j}^{2}}{q_{i}^{2}}+b_{j} \frac{q_{i}^{2}}{q_{j}^{2}}\right) \quad m=2, \ldots, N-1 .
$$

But it is essential to stress that any $\operatorname{sl}(2, \mathbb{R}) \oplus h_{6}$ Hamiltonian, when written in terms of the symplectic realization 6.58)-6.59) will Poisson-commute with all the integrals 6.60 . And the same will happens to the additional integral $\mathcal{I}$, that will be modified only through the centrifugal terms coming from the $J_{+}$generator.

This elementary discussion shows that all the ND Hamiltonians with potentials of the type $\mathcal{V}\left(J_{-}, A_{-}\right)$so far introduced in this Chapter can be supplemented with $(N-1)$ centrifugal terms and giving rise to 'generalized' Hamiltonians in the form

$$
\mathcal{H}_{b}^{(N)}=\frac{1}{2} \sum_{i=1}^{N-1}\left(p_{i}^{2}+\frac{b_{i}}{q_{i}^{2}}\right)+\frac{1}{2} p_{N}^{2}+\mathcal{V}\left(\sum_{i=1}^{N-1} q_{i}^{2}, q_{N}\right)
$$

and whose full set of integrals of the motion for $\mathcal{H}_{b}$ can be obtained as a consequence of their $\operatorname{sl}(2, \mathbb{R}) \oplus h_{6}$ symmetry. Let us make this statement more explicit through two particular examples. 


\section{The generalized ND Sawada-Kotera Hamiltonian}

If we consider the symplectic realization (6.58)- (6.59), the ND Sawada-Kotera Hamiltonian $(6.16)$ is generalized as

$$
\mathcal{H}_{b}^{(N)}=\frac{1}{2} \sum_{i=1}^{N-1}\left(p_{i}^{2}+\frac{b_{i}}{q_{i}^{2}}\right)+\frac{1}{2} p_{N}^{2}+\delta \sum_{i=1}^{N} q_{i}^{2}+\alpha\left(q_{N} \sum_{i=1}^{N-1} q_{i}^{2}+\frac{1}{3} q_{N}^{3}\right)
$$

and the integral of the motion coming from 6.19 now reads

$$
\begin{aligned}
& \mathcal{I}^{(N)}=-2 \alpha q_{N}\left(\sum_{i=1}^{N-1} p_{i} q_{i}\right)^{2}-p_{N}^{2} q_{N}^{2}\left(3 \delta+\alpha q_{N}\right)-q_{N}^{4}\left(3 \delta^{2}+2 \alpha \delta q_{N}\right) \\
& -\frac{\alpha^{2}}{3} q_{N}^{6}-3 \delta p_{N}^{2}\left(\sum_{i=1}^{N-1} q_{i}^{2}\right)-3 \alpha p_{N}^{2} q_{N}\left(\sum_{i=1}^{N-1} q_{i}^{2}\right) \\
& -2 \alpha \delta q_{N}^{3}\left(\sum_{i=1}^{N-1} q_{i}^{2}\right)-\frac{\alpha^{2}}{2} q_{N}^{4}\left(\sum_{i=1}^{N-1} q_{i}^{2}\right)-3 \delta^{2}\left(\sum_{i=1}^{N-1} q_{i}^{2}\right)^{2} \\
& -4 \alpha \delta q_{N}\left(\sum_{i=1}^{N-1} q_{i}^{2}\right)^{2}-2 \alpha^{2} q_{N}^{2}\left(\sum_{i=1}^{N-1} q_{i}^{2}\right)^{2}+\frac{\alpha^{2}}{6}\left(\sum_{i=1}^{N-1} q_{i}^{2}\right)^{3} \\
& -\left[\sum_{i=1}^{N-1}\left(p_{i}^{2}+\frac{b_{i}}{q_{i}^{2}}\right)\left(3 \delta+\alpha q_{N}\right)\right]\left[q_{N}^{2}+\left(\sum_{i=1}^{N-1} q_{i}^{2}\right)\right] \\
& -\frac{3}{4}\left[\sum_{i=1}^{N-1}\left(p_{i}^{2}+\frac{b_{i}}{q_{i}^{2}}\right)\left(3 \delta+\alpha q_{N}\right)\right]^{2}-\frac{3}{4} p_{N}^{4} \text {. }
\end{aligned}
$$

The fact that both quantities are in involution can be straightforwardly checked.

\section{The generalized ND Ramani Hamiltonian}

Just in the same way, the Hamiltonian (6.46) is written in the $\left(b_{1}, b_{2}, \ldots, b_{N-1}\right) \oplus(1,0)$ symplectic realization as

$$
\mathcal{H}_{R}^{(N)}=\frac{1}{2} \sum_{i=1}^{N-1}\left(p_{i}^{2}+\frac{b_{i}}{q_{i}^{2}}\right)+\frac{1}{2} p_{N}^{2}+\sum_{i=2}^{R} \sum_{k=0}^{\left[\frac{i}{2}\right]} \alpha_{i} 2^{i-2 k}\left(\begin{array}{c}
i-k \\
k
\end{array}\right)\left(\sum_{j=1}^{N-1} q_{j}^{2}\right)^{k} q_{N}^{i-2 k}
$$


and the integral of the motion that incorporates the contributions coming from the centrifugal terms arises by taking the same symplectic realization of (6.47), namely

$$
\begin{aligned}
\mathcal{I}_{R}^{(N)} & =-q_{N} \sum_{i=1}^{N-1}\left(p_{i}^{2}+\frac{b_{i}}{q_{i}^{2}}\right)+p_{N}\left(\sum_{i=1}^{N-1} p_{i} q_{i}\right) \\
& +\left(\sum_{l=1}^{N-1} q_{l}^{2}\right)\left(\sum_{i=2}^{R} \sum_{k=0}^{\left[\frac{i-1}{2}\right]} \alpha_{i} 2^{i-1-2 k}\left(\begin{array}{c}
i-1-k \\
k
\end{array}\right)\left(\sum_{j=1}^{N-1} q_{j}^{2}\right)^{k} q_{N}^{i-1-2 k}\right) .
\end{aligned}
$$

The same procedure can be systematically performed onto any Hamiltonian of the type 6.13) and its corresponding integral (6.14).

\subsection{The $\operatorname{sl}(2, \mathbb{R}) \oplus \operatorname{sl}(2, \mathbb{R})$ construction}

It seems also natural to wonder whether a 2D integrable Hamiltonian of the form

$$
\mathcal{H}^{(2)}=\frac{1}{2}\left(p_{x}^{2}+p_{y}^{2}\right)+\mathcal{V}\left(x^{2}, y^{2}\right)
$$

could have any additional interesting feature from the point of view of its generalization to $N$ dimensions. This is strongly motivated by the observation that, as described in in [106], the 2D integrable potentials that admit two centrifugal terms without altering the integrability are just functions of the type $\mathcal{V}\left(x^{2}, y^{2}\right)$.

The answer to this question is affirmative, and a similar coalgebra scheme based on the $\operatorname{sl}(2, \mathbb{R}) \oplus s l(2, \mathbb{R})$ Poisson algebra can be introduced. This algebra is given by the following non-vanishing brackets

$$
\begin{array}{llc}
\left\{J_{3}, J_{+}\right\}=2 J_{+} & \left\{J_{3}, J_{-}\right\}=-2 J_{-} & \left\{J_{-}, J_{+}\right\}=4 J_{3} \\
\left\{K_{3}, K_{+}\right\}=2 K_{+} & \left\{K_{3}, K_{-}\right\}=-2 K_{-} & \left\{K_{-}, K_{+}\right\}=4 K_{3}
\end{array}
$$

and a possible ND symplectic realization for this Poisson algebra is

$$
\begin{aligned}
J_{+}=\sum_{i=1}^{M} p_{i}^{2} & J_{-}=\sum_{i=1}^{M} q_{i}^{2} & J_{3} & =\sum_{i=1}^{M} q_{i} p_{i} \\
K_{+}=\sum_{i=M+1}^{N} p_{i}^{2} & K_{-}=\sum_{i=M+1}^{N} q_{i}^{2} & K_{3} & =\sum_{i=M+1}^{N} q_{i} p_{i} .
\end{aligned}
$$


Obviously, the Hamiltonian (6.66) is just the $M=1, N=2$ symplectic realization for the abstract $\operatorname{sl}(2, \mathbb{R}) \oplus \operatorname{sl}(2, \mathbb{R})$ object

$$
\mathcal{H}=\frac{1}{2}\left(J_{+}+B_{+}\right)+\mathcal{V}\left(J_{-}, K_{-}\right)
$$

and if the integral of the motion $\mathcal{I}^{(2)}$ for 6.66 can be written as a function

$$
\mathcal{I}^{(2)}=\mathcal{I}^{(2)}\left(p_{x}^{2}, x^{2}, x p_{x}, p_{y}^{2}, y^{2}, y p_{y}\right)
$$

this integral can be also written in abstract algebraic terms as

$$
\mathcal{I}=\mathcal{I}\left(J_{+}, J_{-}, J_{3}, K_{+}, K_{-}, K_{3}\right)
$$

From this viewpoint, the ND generalization of the Hamiltonian (6.66) will be given by the ND symplectic realization of (6.68) and (6.69):

$$
\mathcal{H}^{(N)}=\frac{1}{2}\left(\sum_{i=1}^{M} p_{i}^{2}+\sum_{i=M+1}^{N} p_{i}^{2}\right)+\mathcal{V}\left(\sum_{i=1}^{M} q_{i}^{2}, \sum_{i=M+1}^{N} q_{i}^{2}\right) .
$$

The complete integrability of this Hamiltonian is guaranteed by the existence of the following functionally independent integrals: the ND symplectic realization of the 'abstract' integral $\mathcal{I}$

$$
\mathcal{I}^{(N)}=\mathcal{I}\left(\sum_{i=1}^{M} p_{i}^{2}, \sum_{i=1}^{M} q_{i}^{2}, \sum_{i=1}^{M} q_{i} p_{i}, \sum_{i=M+1}^{N} p_{i}^{2}, \sum_{i=M+1}^{N} q_{i}^{2}, \sum_{i=M+1}^{N} q_{i} p_{i}\right),
$$

the $(M-1)$ integrals coming from the first $\operatorname{sl}(2, \mathbb{R})$ sector

$$
\mathcal{C}_{b}^{(m)}=\sum_{1 \leq i<j}^{m}\left(q_{i} p_{j}-q_{j} p_{i}\right)^{2} \quad m=2, \ldots, M
$$

and another set of $(N-M-1)$ integrals coming from the second $s l(2, \mathbb{R})$ sector

$$
\mathcal{D}_{b}^{(k)}=\sum_{M+1 \leq i<j}^{M+k}\left(q_{i} p_{j}-q_{j} p_{i}\right)^{2} \quad k=2, \ldots, N-M .
$$

Finally, it is immediate to realize that centrifugal terms can be also included in this case by making use of the same 'abstract' Hamiltonian 6.79 , but now under the 
$\left(b_{1}, b_{2}, \ldots, b_{M}\right) \oplus\left(b_{M+1}, b_{M+2}, \ldots, b_{N}\right)$ symplectic realization

$$
\begin{array}{lll}
J_{+}=\sum_{i=1}^{M}\left(p_{i}^{2}+\frac{b_{i}}{q_{i}^{2}}\right) & J_{-}=\sum_{i=1}^{M} q_{i}^{2} & J_{3}=\sum_{i=1}^{M} q_{i} p_{i} \\
K_{+}=\sum_{i=M+1}^{N}\left(p_{i}^{2}+\frac{b_{i}}{q_{i}^{2}}\right) & K_{-}=\sum_{i=M+1}^{N} q_{i}^{2} & K_{3}=\sum_{i=M+1}^{N} q_{i} p_{i}
\end{array}
$$

This gives rise to the ND Hamiltonian

$$
\mathcal{H}_{b}^{(N)}=\frac{1}{2} \sum_{i=1}^{M}\left(p_{i}^{2}+\frac{b_{i}}{q_{i}^{2}}\right)+\frac{1}{2} \sum_{i=M+1}^{N}\left(p_{i}^{2}+\frac{b_{i}}{q_{i}^{2}}\right)+\mathcal{V}\left(\sum_{i=1}^{M} q_{i}^{2}, \sum_{i=M+1}^{N} q_{i}^{2}\right)
$$

that will Poisson-commute with the ND integral given by

$$
\mathcal{I}_{b}^{(N)}=\mathcal{I}\left(\sum_{i=1}^{M}\left(p_{i}^{2}+\frac{b_{i}}{q_{i}^{2}}\right), \sum_{i=1}^{M} q_{i}^{2}, \sum_{i=1}^{M} q_{i} p_{i}, \sum_{i=M+1}^{N}\left(p_{i}^{2}+\frac{b_{i}}{q_{i}^{2}}\right), \sum_{i=M+1}^{N} q_{i}^{2}, \sum_{i=M+1}^{N} q_{i} p_{i}\right)
$$

together with the integrals

$$
\begin{aligned}
& \mathcal{C}_{b}^{(m)}=\sum_{1 \leq i<j}^{m}\left\{\left(q_{i} p_{j}-q_{j} p_{i}\right)^{2}+\left(b_{i} \frac{q_{j}^{2}}{q_{i}^{2}}+b_{j} \frac{q_{i}^{2}}{q_{j}^{2}}\right)\right\} \quad m=2, \ldots, M \\
& \mathcal{D}_{b}^{(k)}=\sum_{M+1 \leq i<j}^{M+k}\left\{\left(q_{i} p_{j}-q_{j} p_{i}\right)^{2}+\left(b_{i} \frac{q_{j}^{2}}{q_{i}^{2}}+b_{j} \frac{q_{i}^{2}}{q_{j}^{2}}\right)\right\} \quad k=2, \ldots, N-M .
\end{aligned}
$$

\subsubsection{ND nonlinear oscillators with quartic coupling}

As an example of this construction we consider the anharmonic coupled 2D oscillator considered as the system VI in [97]:

$$
\mathcal{H}^{(2)}=\frac{1}{2}\left(p_{1}^{2}+p_{2}^{2}\right)+\left(q_{1}^{4}+6 q_{1}^{2} q_{2}^{2}+8 q_{2}^{4}\right)+a\left(q_{1}^{2}+4 q_{2}^{2}\right)+\frac{\lambda}{q_{1}^{2}}+\frac{\mu}{q_{2}^{2}}
$$

together with its $2 \mathrm{D}$ integral of the motion

$$
\begin{aligned}
\mathcal{I}^{(2)}= & p_{1}^{4}+4 p_{1}^{2}\left(q_{1}^{4}+6 q_{1}^{2} q_{2}^{2}+a q_{1}^{2}+\frac{\lambda}{q_{1}^{2}}\right)-16 q_{1}^{3} p_{1} q_{2} p_{2}+4 q_{1}^{4} p_{2}^{2} \\
& +4 q_{1}^{4}\left[q_{1}^{4}+4 q_{1}^{2} q_{2}^{2}+4 q_{2}^{4}+2 a\left(q_{1}^{2}+2 q_{2}^{2}\right)+a^{2}\right]+\frac{8 \mu q_{1}^{4}}{q_{2}^{2}} \\
& +8 \lambda\left(q_{1}^{2}+2 q_{2}^{2}\right)+\frac{4 \lambda^{2}}{q_{1}^{4}} .
\end{aligned}
$$


Now, by considering the $(0) \oplus(0)$ symplectic realization of $\operatorname{sl}(2, \mathbb{R}) \oplus \operatorname{sl}(2, \mathbb{R})$, we can write the previous expressions in the algebraic form

$$
\begin{aligned}
\mathcal{H}_{b}= & \frac{1}{2}\left(J_{+}+K_{+}\right)+\left(J_{-}^{2}+6 J_{-} K_{-}+8 K_{-}^{2}\right) \\
& +a\left(J_{-}+4 K_{-}\right)+\frac{\lambda}{J_{-}}+\frac{\mu}{K_{-}}
\end{aligned}
$$

and

$$
\begin{aligned}
\mathcal{I}= & J_{+}^{2}+J_{+}\left(\frac{4 \lambda}{J_{-}}+3 a J_{-}+4 J_{-}^{2}+8 J_{-} K_{-}\right)+4 K_{+} J_{-}^{2} \\
& +\frac{4 \lambda^{2}}{J_{-}^{2}}+8 \lambda J_{-}+4 a^{2} J_{-}^{2}+8 a J_{-}^{3}+4 J_{-}^{4}+a J_{3}^{2} \\
& +\frac{8 \mu J_{-}^{2}}{K_{-}}+16 \lambda K_{-}+16 J_{-}^{2} K_{-}\left(a+J_{-}+K_{-}^{2}\right) \\
& +16 J_{3}\left(J_{3} K_{-}-J_{-} K_{3}\right) .
\end{aligned}
$$

A direct computation show that both functions are in involution with respect to the Poisson bracket 6.67).

The ND integrable generalization of $(6.83)$, including all the possible centrifugal terms, is obtained by substituting in (6.85) and 6.86) the $\left(b_{1}, b_{2}, \ldots, b_{M}\right) \oplus$ $\left(b_{M+1}, b_{M+2}, \ldots, b_{N}\right)$ symplectic realization. The resulting Hamiltonian is

$$
\begin{aligned}
\mathcal{H}_{b}^{(N)}= & \frac{1}{2} \sum_{i=1}^{M}\left(p_{i}^{2}+\frac{b_{i}}{q_{i}^{2}}\right)+\frac{1}{2} \sum_{i=M+1}^{N}\left(p_{i}^{2}+\frac{b_{i}}{q_{i}^{2}}\right) \\
& +\left(\sum_{i=1}^{M} q_{i}^{2}\right)^{2}+6\left(\sum_{i=1}^{M} q_{i}^{2}\right)\left(\sum_{i=M+1}^{N} q_{i}^{2}\right)+8\left(\sum_{i=M+1}^{N} q_{i}^{2}\right)^{2} \\
& +a\left(\sum_{i=1}^{M} q_{i}^{2}+4 \sum_{i=M+1}^{N} q_{i}^{2}\right)+\frac{\lambda}{\left(\sum_{i=1}^{M} q_{i}^{2}\right)}+\frac{\mu}{\left(\sum_{i=M+1}^{N} q_{i}^{2}\right)} .
\end{aligned}
$$

The integrals of the motion for $\mathcal{H}_{b}^{(N)}$ are just the sets 6.81) and 6.82), together with the ND additional one in which the centrifugal terms are non-trivially intertwined within the integral 6.86): 


$$
\begin{aligned}
& \mathcal{I}_{b}^{(N)}=\left(\sum_{i=1}^{M}\left(p_{i}^{2}+\frac{b_{i}}{q_{i}^{2}}\right)\right)^{2} \\
& +\left(\frac{4 \lambda}{\sum_{i=1}^{M} q_{i}^{2}}+3 a \sum_{i=1}^{M} q_{i}^{2}+4\left(\sum_{i=1}^{M} q_{i}^{2}\right)^{2}+8\left(\sum_{i=1}^{M} q_{i}^{2}\right)\left(\sum_{i=M+1}^{N} q_{i}^{2}\right)\right) \sum_{i=1}^{M}\left(p_{i}^{2}+\frac{b_{i}}{q_{i}^{2}}\right) \\
& +4\left(\sum_{i=M+1}^{N} p_{i}^{2}+\frac{b_{i}}{q_{i}^{2}}\right)\left(\sum_{i=1}^{M} q_{i}^{2}\right)^{2}+\frac{4 \lambda^{2}}{\left(\sum_{i=1}^{M} q_{i}^{2}\right)^{2}}+8 \lambda \sum_{i=1}^{M} q_{i}^{2}+4 a^{2}\left(\sum_{i=1}^{M} q_{i}^{2}\right)^{2} \\
& +8 a\left(\sum_{i=1}^{M} q_{i}^{2}\right)^{3}+4\left(\sum_{i=1}^{M} q_{i}^{2}\right)^{4}+a\left(\sum_{i=1}^{M} q_{i} p_{i}\right)^{2}+\frac{8 \mu\left(\sum_{i=1}^{M} q_{i}^{2}\right)^{2}}{\sum_{i=M+1}^{N} q_{i}^{2}}+16 \lambda \sum_{i=M+1}^{N} q_{i}^{2} \\
& +16\left(\sum_{i=1}^{M} q_{i}^{2}\right)^{2}\left(\sum_{i=M+1}^{N} q_{i}^{2}\right)\left(a+\left(\sum_{i=1}^{M} q_{i}^{2}\right)+\left(\sum_{i=M+1}^{N} q_{i}^{2}\right)^{2}\right) \\
& +16\left(\sum_{i=1}^{M} q_{i} p_{i}\right)\left(\left(\sum_{i=1}^{M} q_{i} p_{i}\right)\left(\sum_{i=M+1}^{N} q_{i}^{2}\right)-\left(\sum_{i=1}^{M} q_{i}^{2}\right)\left(\sum_{i=M+1}^{N} q_{i} p_{i}\right)\right) \text {. }
\end{aligned}
$$

Certainly, this expression would be really difficult to find without the aid of the underlying coalgebra symmetry. The very same procedure can be applied to obtain the ND integrable generalization (with and without centrifugal terms) of the System VII in [97. 


\section{Chapter 7}

\section{Conclusions and open problems}

"All truths are easy to understand once they are discovered the point is to discover them."

G. Galilei

The main original results and conclusions of the work here presented can be summarized as follows:

- We have introduced a necessary condition for the generic symplectic realization of a given Poisson algebra in order to provide the integrability of the ND Hamiltonian systems that can be obtained from it through the coalgebra formalism.

- We have worked out explicitly the generic symplectic realizations for different real Lie-Poisson coalgebras with dimension 3, 4, 5 and 6 , and we have introduced an infinite family of algebras for which the integrability criterion holds. In all these cases the corresponding integrable ND Hamiltonians have been presented, together with their explicit integrals of the motion.

- We have shown that the generic ND Hamiltonians defined through a one-particle symplectic realization of the two-photon coalgebra $h_{6}$ are quasi-integrable systems, since an extra integral that does not come from the coalgebra has to be found in order to achieve complete integrability.

- By using different algebraic techniques, we have identified several infinite families of two-photon Hamiltonians for which such remaining integral does exist, and we have found it explicitly. Among these systems we have found new families of ND natural systems, electromagnetic Hamiltonians and geodesic flows defining ND spaces with non-constant curvature. 
- As particular examples of these integrable $h_{6}$ systems, we have found two new families of nonlinear integrable perturbations of the ND isotropic oscillator. The first one is a family of integrable perturbations depending on $N$ parameters and two arbitrary functions including as particular cases several known quartic and sextic coupled nonlinear oscillators. The second family includes homogeneous functions with degree -2 in the coordinates and a radial arbitrary function. As a concrete example of this type we have proposed a new type of integrable ND generalized Calogero-Moser model.

- Finally, we have shown that the ND generalization of many known 2D integrable Hamiltonians can be achieved by making use of the direct sum of certain coalgebras. In particular, we have proven that any 2D integrable potential of the type $\mathcal{V}\left(x^{2}, y\right)$ can be generalized to ND by preserving its complete integrability, and a similar result is obtained for potentials of the type $\mathcal{V}\left(x^{2}, y^{2}\right)$. Moreover, centrifugal terms can be added onto the ND systems and as outstanding examples of this construction we have presented the ND generalized versions of the three integrable Hénon-Heiles systems, as well as of the Ramani series of potentials and we have obtained new ND systems of coupled nonlinear oscillators.

\section{Open problems}

Finally, in the sequel we will propose several open questions that, to our opinion, would deserve further investigation in the near future.

- In general, the integrability conditions presented in Chapter 2 can be generalized to the case in which symplectic realizations with different dimension $s$ are used on each copy of the symmetry algebra, and this possibility would lead to different Hamiltonians.

- Another open possibility is the search for higher dimensional coalgebras that could give rise to new integrable Hamiltonian systems under appropriate symplectic realizations.

- Certainly, it would be also interesting to perform a detailed analysis of some of the new Hamiltonians here presented, working out explicitly the solutions for the equations of motion. We recall that the latter problem can be faced through the cluster variables technique [19] that makes use of the coalgebra symmetry in order to define the appropriate collective dynamical variables.

- In this direction, we would like to mention that the electromagnetic systems and the geodesic flows here presented will be the subject of further investigations. Also, the generalized Calogero-Moser model introduced in Chapter 5 seems to deserve some attention. 
- For most of the Hamiltonians here presented there exists two different sets of integrals of the motion which are quadratic in the momenta. This fact raises the question concerning the separability of all these systems in (two) different coordinate systems. This separability problem would be also related to the explicit solvability of these Hamiltonians.

- It is clear that many other ND Hamiltonian systems can be written as a function of the generators of $h_{6}$. In that case the $(N-2)$ 'universal' integrals (5.8) do exist by construction, and the only task in order to solve the complete integrability problem is to find the additional constant $\mathcal{I}$, in case it exists. A systematic search for this type of systems is worth to be continued.

- It is also well known that the existence of a given coalgebra symmetry for $\mathcal{H}$ allows for the direct construction of integrable deformations of $\mathcal{H}$ through the use of $q$-deformations of the underlying Poisson coalgebra. In the case of $h_{6}$, quantum twophoton/Schrödinger algebras have been constructed [10, 11] and its Poisson versions could be used to provide integrable deformations of some of the systems here presented.

- Another interesting possibility would be the construction of the analogues on ND spaces with constant curvature of the Euclidean Hamiltonians here presented. This could be feasible by using the $s l(2, \mathbb{R})$ approach [24, 26, 29] but now applying the corresponding $h_{6}$-coalgebra symmetry.

- Finally, it is clear that the study of the Quantum Mechanical analogue of some of the new ND integrable systems here presented should be interesting. 


\section{Chapter 8}

\section{Supplements}

"Mathematics, rightly viewed, possesses not only truth, but supreme beauty - a beauty cold and austere, like that of sculpture."

B. Russell

\subsection{Lie and Poisson algebras}

In this supplement, we collect the basic definitions concerning Lie and Poisson algebras. We refer the reader to $[8,59,74,88,94,149,163,172$ for a much deeper presentation.

- Lie algebra. A Lie algebra $A$ is a vector space $\mathcal{V}$ over $\mathbb{C}$ endowed with a bilinear application [, ] named Lie bracket.

$$
[,]: A \times A \rightarrow A
$$

The Lie bracket must satisfy:

1. Antisimmetry

$$
[X, Y]=-[Y, X] \quad \forall X, Y \in A
$$

2. Bilinearity

$$
\begin{gathered}
{[\alpha X+\beta Y, Z]=\alpha[X, Z]+\beta[Y, Z]} \\
{[Z, \alpha X+\beta Y]=\alpha[Z, X]+\beta[Z, Y]} \\
\forall \alpha, \beta, \gamma \in \mathbb{C} \quad \forall X, Y, Z \in A
\end{gathered}
$$




\section{Jacobi Identity}

$$
[X,[Y, Z]]+[Y,[Z, X]]+[Z,[X, Y]]=0 \quad \forall X, Y, Z \in A .
$$

- Lie subalgebra. Let $A^{\prime}$ be a subspace of $A$ as a vector space. Then, if

$$
[P, R] \in A^{\prime} \quad \forall P, R \in A^{\prime}
$$

then $A^{\prime}$ is said to be a Lie subalgebra of $A$.

- Lie-algebra isomorphism. Let $A_{1}$ and $A_{2}$ be two Lie algebras defined over the same field $\mathcal{K}$ and let $\phi$ be a linear invertible mapping between $A_{1}$ and $A_{2}$.

Then if,

$$
\phi\left([X, Y]_{A_{1}}\right)=[\phi(X), \phi(Y)]_{A_{2}} \quad X, Y \in A_{1}
$$

we say $A_{1}$ and $A_{2}$ are isomorphic.

- Ideal. Let $A$ be a Lie algebra and $B$ a subalgebra of $A$, if

$$
[B, A] \subseteq B
$$

then $B$ is said to be an ideal of $A$.

- Structure constants. Let $A$ be a Lie algebra over $\mathbb{C}$, and let $\left\{e_{i}\right\}$ be a basis of $A$. Then any element of $A$ can be written as

$$
X=\sum_{i} x_{i} e_{i}
$$

where $x_{i} \in \mathbb{C}$. The bracket between two elements of the basis can be written as

$$
\left[e_{i}, e_{j}\right]=\sum_{k} C_{i j}^{k} e_{k} .
$$

Where the $C_{i j}^{k}$ quantities are known as structure constants for $A$. From them, the Lie bracket between two arbitrary elements of $A$ can be obtained by applying the bilinearity property. Antisymmetry and the Jacobi relations imply the following relations for the $C_{i j}^{k}$ constants:

$$
\begin{gathered}
C_{i j}^{k}=-C_{j i}^{k} \\
\sum_{l}\left(C_{j k}^{l} C_{i l}^{m}+C_{k i}^{l} C_{j l}^{m}+C_{i j}^{l} C_{k l}^{m}\right)=0 .
\end{gathered}
$$

- Derived algebra. The derived algebra $A^{(1)}$ of a Lie algebra $A$ is defined as the subset

$$
A^{(1)}=\{Z \in A / \exists X, Y \in A / Z=[X, Y]\} .
$$


- Simple Lie algebra. A Lie algebra $A$ is said to be 'simple' if it is not abelian and its only ideals are $\{0\}$ and itself.

- Semisimple Lie algebra. A Lie algebra $A$ is said to be 'semisimple' if it does not contain any non-zero abelian ideal.

-Solvable algebra. Let us consider the sequence of derivations

$$
A^{(1)}=[A, A] \quad A^{(2)}=\left[A^{(1)}, A^{(1)}\right] \quad, \ldots, \quad A^{(i)}=\left[A^{(i-1)}, A^{(i-1)}\right]
$$

if then there exists some $n \in \mathbb{N}$ such that $A^{(n)}=\{0\}$ then $A$ is said to be solvable.

- Radical of $A$. The maximal solvable ideal of $A$ is called radical.

- Nilpotent algebra. Let us now consider the sequence

$$
A^{[1]}=[A, A] \quad A^{[2]}=\left[A, A^{[1]}\right] \quad, \ldots, \quad A^{[i]}=\left[A, A^{[i-i]}\right] .
$$

Then, if there exists some $n \in \mathbb{N}$ such that $A^{[n]}=\{0\}$, then $A$ is said to be nilpotent.

The following properties can be easily proven:

a) $A$ is solvable if and only if the derived algebra of $A$ is nilpotent.

b) If $A$ is nilpotent, then $A$ is solvable.

- Nilradical of a solvable Lie algebra. Let $A$ be a solvable Lie algebra. If it admits the following decomposition as a vector space

$$
A=\mathfrak{n} \oplus \mathfrak{t}
$$

and such that

$$
[\mathfrak{t}, \mathfrak{t}] \subset \mathfrak{n}, \quad[\mathfrak{t}, \mathfrak{n}] \subset \mathfrak{n}
$$

then $\mathfrak{n}$ is called the nilradical of $A$, and the following relation holds:

$$
\operatorname{dim}(\mathfrak{n}) \geq \frac{1}{2} \operatorname{dim}(\mathfrak{t})
$$

\section{Casimir operators}

Casimir Operators play a crucial role in many modern physical theories, and the literature concerning its explicit forms and properties for many Lie algebras can be traced back from, for instance, [1, 33, 34, 43, 44, 58, 159, 60, 61, 62, 103, 118, 139, 140, 141, 145, 159, 170]. 
- Universal Enveloping Algebra. Let $A$ be a Lie Algebra defined over the field $\mathcal{K}$ where [, ] is the Lie bracket. Let $A^{\otimes}$ be the tensor algebra defined from $A$, and let $\mathcal{I}$ be the ideal of $A^{\otimes}$ generated by

$$
[X, Y]-(X \otimes Y-Y \otimes X) \quad X, Y \in A,
$$

then the Universal Enveloping Algebra $\mathcal{U}(A)$ is defined as the quotient

$$
\mathcal{U}(A)=A^{\otimes} / \mathcal{I}
$$

- Center of an algebra. Let $A$ be a Lie algebra, the center of $A^{\otimes}$ is defined as the ideal $\mathcal{I}$ of $A^{\otimes}$ commuting with all the elements of $A^{\otimes}$.

- Casimir Operator. Let $A$ be an $l$-dimensional Lie Algebra and let $U(A)$ be the universal enveloping algebra of $A$. The Casimir elements for $A$ are the elements of the center of $U(A)$ verifying

$$
\left[\mathcal{C}_{i}, J_{j}\right]=0 \quad \forall i=1, \ldots, r, \quad j=1, \ldots, l .
$$

- Number of independet invariants. Let $A$ be a real Lie algebra of dimension $l$, the number of independent invariants (Casimir operators) $r$ of $A$ is

$$
r=l-\mathfrak{R}
$$

where $\mathfrak{R}$ is the rank of the commutator table of $A$ when considered as a matrix. For the purpose of computing this rank, the $\left(J_{i}, i=1, \ldots, l\right)$ algebra generators are regarded as independet numbers [145].

\section{Poisson algebras}

- Poisson algebra. A Poisson algebra $P$ is an associative algebra over a field $\mathcal{K}$ endowed with a Poisson bracket:

$$
\{,\}: A \otimes A \rightarrow A
$$

satisfying the following relations $\forall f, g, h \in P$

$$
\begin{array}{ll}
\{f, g\}=-\{g, f\} & \text { Antisymmetry } \\
\{f, g h\}=g\{f, h\}+\{f, g\} h & \text { Leibnitz rule } \\
\{f,\{g, h\}\}+\{h,\{f, g\}\}+\{g,\{h, f\}\}=0 & \text { Jacobi identity. }
\end{array}
$$

- Poisson bivector. Let $M$ be a $N$-dimensional manifold and let us consider functions belonging to $\mathcal{C}^{\infty}(M)$. If we want to define a Poisson algebra over $\mathcal{C}^{\infty}(M)$, we have to 
define the Poisson bracket by means of a skew-symmetric bivector $\Lambda$ over the local coordinates of the manifold $\left(x_{1}, \ldots, x_{N}\right)$ :

$$
\Lambda=\lambda^{i j}(x) \frac{\partial}{\partial x^{i}} \wedge \frac{\partial}{\partial x^{j}} \quad(i<j) \quad \lambda^{i j}(x) \in \mathcal{C}^{\infty}(M) .
$$

By using the former expression in terms of the bivector, the Poisson bracket becomes

$$
\{f, g\}=\lambda^{i j}(x) \frac{\partial f}{\partial x^{i}} \frac{\partial g}{\partial x^{j}},
$$

where,

$$
\left\{x^{i}, x^{j}\right\}=\lambda^{i j}(x)
$$

is called 'the fundamental Poisson bracket'.

- Casimir functions. Let $f(x)$ be a function in $\mathcal{C}^{\infty}(M)$. The function $f(x)$ is said to be a Casimir function of the Poisson algebra $\mathcal{C}^{\infty}(M)$ if

$$
\{h(x), f(x)\}=0 \quad \forall h(x) \in C^{\infty}(M) .
$$

\subsection{The Yoshida-Ziglin test}

We are going to revisit a useful tool as far as the non-integrability of homogeneous potentials is concerned. Starting from the Ziglin's approach, Yoshida in 1983 was able to provide a sufficient condition for the non integrability of $2 \mathrm{D}$ homogeneous Hamiltonian systems, where the conditions coming from Ziglin's results [186] were given in an explicit form. Several years latter, Yoshida established [183 the same conditions for $N$-dimensional homogeneous potentials. This so-called Yoshida-Ziglin approach to the integrability problem also called the monodromy group approach, has focused many efforts during the last two decades, see for instance [3, 125, 126, 135, 151, 182, 184]. On the other hand, the lack of a generic algorithm or method for proving the non integrability of a general dynamical system remains as one of the most difficult problems in this area.

- Theorem. [3, 183] Let $\mathcal{V}\left(q_{1}, q_{2}, \ldots, q_{N}\right)$ be an $k$-homogeneous potential, where $(k \neq$ $0, \pm 2)$ for the following $N$-dimensional Hamiltonian on the $N$-dimensional Euclidean space:

$$
\mathcal{H}^{(N)}=\sum_{i=1}^{N} \frac{p_{i}^{2}}{2}+\mathcal{V}\left(q_{1}, \ldots, q_{N}\right)
$$

we can define the following quantities:

$$
\Delta \rho_{i}=\sqrt{1+\frac{8 k \xi_{i}}{(k-2)^{2}}}
$$


where $\xi_{i}$, are the eigenvalues evaluated in $c_{i}$, of the following Hessian Matrix

$$
\mathbb{H}=\left(\left.\frac{\partial^{2} \mathcal{V}}{\partial q_{i} \partial q_{j}}\right|_{\left[q_{i}=c_{i}\right]}\right) i, j=1, \ldots, N
$$

and where $c_{i}$, are the solutions of the algebraic system coming from

$$
\left.\frac{\partial V}{\partial q_{i}}\right|_{q_{i}=c_{i}}=c_{i}
$$

Then, if there exists some solution $c_{i}$ to 8.30) such that the quantities $\left(\Delta \rho_{1}, \ldots, \Delta \rho_{N}\right)$ are rationally independent, the $N D$ Hamiltonian $\mathcal{H}$ has no additional global analytical integral $\left(\mathcal{I}\left(q_{i}, p_{i}\right)=\right.$ constant $)$ other than the Hamiltonian itself.

Some comments seem to be pertinent:

a) The quantities $\Delta \rho_{i}$ are known as the Kowaleskaia's exponents, and are crucial in the Painlevé's analysis of integrable systems.

b) $\Delta \rho_{i}, \Delta \rho_{j}$ are said to be rationally independent if $\nexists \mathfrak{q} \in \mathbb{Q} / \frac{\Delta \rho_{i}}{\Delta \rho_{j}}=\mathfrak{q}$.

c) The analysis of the Kowaleskaia's exponents must be carried out for all the possible solutions $c_{i}$ of the system 8.30 .

Hereafter we are showing several examples of the application of this test.

- Example 1. Let us consider the Hamiltonian:

$$
\mathcal{H}^{(3)}=\frac{1}{2}\left(p_{1}^{2}+p_{2}^{2}+p_{3}^{2}\right)+q_{1}^{3}+q_{1}^{2} q_{2}+q_{1} q_{2}^{2}+q_{2}^{3}+q_{1}^{2} q_{3}+q_{2}^{2} q_{3}+q_{1} q_{3}^{2}+q_{2} q_{3}^{2}+q_{3}^{3}
$$

Therefore, we have to analyze the homogeneous potential with degree $k=3$ given by

$$
\mathcal{V}=q_{1}^{3}+q_{1}^{2} q_{2}+q_{1} q_{2}^{2}+q_{2}^{3}+q_{1}^{2} q_{3}+q_{2}^{2} q_{3}+q_{1} q_{3}^{2}+q_{2} q_{3}^{2}+q_{3}^{3}
$$

solving the system,

$$
\begin{gathered}
\left.\frac{\partial V}{\partial q_{i}}\right|_{q_{i}=c_{i}}=c_{i} \quad i=1,2,3 \\
\left\{\begin{array}{l}
3 c_{1}^{2}+2 c_{1} c_{2}+c_{2}^{2}+2 c_{1} c_{3}+c_{3}^{2}=c_{1} \\
c_{1}^{2}+2 c_{1} c_{2}+3 c_{2}^{2}+2 c_{2} c_{3}+c_{3}^{2}=c_{2} \\
c_{1}^{2}+c_{2}^{2}+2 c_{1} c_{3}+2 c_{2} c_{3}+3 c_{3}^{2}=c_{3}
\end{array}\right.
\end{gathered}
$$


we choose this particular solution

$$
c_{1}=c_{2}=c_{3}=\frac{1}{9}
$$

The Hessian matrix is

$$
\mathbb{H}=\left(\begin{array}{ccc}
\frac{10}{9} & \frac{4}{9} & \frac{4}{9} \\
\frac{4}{9} & \frac{10}{9} & \frac{4}{9} \\
\frac{4}{9} & \frac{4}{9} & \frac{10}{9}
\end{array}\right)
$$

and its eigenvalues are

$$
\xi_{1}=2 \quad \xi_{2}=\frac{2}{3} \text { (two times). }
$$

The Kowaleskaia's exponents are

$$
\Delta \rho_{1}=\sqrt{1+\frac{8 \cdot 3 \cdot 2}{(3-2)^{2}}}=7 \quad \Delta \rho_{2}=\Delta \rho_{3}=\sqrt{1+\frac{8 \cdot 3 \cdot \frac{2}{3}}{(3-2)^{2}}}=\sqrt{17} .
$$

As the Kowaleskaia's exponents for this solution are rationally independent

$$
\nexists \mathfrak{q} \in \mathbb{Q} / \rightarrow \sqrt{17}=\mathfrak{q} \cdot 7
$$

so the previous Theorem guarantees that our Hamiltonian is not integrable.

If we formulate the system within the $h_{6}$ language, we would have

$$
\mathcal{H}=\frac{B_{+}}{2}+A_{-} B_{-} \quad \lambda_{1}=\lambda_{2}=\lambda_{3}=1 .
$$

The Yoshida-Ziglin criterion tell us that this Hamiltonian is not integrable. In fact, if we look for possible integrals $\mathcal{I}$ commuting with 8.40 , this search does not lead to any result.

- Example 2. Let us now consider

$$
\mathcal{H}^{(2)}=\frac{1}{2}\left(p_{1}^{2}+p_{2}^{2}\right)+2 q_{1}^{4}+12 q_{1}^{2} q_{2}^{2}+2 q_{2}^{4}
$$

We have to solve this system

$$
\begin{gathered}
\left.\frac{\partial V}{\partial q_{i}}\right|_{q_{i}=c_{i}}=c_{i} \quad i=1,2 \\
\left\{\begin{array}{l}
8 c_{1}^{3}+24 c_{1} c_{2}^{3}=c_{1} \\
24 c_{1}^{2} c_{2}+8 c_{2}^{3}=c_{2} .
\end{array}\right.
\end{gathered}
$$


We choose this particular solution

$$
c_{1}=-\frac{1}{4 \sqrt{2}} \quad c_{2}=-\frac{1}{4 \sqrt{2}}
$$

The Hessian matrix becomes

$$
\mathbb{H}=\left.\left(\begin{array}{cc}
24\left(q_{1}^{2}+q_{2}^{2}\right) & 48 q_{1} q_{2} \\
48 q_{1} q_{2} & 24\left(q_{1}^{2}+q_{2}^{2}\right)
\end{array}\right)\right|_{\left[q_{1}=c_{1}, q_{2}=c_{2}\right]}=\left(\begin{array}{cc}
\frac{3}{2} & \frac{3}{2} \\
\frac{3}{2} & \frac{3}{2}
\end{array}\right)
$$

and the eigenvalues are

$$
\xi_{1}=3 \quad \xi_{2}=0 .
$$

The Kowaleskaia's exponents become

$$
\Delta \rho_{1}=\sqrt{1+\frac{8 \cdot 4 \cdot 3}{(4-2)^{2}}}=5 \quad \Delta \rho_{1}=\sqrt{1+\frac{8 \cdot 4 \cdot 0}{(4-2)^{2}}}=0
$$

and they are rationally dependent. Since we obtain the same result for any other solution $c_{i}$, we conclude that the system would be integrable.

But unfortunately, the Theorem does not provide the expression for the integral. Matching the former potential within the $h_{6}$ framework we can re-write the Hamiltonian in the following form

$$
\mathcal{H}=\frac{B_{+}}{2}+\delta_{1} B_{-}+\delta_{2} \mathcal{F}\left(\mathcal{C}_{\overline{\mathcal{G}}_{+}}\right)+\delta_{3} \mathcal{G}\left(A_{-}\right)
$$

where the arbitrary functions and parameters become $\mathcal{F}, \mathcal{G}, \delta, \lambda$ are

$$
\delta_{1}=0, \quad \delta_{2}=\delta_{3}=1, \quad \mathcal{F}=\left(\mathcal{C}_{\overline{\mathcal{G}}_{+}}\right)^{2}, \quad \mathcal{G}=A_{-}^{4}, \quad \lambda_{1}=\lambda_{2}=1 .
$$

Actually, we are dealing with one our family of integrable systems (5.1), and the integral in the $2 \mathrm{D}$ case is as follows

$$
\begin{gathered}
\mathcal{I}=A_{+}^{2}+\delta_{1} A_{-}^{2}+2 \delta_{3} M A_{-}^{4} \\
\mathcal{I}^{(2)}=\left(p_{1}+p_{2}\right)^{2}+4\left(q_{1}+q_{2}\right)^{4} .
\end{gathered}
$$




\subsection{Symplectic realizations for 5D algebras with $R=3$}

For the sake of completeness, in this supplement we summarize the symplectic realizations of the 5D Poisson algebras with $R=3$. The construction of completely integrable systems coming from them would be obtained by following he procedure described in Chapters 2 and 3. For each algebra we give the Poisson brackets, the Casimir operators and the expression for the generic one-particle symplectic realization.

- $A_{5,13}^{\alpha, \beta, \gamma}$ algebra $(\alpha \gamma \neq 0,|\alpha| \leq 1)$

Poisson brackets

$$
\begin{aligned}
& \left\{J_{1}, J_{5}\right\}=J_{1} \quad\left\{J_{2}, J_{5}\right\}=\alpha J_{2} \\
& \left\{J_{4}, J_{5}\right\}=\gamma J_{3}+\beta J_{4} \quad\left\{J_{3}, J_{5}\right\}=\beta J_{3}-\gamma J_{4} .
\end{aligned}
$$

Casimir functions

$$
\mathcal{C}_{1}=\frac{J_{1}^{\alpha}}{J_{2}} \quad \mathcal{C}_{2}=\frac{J_{1}^{2 \beta}}{J_{3}^{2}+J_{4}^{2}} \quad \mathcal{C}_{3}=J_{3}^{2 \gamma} e^{-2 \arctan \left(\frac{J_{4}}{J_{3}}\right)} .
$$

Symplectic realization

$$
\begin{array}{rlrl} 
& J_{1}=e^{-p} \\
J_{2} & =\frac{1}{k_{1}} e^{\alpha p} & \\
J_{3} & =e^{-\beta p}(A \cos \gamma p+B \sin \gamma p) \\
J_{4} & =e^{\beta p}(B \cos \gamma p-A \sin \gamma p) \\
& J_{5}=q
\end{array}
$$

- $A_{5,16}^{\alpha, \beta}$ algebra $(\beta \neq 0)$

Casimir functions

$$
\mathcal{C}_{1}=\frac{J_{1}^{2 \alpha}}{J_{3}^{2}+J_{4}^{2}} \quad \mathcal{C}_{2}=J_{1}^{2 \beta} e^{-2 \arctan \left(\frac{J_{4}}{J_{3}}\right)} \quad \mathcal{C}_{3}=J_{1} e^{-\frac{J_{2}}{J_{1}}} .
$$

Symplectic realization

$$
\begin{aligned}
& J_{1}=e^{-\alpha p} \\
& J_{2}=-e^{\alpha p}\left(p+\log k_{3}\right) \\
& J_{3}=e^{\alpha p}(A \cos \beta p+B \sin \beta p) \\
& J_{4}=e^{\beta p}(B \cos \beta p-A \sin \beta p) \\
& J_{5}=q
\end{aligned}
$$




$$
k_{3}>0 \quad A=A\left(k_{1}, k_{2}, k_{3}\right) \quad B=B\left(k_{1}, k_{2}, k_{3}\right) .
$$

- $A_{5,17}^{s, \alpha, \beta}$ algebra $(s \neq 0)$

$$
\begin{array}{ll}
\left\{J_{1}, J_{5}\right\}=\alpha J_{1}-J_{2} & \left\{J_{2}, J_{5}\right\}=J_{1}+\alpha J_{2} \\
\left\{J_{4}, J_{5}\right\}=s J_{3}+\beta J_{4} & \left\{J_{3}, J_{5}\right\}=\beta J_{3}-s J_{4} .
\end{array}
$$

Casimir functions

$$
\mathcal{C}_{1}=\frac{\left(J_{1}^{2}+J_{2}\right)^{\beta}}{\left(J_{3}^{2}+J_{4}\right)^{\alpha}} \quad \mathcal{C}_{2}=\left(J_{1}^{2}+J_{2}\right) e^{-2 \alpha \arctan \left(\frac{J_{2}}{J_{1}}\right)} \quad \mathcal{C}_{3}=\left(J_{3}^{2}+J_{4}\right) e^{-\frac{2 \beta}{s} \arctan \left(\frac{J_{4}}{J_{3}}\right)} .
$$

Symplectic realizations

$$
\begin{gathered}
J_{1}=e^{-\alpha p}(A \cos p+A \sin p) \\
J_{2}=e^{-\alpha p}(B \cos p-A \sin p) \\
J_{3}=\sqrt{k_{3}} e^{-\beta p} \cos s p \\
J_{4}=-\sqrt{k_{3}} e^{-\beta p} \sin s p \\
J_{5}=q \\
k_{1}, k_{2}, k_{3}>0 \\
\left.A=\left(k_{1} k_{3}^{\alpha}\right)^{\frac{1}{4 \beta}} \cos \left(\frac{\log \left[k_{2}\left(k_{1} k_{3}^{\alpha}\right)^{-\frac{1}{2 \beta}}\right]}{2 \alpha}\right) \quad B=-\left(k_{1} k_{3}^{\alpha}\right)^{\frac{1}{4 \beta}} \sin \left(\frac{\log \left[k_{2}\left(k_{1} k_{3}^{\alpha}\right)^{-\frac{1}{2 \beta}}\right]}{2 \alpha}\right) .63\right)
\end{gathered}
$$

- $A_{5,18}^{\alpha}$ algebra $\quad(\alpha \geq 0)$

$$
\begin{array}{ll}
\left\{J_{1}, J_{5}\right\}=\alpha J_{1}-J_{2} & \left\{J_{2}, J_{5}\right\}=J_{1}+\alpha J_{2} \\
\left\{J_{4}, J_{5}\right\}=J_{2}+J_{3}+\alpha J_{4} & \left\{J_{3}, J_{5}\right\}=J_{1}+\alpha J_{3}-J_{4} .
\end{array}
$$

Casimir functions

$$
\begin{gathered}
\mathcal{C}_{1}=\frac{J_{1} J_{4}-J_{2} J_{3}}{J_{1}^{2}+J_{2}^{2}} \quad \mathcal{C}_{2}=\left(J_{1}^{2}+J_{2}^{2}\right) e^{-2 \alpha \arctan \left(\frac{J_{2}}{J_{1}}\right)} \quad \mathcal{C}_{3}=\left(J_{1}^{2}+J_{2}^{2}\right) e^{-2 \alpha\left(\frac{J_{1} J_{3}-J_{2} J_{4}}{J_{1}^{2}+J_{2}^{2}}\right)} \\
J_{1}=e^{-\alpha p} A(\cos p+\sin p) \\
J_{2}=e^{-\alpha p} A(\cos p-\sin p) \\
J_{3}=e^{-\alpha p} \mathcal{R}(p) \\
J_{4}=e^{-\alpha p} \mathcal{S}(p) \\
J_{5}=q \\
\quad k_{2}, k_{3}>0
\end{gathered}
$$




$$
\begin{aligned}
\mathcal{R}(p) & =((F \cos p+G \sin p)-A p(\cos p+\sin p)) \\
\mathcal{S}(p) & =((F \cos p-G \sin p)-A p(\cos p-\sin p)) \\
A & =e^{\frac{\pi \alpha}{4}} \sqrt{\frac{k_{2}}{2}} \\
F & =\frac{1}{2 \alpha} \sqrt{\frac{k_{2}}{2}} e^{\frac{\pi \alpha}{4}}\left(\log \left(\frac{e^{\frac{\pi \alpha}{2}} k_{2}}{k_{3}}\right)-2 \alpha k_{1}\right) \\
G & =\frac{1}{2 \alpha} \sqrt{\frac{k_{2}}{2}} e^{\frac{\pi \alpha}{4}}\left(\log \left(\frac{e^{\frac{\pi \alpha}{2}} k_{2}}{k_{3}}\right)+2 \alpha k_{1}\right) .
\end{aligned}
$$




\subsection{The $h_{9}$ Poisson algebra}

It is worth mentioning that if we consider the six $h_{6}$ generators and the Casimir operators of $\left(\mathcal{C}_{\overline{\mathcal{G}}_{+}}, \mathcal{C}_{\overline{\mathcal{G}}_{-}}, \mathcal{C}_{h_{4}}\right)$, this nine objects close a Poisson algebra that we can call $h_{9}$. On one hand, the Casimir operators close an algebra which is isomorphic to $s l(2)$. On the other hand, the brackets between the $s l(2)$-part and $h_{6}$ are not vanishing, and we have the semidirect product structure.

$$
\begin{aligned}
\left\{h_{6}, h_{6}\right\} \subset h_{6} \quad\left\{h_{6}, \operatorname{sl}(2)\right\} & \subset \operatorname{sl}(2) \quad\{\operatorname{sl}(2), \operatorname{sl}(2)\} \subset \operatorname{sl}(2) \\
h_{9} & =h_{6} \odot \operatorname{sl}(2) .
\end{aligned}
$$

Therefore the $h_{9}$ algebra is generated by the following objects

$$
\left\{K, A_{+}, A_{-}, B_{+}, B_{-}, M, \mathcal{C}_{\overline{\mathcal{G}}_{+}}, \mathcal{C}_{\overline{\mathcal{G}}_{-}}, \mathcal{C}_{h_{4}}\right\}
$$

and its commutation rules can be split into the following different subsets:

Between $h_{6}$ generators and $\mathcal{C}_{\overline{\mathcal{G}}_{+}}$:

$$
\begin{array}{lll}
\left\{K, \mathcal{C}_{\overline{\mathcal{G}}_{+}}\right\}=2 \mathcal{C}_{\overline{\mathcal{G}}_{+}} & \left\{A_{+}, \mathcal{C}_{\overline{\mathcal{G}}_{+}}\right\}=0 & \left\{A_{-}, \mathcal{C}_{\overline{\mathcal{G}}_{+}}\right\}=0 \\
\left\{B_{+}, \mathcal{C}_{\overline{\mathcal{G}}_{+}}\right\}=0 & \left\{B_{-}, \mathcal{C}_{\overline{\mathcal{G}}_{+}}\right\}=4 \mathcal{C}_{h_{4}} & \left\{M, \mathcal{C}_{\overline{\mathcal{G}}_{+}}\right\}=0 .
\end{array}
$$

Between $h_{6}$ generators and $\mathcal{C}_{\overline{\mathcal{G}}_{-}}$:

$$
\begin{array}{lll}
\left\{K, \mathcal{C}_{\overline{\mathcal{G}}_{-}}\right\}=-2 \mathcal{C}_{\overline{\mathcal{G}}_{-}} & \left\{A_{+}, \mathcal{C}_{\overline{\mathcal{G}}_{-}}\right\}=0 & \left\{A_{-}, \mathcal{C}_{\overline{\mathcal{G}}_{-}}\right\}=0 \\
\left\{B_{+}, \mathcal{C}_{\overline{\mathcal{G}}_{-}}\right\}=-4 \mathcal{C}_{h_{4}} & \left\{B_{-}, \mathcal{C}_{\overline{\mathcal{G}}_{-}}\right\}=0 & \left\{M, \mathcal{C}_{\overline{\mathcal{G}}_{-}}\right\}=0 .
\end{array}
$$

Between $h_{6}$ generators and $\mathcal{C}_{h_{4}}$ :

$$
\begin{array}{lll}
\left\{K, \mathcal{C}_{h_{4}}\right\}=0 & \left\{A_{+}, \mathcal{C}_{h_{4}}\right\}=0 & \left\{A_{-}, \mathcal{C}_{h_{4}}\right\}=0 \\
\left\{B_{+}, \mathcal{C}_{h_{4}}\right\}=-2 \mathcal{C}_{\overline{\mathcal{G}}_{+}} & \left\{B_{-}, \mathcal{C}_{h_{4}}\right\}=2 \mathcal{C}_{\overline{\mathcal{G}}_{-}} & \left\{M, \mathcal{C}_{h_{4}}\right\}=0 .
\end{array}
$$

Between the $\left\{\mathcal{C}_{\overline{\mathcal{G}}_{+}}, \mathcal{C}_{\overline{\mathcal{G}}_{-}}, \mathcal{C}_{h_{4}}\right\} \equiv \operatorname{sl}(2)$ Casimirs:

$$
\left\{\mathcal{C}_{h_{4}}, \mathcal{C}_{\overline{\mathcal{G}}_{+}}\right\}=2 M \mathcal{C}_{\overline{\mathcal{G}}_{+}} \quad\left\{\mathcal{C}_{h_{4}}, \mathcal{C}_{\overline{\mathcal{G}}_{-}}\right\}=-2 M \mathcal{C}_{\overline{\mathcal{G}}_{-}} \quad\left\{\mathcal{C}_{\overline{\mathcal{G}}_{+}}, \mathcal{C}_{\overline{\mathcal{G}}_{-}}\right\}=-4 M \mathcal{C}_{h_{4}} .
$$

As a consequence, if we take $M$ as a constant $h_{9}$ is a Lie-Poisson algebra.

Finally the Casimir operators for $h_{9}$ algebra are $M$ and

$$
\begin{aligned}
& \mathcal{C}=\frac{1}{M}\left(\mathcal{C}_{\overline{\mathcal{G}}_{+}} \mathcal{C}_{\overline{\mathcal{G}}_{-}}-\mathcal{C}_{h_{4}}^{2}\right) \\
& \mathcal{C}_{h_{6}}=\left(M B_{+}-A_{+}^{2}\right)\left(M B_{-}-A_{-}^{2}\right)-\left(M K-A_{-} A_{+}+M^{2} / 2\right)^{2}
\end{aligned}
$$

where we recall that the Casimirs of the subalgebras are taken as independent objects with respect to the $h_{6}$ generators. 


\section{Bibliography}

[1] Abellanas L, Martínez Alonso L. A general setting for Casimir invariants, Journal of Mathematical Physics 16, 1580 (1974). [p. 51, 117]

[2] Aizawa Y, Saito N. Stability of isolating integrals. 1. Efect of perturbation in potential function, Journal of the Physical Society of Japan 32, 1636 (1972). [p. 95]

[3] Almeida M A, Moreira I C, Santos F C. On the Ziglin-Yoshida analysis for some classes of homogeneous hamiltonian systems, Brazilian Journal of Physics 28, 470 (1998). [p. 119

[4] Arnold V I, Kozlov V V, Neishtadt A I. Mathematical aspects of classical and celestial mechanics, (Berlin: Springer) (1997). [p.77]

[5] Audin M. Spinning Tops: A Course on Integrable Systems, (Cambridge: Cambridge University Press) (1999). [p. 9

[6] Babelon O, Bernard D, Talon M. Introduction to Classical Integrable Systems, (Cambridge: Cambridge University Press) (2007). [p. 9]

[7] Baker S, Enolskii V Z, Fordy A P. Integrable quartic potentials and coupled KdV equations, Physics Letters A 201, 167 (1995). [p. 84

[8] Ballesteros A. Contracción de biálgebras de Lie y deformaciones cuánticas de simetrías cinemáticas, Tesis Doctoral, Facultad de Ciencias, Universidad de Valladolid (1995) [p. 9, 17, 115

[9] Ballesteros A, Corsetti M, Ragnisco O. N-dimensional classical integrable systems from Hopf algebras, Czechoslovak Journal of Physics 46, 1153 (1996). [p. 9, 29, 54

[10] Ballesteros A, Herranz F J, Parashar P. A Jordanian quantum two-photon Schrödinger algebra, Journal of Physics A: Mathematical and General 30, 8587 (1997). [p. xxxix, 55, 113 
[11] Ballesteros A, Herranz F J, Parashar P. Quantum two-photon algebra from nonstandard $U_{z}(s l(2, \mathbb{R}))$ and a discrete time Schrödinger equation, Modern Physics Letters A 13, 1241 (1998). [p. xxxix 113

[12] Ballesteros A, Ragnisco O. A systematic construction of completely integrable Hamiltonians from coalgebras, Journal of Physics A: Mathematical and General 31, 3791 (1998). [p. 9, 13, 15, 16, 17, 27, 28, 30, 54, 55, 57, 58

[13] Ballesteros A, Herranz F J. Integrable deformations of oscillator chains from quantum algebras, Journal of Physics A: Mathematical and General 32, 8851 (1999). [p. 9, 13, 17, 23, 30, 31, 32,

[14] Ballesteros A, Celeghini E, Herranz F J. Quantum $1+1$ extended Galilei algebras: from Lie bialgebras to quantum $R$-matrices and integrable systems, Journal of Physics A: Mathematical and General 33, 3431 (2000). [p. 13, 17, 34, 54, 66,

[15] Ballesteros A, Herranz F J. Quasi-integrable and superintegrable systems from a 'deformed-mass' two-photon algebra, Czechoslovak Journal of Physics 50, 1239 (2000). [p. 17

[16] Ballesteros A, Herranz F J. Two-Photon algebra and integrable Hamiltonian systems, Journal of Nonlinear Mathematical Physics 8, 18 (2001). [p. 13, 20, 53, 55, 57. 64, 79.

[17] Ballesteros A, Ragnisco O. Classical Hamiltonian systems with sl(2) coalgebra symmetry and their integrable deformations, Journal of Mathematical Physics 43, 954 (2002). [p. 9]

[18] Ballesteros A, Musso F, Ragnisco O. Comodule algebras and integrable systems, Journal of Physics A: Mathematical and General 35, 8197 (2002). [p. 9, 14]

[19] Ballesteros A, Ragnisco O. Classical dynamical systems from q-algebras: 'cluster' variables and explicit solutions, Journal of Physics A: Mathematical and General 36, 10505 (2003). [p. xxxviii, 9, 13, 18, 112

[20] Ballesteros A, Blasco A, Civitarese O, Herranz F J, Reboiro M. Deformed algebras and effective Hamiltonians, Symmetries in Gravity and Field Theory, Universidad de Salamanca, 157 (2003). [p. 11]

[21] Ballesteros A, Herranz F J, Musso F, Ragnisco O. Superintegrability in Classical and Quantum Systems CRM Proceedings and Lecture Notes 37 ed P Tempesta et al (Providence, RI: AMS), 1 (2004). [p. 9, 13, 17, 18, 21, 24, 26, 31, 54, 58 
[22] Ballesteros A, Herranz F J, Ragnisco O. Curvature from quantum deformations, Physics Letters B 610, 107 (2005). [p. 13, 17, 32

[23] Ballesteros A, Blasco A, Ragnisco O. Poisson coalgebras, symplectic realizations and integrable systems, Monografías de la Real Academia de Ciencias de Zaragoza 29, 27 (2006). [p. xii, 11 ]

[24] Ballesteros A, Herranz F J. Universal integrals for superintegrable systems on $N$ dimensional spaces of constant curvature, Journal of Physics A: Mathematical and Theorerical 40, F51 (2007). [p. Xxxix, 13, 23, 24, 54, 61, 66, 77, 113

[25] Ballesteros A, Enciso A, Herranz F J, Ragnisco O. N-dimensional sl(2)-coalgebra spaces with non-constant curvature, Physics Letters B 652, 376 (2007). [p. 13. 24,62

[26] Ballesteros A, Enciso A, Herranz F J, Ragnisco O. A maximally superintegrable system on an n-dimensional space of non-constant curvature, Physica D 237, 505 (2008). [p. xxxix, 9, 13, 24, 77, 113,

[27] Ballesteros A, Blasco A. N-dimensional superintegrable systems from symplectic realizations of Lie coalgebras, Journal of Physics A: Mathematical and Theoretical 41, 304028 (2008). [p. xii, 9, 11, 17, 18, 53, 54, 66

[28] Ballesteros A, Blasco A, Herranz F J. N-dimensional superintegrability from twophoton coalgebra symmetry, Journal of Physics A: Mathematical and Theoretical 42, 265205 (2009). [p. xii, 11, 56, 79

[29] Ballesteros A, Enciso A, Herranz F J, Ragnisco O. Superintegrability on Ndimensional curved spaces: Central potentials, centrifugal terms and monopoles, Annals of Physics 324, 1219 (2009). [p. xxxix, 13, 24, 77, 113

[30] Ballesteros A, Blasco A. Integrable perturbations of the $N$-dimensional isotropic oscillator, Physics Letters A, submitted (2009). [p. xii, 11

[31] Ballesteros A, Blasco A, Herranz F J, Musso F, Ragnisco O. (Super)integrability from coalgebra symmetry: formalism and applications, Journal of Physics: Conference Series 175, 012004 (2009). [p. xii, 9, 11]

[32] Ballesteros A, Blasco A. ND integrable systems admitting centrifugal terms, in preparation (2009). [p. xii, 11

[33] Beltrametti E G, Blasi A. On the number of Casimir operators associated with any Lie group, Physics Letters 20, 62 (1996). [p. 117 
[34] Berjdis F, Besimuller E. Casimir operators for $F_{4}, E_{6}, E_{7}$ and $E_{8}$, Journal of Mathematical Physics 22, 1857 (1981). [p. 117

[35] Bérubé J, Winternitz P. Integrable and superintegrable quantum systems in a magnetic field, Journal of Mathematical Physics 45, 1959 (2004). [p. 61]

[36] Blasco A. Métodos hamiltonianos en óptica cuántica no lineal, Diploma de Estudios Avanzados (DEA), Universidad de Burgos (2002). [p. 9, 17]

[37] Blaszak M, Sergyeyev A. Maximal integrability of Benenti systems, Journal of Physics A: Mathematical and General 38, L1 (2005). [p. 9]

[38] Boccaletti D, Pucacco G. Theory of Orbits 1: Integrable systems and nonperturbative methods, (Berlin: Springer) (2004). [p. 92

[39] Boccaletti D, Pucacco G. Theory of Orbits 2: Perturbative and Geometrical Methods, (Berlin: Springer) (2002). [p. 92

[40] Bolsinov A V, Fomenko A T. Integrable Hamiltonian Systems: Geometry, Topology, Classification, CRC Press (2004). [p. 9]

[41] Bountis T, Segur H, Vivaldi F. Integrable Hamiltonian-systems and the Painlevé property, Physical Review A 25, 1257 (1982). [p. 95]

[42] Bourdier A, Gond S. Dynamics of a charged particle in a lineary polarized travelling electromagnetic wave, Physical Review E 63, 036609 (2001). [p.61]

[43] Boyko V, Patera J, Popovich R. Computation of invariants of Lie algebras by means of moving frames, Journal of Physics A: Mathematical and General 39, 5749 (2006). [p. 117

[44] Boyko V, Patera J, Popovich R. Invariants of triangular Lie algebras, Journal of Physics. A: Mathematical and Theoretical 40, 7557 (2007). [p. 33, 117

[45] Breiderhoff J, Musso F, Ragnisco O. Exact solution to a supersymmetric Gaudin model, Journal of Mathematical Physics 46, 032109 (2005). [p. 14

[46] Brif C. Two-Photon algebra eigenstates: an unified approach to squeezing, Annals of Physics 251, 180 (1996). [p. 53, 55]

[47] Bruschi M, Calogero F. Integrable systems of quartic oscillators, Physics Letters A 273, 173 (2000). [p. 77

[48] Bruschi M, Calogero F. Integrable systems of quartic oscillators II, Physics Letters A 327, 320 (2004). [p. 77 
[49] Burdet G, Patera J, Perrin M, Winternitz P. The optical group and its subgroups, Journal of Mathematical Physics 19, 1758 (1978). [p. 53

[50] Burdet G, Patera J, Perrin M, Winternitz P. Sous-Algèbras de l'algèbre de Schrödinger, Annales des Sciences Mathématiques du Québec II, 81 (1978). [p. 53

[51] Cairò L, Llibre J. Darbouxian first integrals and invariants for real quadratic systems having an invariant conic, Journal of Physics A: Mathematical and General 35, 589 (2002). [p. 9]

[52] Calogero F. Solution of a three body problem in one dimension, Journal of Mathematical Physics 10, 2191 (1969). [p. 9]

[53] Calogero F. Solution of the one-dimensional N-body problems with quadratic and/or inversely quadratic pair potentials, Journal of Mathematical Physics 12, 419 (1971). [p. 9, 69, 77]

[54] Calogero F. A solvable Hamiltonian system, Journal of Mathematical Physics 36, 4832 (1995). [p. 9]

[55] Calogero F. An integrable Hamiltonian system, Physics Letters A 201, 306 (1995). [p. 9,28

[56] Calogero F, Van Diejen J F. An exactly solvable Hamiltonian system: quantum version, Physics Letters A 205, 143 (1995). [p. 14,35

[57] Campoamor-Stursberg R. Invariants of solvable rigid Lie algebras up to dimension 8, Journal of Physics. A: Mathematical and General 35, 6293 (2002). [p. 33

[58] Campoamor-Stursberg R. Intrinsic formulae for the Casimirs operators of semidirect products of the exceptional Lie Algebra $G_{2}$ and a Heisenberg Lie Algebra, Journal of Physics A: Mathematical and General 37, 9451 (2004). [p. 117

[59] Campoamor-Stursberg R. Some remarks concerning the invariants os rank one solvable real Lie algebras, Algebra Colloquium 12, 497 (2005). [p. 10, 51, 115, 117]

[60] Campoamor-Stursberg R. A new matrix method for the Casimir operators of the Lie algebra $w \mathfrak{s p}(N, \mathbb{R})$ and $I \mathfrak{s p}(2 N, \mathbb{R})$, Journal of Physics A: Mathematical and General 38, 4187 (2005). [p. 117

[61] Campoamor-Stursberg R. Determinantal formulae for the Casimir operators of inhomogeneous Lie algebras, Journal of Physics A: Mathematical and General 39, 2325 (2006). [p. 33, 117 
[62] Campoamor-Stursberg R. Invariants of nine dimensional Lie algebras with nontrivial Levi decomposition, (2006). arXiv:math.ph/0605045v1 [p. 117

[63] Cariñena J F, Ibort A, Marmo G, Perelomov A. On the geometry of Lie algebras and Poisson tensors, Journal of Physics A: Mathematical and General 27, 7425 (1994). [p. 33

[64] Cariñena J F, Rañada M F, Santander M. Central potentials on spaces of constant curvature: The Kepler problem on the two-dimensional sphere $\mathbb{S}^{2}$ and the hyperbolic plane $\mathbb{H}^{2}$, Journal of Mathematical Physics 46, 052702 (2005). [p. 9]

[65] Cariñena J F, Nunes da Costa J M, Santos P. Internal deformations of Lie algebroids and symplectic realizations, Journal of Physics A: Mathematical and General 39, 6897 (2006). [p. 18

[66] Celeghini E, Giachetti R, Sorace E, Tarlini M. The three dimensional Euclidean quantum group $E(3)_{q}$, Journal of Mathematical Physics 32, 1159 (1991). [p. 29]

[67] Celeghini E, Giachetti R, Sorace E, Tarlini M. Contractions of quantum groups, Lecture Notes in Mathematics n. 1510, p.221, Springer-Verlag, Berlín (1992). [p. 29]

[68] Chang Y F, Tabor M, Weiss J. Analytical structure of the Hénon-Heiles Hamiltonian in integrable and non-integrable regimes, Journal of Mathematical Physics 23, 531 (1982). [p. 95

[69] Chari V, Pressley A. A Guide to Quantum Groups (Cambridge: Cambridge University Press) (1994). [p. 9, 16, 17, 29

[70] Chong Z W, Gibbons G W, Lü H, Pope C N. Separability and Killing tensors in Kerr-Taub-Nut-de Sitter metrics in higher dimensions, Physics Letters B 609, 124 (2005). [p. 62

[71] Choodnovsky G V, Choodnovsky D V. Novel first integrals for the Fermi-PastaUlam lattice with cubic nonlinearity and for other many-body systems in one and three dimensions, Lettere al Nuovo Cimento Vol 19, 291 (1977). [p. 85

[72] Cleary P W. Integrability and orbits in quartic polynomial potentials, Journal of Mathematical Physics 30, 2214 (1989). [p. 77]

[73] Cleary P W. Nonexistence and existence of various order integrals for two-and three-dimensional polynomial potentials, Journal of Mathematical Physics 31, 1351 (1990). [p. 9 
[74] Cornwell J J. Group Theory in Physics, (Cambridge: Academic Press) (1997). [p. 115

[75] Daskaloyannis C, Ypsilantis K. Unified treatment and classification of superintegrable systems with integrals quadratic in momenta on a two-dimensional manifold, Journal of Mathematical Physics 47, 042904 (2006). [p. 9. 17

[76] Diaf A, Kerris A T, Lassaut M, Lombard R J. A new model of the Calogero type, Journal of Physics A: Mathematical and General 39, 7305 (2006). [p. 89]

[77] Dorizzi B, Grammaticos B, Ramani A, Winternitz P. Integrable Hamiltonian systems with velocity-dependent potentials, Journal of Mathematical Physics 26, 3070 (1985). [p. 61, 77, 85

[78] Dorizzi B, Grammaticos B, Hietarinta J, Ramani A, Schwarz F. New integrable three-dimensional quartic potentials, Physics Letters A 116, 432 (1986). [p. 61, 77, 85,

[79] Drinfel'd V G. Proc. Int. Congress of Mathematicians. (Berkeley 1986) ed A V Gleason (Providence, RI: AMS), 798 (1987). [p. 14, 16, 17, 29

[80] Evans N W. Superintegrability in classical mechanics, Physical Review A 41, 5666 (1990). [p. 9

[81] Evans N W. Superintegrability of the Winternitz system, Physics Letters A 147, 483 (1990). [p. 9, 77]

[82] Evans N W, Verrier P E. Superintegrability of the caged anisotropic oscillator, Journal of Mathematical Physics 49, 092902 (2008). [p. 9]

[83] Ferrer S, Hanssmann H, Palacián J, Yanguas P. On perturbed oscillators in 1-1-1 resonance: the case of axially symmetric cubic potentials, Journal of Geometry and Physics 40, 320 (2002). [p. 77]

[84] Fordy A P, Gibbons J. Some remarkable non-linear transformations, Physics Letters A 75, 325 (1980). [p. 95

[85] Fordy A P, Wojciechowski S, Marshall I. A family of integrable quartic potentials related to symmetric spaces, Physics Letters A 113, 395 (1986). [p. 77

[86] Fordy A P. The Hénon-Heiles system revisited, Physica D 52, 204 (1990). [p. 92

[87] Fradkin D M. 3-dimensional isotropic harmonic oscillator ans SU(3), American Journal of Physics 33, 207 (1965). [p. 77] 
[88] Frappat L, Sciarrino A, Sorba P. Dictionary on Lie Algebras and Superalgebras, Academic Press, Great Britain (2000). [p. 115]

[89] Fris J, Mandrosov V, Smorodinsky Y A, Uhlir M, Winternitz P. On quantum symmetries in quantum mechanics, Physics Letters 16, 354 (1965). [p. 24, 77]

[90] Garnier M R. Sur une classe de systèmes différentiels abéliens déduits de la théorie des équations linéaires, Rendiconti del Circolo Matematico di Palermo 43, 155 (1919). [p. 9.77

[91] Gaudin M. La Fonction d'onde de Bethe (Paris: Masson) (1983). [p. 28

[92] Gilmore R. Spectrum of Casimir invariants for the simple classical Lie groups, Journal of Mathematical Physics 11, 1855 (1970). [p.79

[93] Grabowski J, Marmo G, Michor P W. Construction of of completely integrable systems by Poisson mappings, Modern Physics Letters A 14, 2109 (1999). [p. 54

[94] Graff de W A. Classification of solvable Lie algebras, Experimental Mathematics 14:1, 15 (2000). [p. 115

[95] Grammaticos B, Dorizzi B, Padjen R. Painlevé property and integrals of motion for the Henon-Heiles system, Physics Letters A 89, 111 (1982). [p. 77, 95]

[96] Grammaticos B, Dorizzi B, Ramani A. Integrability of Hamiltonians with thirdand fourth-degree polynomial potentials, Journal of Mathematical Physics 24, 2289 (1983). [p. 9, 77]

[97] Grammaticos B, Dorizzi B, Ramani A, Hietarinta J. Extending integrable Hamiltonian systems from 2 to $N$ dimensions, Physics Letters A 109, 81 (1985). [p. 77. 91, 92, 107, 109

[98] Grammaticos B, Ramani A. Why some integrable (2-D) Hamiltonians cannot be extended to higher dimensions, Physics Letters A 139, 299 (1989). [p. 8, 91]

[99] Gravel S, Winternitz P. Superintegrability with third-order integrals in quantum and classical mechanics, Journal of Mathematical Physics 43, 5902 (2002). [p. 9]

[100] Gutzwiller M C. Chaos in Classical and Quantum Mechanics, Interdisciplinary Applied Mathematics, Vol. 1 (Springer: New York) (1990). [p. 77, 92

[101] Hall L S. A theory of exact and approximate configurational invariants, Physica D 90, 116 (1983). [p. 77] 
[102] Hénon M, Heiles C. The applicability of the third integral of motion: some numerical experiments, Astronomical Journal 69, 73 (1964). [p. 92

[103] Herranz F J, Santander M. Casimir invariants for the complete family of quasisimple orthogonal algebras, Journal of Physics A: Mathematical and General 30, 5411 (1997). [p. 117

[104] Hietarinta J. Integrable families of Hénon-Heiles-type hamiltonians and a new duality, Physical Review A 28, 3670 (1983). [p. 95]

[105] Hietarinta J. A search for integrable two-dimensional Hamiltonians systems with polynomial potential, Physics Letters A 96, 273 (1983). [p. 77, 84

[106] Hietarinta J. Direct methods for the search of the second invariant, Physics Reports 147, 87 (1987). [p. 9, 61, 77, 93, 99, 100, 105

[107] Horwood J T. Higher order first integrals in classical mechanics, Journal of Mathematical Physics 48, 102902 (2007). [p. 9]

[108] Inozemtsev V I. Integrable models of motion of two interacting particles in the external field, Journal of Physics A: Mathematical and General 17, 815 (1984). [p. 61]

[109] Inozemtsev V I. New completely integrable multiparticle dynamical systems, Physica Scripta 29, 518 (1984). [p. 9]

[110] Katok A, Hasselblatt B. Introduction to the modern theory of dynamical systems, (Cambridge: Cambridge University Press) (1995). [p. 62

[111] Kalnins E G, Williams G C, Miller W, Pogosyan G S. On superintegrable symmetry-breaking potentials in $N$-dimensional Euclidean space, Journal of Physics A: Mathematical and General 35, 4755 (2002). [p. 9]

[112] Karimipour V. A solvable Hamiltonian system: integrability and action-angle variables, Journal of Mathematical Physics 38, 1577 (1997). [p. 9, 28

[113] Karimipour V. Integrable structure of the new Calogero models, Journal of Mathematical Physics 39, 913 (1998). [p. 9, 28

[114] Kasperczuk S P. Poisson reduction, poisson bialgebras and complete integrability, Acta Physica Polonica B 34, 17 (2003). [p. 54

[115] Koenigs G. Leçons sur la théorie génerale des surfaces vol 4 ed G Darboux (New York: Chelsea) 368 (1972). [p. 62 
[116] Krtous P, Kubiznak D, Page D N, Vasudevan M. Constants of geodesic motion in higher-dimensional black-hole spacetimes, Physical Review D 76, 084034 (2007). [p. 62 ]

[117] Lakshmanan M, Sahadevan R. Painlevé analysis, Lie symmetries, and integrability of coupled nonlinear oscillators of polynomial type, Physics Reports 224, 1 \& 2 (1993). [p. 9, 77, 86, 96, 97, 98

[118] Leveille M. Casimir invariants for the eight-dimensional subgroups of the Poincaré group P(1,4), Journal of Mathematical Physics 25, 3331 (1984). [p. 117]

[119] Maciejewski A J, Przybylska M. Darboux polynomials and first integrals of natural polynomial Hamiltonian systems, Physics Letters A 326, 219 (2004). [p. 9]

[120] Maciejewski A J, Przybylska M. All meromorphically integrable 2D Hamiltonian system with homogeneous potential of degree 3, Physics Letters A 327, 461 (2004). [p. 9]

[121] Marciniak K, Rauch-Wojciechowski S. Integrable perturbations of the Harmonic oscillator and Poisson pencils, Inverse Problems 17, 19 (2001). [p. 77, 95]

[122] Marciniak K, Rauch-Wojciechowski S. On integrable perturbations of harmonic oscillator, Reports on Mathematical Physics 48, 139 (2001). [p. 77 ]

[123] Marquette I. Winternitz P. Superintegrable systems with a third-order integrals of motion, Journal of Physics A: Mathematical and Theoretical 41, 304031 (2008). [p. 9]

[124] McSween E, Winternitz P. Integrable and superintegrable hamiltonian systems in magnetic fields, Journal of Mathemaical Physics 41, 2957 (2000). [p. 61]

[125] Morales J J. Meromorphic nonintegrability of Hamiltonian systems, Reports on Mathematical Physics 48, 183 (2001). [p. 9, 119]

[126] Morales J J, Ramis J P. Integrability of dynamical systems through differential Galois theory: a practical guide, Jornada Temática sobre integrabilidad en sistemas Hamiltonianos, Zaragoza (2009). [p. 119

[127] Moser J. Three integrable Hamiltonian systems connected with isospectral deformations, Advances in Mathematics 16, 197 (1975). [p. 9, 69, 77

[128] Mubarakzyanov G M. O razreshimykh algebrakh Lie, Izv. Vyš̌. Učehn. Zaved. Matematika 32, 114 (1963). [p. 39] 
[129] Mubarakzyanov G M. Klassifikaciya vehestvennykh struktur Lie pyatovo poryadka, Izv. Vysš. Učehn. Zaved. Matematika 34, 99 (1963). [p. 39]

[130] Mubarakzyanov G M. Klassifikaciya razreshimykh algebr Lie Shestovo poryadka sodnim nenilpotantym bazisnym elemtom, Izv. Vysš. Učehn. Zaved. Matematika 35, 104 (1963). [p. 39

[131] Mubarakzyanov G M. Nekotorye teoremy o razreshimykh algebrakh Lie, Izv. Vyš̌. Učehn. Zaved. Matematika 35, 95 (1963). [p. 39

[132] Musso F, Ragnisco O. Exact solution of the quantum Calogero-Gaudin system and its q-deformation, Journal of Mathematical Physics 41, 7386 (2000). [p. 14. 29,30

[133] Musso F, Ragnisco O. The spin-1/2 Calogero-Gaudin system and its qdeformation, Journal of Physics A: Mathematical and General 34, 2625 (2001). [p. 14, 29, 30,

[134] Musso F, Petrera M, Satta G, Ragnisco O. Gaudin model with $\mathfrak{U}_{\mathfrak{q}}(\mathfrak{o s p}(\mathbf{l} \mid \mathbf{2}))$, Nuclear Physics B 716, 543 (2005). [p. 14

[135] Nakagawa K, Yoshida H. A list of all integrable 2D homogeneous polynomial potentials with a polynomial integral of order at most 4 in the momenta, Journal of Physics A: Mathematical and General 34, 8611 (2001). [p. 8, 9, 119]

[136] Nakagawa K, Maciejewski A J, Przybyslka M. New integrable Hamiltonian system with first integral quartic in the momenta, Physics Letters A 343, 171 (2005). [p. 9]

[137] Nersessian A, Pogosyan G. Relation of the oscillator and Coulomb systems on spheres and pseudospheres, Physical Review A 63, 020103 (2001). [p. 9]

[138] Newell A C, Tabor M, Zang Y B. A unified approach to Painlevé expansions, Physica D 29, 1 (1987). [p. 95]

[139] Ndogmo J C. Invariants of solvable Lie algebras of dimension six, Journal of Physics. A: Mathematical and General 33, 2273 (2000). [p. 117]

[140] Ndogmo J C. Invariants of a semi-direct sum of Lie Algebras, Journal of Physics A: Mathematical and General 37, 5635 (2004). [p. 117]

[141] Nwachuku C O, Raschid M A. Eigenvalues of the Casimir operators and symplectic groups, Journal of Mathematical Physics 17, 1611 (1976). [p. 117

[142] Ohn C. $A{ }^{*}$-product on sl(2) and the corresponding nonstandard Quantum-U্U(sl(2)), Letters in Mathematical Physics 25, 85 (1992). [p. 30] 
[143] Page D N, Kubiznak D, Vasudevan M, Krtous P. Complete integrability of geodesic motion in general higher-dimensional rotating black-hole spacetimes, Physical Review Letters 98, 061102 (2007). [p. 62

[144] Palacián J, Yanguas P. Painlevé analysis and integrable cases of coupled cubic oscillators in the plane, Chaos, Solitons and Fractals 11, 879 (2000). [p. 77

[145] Patera J, Sharp R T, Winternitz P, Zassenhaus H. Invariants of real low dimension Lie algebras, Journal of Mathematical Physics 17, 986 (1976). [p. 10, 20, 25. 33, 39, 46, 51, 55, 79, 117,118

[146] Paternain G P. Geodesic flows, (Boston: Birkhäuser) (1999). [p. 62

[147] Perelomov A M. Integrable systems of classical mechanics and Lie algebras, (Basel: BirhäuserVerlag) (1990). [p. 8, 9, 77]

[148] Perroud M. The fundamental invariants of inhomogeneous classical groups, Journal of Mathematical Physics 24, 1381 (1983). [p. 33

[149] Pfeifer W. The Lie Algebras $S U(N)$, an introduction, Birkhäuser Verlag, Basel (2003). [p. 115

[150] Popovich R O, Boyko V M, Nesterenko M O, Lutfullin M W. Realizations of real low-dimensional Lie algebras, Journal of Physics. A: Mathematical and General 36, 7337 (2003). [p. 10

[151] Pryzbylska M. Finiteness of integrable n-dimensional homogeneous polynomial potentials, Physics Letters A 369, 180 (2007). [p. 9, 119]

[152] Pucacco G. On integrable Hamiltonians with velocity dependent potentials, Celestial Mechanics and Dynamical Astronomy 90, 111 (2004). [p. 61

[153] Pucacco G, Rosquist K. Integrable Hamiltonian with vector potentials, Journal of Mathematical Physics 46, 012701 (2005). [p. 61]

[154] Ramani A, Dorizzi B, Grammaticos B. Painlevé conjecture revisited, Physical Review Letters 49, 1539 (1982). [p. 9, 77, 92, 99

[155] Ramani A, Hietarinta J, Dorizzi B, Grammaticos B. Complete Painlevé analysis for coupled quartic oscillators in $N$ dimensions, Physics Letters A 109, 55 (1985). $[\mathrm{p} .77]$

[156] Ravoson V, Gavrilov L, Gaboz R. Separability and Lax pairs for Hénon-Heiles system, Journal of Mathematical Physics 34, 2385 (1993). [p. 95] 
[157] Ravoson V, Ramani A, Grammaticos B. Generalized separability for a Hamiltonian with non separable quartic potential, Physics Letters A 191, 91 (1994). [p. 9]

[158] Rodriguez M A, Winternitz P. Quantum superintegrability and exact solvability in $n$ dimensions, Journal of Mathematical Physics 43, 1309 (2002). [p. 9

[159] Rubin J L, Winternitz P. Solvable Lie algebras with Heisenberg ideals, Journal of Physics A: Mathematical and General 26, 1123 (1993). [p. 117]

[160] Ruijsenaars S N, Schneider H. A new class of integrable systems and its relations to solitons, Annals of Physics 170, 370 (1986). [p. 9, 27, 30]

[161] Salerno M, Enol'skii V Z, Leykin D V. Canonical transformation between integrable Hénon-Heiles systems, Physical Review E 49, 5897 (1994). [p. 95

[162] Santander M. Geometric aspects of integrability: an elementary overview, Jornada Temática de Integrabilidad en Sistemas Hamiltonianos Zaragoza (2009). [p. 8, 9

[163] Shapukov B N. Grupos y álgebras de Lie, Ed. URSS, Moscu (2001) [p. 115

[164] Snobl L, Winternitz P. A class of solvable Lie algebras and their Casimir invariants, Journal of Physics A: Mathematical and General 38, 2687 (2005). [p. 33]

[165] Sutherland B. Exact results for a quantum many-body problem in one dimension, Physics Review A 4, 2019 (1971). [p. 9]

[166] Tabor M. Chaos and integrability in nonlinear dynamics, (New York: John Wiley \& Sons) (1989). [p. 9]

[167] Tarasov V E, Khozdzhaev K Sh, Chirkov A G. Concerning the full integrability of Hamiltonian equations of charged particle motion in a weakly inhomogeneous magnetic field, Technical Physics 46, 14 (2001). [p. 61]

[168] Tjin T. Introduction to quantized Lie groups and algebras, International Journal of Modern Physics A 7, 6175 (1992). [p. 9, 16, 17

[169] Toda M. Vibration of a chain with nonlinear interaction, Journal of the Physical Society of Japan 22, 431 (1967). [p. 9

[170] Tremblay S, Winternitz P. Invariants of the nilpotent and solvable triangular Lie algebras, Journal Physics A: Mathematical and General 34, 9085 (2001). [p. 117

[171] Turkowski P. Solvable Lie-algebras of dimension 6, Journal of Mathematical Physics 31, 1344 (1990) [p. 33 
[172] Turkowski P. Structure of real Lie Algebras, Linear Algebra and its applications 171, 197 (1992). [p. 115

[173] Vaksman L, Korogodskii L I. Algebra of bounded-functions on a quantum group of motions of the plane and q-analogs of Bessel-functions, Doklady Akademii Nauk USSR 34, 1036 (1989). [p. 30

[174] Vasudevan M, Stevens K A. Integrability of particle motion and scalar fields propagation in Kerr-(anti-) de Sitter black hole spacetimes in all dimensions, Physical Review D 72, 124008 (2005). [p. 62

[175] Verrier P E, Evans N W. A new superintegrable Hamiltonian, Journal of Mathematical Physics 49, 022902 (2008). [p. 9]

[176] Vigo M I, Sansaturio M E, Ferrándiz J M. Integrability of Hamiltonians with polynomial potentials, Journal of Computational and Applied Mathematics 158, 213 (2004). [p. 77 ]

[177] Wojciechowska M. Reduction to quadratures of integrable generalizations of the Calogero system, Journal of Physics A: Mathematical and General 17, 1993 (1984). [p. 69]

[178] Wojciechowski S. Representations of the algebra sl $(2, \mathbb{R})$ and integration of Hamiltonian systems, Physics Letters A 64, 273 (1977). [p. 23

[179] Wojciechowski S. Construction of integrable systems by dressing a free motion with a potential, Physics Letters 96 A, 389 (1983). [p. 9, 10, 59, 77, 79, 85, 88,

[180] Wojciechowski S. Integrability on one particle in a perturbed central quartic potential, Physica Scripta 31, 433 (1985). [p. 9]

[181] Yehia H M. Atlas of two-dimensional irreversible conservative Lagrangian mechanical systems with a second quadratic integral, Journal of Mathematical Physics 48, 082902 (2007). [p. 9]

[182] Yoshida H. Existence of exponentially unstable periodic solutions and the nonintegrability of homogeneous Hamiltonian systems, Physica 21D, 163 (1986). [p. 9, 119

[183] Yoshida H. A criterion for the non-existence of an additional integral in Hamiltonian systems with a homogeneous potential, Physics Letters A 141, 108 (1989). [p. 9, 119 
[184] Yoshida H. A new necessary condition for the integrability of Hamiltonian systems with a two-dimensional homogeneous potential, Physica D 128, 53 (1999). [p. 8 , 9. 119

[185] Zhang W M, Feng D H, Gilmore R. Coherent states: Theory and some applications, Reviews of Modern Physics 62, 867 (1990). [p. 53]

[186] Ziglin S L. Branching of solutions and the nonexistence of first integrals in Hamiltonian mechanics II, Functional Analysis and Its Applications 16, 181 (1983). [p. 119 